\author{
SANDIA REPORT \\ SAND2009-2858 \\ Unlimited Release \\ Printed May 2009
}

\title{
Application of the MELCOR Code to Design Basis PWR Large Dry Containment Analysis
}

Jack Tills, Allen Notafrancesco, and Jesse Phillips

Prepared by

Sandia National Laboratories

Albuquerque, New Mexico 87185 and Livermore, California 94550

Sandia is a multiprogram laboratory operated by Sandia Corporation, a Lockheed Martin Company, for the United States Department of Energy's

National Nuclear Security Administration under Contract DE-AC04-94AL85000.

Approved for public release; further dissemination unlimited. 
Issued by Sandia National Laboratories, operated for the United States Department of Energy by Sandia Corporation.

NOTICE: This report was prepared as an account of work sponsored by an agency of the United States Government. Neither the United States Government, nor any agency thereof, nor any of their employees, nor any of their contractors, subcontractors, or their employees, make any warranty, express or implied, or assume any legal liability or responsibility for the accuracy, completeness, or usefulness of any information, apparatus, product, or process disclosed, or represent that its use would not infringe privately owned rights. Reference herein to any specific commercial product, process, or service by trade name, trademark, manufacturer, or otherwise, does not necessarily constitute or imply its endorsement, recommendation, or favoring by the United States Government, any agency thereof, or any of their contractors or subcontractors. The views and opinions expressed herein do not necessarily state or reflect those of the United States Government, any agency thereof, or any of their contractors.

Printed in the United States of America. This report has been reproduced directly from the best available copy.

Available to DOE and DOE contractors from

U.S. Department of Energy

Office of Scientific and Technical Information

P.O. Box 62

Oak Ridge, TN 37831

Telephone: (865) 576-8401

Facsimile: (865) 576-5728

E-Mail: $\quad$ reports@adonis.osti.gov

Online ordering: http://www.osti.gov/bridge

Available to the public from

U.S. Department of Commerce

National Technical Information Service

5285 Port Royal Rd.

Springfield, VA 22161

Telephone: $\quad$ (800) 553-6847

Facsimile: $\quad$ (703) 605-6900

E-Mail: $\quad$ orders@ntis.fedworld.gov

Online order: $\quad$ http://www.ntis.gov/help/ordermethods.asp?loc=7-4-0\#online

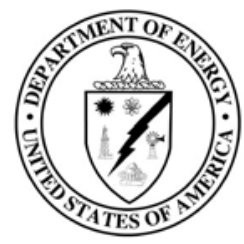


SAND2009-2858

Unlimited Release

Printed May 2009

\title{
Application of the MELCOR Code to Design Basis PWR Large Dry Containment Analysis
}

\author{
Jack Tills \\ Jack Tills \& Associates, Inc. \\ Sandia Park, New Mexico 87047-0549 \\ Sandia Contract No. 849602 \\ Allen Notafrancesco \\ USNRC, Office of Nuclear Regulatory Research \\ Rockville, Maryland 20852-2738 \\ Jesse Phillips \\ Reactor Modeling and Analysis Department \\ Sandia National Laboratories \\ P.O. Box 5800 \\ Albuquerque, New Mexico 87185-0748
}

\begin{abstract}
The MELCOR computer code has been developed by Sandia National Laboratories under USNRC sponsorship to provide capability for independently auditing analyses submitted by reactor manufactures and utilities. MELCOR is a fully integrated code (encompassing the reactor coolant system and the containment building) that models the progression of postulated accidents in light water reactor power plants. To assess the adequacy of containment thermal-hydraulic modeling incorporated in the MELCOR code for application to PWR large dry containments, several selected demonstration designs were analyzed. This report documents MELCOR code demonstration calculations performed for postulated design basis accident (DBA) analysis (LOCA and MSLB) inside containment, which are compared to other code results. The key processes when analyzing the containment loads inside PWR large dry containments are 1) expansion and transport of high mass/energy releases, 2) heat and mass transfer to structural passive heat sinks, and 3) containment pressure reduction due to engineered safety features. A code-to-code benchmarking for DBA events showed that MELCOR predictions of maximum containment loads were equivalent to similar predictions using a qualified containment code known as CONTAIN. This equivalency was found to apply for both single- and multi-cell containment models.
\end{abstract}




\section{Contents}

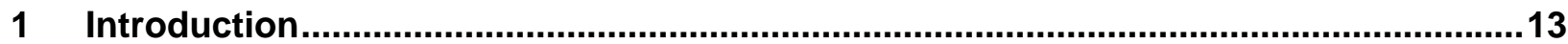

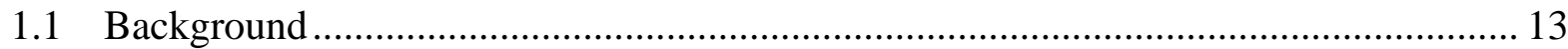

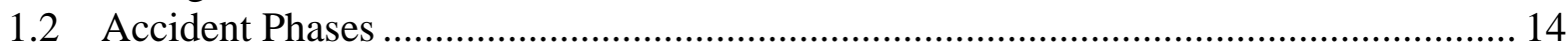

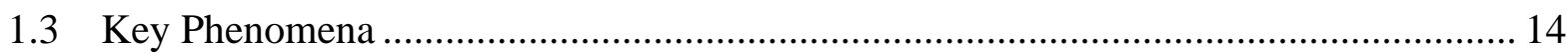

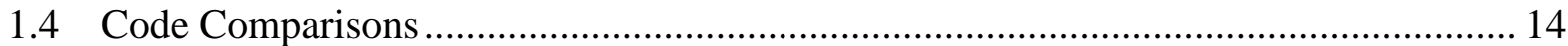

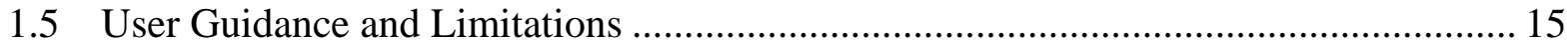

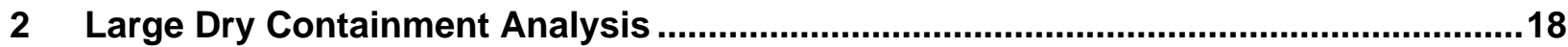

2.1 LOCA Short-term Accident Analysis ................................................................... 19

2.1.1 Scenario and Key Result ............................................................................. 19

2.1.2 Code Comparisons ........................................................................................ 19

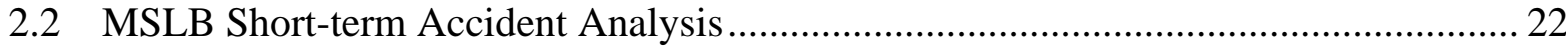

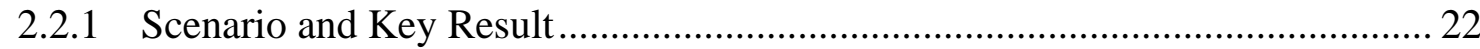

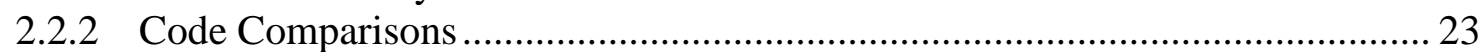

2.3 User Guidance for Single Cell Containment Model ................................................... 24

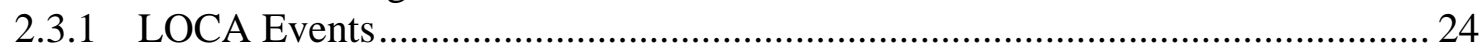

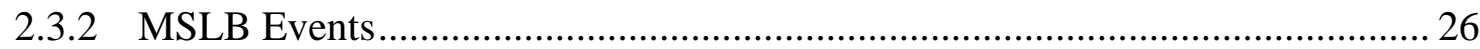

3 AP1000 Containment Analysis (Advanced Light Water Reactor) ..............................55

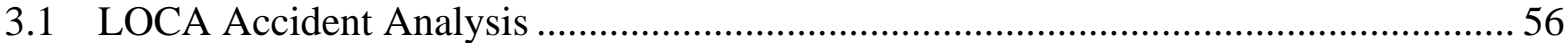

3.1.1 Single vs. Multi-cell Models................................................................... 56

3.1.2 Code Comparisons ................................................................................. 58

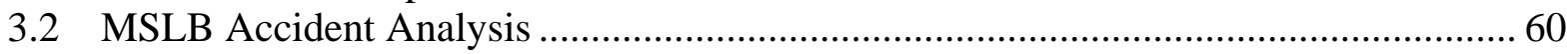

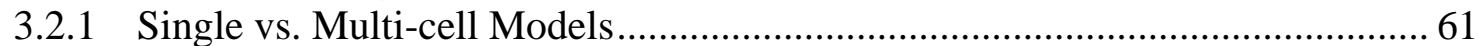

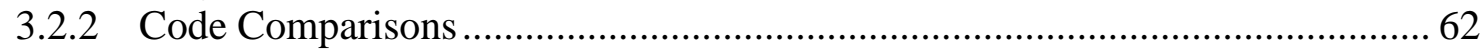

3.3 User Guidance for Multi-cell Containments...................................................... 63

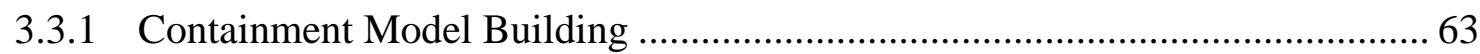

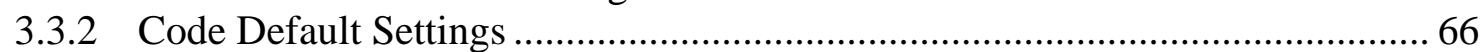

3.3.3 Comments on Input Format \& Output Processing........................................... 67

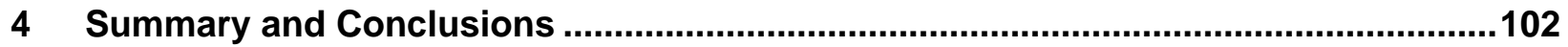

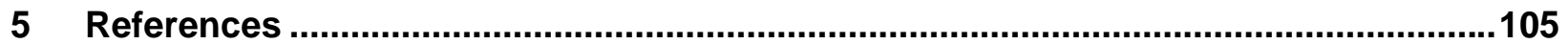

Appendix A. Simulation of the Blowdown Containment Response to a Loss-of-Coolant Accident ....................................................................................................106

Appendix B. Modeling Fan Cooler Performance for Design Basis Accident Analysis ...138

Appendix C. LOCA CONTAIN and MELCOR Input Files Used for PWR Large Dry Containment Calculations 


\section{Figures}

Figure 2.1 Typical large dry containment showing the openness of the large volume above

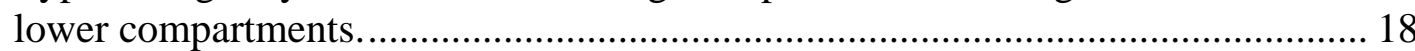

Figure 2.2 Mass and enthalpy blowdown source for LOCA scenario (large dry PWR demonstration plant). 30

Figure 2.3 MELCOR calculation of the containment pressure profile for the large dry PWR LOCA scenario.

Figure 2.4 Steam injection mass rates during the slow pressurization phase of the large dry PWR plant LOCA scenario.

Figure 2.5 MELCOR-calculated containment pressure profiles for large dry PWR plant LOCA scenario, showing the relative effect of excluding engineered safety features (fan cooler or sprays) and passive heat sinks.

Figure 2.6 Comparison of MELCOR-calculated containment pressure profile for a large dry PWR plant LOCA scenario with the CONTAIN code equivalency band for pressure.

Figure 2.7 Comparison of MELCOR-calculated containment gas temperature profile for a large dry PWR plant LOCA scenario with the CONTAIN code equivalency band for pressure.

Figure 2.8 MELCOR-calculated containment gas and saturation temperature for a large dry PWR plant LOCA scenario using an injection spray droplet size of 0.0001 meter diameter.

Figure 2.9 MELCOR-calculated containment gas and saturation temperature for a large dry PWR plant LOCA scenario using an injection spray droplet size of 0.00025 meter diameter.

Figure 2.10 MELCOR-calculated containment gas and saturation temperature for a large dry PWR plant LOCA scenario using an injection spray droplet size of 0.001 meter diameter.

Figure 2.11 Comparison of MELCOR-calculated containment gas temperature profile (with injection spray drop diameter $=0.00025$ meters) for a large dry PWR plant LOCA scenario with the CONTAIN code equivalency band for pressure (injection drop diameter $=0.0005$ meters).

Figure 2.12 Comparison of MELCOR-calculated containment gas pressure for PWR DECLG event for the reference spray diameter droplet size (0.0005 meters) and a sensitivity case with droplet size reduced by 50\% (0.00025 meters), showing that pressure prediction for both cases (demo and sensitivity case) lie within the CONTAIN equivalency band derived using a spray droplet size of 0.0005 meters.

Figure 2.13 Mass and enthalpy blowdown source for MSLB scenario (large dry PWR demonstration plant).

Figure 2.14 MELCOR-calculated containment gas pressure profile for an MSLB event in a large dry PWR containment.

Figure 2.15 MELCOR-calculated containment gas temperature profiles for an MSLB event in a large dry PWR containment.

Figure 2.16 MELCOR-calculated containment superheating for an MSLB event in a large dry PWR containment.

Figure 2.17 MELCOR-calculated heat removal rates for an MSLB event in a PWR large dry containment. 
Figure 2.18 MELCOR-calculated gas pressure compared to the CONTAIN (ideal EOS) equivalency band for pressure during an MSLB event in a large dry PWR containment.

Figure 2.19 MELCOR-calculated gas temperature compared to the CONTAIN (ideal EOS) equivalency band for pressure during an MSLB event in a large dry PWR containment.

Figure 2.20 The effect of fan cooler modeling on gas pressure for a typical MSLB event as calculated with CONTAIN ideal and non-ideal EOS for water, and by the MELCOR code without the fan cooler modeling.

Figure 2.21 The effect of fan cooler modeling on gas temperatures for a typical MSLB event as calculated with CONTAIN ideal and non-ideal EOS for water, and calculated by the MELCOR code without the fan cooler modeling.

Figure 2.22 MELCOR-calculated gas pressure compared to the CONTAIN (non-ideal EOS) equivalency band for pressure during an MSLB event in a large dry PWR containment (excluding fan cooler activation).

Figure 2.23 MELCOR-calculated gas temperature compared to the CONTAIN (non-ideal EOS) equivalency band for pressure during an MSLB event in a large dry PWR containment (excluding fan cooler activation).

Figure 2.24 MELCOR-calculated gas pressure compared to the CONTAIN (non-ideal EOS) equivalency band for pressure during an MSLB event in a large dry PWR containment (excluding fan cooler activation) where the MELCOR spray droplet diameter is reduced by $50 \%$ compared to the CONTAIN input. 52

Figure 2.25 MELCOR-calculated gas temperature compared to the CONTAIN (non-ideal EOS) equivalency band for pressure during an MSLB event in a large dry PWR containment (excluding fan cooler activation) where the MELCOR spray droplet diameter is reduced by 50\% compared to the CONTAIN input............................. 53

Figure 2.26 MELCOR-calculated pressure sensitivity to determination and treatment of unflashed liquid water from LOCA scenario in large dry PWR plant.................... 54

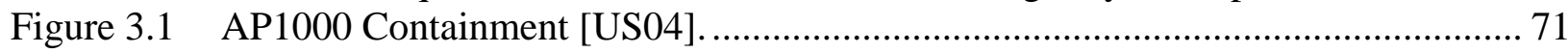

Figure 3.2 AP1000 Containment Nodalization Model..................................................... 72

Figure 3.3 Two-phase water injections for DECLG LOCA (vessel side break flow)............. 73

Figure 3.4 Steam injections into the AP1000 steam generator compartments, post-blowdown and ADS-4.

Figure 3.5 Outer containment shell water flood rate for PCS (both LOCA and MSLB events). 75

Figure 3.6 Comparison of MELCOR-calculated pressure during the AP1000 LOCA event, single vs. multi-cell representations. 76

Figure 3.7 Comparison of MELCOR-calculated gas temperatures during the AP1000 LOCA event, single vs. multi-cell representations.......................................................... 77

Figure 3.8 Comparison of MELCOR-calculated long-term pressure profiles during the AP1000 LOCA event, single vs. multi-cell representations. ............................................ 78

Figure 3.9 Comparison of MELCOR- and CONTAIN-calculated containment pressure response for the AP1000 DECLG LOCA event. 79

Figure 3.10 Comparison of MELCOR- and CONTAIN-calculated short-term gas temperature response in the region above the AP1000 operation deck during the DECLG LOCA event. 
Figure 3.11 Comparison of MELCOR- and CONTAIN-calculated short-term gas temperature response in the region below the AP1000 operation deck during the DECLG LOCA event.

Figure 3.12 Comparison of MELCOR- and CONTAIN-calculated long-term gas temperature response in the region above the AP1000 operation deck during the DECLG LOCA

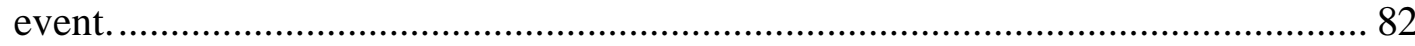

Figure 3.13 Comparison of MELCOR- and CONTAIN-calculated long-term gas temperature response in the region below the AP1000 operation deck during the DECLG LOCA event.

Figure 3.14 Comparison of CONTAIN- and MELCOR-calculated heat removal rates for the AP1000 containment shell above the operating deck during the DECLG LOCA event.

Figure 3.15 Comparison of CONTAIN- and MELCOR-calculated heat removal rates for the AP1000 containment cell \#3 (CMT, CVCS, and accumulator room SE and NE) below the operating deck during the DECLG LOCA event.................................. 85

Figure 3.16 Comparison of CONTAIN- and MELCOR-calculated air/steam flow from the reactor cavity compartment (cell \#1) to break room (cell \#4) . ............................... 86

Figure 3.17 Air velocities in the PCS riser exit during AP1000 DECLG LOCA event. ........... 87 Figure 3.18 Transient exterior film mass at locations above the spring-line (s1_17w) and near the bottom of the PCS riser (s1_14aw) during the AP1000 DECLG LOCA event. 88

Figure 3.19 Steam injection mass rates for the AP1000 MSLB event.................................... 89

Figure 3.20 Comparison of MELCOR-calculated containment pressure for single and multi-cell models of the AP1000 plant during an MSLB event......................................... 90

Figure 3.21 Comparison of MELCOR-predicted temperature profiles using the single and multicell models for the AP1000 MSLB event........................................................... 91

Figure 3.22 MELCOR-calculated maximum temperature profile showing the degree of superheat predicted using the single cell containment model.... 92

Figure 3.23 MELCOR-calculated maximum temperature profile showing the degree of superheat predicted using the multi-cell containment model for cell \#7................ 93

Figure 3.24 MELCOR-calculated containment pressure response compared to the CONTAIN equivalency band for the AP1000 MSLB event (cell \#22 pressure plotted)........... 94

Figure 3.25 MELCOR-calculated containment maximum temperature response compared to the CONTAIN equivalency band for the AP1000 MSLB event (cell \#7 gas temperature plotted). 95

Figure 3.26 Comparison of MELCOR- and CONTAIN-calculated gas temperature stratification within the AP1000 containment for the MSLB event. 96

Figure 3.27 MELCOR-calculated containment pressure response compared to the CONTAIN equivalency band for the AP1000 MSLB event (cell \#22 pressure plotted), where the calculations retain below operating deck structures for the entire calculation period.

Figure 3.28 MELCOR-calculated containment maximum temperature response compared to the CONTAIN equivalency band for the AP1000 MSLB event (cell \#7 gas temperature plotted), where the calculations retain below operating deck structures for the entire calculation period. 98

Figure 3.29 Comparison of MELCOR- and CONTAIN-calculated gas temperature stratification within the AP1000 containment for the MSLB event, where the calculations retain below operating deck structures for the entire calculation period. 99 
Figure 3.30 CONTAIN-calculated steam mole fractions for the above operating deck region for the AP1000 MSLB event (steam injection location is cell \#7)............................. 100

Figure 3.31 MELCOR-calculated steam mole fractions for the above operating deck region for the AP1000 MSLB event (steam injection location is cell \#7)............................. 101

Figure A-1. Temperature flash model for determining percentage of flashed water for various injection enthalpies.

Figure A-2. Pressure flash model for determining percentage of flashed water for various injection enthalpies.

Figure A-3. Sketch of PWR large dry containment represented as a single volume (primary system break in cold leg).

Figure A-4. A typical blowdown injection profile for a PWR double-ended cold leg break (DECLG).....

Figure A-5. Single volume containment gas pressure response for DECLG break using a temperature flash method for treating the two-phase separation, with adiabatic boundary conditions and removal of liquid water to pool region.

Figure A-6. Single volume containment gas temperature response for DECLG break using a temperature flash method for treating the two-phase separation, with adiabatic boundary conditions and removal of liquid water to pool region.

Figure A-7. Single volume MELCOR containment gas pressure response for DECLG break using a temperature flash method for treating the two-phase separation, with adiabatic boundary conditions with and without removal (dropout) of liquid water to pool region.

Figure A-8. Single volume containment gas pressure response for DECLG break using a pressure flash method for treating the two-phase separation, with adiabatic boundary conditions and removal of liquid water to pool region.

Figure A-9. Single volume containment gas temperature response for DECLG break using a pressure flash method for treating the two-phase separation, with adiabatic boundary conditions and removal of liquid water to pool region.

Figure A-10. Gas and saturation temperature profiles calculated for single volume containment during DECLG blowdown, adiabatic conditions and dropout, by CONTAIN (nonideal EOS for water) using the pressure flash method for phase separation. ........ 123

Figure A-11.Comparison of pressure and temperature flash methods for treating the separation of two-phase water injections in the CONTAIN code. The calculations are for a single volume with nonadiabatic boundary conditions and activation of sprays and fan coolers at maximum capacity. Dropout of unflashed water for both calculations is set via keyword DROPOUT in the FLOWS input block................................... 124

Figure A-12. Single volume containment gas pressure response for DECLG break using the MELCOR temperature and pressure flash methods for treating the two-phase separation, with adiabatic boundary conditions and removal of liquid water to pool region.

Figure A-13. Sketch of two-volume containment, where the cold leg break is located within the steam generator compartment or break room. The volume outside the break room is included in the containment volume bounded by the containment shell. Two paths leading from the break room are shown: top opening for steam/air exit to containment, and lower opening for the draining of unflashed water to the containment pool region. 126

Figure A-14. Comparison of MELCOR and CONTAIN prediction of break room pressure for DECLG event using a multi-cell nodalization for the break room/containment. The 
calculations are performed using a temperature flash method to calculate phase separation in the break room. Adiabatic boundary conditions and unflashed water dropout is assumed.

Figure A-15. Comparison of MELCOR and CONTAIN prediction of containment pressure for DECLG event using a multi-cell nodalization for the break room/containment. The calculations are performed using a temperature flash method to calculate phase separation in the break room. Adiabatic boundary conditions and unflashed water dropout is assumed.

Figure A-16. Comparison of MELCOR and CONTAIN prediction of break room gas temperature for DECLG event using a multi-cell nodalization for the break room/containment. The calculations are performed using a temperature flash method to calculate phase separation in the break room. Adiabatic boundary conditions and unflashed water dropout is assumed.

Figure A-17. Comparison of MELCOR and CONTAIN prediction of containment gas temperature for DECLG event using a multi-cell nodalization for the break room/containment. The calculations are performed using a temperature flash method to calculate phase separation in the break room. Adiabatic boundary conditions and unflashed water dropout is assumed.

Figure A-18. Comparison of MELCOR multi-cell and single cell containment pressure response for a DECLG event using the temperature flash method for phase separation. .... 131

Figure A-19. Comparison of MELCOR multi-cell and single cell containment gas pressure response for a DECLG event using the temperature flash method for phase separation.

Figure A-20. Comparison of MELCOR and CONTAIN gas pressure profiles for a DECLG event with adiabatic boundary conditions and dropout of unflashed water. The comparisons show the near identical results obtained using either temperature flash in the MELCOR multi-cell configuration or pressure flash in the CONTAIN single cell configuration.

Figure A-21.Comparison of MELCOR and CONTAIN gas temperature profiles for a DECLG event with adiabatic boundary conditions and dropout of unflashed water. The comparisons show the near identical results obtained using either temperature flash in the MELCOR multi-cell configuration or pressure flash in the CONTAIN single cell configuration.

Figure A-22. Comparison of containment pressure (cell \#1) for a two-cell MELCOR calculation of a DECLG event with adiabatic boundary and temperature flash conditions simulated.

Figure A-23. Comparison of containment gas temperature for a two-cell MELCOR calculation of a DECLG event with adiabatic boundary and temperature flash conditions simulated. 136

Figure A-24. Comparison of containment pressure for MELCOR calculation of a DECLG event with adiabatic boundary and temperature flash conditions simulated, showing the affect on pressure due to unflashed liquid water retention in atmosphere and

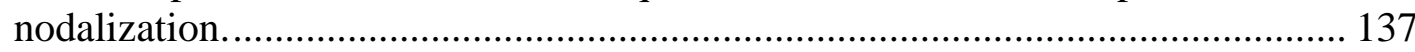

Figure B-1. Sketch of a typical fan cooler unit. 143

Figure B-2. Typical fan cooler performance curves as a function of coolant (secondary) inlet temperature. (Note: Containment temperature is the saturation temperature-dry conditions are assumed at the initial air pressure and gas temperature of $1.0135 \mathrm{e} 5$ $\mathrm{Pa}$ and $311 \mathrm{~K}$.) 
Figure B-3. MELCOR-calculated fan cooler total heat removal for rated heat removal rates of 21 and 23.7 MW. Inlet coolant temperature is $325 \mathrm{~K}$, and sensible heat transfer multiplier $\boldsymbol{F}_{\boldsymbol{H}}$ is set equal to 0.15 .

Figure B-4. MELCOR-calculated sensible-to-total heat removal ratio for variations in the sensible heat removal multiplier. A multiplier $\boldsymbol{F}_{\boldsymbol{H}}$ of 0.15 is used in throughout the report for the fan cooler model input.

\section{Tables}

Table 1.1. Short-term accident phases for a large dry PWR containment.

Table 2.1. Maximum pressure and temperatures for a short-term DBA LOCA in a large dry PWR containment.

Table 2.2. Superheating for the short-term DBA LOCA at 150 seconds in a large dry PWR containment.

Table 2.3. Engineered safety features input parameters for the MELCOR demonstration calculation of the DBA MSLB in a large dry PWR containment.

Table 2.4. Maximum containment loads calculated for the DBA MSLB using CONTAIN and MELCOR codes with and without fan coolers.

Table 2.5. General modeling recommendations for a design basis MELCOR short-term high energy break calculation in a PWR large dry containment.

Table 2.6. Input guidance for modeling a short-term LOCA calculation in a PWR large dry

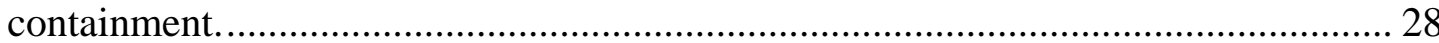

Table 2.7. Material diffusion lengths (meters) for various time constants (seconds)................ 29

Table 2.8. Maximum time-step (seconds) to prevent surface temperature oscillations............... 29

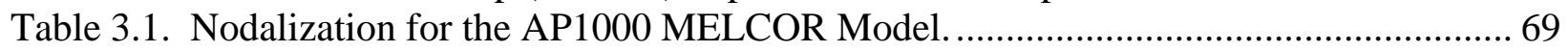

Table 3.2. Calculated peak pressure for LOCA (DECLG) event in the AP1000 plant.............. 70

Table 3.3. Calculated peak pressure and temperature for MSLB event in the AP1000 plant ..... 70

Table A-1. Comparison of CONTAIN/MELCOR model inputs for various flashing treatments used to predict short-term containment response for design basis accident loss-of-

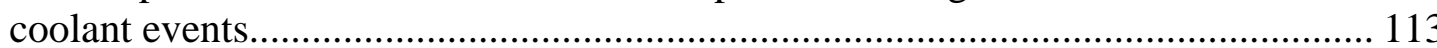

Table B-1. Typical fan cooler design parameters for normal and accident mode operation...... 142 


\section{Nomenclature}

CMT core makeup tank

CONTAIN computer code

CONTEMPT computer code

CPS specific heat

$\mathrm{CVH} \quad$ MELCOR model package

CVCS chemical and volume control system

CVTR Carolinas Virginia Tube Reactor

DBA design basis accident

$\mathrm{DCH}$ direct containment heating

DECLG double-ended cold leg

ECCS emergency core cooling system

EOS equation-of-state

ESF engineered safety feature

EXEC MELCOR model package

FCL MELCOR model fan cooler package

FSAR Final Safety Accident Report

FSER Final Safety Evaluation Report

HMTA heat and mass transfer analogy

HS MELCOR model package

LOCA loss-of-coolant accident

M\&E mass and enthalpy

MARCH computer code

MELCOR computer code

MELGEN preprocessor for MELCOR code

MP MELCOR model package

MSLB main steam line break

NRC Nuclear Regulatory Commission

PCS passive containment cooling system

PWR pressurized water reactor

RCS reactor coolant system

RHO density

SNL Sandia National Laboratories

SPR MELCOR model package

SRP Standard Review Plan

SRV safety relief valve

THC thermal conductivity

WGOTHIC computer code 


\section{Introduction}

\subsection{Background}

The MELCOR computer code [Gau05a, Gau05b] was developed by Sandia National Laboratories (SNL) under U.S. Nuclear Regulatory Commission (NRC) sponsorship to provide capability for independently auditing analyses submitted by reactor manufacturers and utilities. MELCOR is a fully integrated code (encompassing the reactor coolant system [RCS] and the containment building) that models the progression of postulated accidents in light water reactor power plants. Characteristics of accident progression that can be treated with MELCOR include the thermal-hydraulic response in the RCS, reactor cavity, containment and confinement buildings, and a variety of severe accident related processes.

To assess the adequacy of containment thermal-hydraulic modeling incorporated in the MELCOR code for application to pressurized water reactor (PWR) large dry containments, several selected demonstration designs were analyzed. This report documents MELCOR code demonstration calculations performed for postulated design basis accident (DBA) analysis (for loss-of-coolant accident [LOCA] and main steam line breaks [MSLBs]) inside containment that are compared to other code results. The NRC provides guidance through a variety of Standard Review Plans (SRPs) to nuclear reactor licensees about what types of calculations need to be performed and what calculational methods can be used to demonstrate the adequacy of their containment systems designs. As such, these licensing methods were used as a guidepost for assessing MELCOR's performance in design basis containment analysis.

The CONTAIN code [Mur97] also was developed by SNL and is a specialized computer code used to perform thermal-hydraulic calculations inside containment following a variety of postulated high energy breaks, and serves as a repository of accumulated knowledge in the area of containment analysis technology. CONTAIN incorporates the best current understanding of all relevant phenomena, and has an extensive validation base. The code is the NRC's principal containment analysis tool used to audit industry's safety analysis calculations. Accordingly, CONTAIN results are used to compare against MELCOR calculations. Specifically, targeted comparisons are evaluated for postulated short-term design basis LOCA and MSLB sequences inside PWR large dry containments. Appropriately, the code user guidance will be similar to the existing licensing framework, e.g., as specified in the relevant SRP section. Thus, the calculated results would tend to be bounding in nature or biased in a conservative manner.

Underlying insights were derived from previous efforts, such as:

- An Assessment of CONTAIN 2.0: A Focus on Containment Thermal Hydraulics (Including Hydrogen Distributions), USNRC ADAMS Accession No. ML022140438;

- CONTAIN Code Qualification Report/User Guide for Auditing Design Basis PWR Calculations, USNRC ADAMS Accession No. ML022490381; and

- An Assessment of MELCOR 1.8.6: Design Basis Accident Tests of the Carolinas Virginia Tube Reactor (CVTR) Containment (Including Selected Separate Effects Tests), SAND2008-1224.

Section 2 of this report covers a typical large dry containment design, and Section 3 covers the AP1000 containment design. Result comparisons for pressure and temperature loads are discussed, as is recommendation/guidance for applying MELCOR to DBA analysis. Supportive information is supplied in three appendices. Appendix A discusses comparative flashing models 
for CONTAIN and MELCOR codes during periods of two-phase blowdowns. Appendix B presents comparisons of code treatments or models for fan coolers, as well as a discussion regarding benchmarking fan cooler parameter input to fan cooler performance characteristics. Appendix C presents the code input files for the various demonstrations calculations for large dry containments for CONTAIN and MELCOR inputs, respectively. Because the AP1000 input files may contain vendor proprietary information, they are not included herein.

\subsection{Accident Phases}

Generally, a containment functional DBA evaluation includes calculations of the key containment loads, i.e., pressure and temperature effects associated with a postulated large rupture of the primary or secondary coolant system piping. The focus of this report is to provide adequate MELCOR code modeling guidance when performing design basis peak containment pressure and temperature transient response calculations as part of auditing the licensing basis of PWR large dry containment designs.

A number of short-term events may be partitioned into phases, which are dependent on the blowdown characteristics and the actuation of various engineered safety features (ESFs), e.g., containment sprays and fan coolers. Table 1.1 shows the sequence of events for two postulated accident types in a PWR large dry containment. For LOCAs, a two-phase steam/water injection in the lower containment region rapidly pressurizes the containment within 20-30 seconds. Following this initial pressurization, a less severe injection of nearly pure steam continues the pressurization event while the ESFs are activated. These safety features retard the rate of pressurization somewhat until the steam injection rate is reduced to a level where a short-term pressure maximum is reached, usually within five minutes. In the case of secondary coolant system ruptures, such as MSLBs, steam is injected into the containment in a continuous, but declining rate. As with the LOCAs, ESFs are activated during the high steam injection period, which typically lasts about a minute. The containment phases for the short-term analyses may be divided into a rapid pressurization phase and a slow pressurization phase. The maximum containment loads occur during the slow pressurization phase.

\subsection{Key Phenomena}

The key processes when analyzing the containment loads inside PWR large dry containments are: 1) the expansion and transport of high mass/energy releases into the containment free volume; 2) heat and mass transfer from the containment gas volume to structural passive heat sinks; and 3) containment pressure reduction due to functioning ESFs.

\subsection{Code Comparisons}

This report addresses the adequacy of the MELCOR code for DBA application in two ways: 1) equivalency to traditional analysis; and 2) confirmed conservatism derived from validated code exercises. First, the code is shown to provide equivalency to traditional codes, such as CONTEMPT [Har79] or CONTAIN. Establishment of a criterion for equivalency is based on the agreement between MELCOR and these traditional analyses where bottom-line comparisons are stressed, i.e., for pressures and temperatures. A quantitative measure of equivalency has been set for key result comparisons; an equivalent band for results is within $+/-5 \%$ variation (e.g., calculated differences in pressure gauge or temperature rise). This $5 \%$ value represents a relatively negligible deviation for calculated comparisons. 
In general, variations in results between codes may be grouped into two categories: 1) variation due to different settings of default parameters; and 2) variations caused either by phenomenological modeling differences or default options that invoke these differences. In the first category are input parameters that define heat transfer correlations for atmospheric flow regimes. Parity of the codes for this category is treated by suitable selection of parameters in the code input (matching), although the need to understand appropriate selection for licensing application remains an issue in some cases. The second category is often more difficult to address because clear application of conservative modeling is often not clear or easily applied via input. For example, into this category would be the treatment of simultaneous gas and liquid flow through break room pathways (single or two-phase flow capability), the modeling of film condensate on structures (maximum film accumulation or drain-down with film tracking), and modeling of flashing for two-phase water injections with liquid dropout (saturation or superheated final state).

Another potentially important code-to-code variation within the second category is exemplified by the default inter-compartmental flow modeling presented in the MELCOR code versus the CONTAIN code. The MELCOR code is representative of most lumped-parameter codes in that within the flow modeling there is an inherent tendency to over-mix compartments or cells that divide a relatively open region with large inter-connecting flow areas. The problem is especially troublesome for elevated injections that typically result in a stratified containment atmosphere. CONTAIN, on the other hand, while also being a lumped-parameter code, has addressed the over-mixing problem by including a hybrid flow solver that limits mixing under certain situations, such as when the flows are predominantly driven by differences in cell gas density variations. The second category differences are often imbedded in the modeling to such a degree that matching code-to-code results is not possible with simple and direct changes in input or defaults. Reasonable variations in key results (pressure and temperature) can therefore always be anticipated for different codes. The important question to answer is whether those variations are significant and point to critical concerns for model differences. To address this type of questioning, we again make use of the equivalency band to focus attention only on those causes that would make one code trend either to the equivalency band boundary or outside.

In each category, therefore, investigations are presented here to highlight, for containment model and scenario, the various situations that potentially lead to significant variation $(>5 \%)$ in results calculated by MELCOR and CONTAIN. As will be shown, differences in defaults can largely be dealt with by input, and modeling differences such as mixing, while noted, are often minimized by the containment type, scenario, and otherwise conservative approach emphasized for DBA containment analysis.

\subsection{User Guidance and Limitations}

Sections 2 and 3 of this report present a demonstration calculation for a specific containment type along with a particular postulated accident sequence; the selection of key MELCOR userdefined models is discussed. Appendix $\mathrm{C}$ includes the commented input listing for the PWR large dry containment demonstration case. Recommendations are made in each section to guide the user in selecting parameters that enable equivalency and/or conservative predictions of key results. Furthermore, by using any of these modeling or parametric recommendations, userdirected code sensitivities can be pursued in an efficient manner.

A typical design basis PWR large dry containment application uses a single compartment to model the containment. As a result, the geometric descriptions of most containments found in 
plant safety analysis reports are for single compartment analyses. In many cases, the single compartment analyses, where it is assumed that the containment is characterized by a uniformly mixed volume, has been shown to be conservative for maximum pressure estimates based on comparisons of multiple and single compartment CONTAIN analyses of various scaled and configured containment experiments. For LOCAs where the break location is at a low elevation and the containment is relatively open, the degree of stratification is minimal and a single compartment analysis is appropriate even for long-term scenarios. Additionally, most containments are designed with water spray systems that create a high level of turbulence when activated shortly after a pipe rupture. These spray systems induce mixing currents within large open regions of the containment so that an assumption of a uniform atmosphere in the containment is reasonably accurate. Yet, in some cases we can anticipate transitory degrees of stratification, as in the case of an elevated secondary system break. Within the context of DBAs, however, these stratifications are also rapidly diminished by spray-induced turbulence.

In the AP1000, active containment mixing systems are not incorporated in the design; therefore, local temperatures and gas/steam mixture concentrations need to be better resolved for more accurate pressure predictions. As such, the containment volume is subdivided into compartmental regions. 


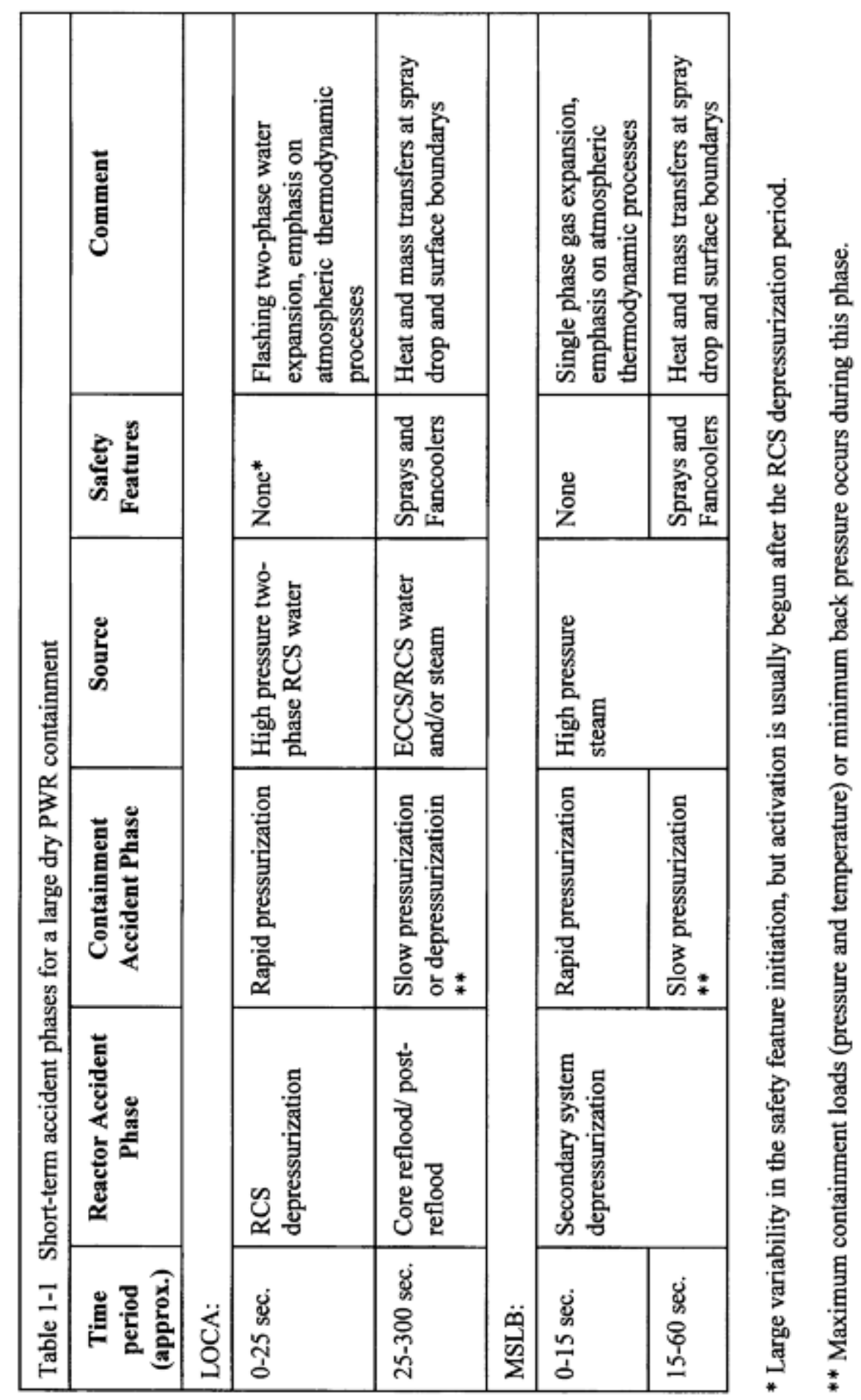

Table 1.1. Short-term accident phases for a large dry PWR containment. 


\section{Large Dry Containment Analysis}

In Section 2, methods are discussed that can be used to model the DBA response of PWR large dry containments with MELCOR. Figure 2.1 depicts a typical large dry containment, showing the large and relatively open containment space within the reactor building. The open space above the operation deck, surrounding the steam generators, represents $\sim 80 \%$ of the free volume within the building.

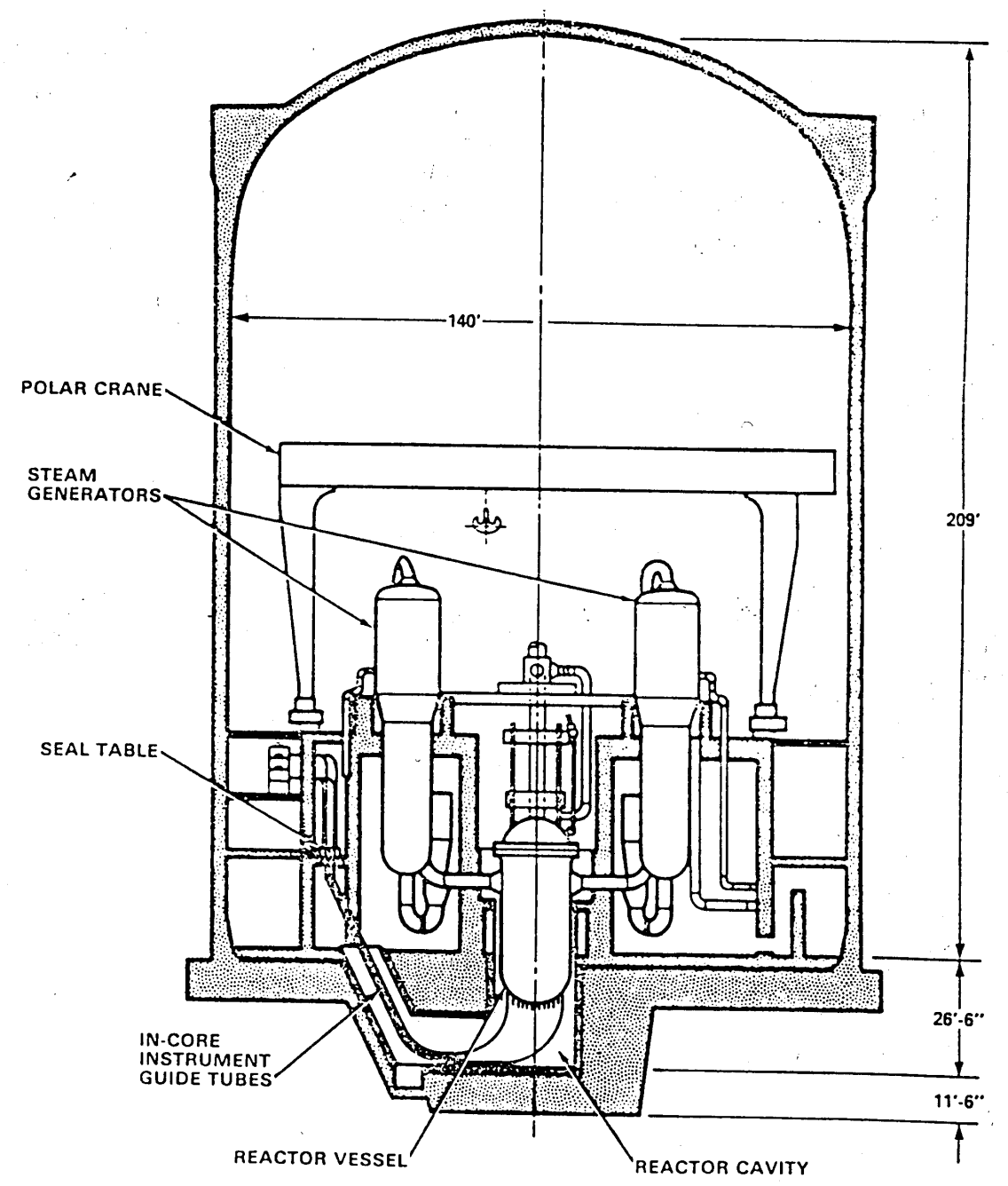

Figure 2.1 Typical large dry containment showing the openness of the large volume above lower compartments.

For large dry containments, two types of short-term accident types are discussed and calculated: 1) the design basis LOCA scenario for determining peak pressure and temperature conditions inside containment during a two-phase water blowdown from the reactor cooling system; and 2) the design basis MSLB scenario for demonstrating a similar evaluation for a single phase steam blowdown from the secondary reactor cooling system. These two types of accidents, discussed in Sections 2.1 and 2.2, respectively, include the actuation of the ESF to mitigate the pressure and 
temperature increases during the slow pressurization phase of the accident. In the demonstration calculations for each accident type, the containment free volume and passive heat sinks are identical. Only maximum containment loads are investigated in this report, meaning that the inputs are biased accordingly (no atmospheric/pool heat or mass transfer, no atmospheric radiation, and maximum steel shell-to-concrete air gaps included, as well as paint resistances).

\subsection{LOCA Short-term Accident Analysis}

\subsubsection{Scenario and Key Result}

The LOCA scenario, summarized in Table 1.1, is initiated with a large break (typically, doubleended) rupture in either the cold or hot leg primary system coolant pipe attached to the reactor pressure vessel. A break of this type will produce a rapid depressurization of the reactor pressure vessel (primary system). The blowdown of the pressure vessel will release initially high pressure water into the containment followed by a much smaller release of highly superheated steam (Figure 2.2). The high pressure liquid water will flash and subsequently condense in the atmosphere as liquid droplets that quickly deposit on the containment building floor. The expanding steam component will rapidly pressurize the containment building, with a portion of the hot steam condensing on colder containment structures. The rapid pressurization phase of the accident, which usually lasts 20-30 seconds during the vessel blowdown, is responsible for most of the pressure/temperature rise that occurs in the containment during a LOCA event (Figure 2.3). Because the process is so rapid, the pressurization is nearly adiabatic and limited through the accommodation of the blowdown steam in the large containment free volume.

Shortly after the rapid pressurization phase, a reflooding of the reactor vessel occurs as the emergency cooling system is activated. Accumulator water is injected, the coolant water is heated, and steaming occurs; steam at a reduced rate, as compared to the blowdown, is injected into the containment (Figure 2.4). The addition of the reflood steam source to the containment continues the pressurization process, as shown in Figure 2.3.

A signal to activate the ESF is initiated by the pressure increase in the containment. Times for initiation may range from a few seconds to tens of seconds. The safety features actively remove energy from the containment atmosphere by condensing out steam on spray droplets and on the condensing coils of the fan coolers. Additionally, during this extended slow pressurization period, large amounts of steam are condensing on relatively cold structures throughout the containment building. The removal of steam by condensation is a major contributing process, controlling the pressure and temperature maximums reached during the accident event. For example, Figure 2.5 shows pressure profiles for various calculations that selectively exclude the fan coolers, sprays, and passive heat sinks, with the largest change in containment pressure shown in the case without passive heat sinks.

\subsubsection{Code Comparisons}

Pressure responses calculated with MELCOR for a PWR LOCA event can be compared to results obtained using the CONTAIN code, where the MELCOR results are overlaid on the CONTAIN equivalency band for pressure, +/- 5\% variance. The equivalency band can, in turn, be derived with either non-ideal or (default) ideal equations-of-state (EOS) for water using the CONTAIN code. Previous CONTAIN analyses [Til02a] have been performed using the code default, ideal EOS for water. A discussion of the CONTAIN EOS implementation on containment pressure during a water flashing condition (LOCA) is discussed in Appendix A. In 
general, the default treatment produces a slightly higher pressure than obtained using the nonideal EOS for water. Because MELCOR uses water properties that are also based on the nonideal EOS, all comparisons to CONTAIN are based on results obtained using the non-ideal EOS for water. Comparisons between MELCOR and CONTAIN (equivalency band) for containment gas pressure and temperature are shown in Figures 2.6 and 2.7, respectively.

Tabulated pressure and temperature maximums during the accident phases are given in Table 2.1 for MELCOR compared to both the CONTAIN and CONTEMPT predicted maximums. These results show that when the recommendations for short-term LOCA modeling and input preparation, as discussed below, are followed, the MELCOR calculation for pressure loading is consistent with previously qualified containment analysis methods, i.e., CONTAIN and CONTEMPT codes. The sensitivity calculations shown in Figure 2.5 demonstrate that the key phenomena/processes associated with a maximum pressure analysis are, for the slow pressurization phase, heat and mass transfer to passive heat sinks and, secondly, heat and mass removal from the atmosphere due to the spray system. The addition of fan coolers is observed to have a small effect. These results are consistent with the previously qualified CONTAIN code results, and therefore demonstrate the adequacy of the MELCOR code to calculate the design basis maximum pressure loads for a large dry containment, specifically when dominated by the key phenomena as represented by condensation heat transfer to the walls of the containment building, and from bulk condensation in the atmosphere during spray periods.

With respect to the containment gas (or vapor) temperature comparisons, it is apparent that there is a difference in the models that produce, in the case of MELCOR, a slightly higher temperature calculation during the slow pressurization phase of the accident. During the slow pressurization period, both vapor mass and sensible heat transfer from the containment atmosphere are occurring as a result of the ESF activation. For both CONTAIN and MELCOR codes, ESF activation serves to reduce containment superheating caused by the injection of highly superheated steam into the containment. In the case of the MELCOR code, the superheat reduction is somewhat less, due primarily to differences in the spray heat and mass transfer modeling. The relative effect for energy transfer is demonstrated with the temperature results presented in Table 2.2 for the amount of containment superheating predicted for each code at 150 seconds, excluding selectively each ESF and then all ESF features. It is noted that for both codes, the variations in saturation temperatures for each case is essentially identical, and therefore indicates that the increased pressure resulting from superheating (MELCOR) during the slow pressurization phase is minor. Because energy transfer during the slow pressurization phase is dominated by mass transfer (condensation on cool structures), the slight over-prediction of superheating by the MELCOR spray modeling is not considered significant for LOCA containment analysis. Nevertheless, a small adjustment in spray droplet size can be shown to alter the degree to which the gas temperature profile trends to the saturation line. As an example, the gas temperatures for various spray droplet sizes are shown in Figures 2.8 through 2.10. (The similar responses for Figures 2.8 and 2.9 indicate the reduced sensitivity for temperature when spray droplet diameters are input less than $\sim 0.00025$ meters.) Reducing the spray droplet size (diameter) in the MELCOR calculation from CONTAIN input value of 0.0005 meters to 0.00025 meters (50\% reduction), however, causes a drop in superheating such that the MELCOR gas temperature profile lies within the CONTAIN calculated equivalency band for temperature 
(Figure 2.11). ${ }^{1}$ The MELCOR pressure comparisons with respect to the CONTAIN equivalency band for spray droplet diameters of 0.0005 meters and 0.00025 meters are shown in Figure 2.12.

Code adequacy with respect to heat transfer during the rapid pressurization phase is an area that needs further discussion. In traditional containment analysis methods, it is common to specify an empirical correlation, i.e., the Tagami correlation, to estimate steam condensation on structures during the rapid pressurization period when forced convective condensation is occurring. However, in a LOCA event the rapid pressurization is of such short duration that forced convective condensation during this phase of the accident is relatively insignificant for the prediction of containment pressure and temperature. Because the forced convective condensation phenomenon is relatively unimportant during the rapid pressurization phase, the MELCOR code with a free convective condensation model is adequate.

We extend the use of free convective condensation modeling into the slow pressurization phase, realizing that this phase of an accident is characterized by natural circulation convection processes, and the free convective model is nearly equivalent to results obtained using the Uchida empirical correlation, for instance in the CONTEMPT calculation during this phase of the accident. Some added conservatism is interjected into the MELCOR and CONTAIN heat and mass transfer modeling, compared to the CONTEMPT model, by accounting for liquid film thermal resistance on the surface of passive heat sinks.

In the MELCOR code, condensation phenomena, whether occurring on structure surfaces or spray droplet surface, is determined using a heat and mass transfer analogy (HMTA) methodology where steam diffuses through an air/steam boundary layer next to the condensing interface. This method for treating steam condensation in the presence of a non-condensible gas has been well documented and validated in the open literature and through relevant MELCOR code assessments [Til08]. For the prediction of short-term maximum pressure and temperature occurring during both the rapid and slow pressurization periods, the conservative nature of the calculation is assured through the use of a free convective algorithm that establishes the analogy between heat and mass transfer at a structure surface, and by assuming immediate and uniform mixing of steam and gases throughout the containment volume. With a single compartment model, the highest average air concentration (i.e., the largest resistance affecting steam transported to a liquid film interface) is approximated.

During the slow pressurization phase, in addition to the large removal of steam from condensation on structures, spray pressure suppression can also be important, as shown in Figure 2.5. In fact, one conservative assumption for the maximum containment loads analysis limits the spray activation to only one spray train during the accident. For the spray processes, the MELCOR spray model has been validated through separate effects (JAERI spray tests) and integral effects tests (Carolinas Virginia Tube Reactor [CVTR] spray tests) documented in reference Til08. The test comparisons show that the code's spray modeling accurately predicts pressure suppression by spray sources in a containment atmosphere. Additionally, improvement in atmosphere temperature reduction (i.e., following the saturation curve) has been indicated in separate effects tests where the default spray droplet size is reduced from the default $(0.001$ meters) to a setting of 0.0002 meters to minimize atmospheric superheating. In the case of the

\footnotetext{
${ }^{1}$ Note that the spray models for each code are based on a heat and mass transfer analogy for condensation/evaporation on droplets; however, the implementation of each model is slightly different, which can explain a variation of superheating within the range of spray droplet size where temperature sensitivity is demonstrated. Spray droplet size (median diameter) for a typical spray nozzle is reported as ranging between 200 to $500 \mu \mathrm{m}$ [Spray Engineering Company, specification report on Spraco model 1713A nozzle].
} 
fan coolers, which represent a less important phenomenon for maximum load analysis, there have been no validation tests of fan cooler modeling for pressure suppression. In this modeling area, it has been sufficient to indicate by model comparison that the MELCOR fan cooler model results are equivalent to the energy removal rates calculated by the CONTAIN code. (For further discussion on fan cooler modeling during accident events (LOCA) that involve saturated atmospheric conditions, see Appendix B).

All comparative results plotted in Figures 2.6 and 2.7 came from a single cell CONTAIN and MELCOR calculation. The input decks for these calculations are provided in Appendix C.

\subsection{MSLB Short-term Accident Analysis}

\subsubsection{Scenario and Key Result}

The MSLB scenario, summarized in Table 1.1, is initiated with a break in the secondary cooling system, i.e., the main steam line connected to the steam generator. A break in the secondary cooling system can occur in a region above the operation deck, and therefore is typically at an elevated location compared to a primary system pipe break. The blowdown of the secondary system is limited by the inventory of steam/water contained within the system. High pressure steam is released from the break and will rapidly pressurize the containment. The injection, shown in Figure 2.13, is characterized as a stream of single phase superheated steam, lasting approximately one minute. As the hot steam expands to pressurize the containment atmosphere, some of the steam will initially condense on the colder containment structures, and then additional condensation and pressure reduction occurs following activation of the ESFs (fan coolers and sprays). The main difference between the LOCA and MSLB scenarios is in the injection characteristics where the single phase MSLB results in a significant degree of containment gas/vapor superheating during the blowdown; whereas, the LOCA two-phase injection produces a pressurization profile (for a single cell configuration) that essentially follows the saturation curve, with little or no superheating. Consequently, the MSLB event presents unique challenges to the containment modeling, specifically the treatment of sensible to latent heat transfers for heat sinks (e.g., containment shell) that can affect atmospheric superheating as well as the performance of certain ESFs (e.g., fan cooler) operating in a highly superheated environment.

Gas pressure and temperature profiles calculated with MELCOR for the single cell MSLB demonstration case that include both fan coolers and sprays are shown in Figures 2.14 and 2.15. (ESF operating parameters are listed in Table 2.3.) A single pair of fan coolers is activated at 13 seconds and the sprays begin injection at 45 seconds. The steam flow to the containment from the secondary system break terminates at 60 seconds, and the calculation continues for another $\sim 40$ seconds. A significant reduction of pressure from the maximum value, at $\sim 60$ seconds, is noted when the steam source terminates. In the case of gas temperatures, a maximum temperature is observed to occur early, just prior to the activation of sprays at 45 seconds. The atmosphere is significantly superheated during the event, as shown in Figure 2.16, where the maximum superheating is $\sim 75 \mathrm{~K}$. Superheating is reduced during the spray period, where at 100 seconds superheating is less than $20 \mathrm{~K}$. During the spray period when the steam is being injected, most of the spray incoming water is evaporated, causing a rapid drop in the containment superheating.

The three contributors to heat removal from the atmosphere are passive heat sinks (structures), sprays, and the fan coolers. The profiles for heat removal for each contributor are shown in 
Figure 2.17. From these profiles it is obvious that heat transfer to heat sinks (mainly due to condensation) is the major contributor limiting pressure and gas temperature. In terms of the active ESFs (sprays and fan coolers), sprays are seen to provide the more effective pressure and temperature control. The fan cooler heat removal is modeled in the MELCOR code using a MARCH-type fan cooler model that is calibrated to saturation temperatures (see Appendix B); however, during periods of high superheating, the model tends to over-predict heat removal by approximately a factor of two for the demonstration scenario. Due to the low importance ranking of fan cooler performance for containment loads analysis, the fan cooler heat removal error is of minor consequence to the calculated pressure and gas temperature profiles for this MSLB event.

\subsubsection{Code Comparisons}

The CONTAIN code application for the MSLB event (with high superheating), using the mechanistic fan cooler modeling, is known to experience difficulties associated with numerical convergence. The numerical problems are aggravated further when the non-ideal EOS for water is specified; consequently, a successful CONTAIN calculation with the non-ideal EOS has not been achieved for these demonstration comparisons. The first calculation of the MSLB event using the CONTAIN code was therefore performed using an ideal EOS for water. A second effort was made to demonstrate that without inclusion of fan cooler heat removal, the containment pressures and temperatures are nearly identical to the demonstration case with the fan cooler modeling. Finally, a more consistent comparison between codes was performed using the non-ideal EOS for water option in CONTAIN (without fan cooler modeling) that compared favorably for maximum containment loads with a similar MELCOR MSLB case. These series of comparisons are summarized in Table 2.4, and discussed further below.

Pressure and temperature responses calculated with MELCOR and compared to results using the CONTAIN code (ideal EOS) are shown in Figures 2.18 and 2.19. These figures show that the MELCOR results for pressure lie within the CONTAIN equivalency band; however, there is a trend observed for MELCOR where the calculated temperature rises toward the upper boundary of the CONTAIN equivalency band as the maximum temperature is approached.

A comparison of various CONTAIN and MELCOR calculations that show the relative insensitivity of pressure to fan cooler operation and, in the case of CONTAIN, an optional choice using either ideal or non-ideal EOS for water, are shown in Figure 2.20. Figure 2.21 provides an identical comparison of calculations but for containment gas temperatures. In this figure, the insensitivity shown for fan cooler operation is also demonstrated; however, the effect on gas temperature between ideal and non-ideal EOS for water is apparent, and the agreement between CONTAIN and MELCOR for the calculations where both codes employ similar EOS (non-ideal EOS) is clearly indicated prior to the spray period. Comparisons of pressure and temperature for the two codes, now obtained without fan coolers and using non-ideal EOS for water, are shown in Figures 2.22 and 2.23.

As in the previous discussion for the LOCA event, we also see that there is a greater tendency toward superheating for MELCOR during spray periods when both the CONTAIN and MELCOR spray models use the same initial spray droplets diameters, i.e., 0.0005 meters. Reducing the MELCOR spray droplet diameters by 50\% (changing the droplet diameter input from 0.0005 meters to 0.00025 meters) improves the agreement between codes, as observed in Figures 2.24 and 2.25 . 


\subsection{User Guidance for Single Cell Containment Model}

\subsubsection{LOCA Events}

As discussed in Section 1, there are only a few phenomena that affect key results for the large dry short-term scenarios. Table 2.5 shows modeling recommendations for those phenomena, consistent with the code qualification criteria established here. In the following discussion on input preparation, these recommendations are discussed in terms of specific MELCOR input (Table 2.6). In general, the recommendations follow those for the qualified CONTAIN code as listed in reference Til02a. Details and formatting of the modeling inputs can be found in the MELCOR and MELGEN input listings provided in Appendix C.

Time-stepping. The maximum time-step is selected primarily based on the need for accuracy (small time-stepping) in both the advancement of the control volume dependent variables (pressure and temperature) and the energy transfer from atmosphere to structures. To meet accuracy criteria, the time-stepping is limited to values of $\sim 0.01$ seconds. With respect to energy transfers, the structure surface node thickness is kept to a fraction of the material diffusion length (Table 2.7) and small enough to prevent surface temperature oscillations that may develop for an explicit coupling of atmosphere and structure energy transfers (Table 2.8). ${ }^{2}$

Nodalization and thermodynamic model. As noted above, a single control volume is used to conservatively predict the slow pressurization maximums due to a slight over-prediction of containment air mass fraction using this model. The control volume input for specifying thermodynamic modeling (nonequilibrium atmosphere and pool coupling) is a standard setting, and geometry is set for equivalency to applied code input or plant data.

Flashing and liquid water dropout. A characteristic feature of a LOCA blowdown is that the initial mass release is high pressure liquid water that flashes on entering the containment. Unflashed water can remain suspended in the atmosphere or drop out, moving directly to the containment floor or pool. The most conservative estimate for energy transfer to the atmosphere is to assume complete mixing of all liquid water with the atmosphere (temperature equilibrium or temperature flashing) with a dropout of unflashed water. This type of modeling is specified by injecting the released liquid water as an external mass source to the vapor component (MASS.3) of the containment atmosphere. Dropout is modeled by specifying the parameter IPFSW=2. The conservative feature of this modeling is demonstrated in Figure 2.26, where the temperature flash model is compared to two alternative models (pressure flash with dropout and temperature flash without dropout). For example, the pressure flash model is defined by modeling the amount of unflashed liquid water with a constant enthalpy expansion of two-phase water at the containment pressure. A case with no dropout is modeled by setting the allowed density of suspended fog to a high value $\left(10 \mathrm{~kg} / \mathrm{m}^{3}\right)$ which will always be above the calculated value.

Atmosphere-to-pool heat and mass transfer. Convective energy and mass transfer for horizontal, pool surface to the overlying atmosphere is difficult to accurately model; therefore, for conservative purposes it has been common practice for audit calculations to eliminate this transfer process. For MELCOR, the elimination is accomplished by setting the sensitivity

\footnotetext{
${ }^{2}$ Oscillation time-step limit derived from Equation (2-2 and 2-3) in Mur97, page 2-9. Note: surface paint is excluded from this time-step limitation because paint thickness is incorporated only as an additional resistance to energy flow in the first or surface mesh; therefore, paint thickness is not explicitly modeled for structures. This treatment for incorporating paint resistance but not capacity within a surface mesh is essentially the method implemented for painted surfaces as treated in the CONTAIN code.
} 
coefficients that define the atmosphere-to-pool convective correlation to a very small value. The sensitivity coefficient is 4407 .

Material properties. Material properties of all materials (steel, stainless steel, and concrete) are specified in the MP package input. These properties (specific heat-CPS, thermal conductivityTHC, density - RHO) are set to equivalent values included in applied codes or plant data. Because MELCOR does not have an explicit modeling method for treating painted surfaces, a method must be specified. One approach is similar to that used in the CONTAIN code, which is to add the thermal resistance of the paint thickness to the total resistance of the structure surface node. The effective, painted surface node conductivity is therefore included in the material properties package input, and specified for the surface node of painted structures in the HS package.

Structure heat and mass transfer. It has been common practice for licensing codes, such as CONTAIN, to use best-estimate natural (free) convective correlations for conservative heat and mass transfer calculations during both the rapid and slow pressurization phase of a LOCA containment analysis. The best-estimate correlations are based on validation exercises conducted with both separate and integral tests that include the effects of non-condensible gases on the transfer process. To use a best-estimate correlation for natural convective heat and mass transfer with MELCOR, the sensitivity coefficient 4110 that sets the correlation multiplier is changed from the default value 0.10 to 0.14 (CONTAIN equivalent correlation).

By default, all structures (inclined) are modeled with film tracking in MELCOR Version 1.8.6, where the structures are assumed to exist as a single structure in a film tracking network of one. As a result, the physical length of the structure directly affects the quasi-steady film thickness. In many codes, film tracking is either not modeled for licensing (CONTEMPT) or set to a maximum value to assure a conservative (reduced) prediction (CONTAIN) for energy transfer. For MELCOR, we set the structure length to a maximum value consistent with the height of the compartment within which the structure is contained. In most cases, if the structure geometry is taken from code input, the structure length BNDZL will be set to the specified characteristic length of the structure.

Engineered Safety Feature-Sprays. The spray modeling input specifies the values for spray temperature, flow rate, and droplet diameter based on equivalency with applied code input or plant data. In the case of the droplet diameter, spray efficiency can be affected by the specified diameter. Generally, the mass mean diameter for the nozzle spray droplet distribution is a reasonable choice. However, it should be noted that using a large droplet diameter can increase superheating in the containment. For the CONTAIN code, the default spray droplet is set to 0.0005 meters; MELCOR default spray droplet diameter is set higher to 0.001 meters. For consistency with validation studies of both separate and integral tests, we use the smaller droplet diameter of 0.0005 meters for the MELCOR LOCA calculation to improve spray efficiency and reduce the degree of containment superheating. However, sensitivity analysis with respect to spray droplet size is recommended where the size should be varied by $\sim 50 \%$ to provide a reasonable uncertainty on atmospheric superheating. In general, the separate and integral effects tests for sprays [Til08] have tended to show that spray activation will tend to rapidly reduce atmospheric temperature, along a saturation curve; therefore, results from a smaller spray droplet diameter calculation, as suggested here, is likely to provide a more realistic gas temperature profile during spray activation.

Engineered Safety Feature-Fan coolers. The fan cooler modeling in MELCOR is a nonmechanistic model that uses the heat transfer correlation developed for the MARCH 
containment code. The model has been modified to include identification of the energy transfer from the atmosphere by sensible and latent heat, where the fraction of sensible heat is specified by user input. In the LOCA calculations, the sensible heat fraction is set to 0.15. Because fan cooler ratings are provided, generally, for both operation and accident conditions ( $400 \mathrm{~K})$, it is important that the rating input for the MELCOR model be calibrated according to accident conditions. This calibration or benchmarking of the model to actual fan cooler performance is discussed in Appendix B. In most cases, only a restricted number or pairs of fan coolers are allowed for licensing calculations, and therefore the heat removal contribution of fan coolers as one element of the total ESFs is relatively insignificant. Consequently, a low-order accurate fan cooler model is adequate for licensing purposes. The rating parameter used in the demonstration calculation is based on a typical single pair of fan coolers operating at accident conditions of $\sim 400 \mathrm{~K}$ (saturated), with a heat removal rate of $20 \mathrm{MW} /$ fan cooler (see Appendix B).

\subsubsection{MSLB Events}

The MELCOR demonstration input deck for the MSLB event was prepared identically to the case used for the LOCA scenario, except for the break source where two-phase water was replaced with the single phase steam injection from the secondary system. Consequently, the setting of parameters listed in Table 2.5 also applies to a short-term MSLB event in a large dry PWR containment.

In the case of the MSLB scenario, in addition to the qualification of the code through benchmarking with CONTAIN, it is important to point out that the MELCOR code has been applied to an integral test (CVTR facility) for an MSLB-type scenario, with documentation provided in reference Til08. Included in this referenced report are appendices that also address separate effects test comparison for the MELCOR heat and mass transfer modeling in both saturated and superheated environments. Furthermore, the same reference also includes comparisons of calculated containment loads to measurements taken during spray periods within the CVTR facility and for separate effects tests in a single volume vessel. These validation exercises supported the conclusion that key models for MSLB events (passive heat and mass transfer modeling, and spray modeling) are appropriately implemented into the MELCOR code.

Additionally, it was concluded in reference Til08, that single volume modeling of the containments during the CVTR tests produces a conservative estimate of containment maximum loads compared to more detailed multi-cell representations that more accurately capture temperature stratification effects for an elevated MSLB steam injection. This conclusion however is geometry- and scenario-dependent (for example, the modeling may be dependent on spray or fan cooler activation time), and therefore we cannot make a general statement that single cell containment models are always conservative compared to multi-cell models (see Section 3). In most cases, however, where spray systems are activated and containment atmosphere approaches a uniform steam/air mixture, a recommendation that MSLB events be calculated with single volume containment models as with the LOCA events (well-mixed atmosphere due to the low elevation of the break) is appropriate.

The demonstration calculations pointed out a weakness in the MELCOR modeling for fan coolers during periods of high superheating. The MARCH-type fan cooler modeling that is the basis for the MELCOR fan cooler package FCL is a modeling approach that is only applicable to scenarios where saturated conditions exist in the containment. The FCL models make no distinction between gas temperatures that are superheated or saturated. As a result, significant over-prediction of heat removal can be observed for this fan cooler model. Because over- 
prediction of heat removal represents a non-conservative approach, this fan cooler model is not recommended for use in scenarios like the MSLB event where significant superheating may occur. Fortunately, the fan cooler heat removal rates are only a small contributor to the total heat extraction during a typical MSLB event, and therefore whether or not the fan coolers are included makes little difference to the maximum containment loads predicted. Because nonconservative models are not an acceptable approach for design basis code applications, we recommend the MELCOR FCL package not be used, or if used, that sensitivity calculations be performed to show that the fan cooler modeling has essentially only a minor affect on the predicted loads.

The spray modeling in the MELCOR code is similar to the CONTAIN treatment that uses a heat and mass transfer analogy to determine mass transfers (condensation/evaporation) from atmosphere to spray droplets. The approach is similar, yet the equations for establishing various parameters used in the models (e.g., droplet Reynolds number) are different and, therefore, there are some small variations in the results, as reflected in the calculated superheat declining rates when sprays are activated. Because this trend observed for calculated superheating appears conservative with respect to CONTAIN results (and results in a longer period for the sprays to eliminate superheating), it is recommended that the suggestions in Table 2.6 be followed, where the spray droplet size for injection be based on the spray nozzle mean droplet diameter, and that sensitivity calculations be considered with the spray droplet size reduced by $50 \%$.

Table 2.1. Maximum pressure and temperatures for a short-term DBA LOCA in a large dry PWR containment.

\begin{tabular}{|c|c|c|c|c|c|c|}
\hline \multirow{2}{*}{$\begin{array}{c}\text { Accident } \\
\text { Phase }\end{array}$} & \multicolumn{3}{|c|}{ Maximum Pressure, bar } & \multicolumn{3}{c|}{ Maximum Temperature, K } \\
\cline { 2 - 7 } & MELCOR & CONTAIN & CONTEMPT & MELCOR & CONTAIN & CONTEMPT \\
\hline $\begin{array}{c}\text { Rapid } \\
\text { Pressurization }\end{array}$ & 4.17 & 4.17 & 4.12 & 405 & 405 & 406 \\
\hline $\begin{array}{c}\text { Slow } \\
\text { Pressurization }\end{array}$ & 5.0 & 5.10 & 5.07 & 428 & 420 & 417 \\
\hline
\end{tabular}

Table 2.2. Superheating for the short-term DBA LOCA at 150 seconds in a large dry PWR containment.

\begin{tabular}{|l|l|l|l|l|l|l|l|l|}
\hline $\begin{array}{c}\text { Calculation I } \\
\text { Degrees }\end{array}$ & \multicolumn{3}{|c|}{ Demo } & \multicolumn{2}{c|}{$\begin{array}{c}\text { No Spray or Fan } \\
\text { Cooler }\end{array}$} & \multicolumn{2}{c|}{ No Spray } & \multicolumn{2}{c|}{ No Fan Cooler } \\
\hline & CONTAIN & MELCOR & CONTAIN & MELCOR & CONTAIN & MELCOR & CONTAIN & MELCOR \\
\hline Tvap, K & 415.01 & 427.23 & 452.32 & 450.58 & 450.64 & 450.86 & 415.86 & 427.46 \\
\hline Tsat, K & 410.82 & 410.56 & 410.17 & 412.98 & 409.82 & 412.01 & 411.24 & 411.39 \\
\hline $\begin{array}{l}\text { Superheat, } \\
\text { Degrees K }\end{array}$ & 4.2 & 16.7 & 42.15 & 37.6 & 40.82 & 38.9 & 4.29 & 16.04 \\
\hline
\end{tabular}

Table 2.3. Engineered safety features input parameters for the MELCOR demonstration calculation of the DBA MSLB in a large dry PWR containment.

\begin{tabular}{|l|l|l|l|l|}
\hline \multicolumn{2}{|c|}{ Spray } & \multicolumn{2}{c|}{ Fan Cooler } \\
\hline $\begin{array}{l}\text { Spray droplet } \\
\text { diameter }(\mathbf{m})\end{array}$ & $\begin{array}{l}\text { Spray flow } \\
\left(\mathbf{m}^{3} / \mathbf{s}\right)\end{array}$ & $\begin{array}{l}\text { Spray } \\
\text { temperature (K) }\end{array}$ & $\begin{array}{l}\text { Rated capacity } \\
(\mathrm{MW})\end{array}$ & $\begin{array}{l}\text { Rated inlet gas } \\
\text { temperature (K) }\end{array}$ \\
\hline 0.0005 & 0.110 & 310.78 & 19 & 400 \\
\hline
\end{tabular}


Table 2.4. Maximum containment loads calculated for the DBA MSLB using CONTAIN and MELCOR codes with and without fan coolers.

\begin{tabular}{|l|l|l|l|l|}
\hline \multirow{2}{*}{$\begin{array}{l}\text { Containment } \\
\text { Maximum Load }\end{array}$} & \multicolumn{2}{|c|}{ CONTAIN* $^{*}$} & \multicolumn{2}{c|}{ MELCOR $^{\star *}$} \\
\cline { 2 - 5 } & $\begin{array}{l}\text { Fan Coolers } \\
\text { Ideal EOS }\end{array}$ & $\begin{array}{l}\text { No Fan Coolers } \\
\text { Non-ideal EOS }\end{array}$ & $\begin{array}{l}\text { Fan Coolers } \\
\text { Non-ideal EOS }\end{array}$ & $\begin{array}{l}\text { No Fan Coolers } \\
\text { Non-ideal EOS }\end{array}$ \\
\hline Temperature, K & 473 & 479 & 478 & 479 \\
\hline Pressure, bar & 4.78 & 4.81 & 4.71 & 4.77 \\
\hline
\end{tabular}

$*$ Injection spray diameter $=0.0005$ meters

$* *$ Injection spray diameter $=0.0005$ or 0.00025 meters

Table 2.5. General modeling recommendations for a design basis MELCOR short-term high energy break calculation in a PWR large dry containment.

\begin{tabular}{|l|l|}
\hline \multicolumn{1}{|c|}{ Phenomena } & \multicolumn{1}{c|}{ Modeling Recommendations } \\
\hline Multi-component gas composition & Nodalize the containment as a single compartment. \\
\hline Two-phase liquid expansion & $\begin{array}{l}\text { Use a temperature flash method for liquid expansion, with } \\
\text { dropout of unflashed liquid from the atmosphere. }\end{array}$ \\
\hline Convective condensation & $\begin{array}{l}\text { Use a free convective heat transfer correlation for the HMTA } \\
\text { modeling on vertical surfaces. }\end{array}$ \\
\hline Structure heat transfer & $\begin{array}{l}\text { Account for liquid film and paint resistance for surfaces; include } \\
\text { any steel-liner-to-concrete air gaps at constant, full width. }\end{array}$ \\
\hline Spray droplet heat and mass transfer & $\begin{array}{l}\text { Use a mass mean spray droplet size for the injected spray droplet } \\
\text { diameter. }\end{array}$ \\
\hline Fan cooler heat and mass transfer & $\begin{array}{l}\text { Calibrate the fan cooler input parameters to specified fan cooler } \\
\text { heat transfer curves at accident conditions. }\end{array}$ \\
\hline
\end{tabular}

Table 2.6. Input guidance for modeling a short-term LOCA calculation in a PWR large dry containment.

\begin{tabular}{|c|c|c|}
\hline Input Package & Parameter(s) & Comment \\
\hline \multicolumn{3}{|l|}{ MELCOR: } \\
\hline EXEC & DTMAX $\sim 0.01$ seconds & $\begin{array}{l}\text { Small time-step for accuracy, and to avoid surface } \\
\text { temperature oscillations. }\end{array}$ \\
\hline \multicolumn{3}{|l|}{ MELGEN: } \\
\hline $\mathrm{CVH}$ & $\begin{array}{l}\text { CVnnn00, ICVTHR = 2; } \\
\text { CVnnnBk }\end{array}$ & $\begin{array}{l}\text { Single cell nodalization, nonequilibrium } \\
\text { thermodynamics; free volume equivalency. }\end{array}$ \\
\hline $\mathrm{CVH}$ & IPFSW $=2$ & $\begin{array}{l}\text { Pool allowed, no fog; condensed liquid water } \\
\text { moved to pool. }\end{array}$ \\
\hline $\mathrm{CVH}$ & MASS.3; AE & Blowdown mass and energy source to atmosphere. \\
\hline $\mathrm{CVH}$ & Sensitivity coefficient 4407 & $\begin{array}{l}\text { Set all coefficients to } 1.0 \mathrm{e}-10 \text { to effectively } \\
\text { eliminate heat and mass transfer from atmosphere- } \\
\text { to-pool surface. }\end{array}$ \\
\hline $\mathrm{MP} / \mathrm{HS}$ & RHO, CPS, THC & $\begin{array}{l}\text { Density, thermal conductivity, and specific heat } \\
\text { capacity for air, stainless steel, steel, and concrete } \\
\text { set for equivalency. }\end{array}$ \\
\hline $\mathrm{MP} / \mathrm{HS}$ & THC & $\begin{array}{l}\text { Surface node effective thermal conductivity to } \\
\text { account for added thermal resistance of surface } \\
\text { paint. }\end{array}$ \\
\hline $\mathrm{MP} / \mathrm{HS}$ & THC; XVALUE; MATNAM & Air gaps of constant thickness, full gap width. \\
\hline
\end{tabular}




\begin{tabular}{|l|l|l|}
\hline \multicolumn{1}{|c|}{ Input Package } & \multicolumn{1}{|c|}{ Parameter(s) } & \multicolumn{1}{c|}{ Comment } \\
\hline HS & --- & $\begin{array}{l}\text { No atmosphere-to-structure thermal radiation; } \\
\text { default. }\end{array}$ \\
\hline HS & TEMPIN & Initial temperature for equivalency. \\
\hline HS & XVALUE & $\begin{array}{l}\text { Surface node thickness as fraction of thermal } \\
\text { diffusion length. }\end{array}$ \\
\hline HS & BNDZL & $\begin{array}{l}\text { Length of structure-cautionary note for film } \\
\text { tracking (see text). }\end{array}$ \\
\hline HS & $\begin{array}{l}\text { Sensitivity coefficient 4110, } \\
\text { location \#1 }\end{array}$ & $\begin{array}{l}\text { Set natural convective correlation multiplier to } \\
0.14 \text { (equivalent setting to CONTAIN convective } \\
\text { correlation). }\end{array}$ \\
\hline SPR & $\begin{array}{l}\text { TDROPO, IFLOCF, DIAMO; } \\
\text { FALLHS }\end{array}$ & $\begin{array}{l}\text { Initial spray droplet temperature, flow rate, and } \\
\text { diameter set for equivalency; generally, 0.0005 } \\
\text { meter diameter or less for 100\% efficiency; } \\
\text { equivalent elevation for fall height. }\end{array}$ \\
\hline FCL & $\begin{array}{l}\text { ESFFCLnn101, } \\
\text { ESFFCLnn102, } \\
\text { ESFFCLnn103 }\end{array}$ & $\begin{array}{l}\text { Calibrated fan cooler for rated output at accident } \\
\text { condition ( 400 K). }\end{array}$ \\
\hline
\end{tabular}

Table 2.7. Material diffusion lengths (meters) for various time constants (seconds).

\begin{tabular}{|l|l|l|l|l|l|l|}
\hline \multirow{2}{*}{ Material } & \multicolumn{6}{|c|}{ Time scale, $\mathbf{\Delta t}$} \\
\cline { 2 - 7 } & $\mathbf{0 . 0 0 1}$ & \multicolumn{1}{|c|}{$\mathbf{0 . 0 1}$} & \multicolumn{1}{c|}{$\mathbf{0 . 1}$} & \multicolumn{1}{c|}{$\mathbf{1 0}$} & $\mathbf{1 0 0}$ \\
\hline Steel & $2.19 \mathrm{e}-4$ & $6.91 \mathrm{e}-4$ & $2.19 \mathrm{e}-3$ & $6.19 \mathrm{e}-3$ & $2.19 \mathrm{e}-2$ & $6.19 \mathrm{e}-2$ \\
\hline $\begin{array}{l}\text { Stainless } \\
\text { steel }\end{array}$ & $1.38 \mathrm{e}-4$ & $4.37 \mathrm{e}-4$ & $1.38 \mathrm{e}-3$ & $4.37 \mathrm{e}-3$ & $1.38 \mathrm{e}-2$ & $4.37 \mathrm{e}-2$ \\
\hline Concrete & $5.25 \mathrm{e}-5$ & $1.66 \mathrm{e}-4$ & $5.25 \mathrm{e}-4$ & $1.66 \mathrm{e}-3$ & $5.25 \mathrm{e}-3$ & $1.66 \mathrm{e}-2$ \\
\hline
\end{tabular}

Table 2.8. Maximum time-step (seconds) to prevent surface temperature oscillations.

\begin{tabular}{|l|l|c|c|}
\hline \multirow{2}{*}{ Material } & \multicolumn{3}{|c|}{$\mathbf{\Delta t}_{\text {oscillation }}$} \\
\cline { 2 - 4 } & $\begin{array}{l}\mathbf{h}=\mathbf{1 5 0 0} \\
\mathbf{W} / \mathbf{m}^{\mathbf{2}}-\mathbf{K}^{*}\end{array}$ & $\mathbf{h}=\mathbf{8 0 0}$ & $\mathbf{h}=\mathbf{4 0 0}$ \\
\hline Steel & 69.64 & 244.81 & 979.26 \\
\hline Stainless steel & 27.85 & 97.92 & 391.69 \\
\hline Concrete & 1.24 & 4.35 & 17.41 \\
\hline
\end{tabular}

* atmosphere-to-surface material node (backed by same material) heat transfer coefficient (sensible and latent heat combined). 


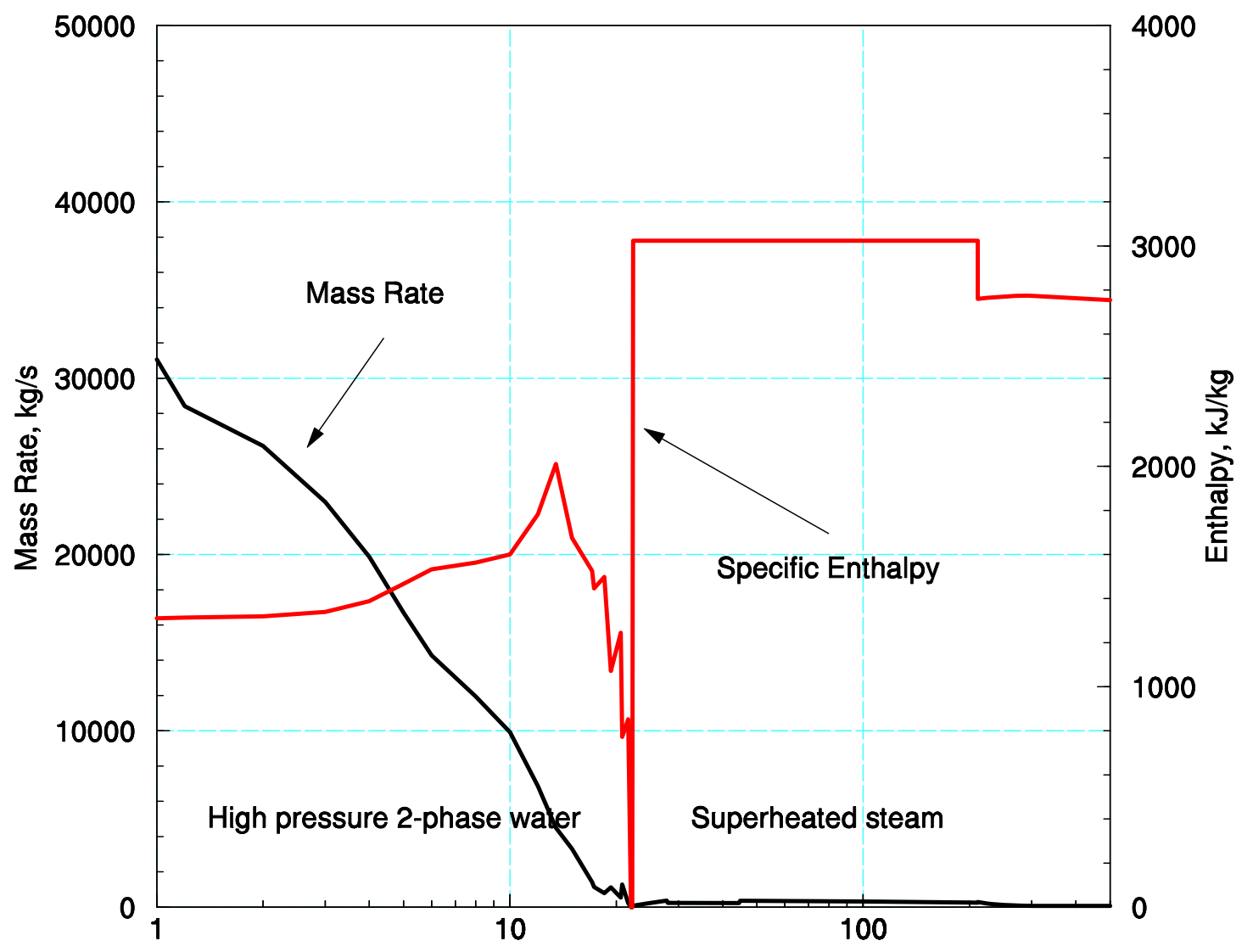

Time, seconds

Figure 2.2 Mass and enthalpy blowdown source for LOCA scenario (large dry PWR demonstration plant). 


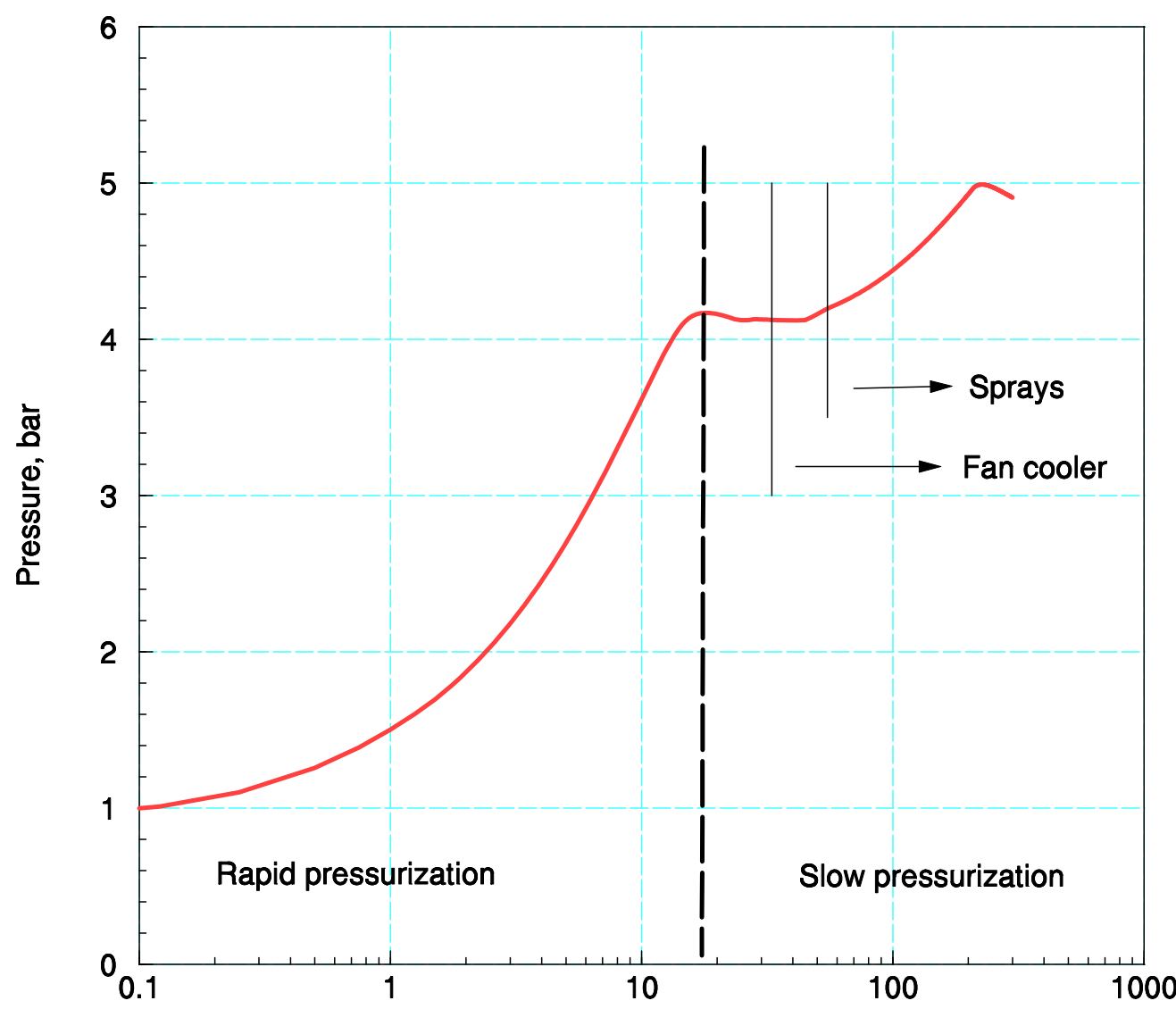

Time, seconds

Figure 2.3 MELCOR calculation of the containment pressure profile for the large dry PWR LOCA scenario. 


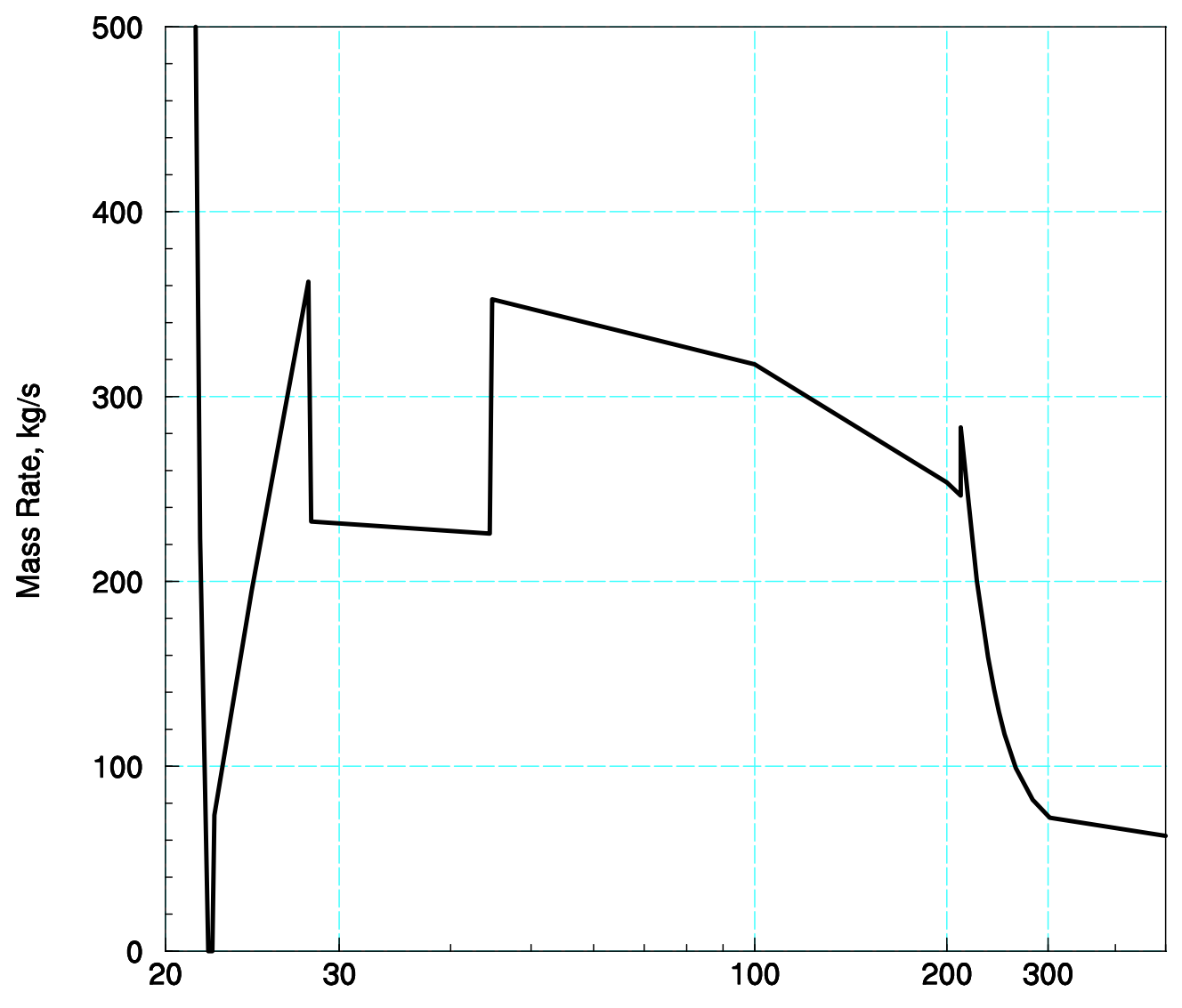

Time, seconds

Figure 2.4 Steam injection mass rates during the slow pressurization phase of the large dry PWR plant LOCA scenario. 


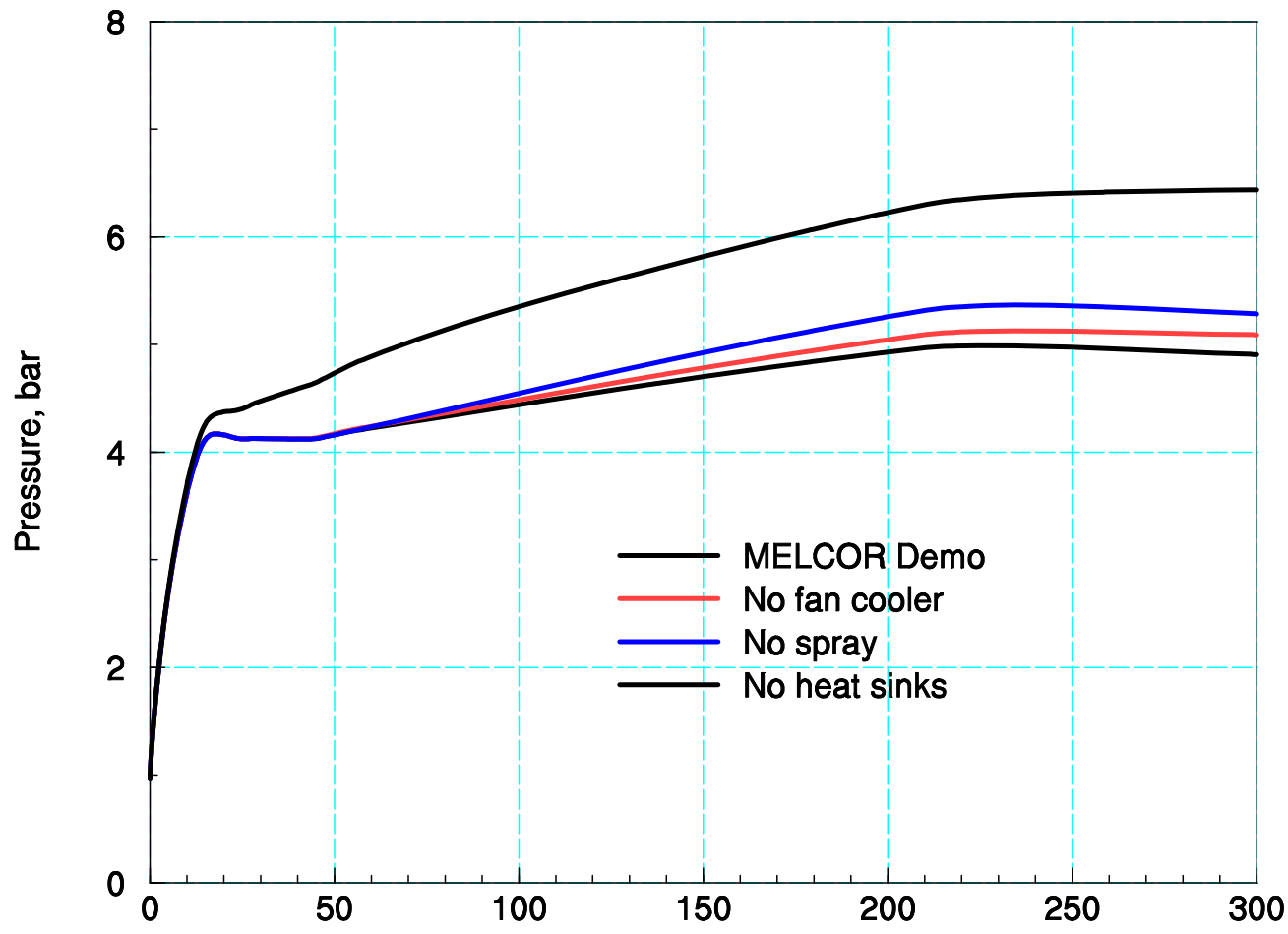

Time, seconds

Figure 2.5 MELCOR-calculated containment pressure profiles for large dry PWR plant LOCA scenario, showing the relative effect of excluding engineered safety features (fan cooler or sprays) and passive heat sinks. 


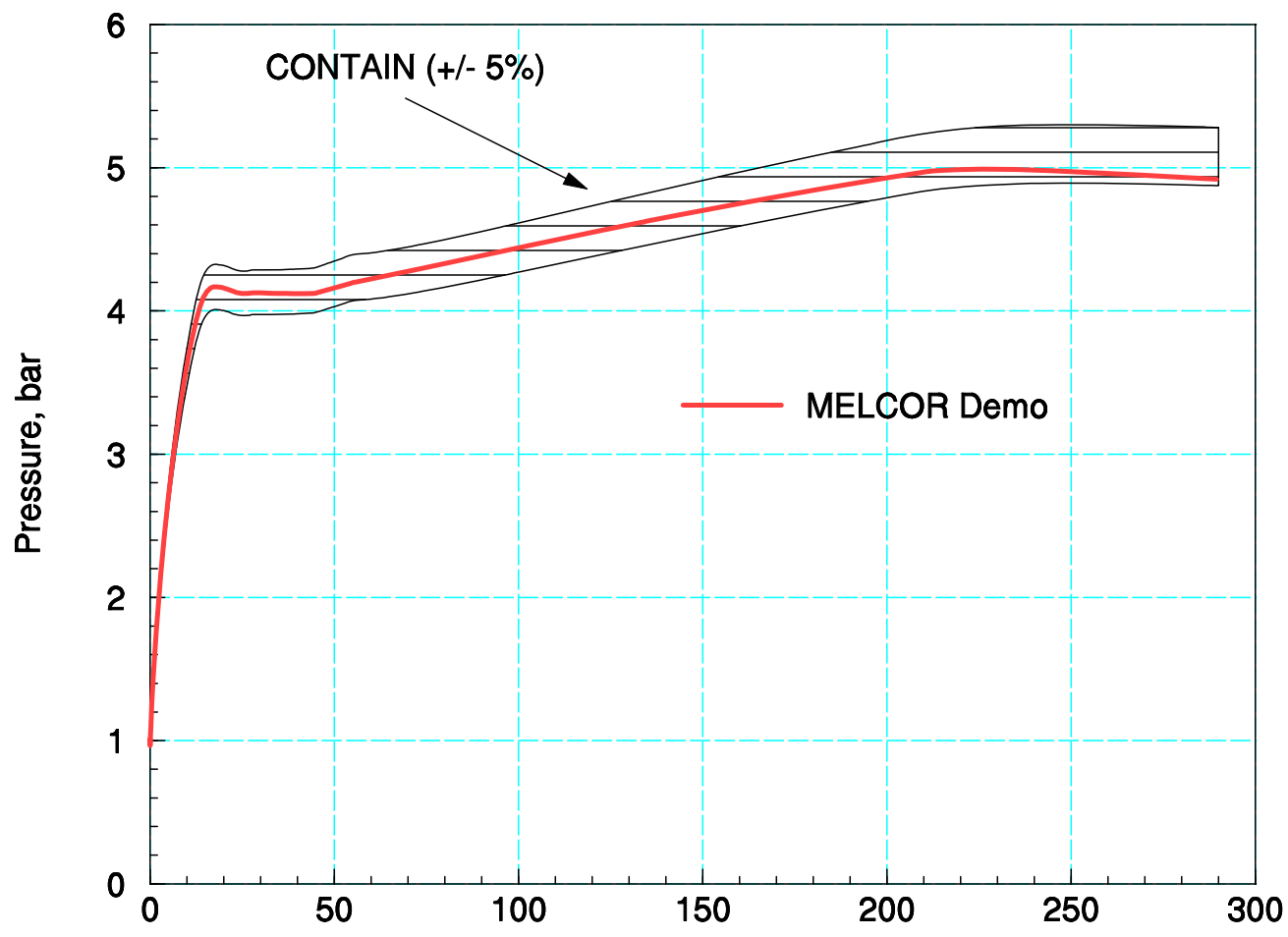

Time, seconds

Figure 2.6 Comparison of MELCOR-calculated containment pressure profile for a large dry PWR plant LOCA scenario with the CONTAIN code equivalency band for pressure. 


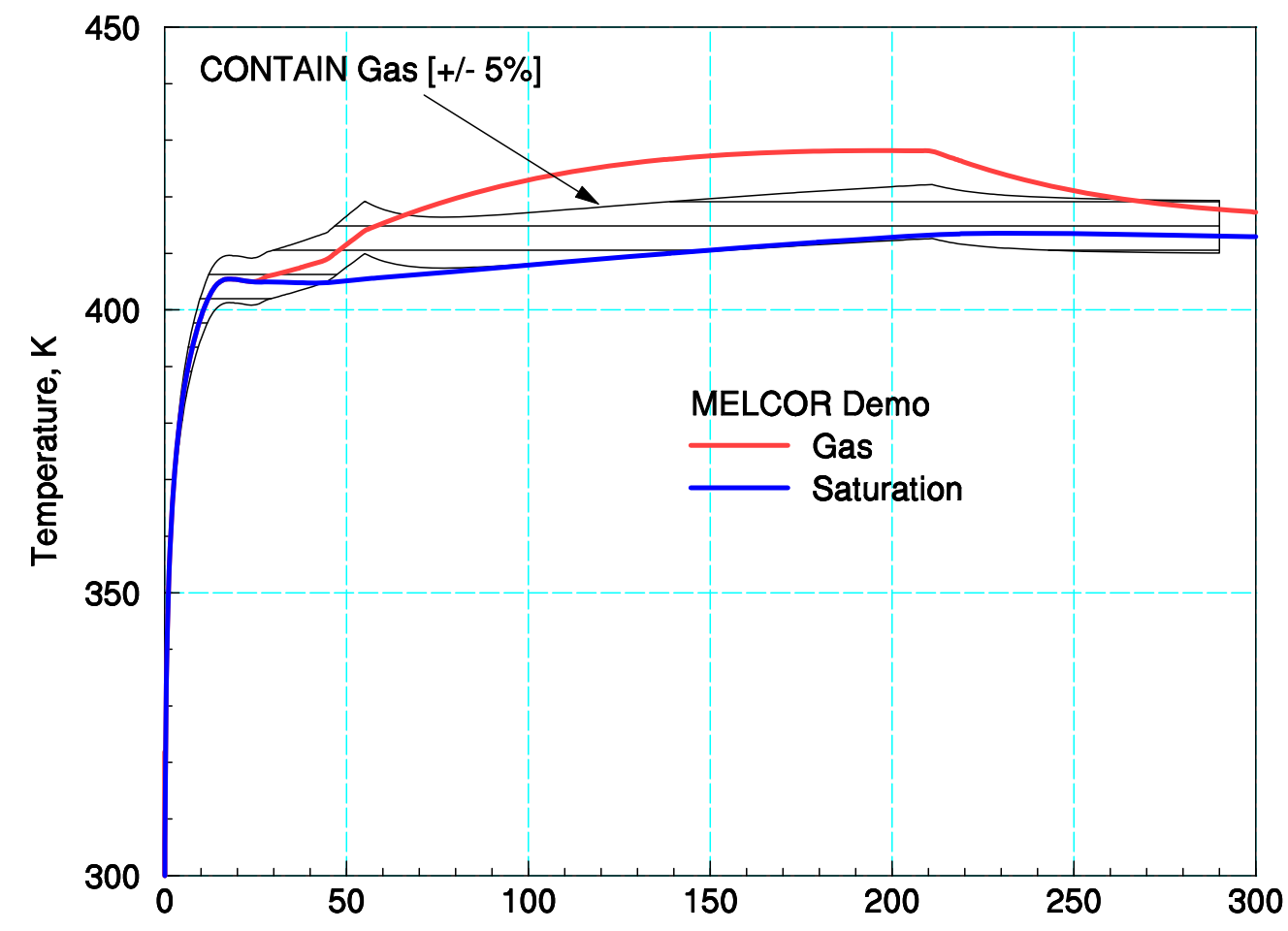

Time, seconds

Figure 2.7 Comparison of MELCOR-calculated containment gas temperature profile for a large dry PWR plant LOCA scenario with the CONTAIN code equivalency band for pressure. 


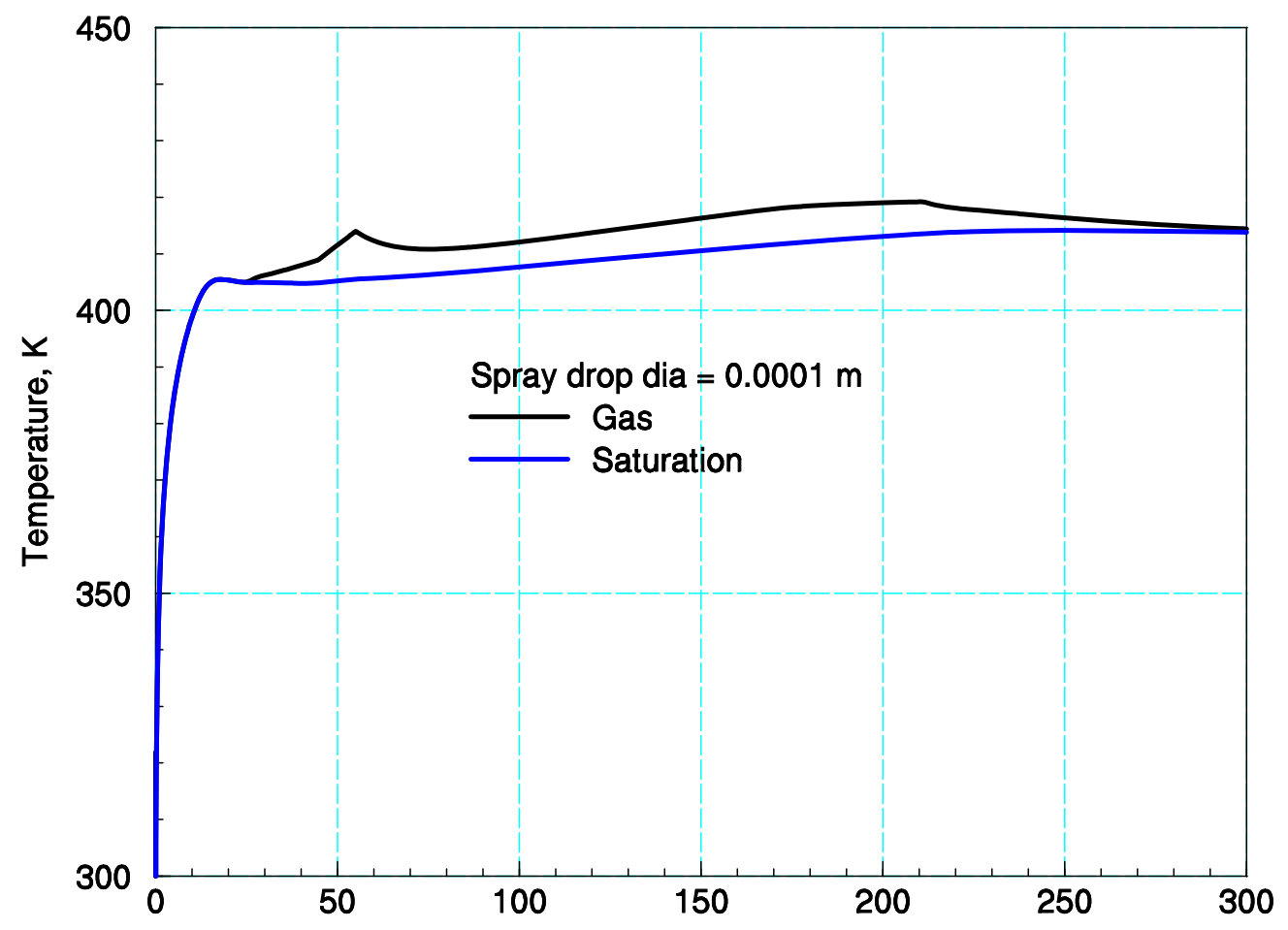

Time, seconds

Figure 2.8 MELCOR-calculated containment gas and saturation temperature for a large dry PWR plant LOCA scenario using an injection spray droplet size of 0.0001 meter diameter. 


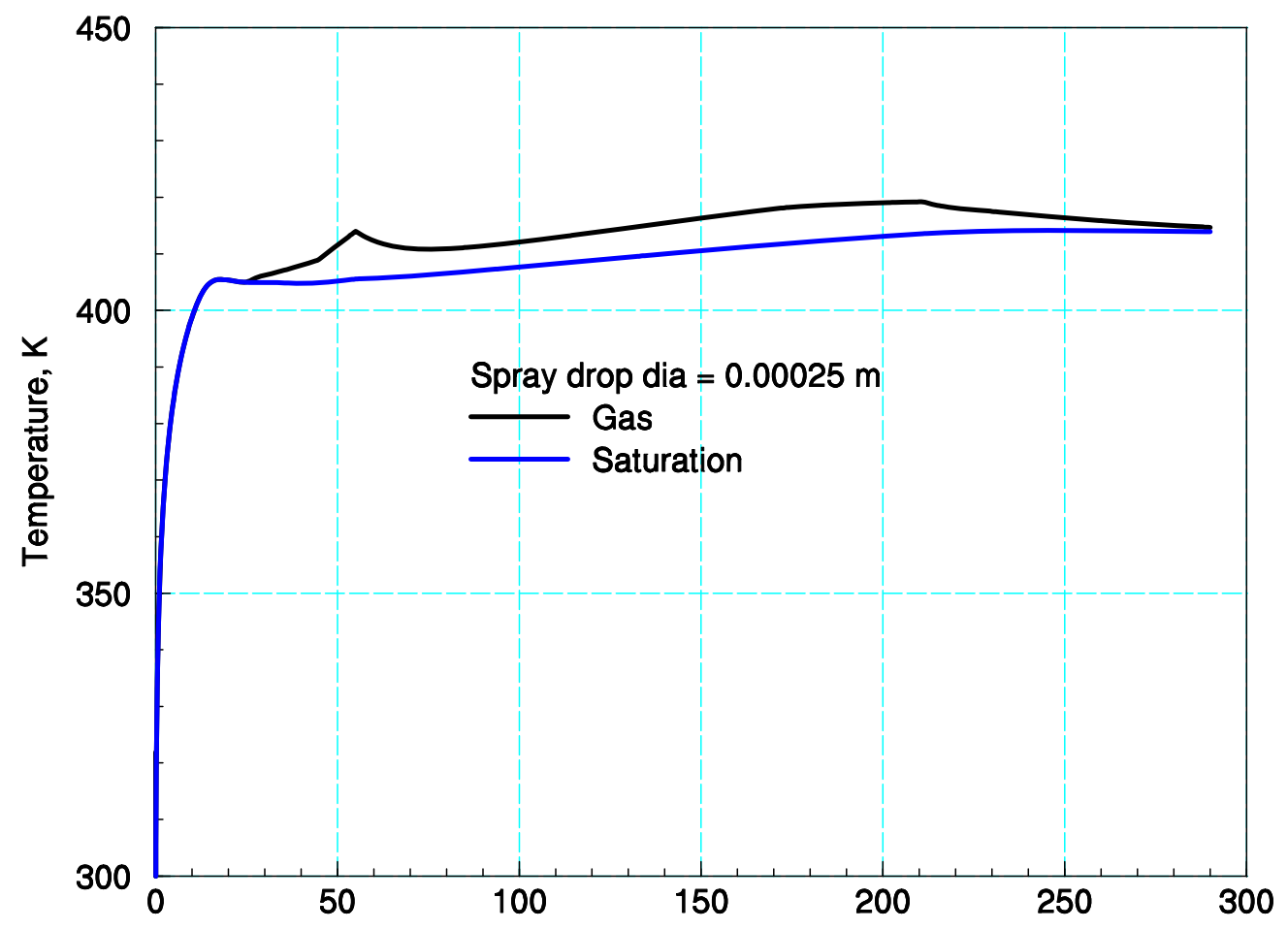

Time, seconds

Figure 2.9 MELCOR-calculated containment gas and saturation temperature for a large dry PWR plant LOCA scenario using an injection spray droplet size of 0.00025 meter diameter. 


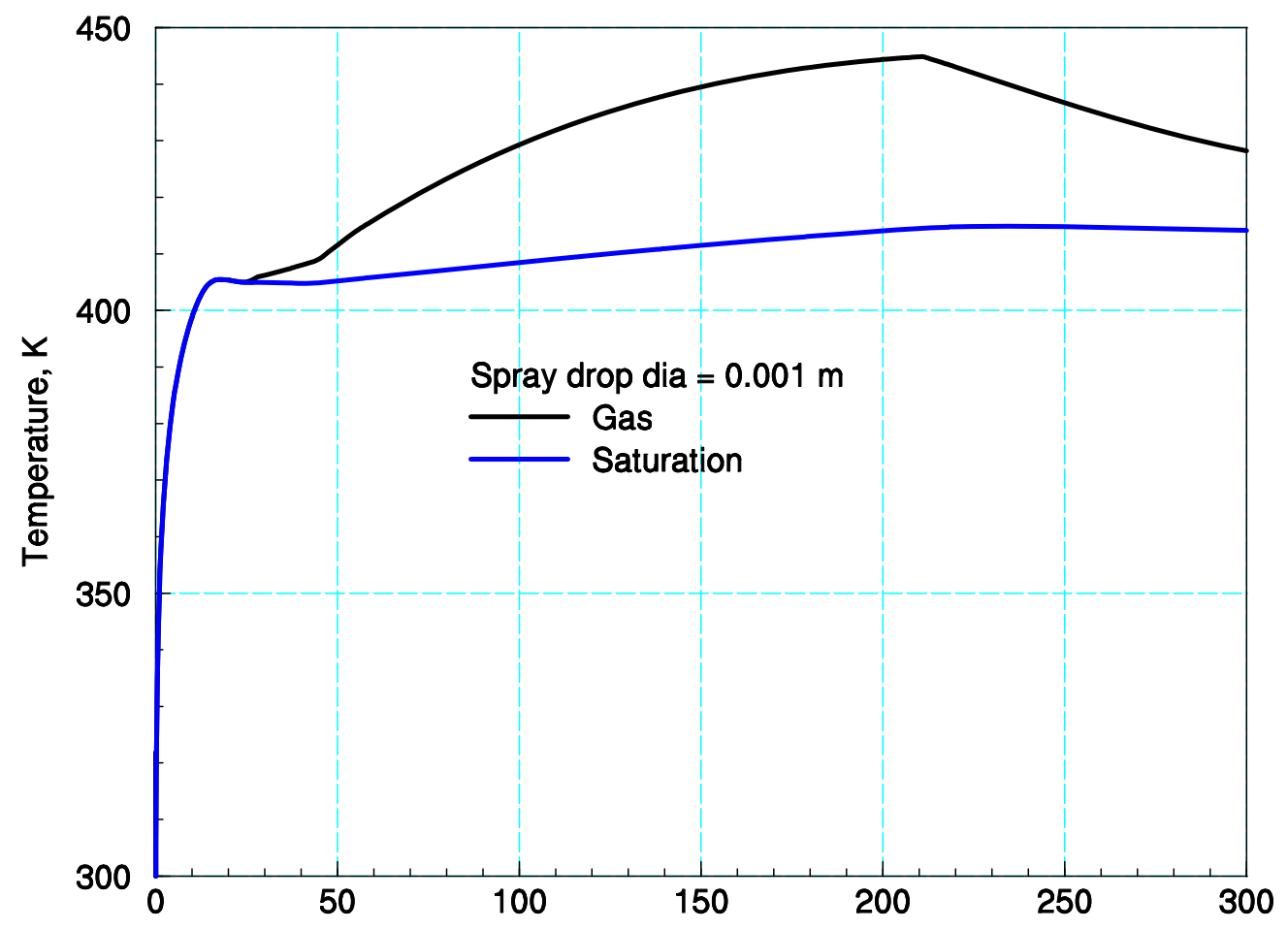

Time, seconds

Figure 2.10 MELCOR-calculated containment gas and saturation temperature for a large dry PWR plant LOCA scenario using an injection spray droplet size of 0.001 meter diameter. 


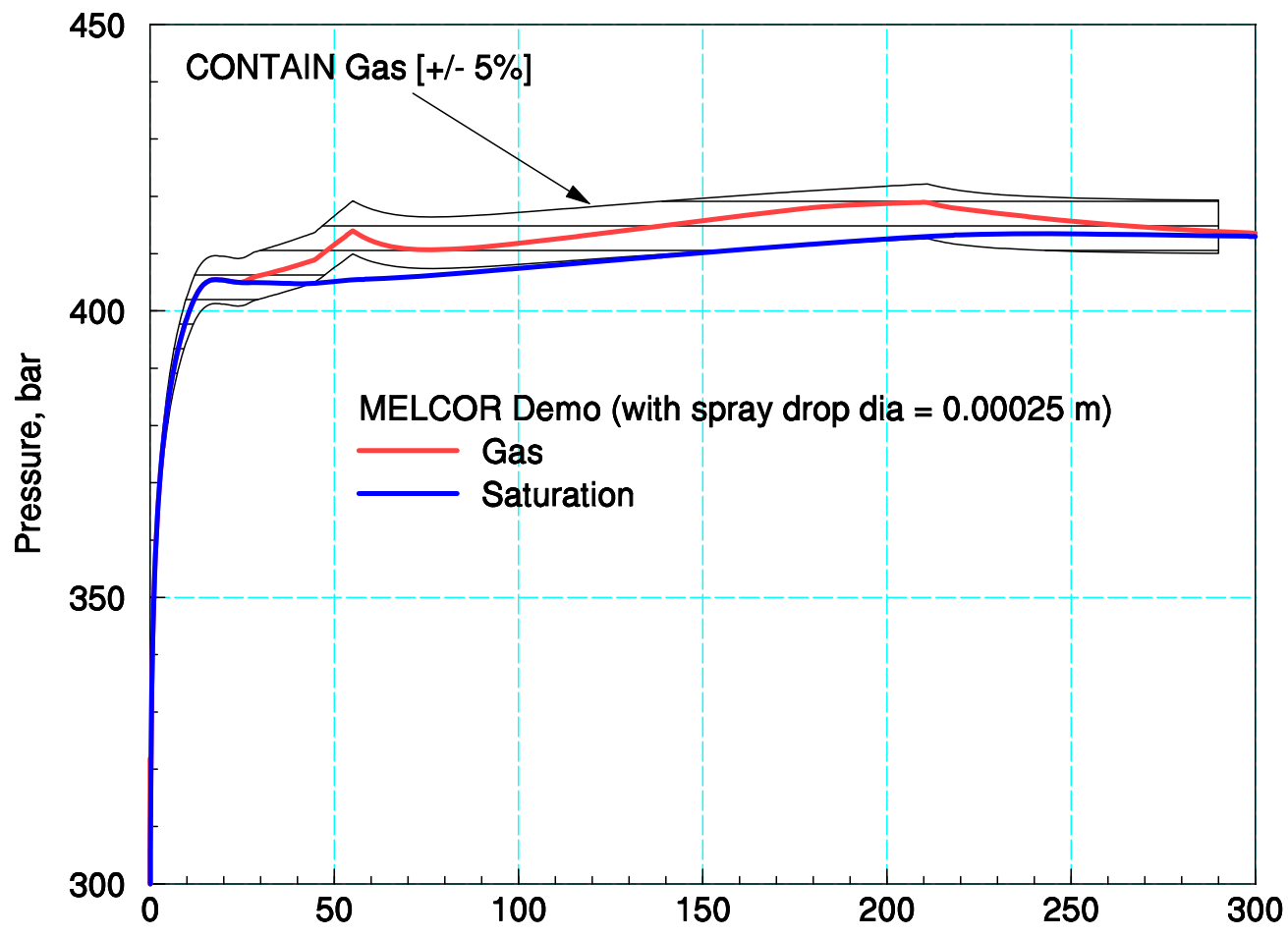

Time, seconds

Figure 2.11 Comparison of MELCOR-calculated containment gas temperature profile (with injection spray drop diameter $=0.00025$ meters) for a large dry PWR plant LOCA scenario with the CONTAIN code equivalency band for pressure (injection drop diameter $=0.0005$ meters). 


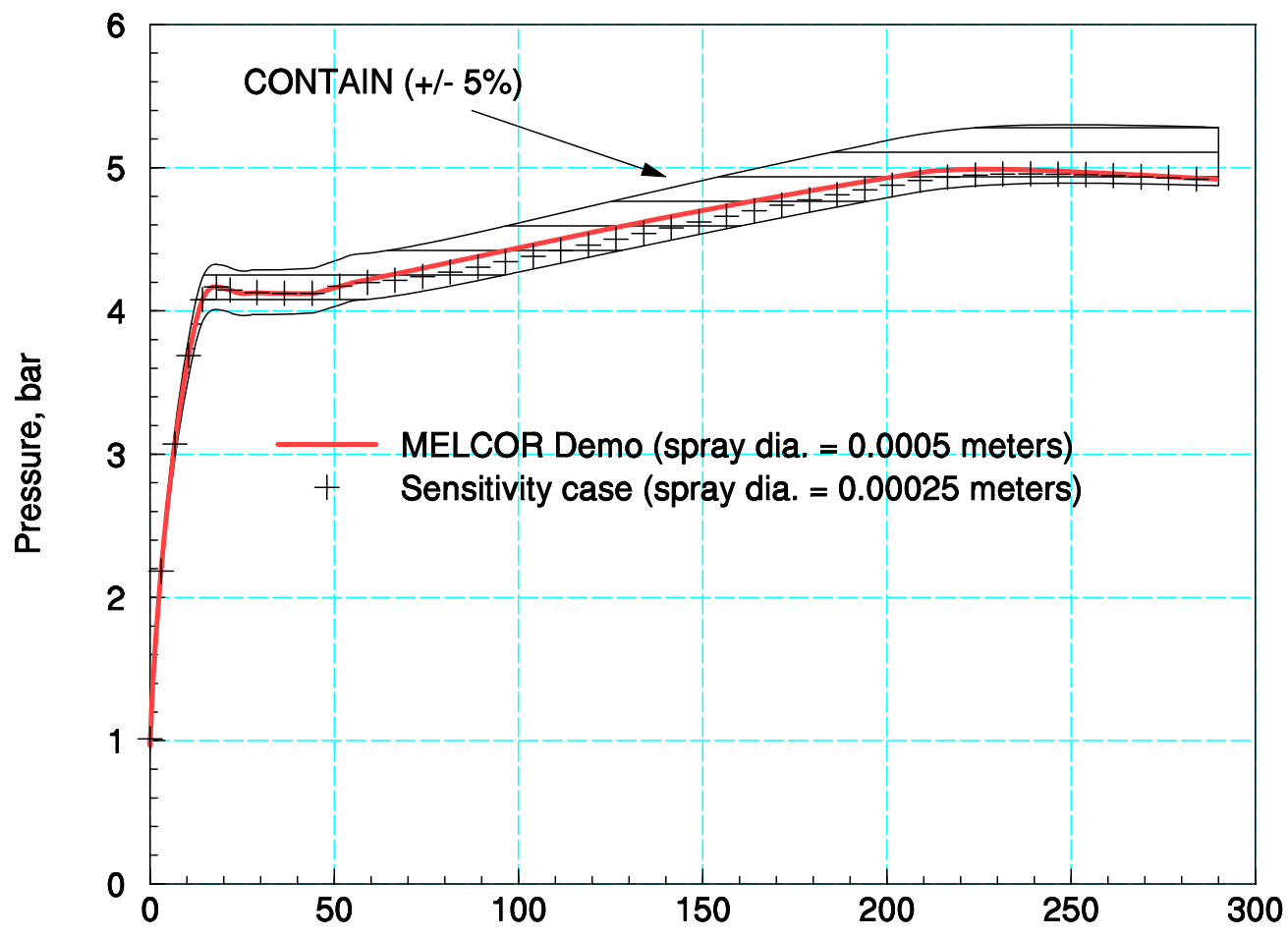

Time, seconds

Figure 2.12 Comparison of MELCOR-calculated containment gas pressure for PWR DECLG event for the reference spray diameter droplet size ( 0.0005 meters) and a sensitivity case with droplet size reduced by $50 \%$ ( 0.00025 meters) showing that pressure prediction for both cases (demo and sensitivity case) lie within the CONTAIN equivalency band derived using a spray droplet size of 0.0005 meters. 


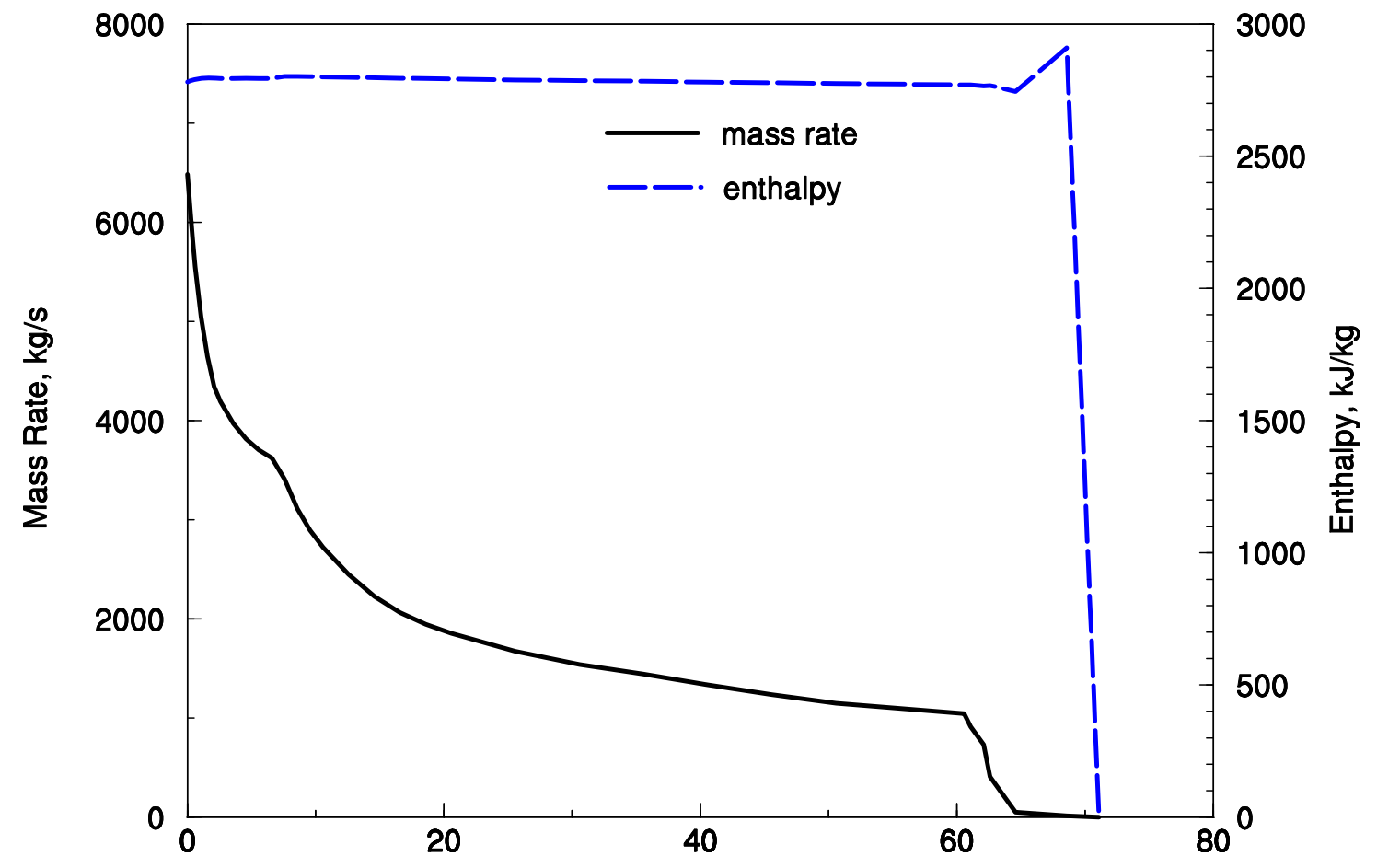

Time, seconds

Figure 2.13 Mass and enthalpy blowdown source for MSLB scenario (large dry PWR demonstration plant). 


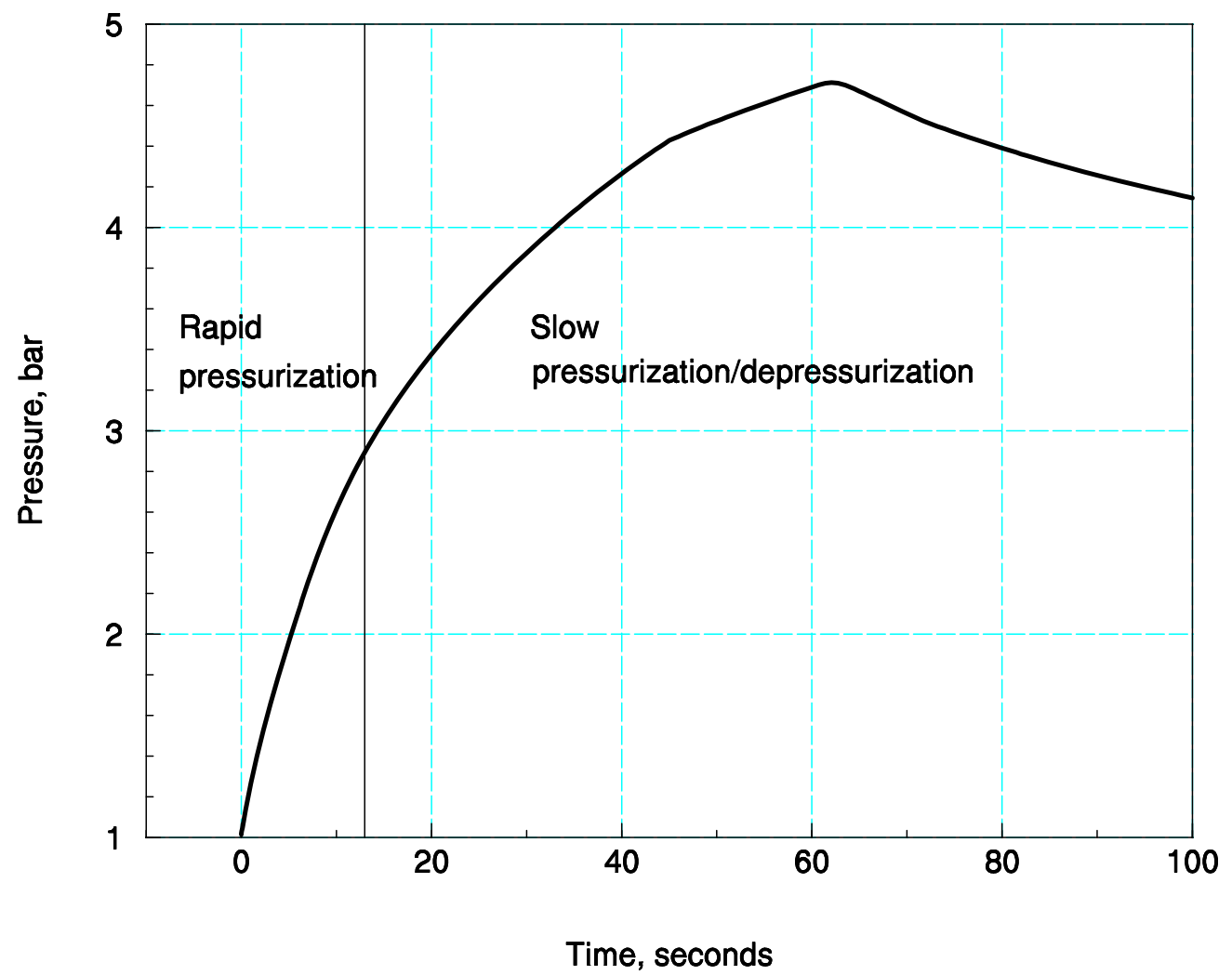

Figure 2.14 MELCOR-calculated containment gas pressure profile for an MSLB event in a large dry PWR containment. 


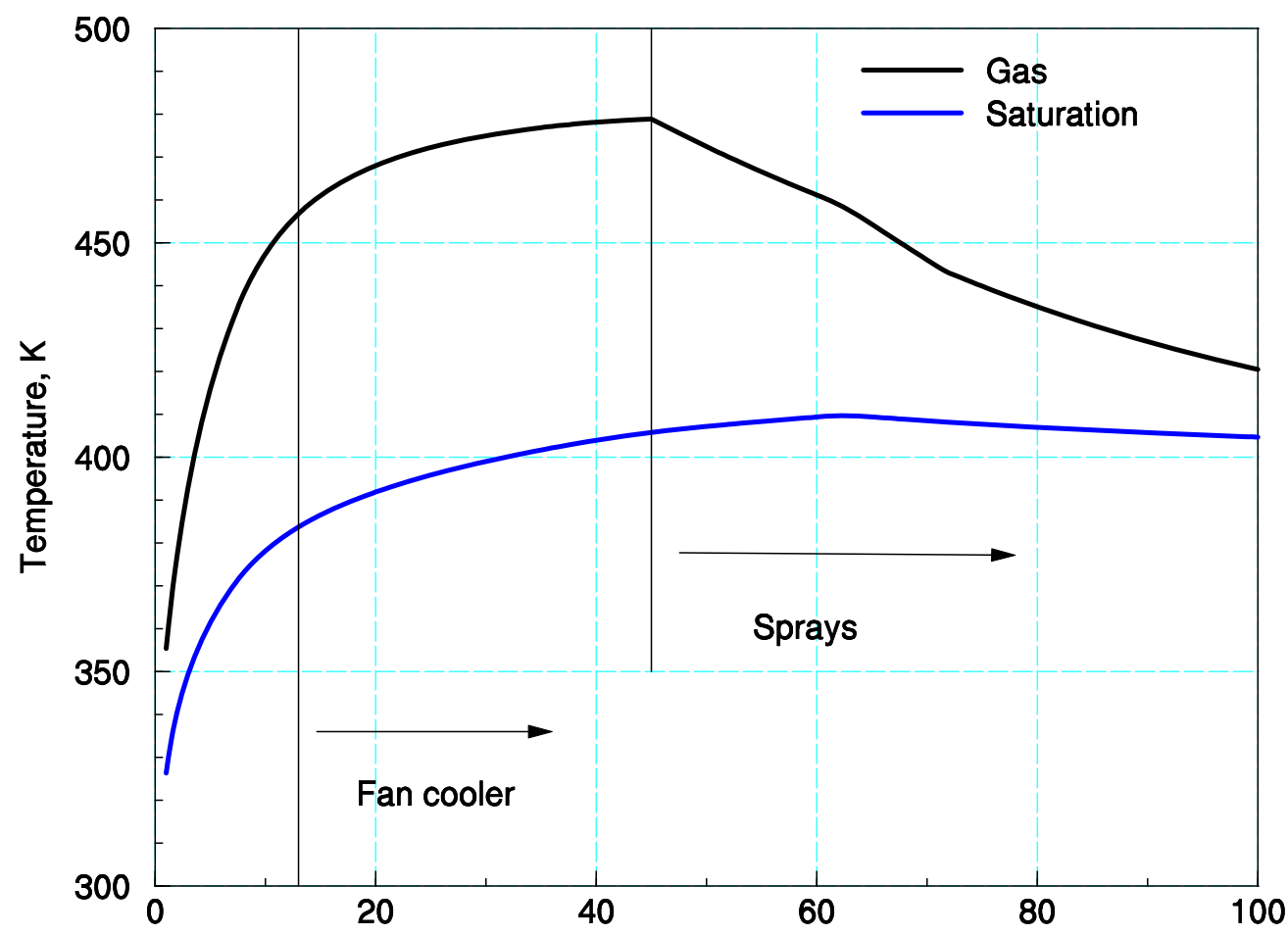

Time, seconds

Figure 2.15 MELCOR-calculated containment gas temperature profiles for an MSLB event in a large dry PWR containment. 


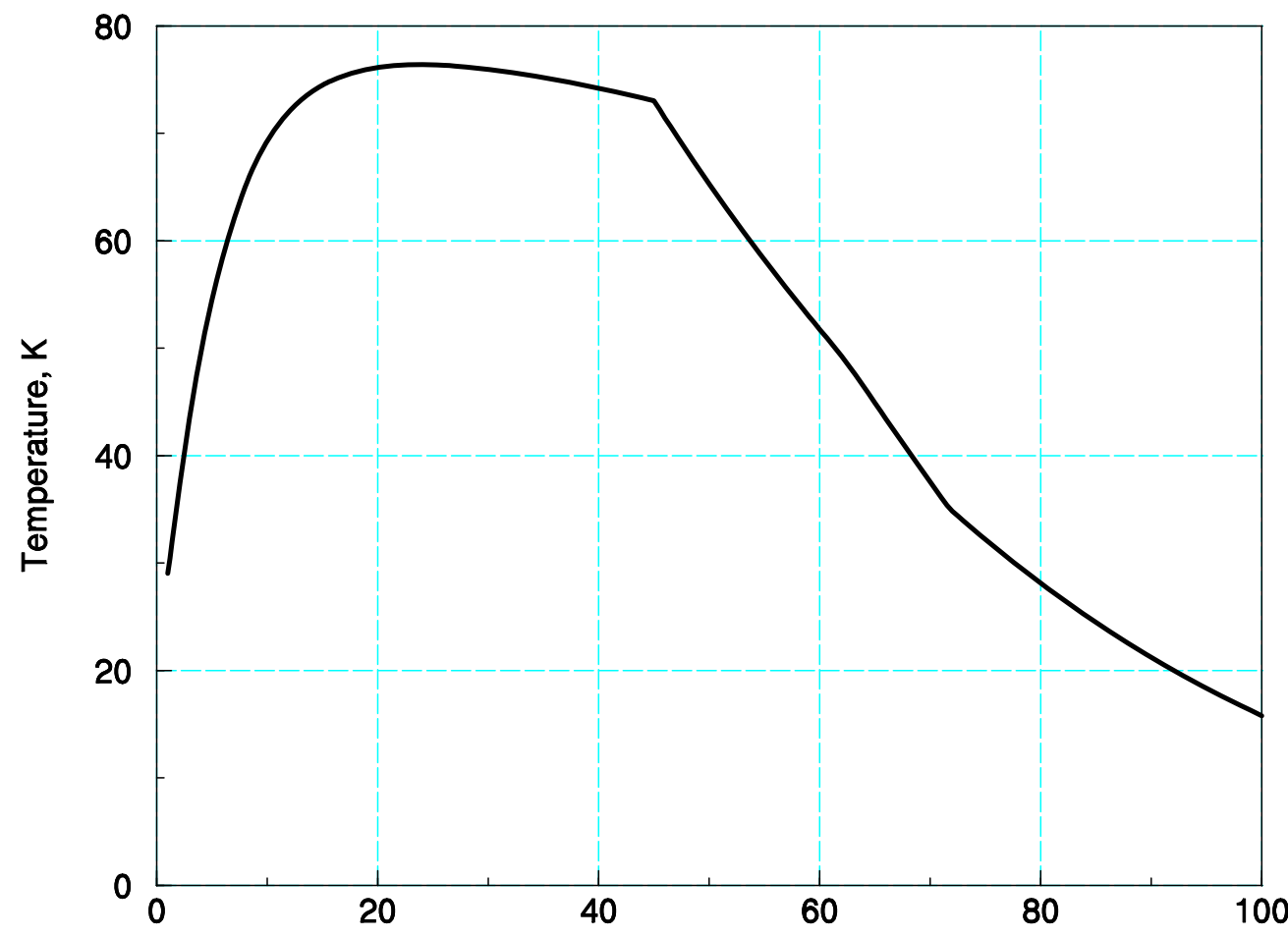

Time, seconds

Figure 2.16 MELCOR-calculated containment superheating for an MSLB event in a large dry PWR containment. 


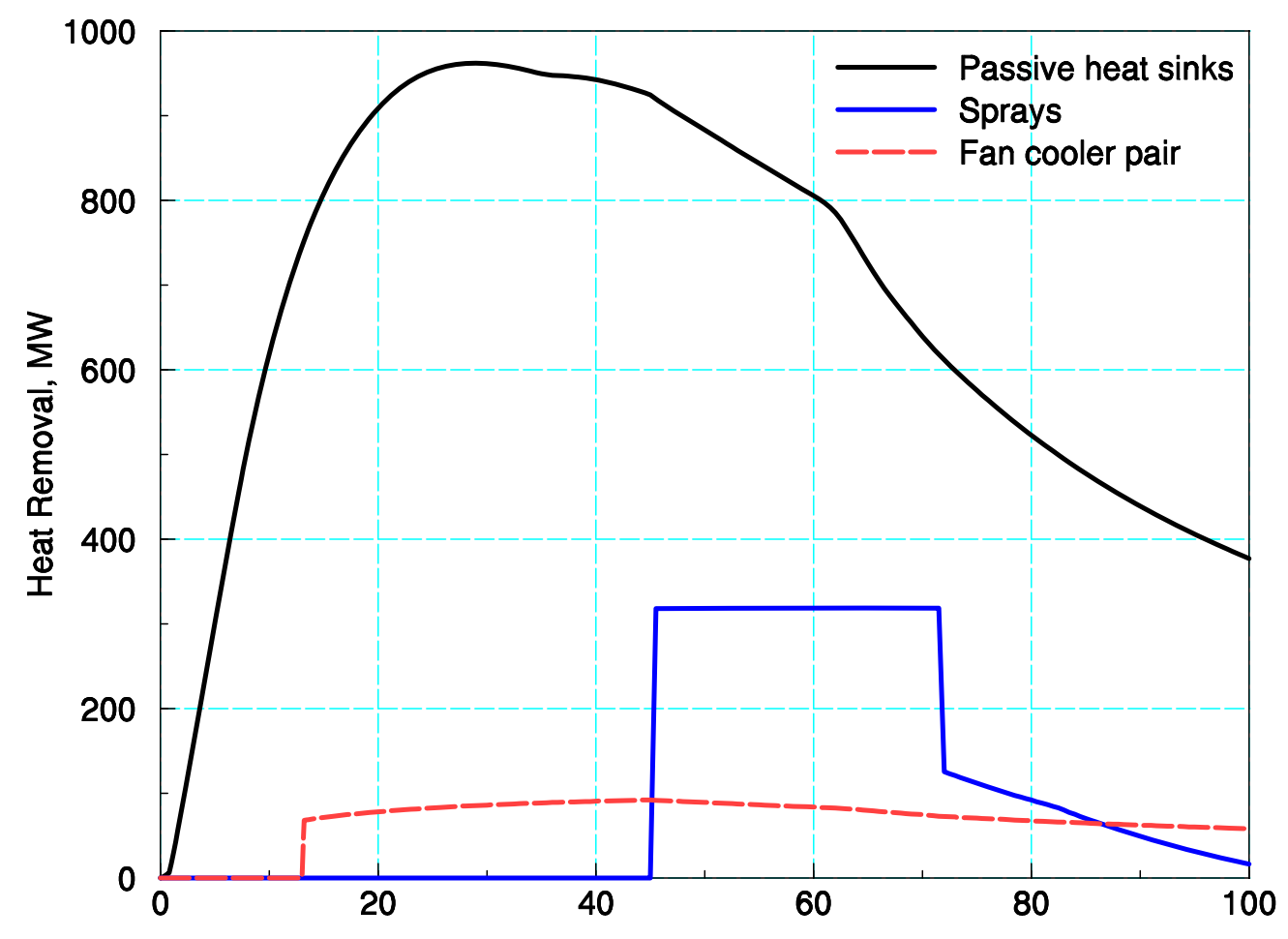

Time, seconds

Figure 2.17 MELCOR-calculated heat removal rates for an MSLB event in a PWR large dry containment. 


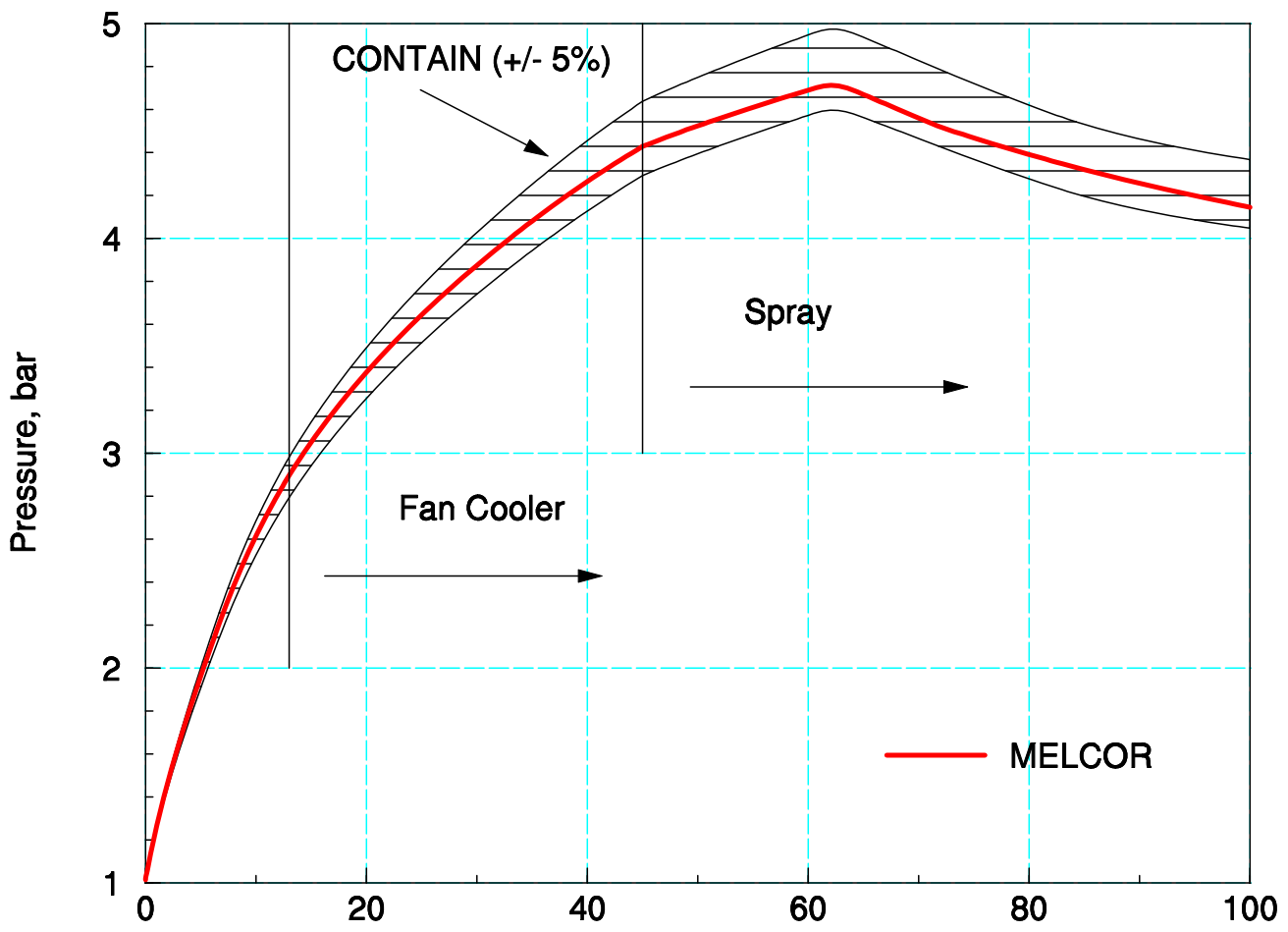

Time, seconds

Figure 2.18 MELCOR-calculated gas pressure compared to the CONTAIN (ideal EOS) equivalency band for pressure during an MSLB event in a large dry PWR containment. 


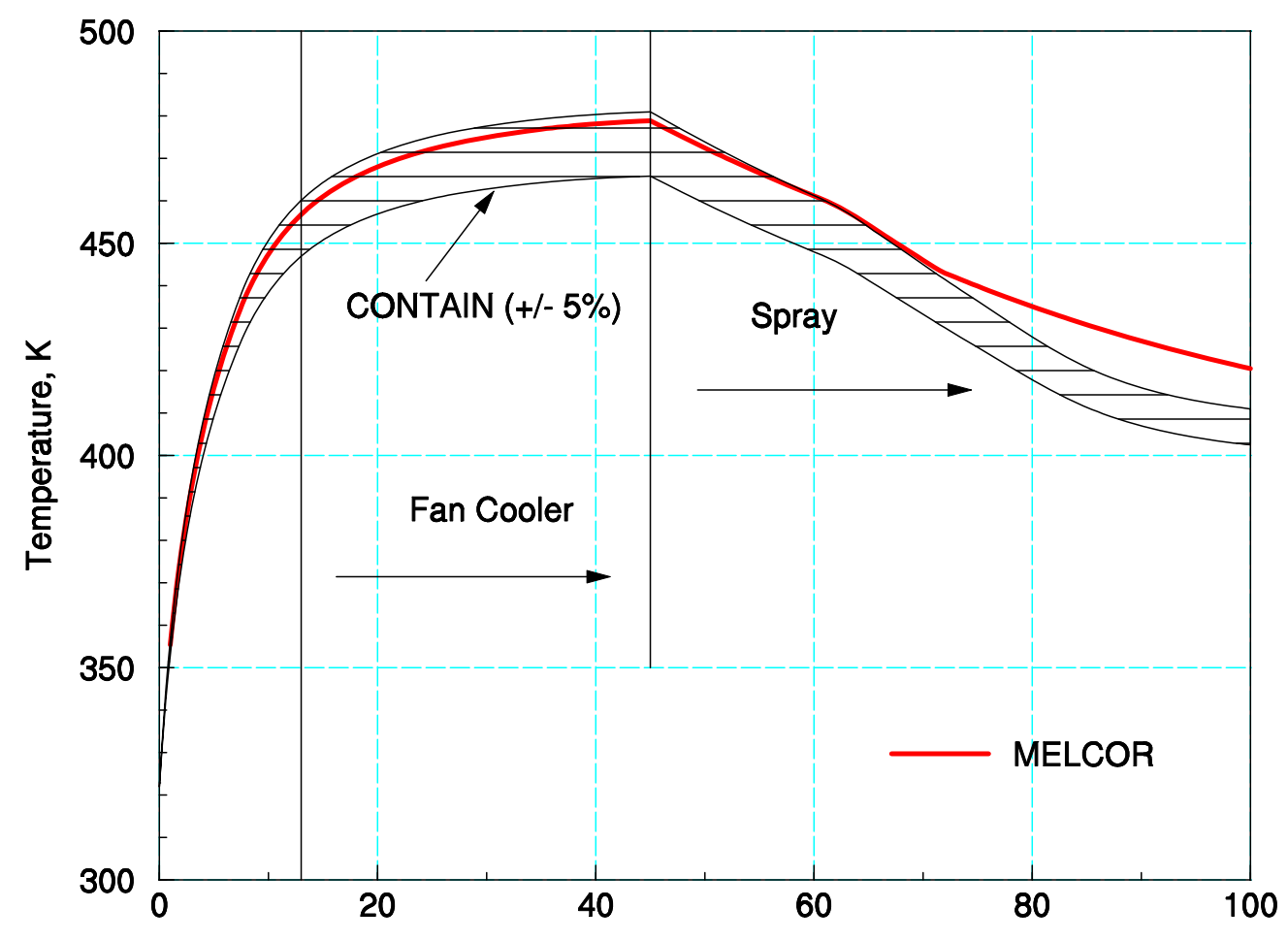

Time, seconds

Figure 2.19 MELCOR-calculated gas temperature compared to the CONTAIN (ideal EOS) equivalency band for pressure during an MSLB event in a large dry PWR containment. 


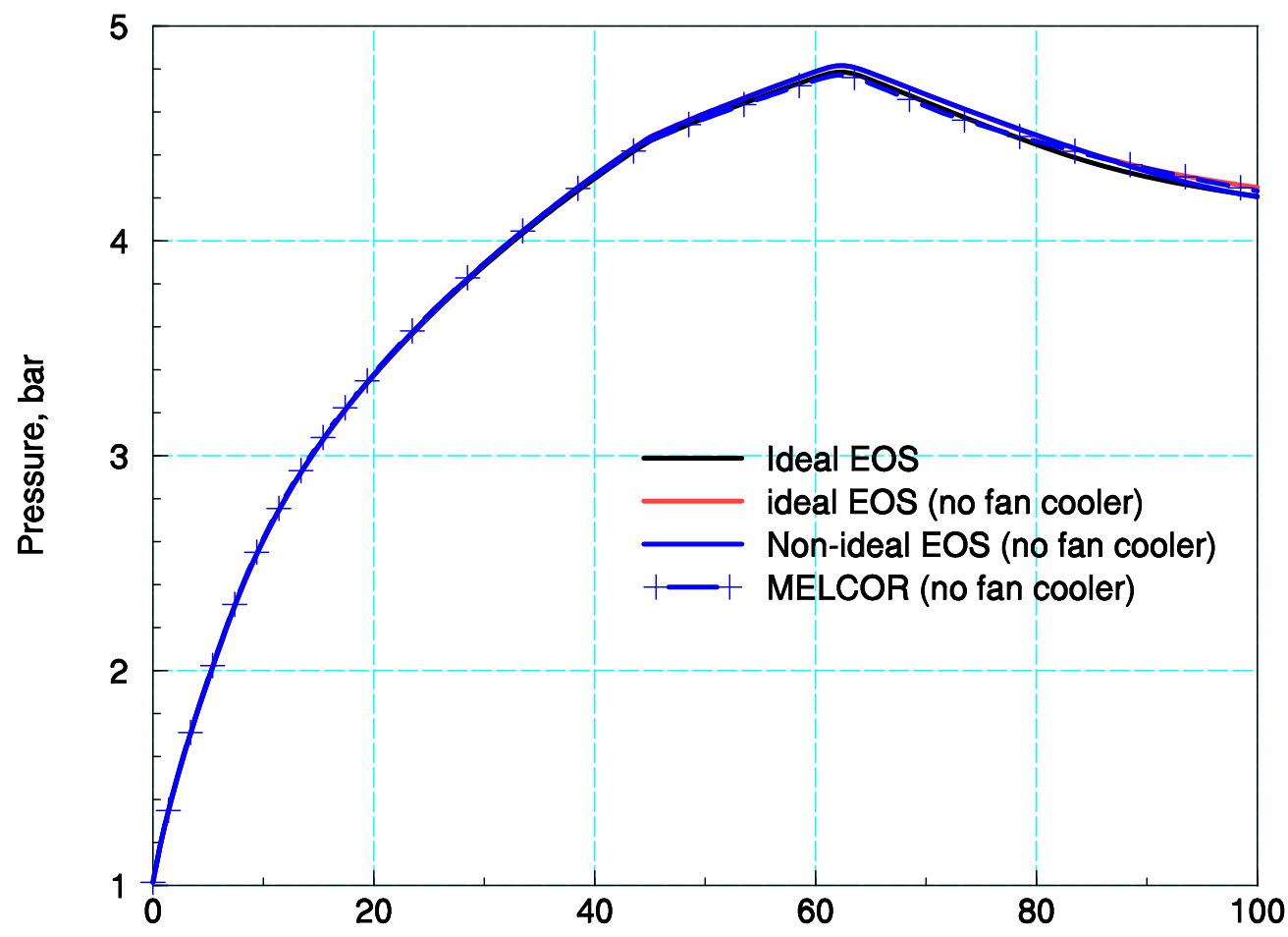

Time, seconds

Figure 2.20 The effect of fan cooler modeling on gas pressure for a typical MSLB event as calculated with CONTAIN ideal and non-ideal EOS for water, and by the MELCOR code without the fan cooler modeling. 


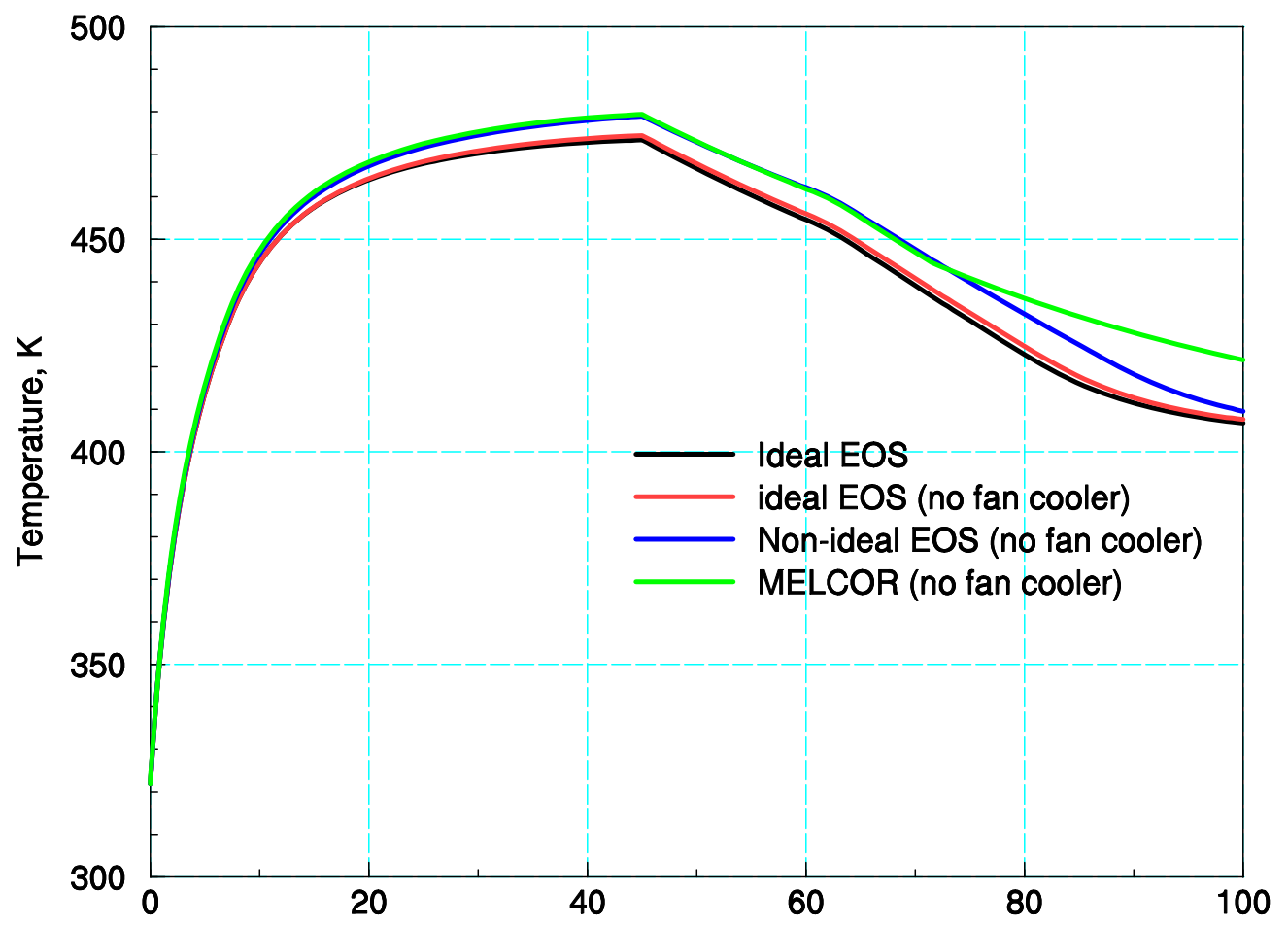

Time, seconds

Figure 2.21 The effect of fan cooler modeling on gas temperatures for a typical MSLB event as calculated with CONTAIN ideal and non-ideal EOS for water, and calculated by the MELCOR code without the fan cooler modeling. 


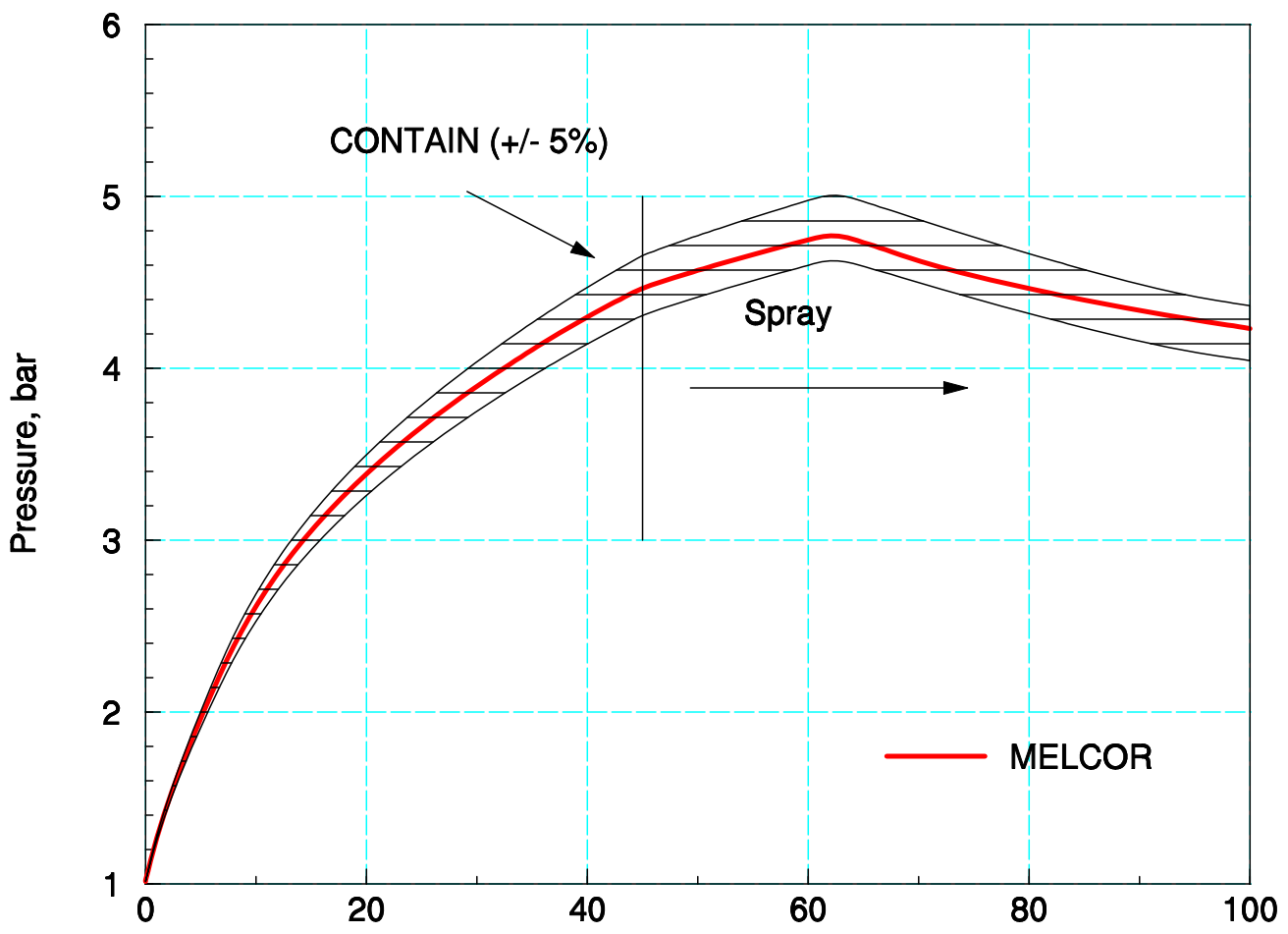

Time, seconds

Figure 2.22 MELCOR-calculated gas pressure compared to the CONTAIN (non-ideal EOS) equivalency band for pressure during an MSLB event in a large dry PWR containment (excluding fan cooler activation). 


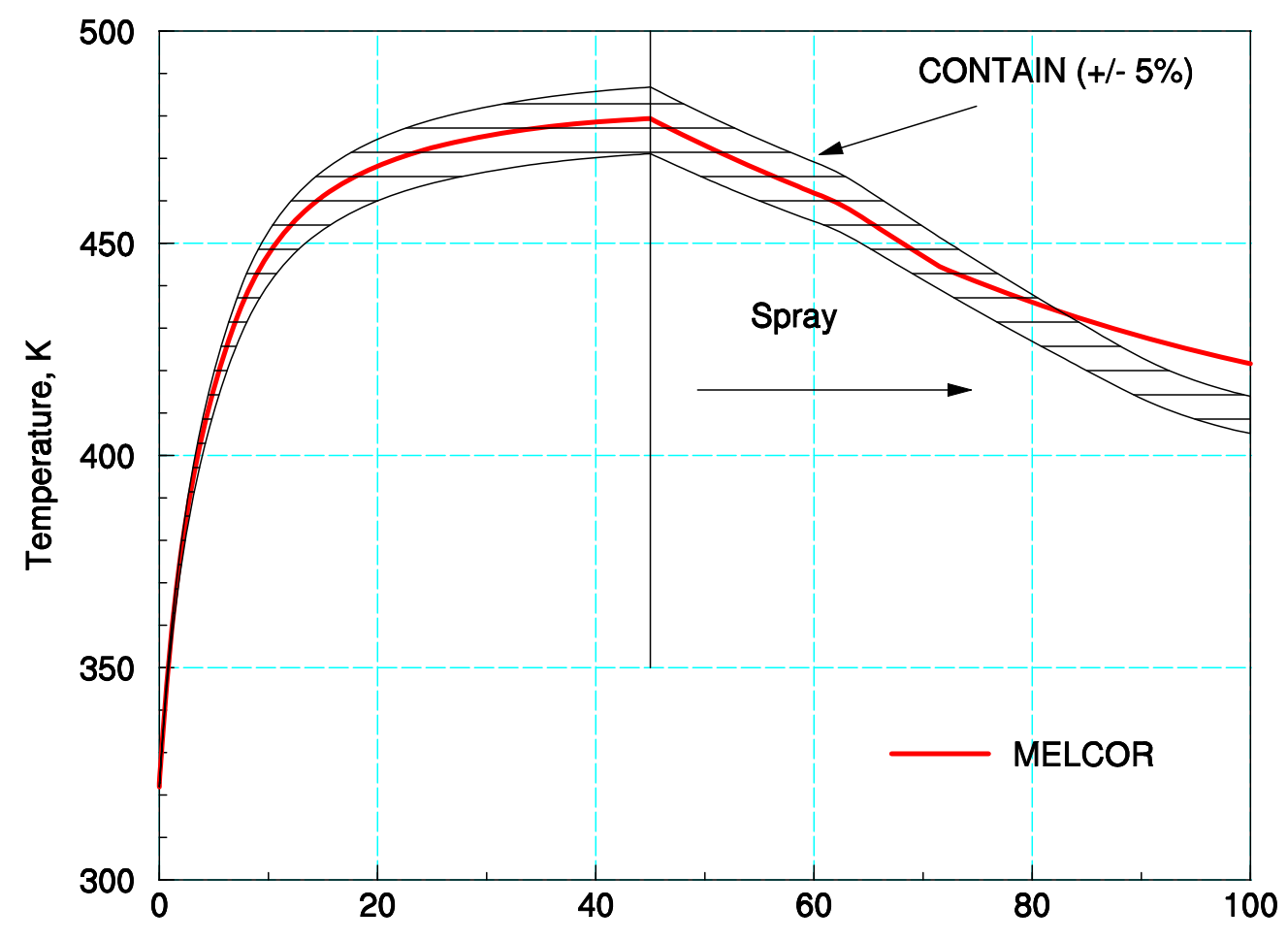

Time, seconds

Figure 2.23 MELCOR-calculated gas temperature compared to the CONTAIN (non-ideal EOS) equivalency band for pressure during an MSLB event in a large dry PWR containment (excluding fan cooler activation). 


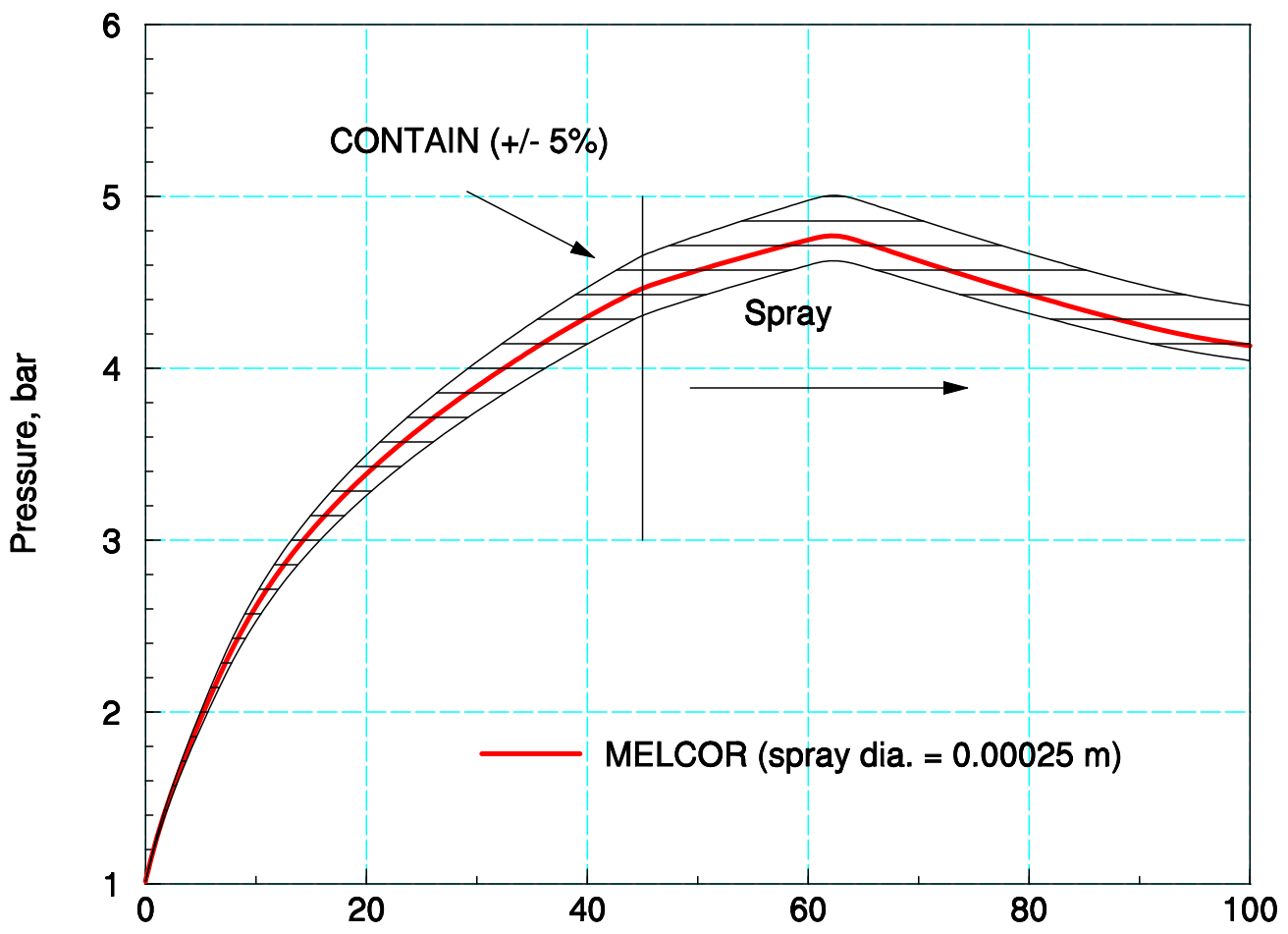

Time, seconds

Figure 2.24 MELCOR-calculated gas pressure compared to the CONTAIN (non-ideal EOS) equivalency band for pressure during an MSLB event in a large dry PWR containment (excluding fan cooler activation) where the MELCOR spray droplet diameter is reduced by $50 \%$ compared to the CONTAIN input. 


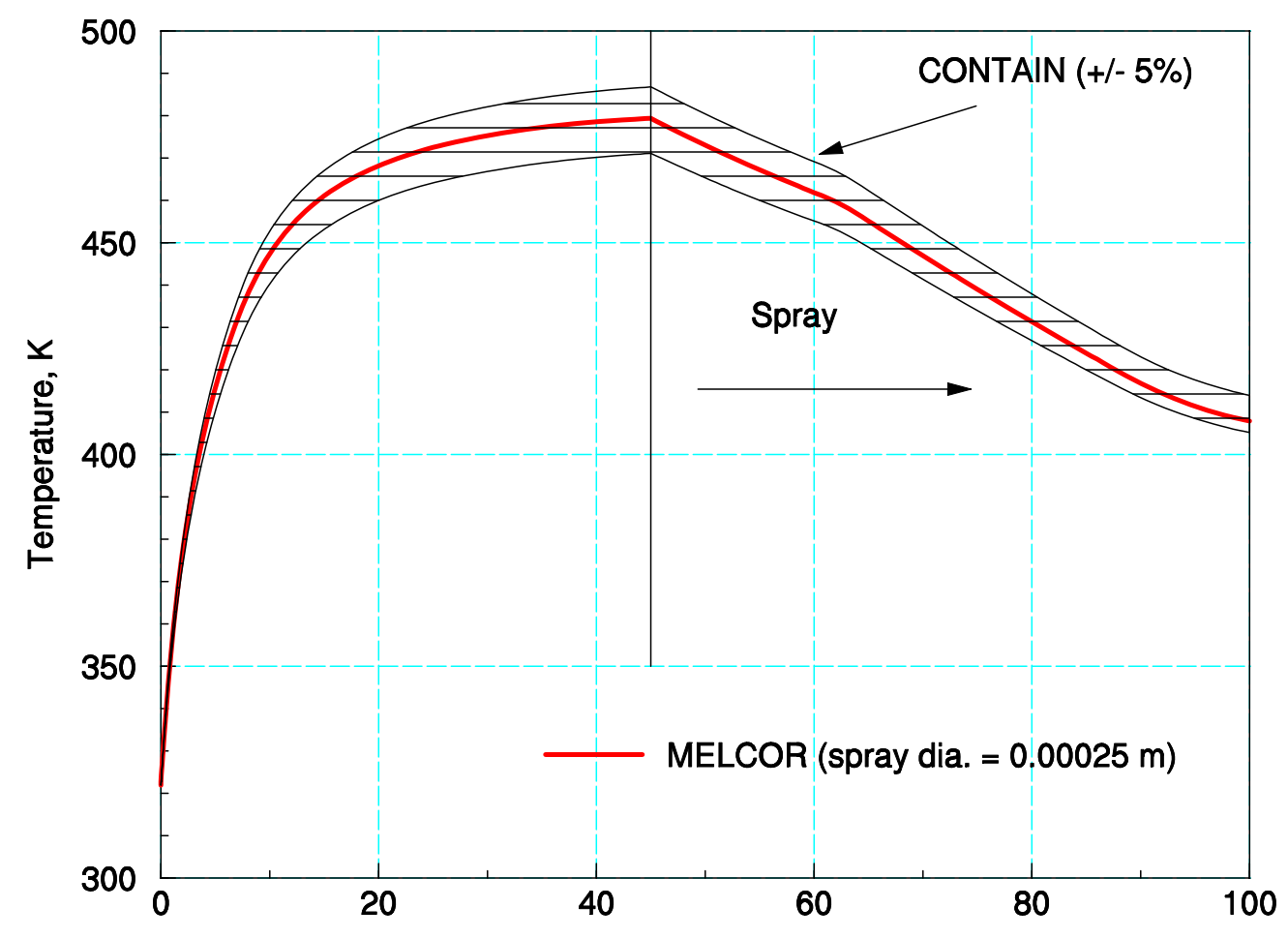

Time, seconds

Figure 2.25 MELCOR-calculated gas temperature compared to the CONTAIN (non-ideal EOS) equivalency band for pressure during an MSLB event in a large dry PWR containment (excluding fan cooler activation) where the MELCOR spray droplet diameter is reduced by $50 \%$ compared to the CONTAIN input. 


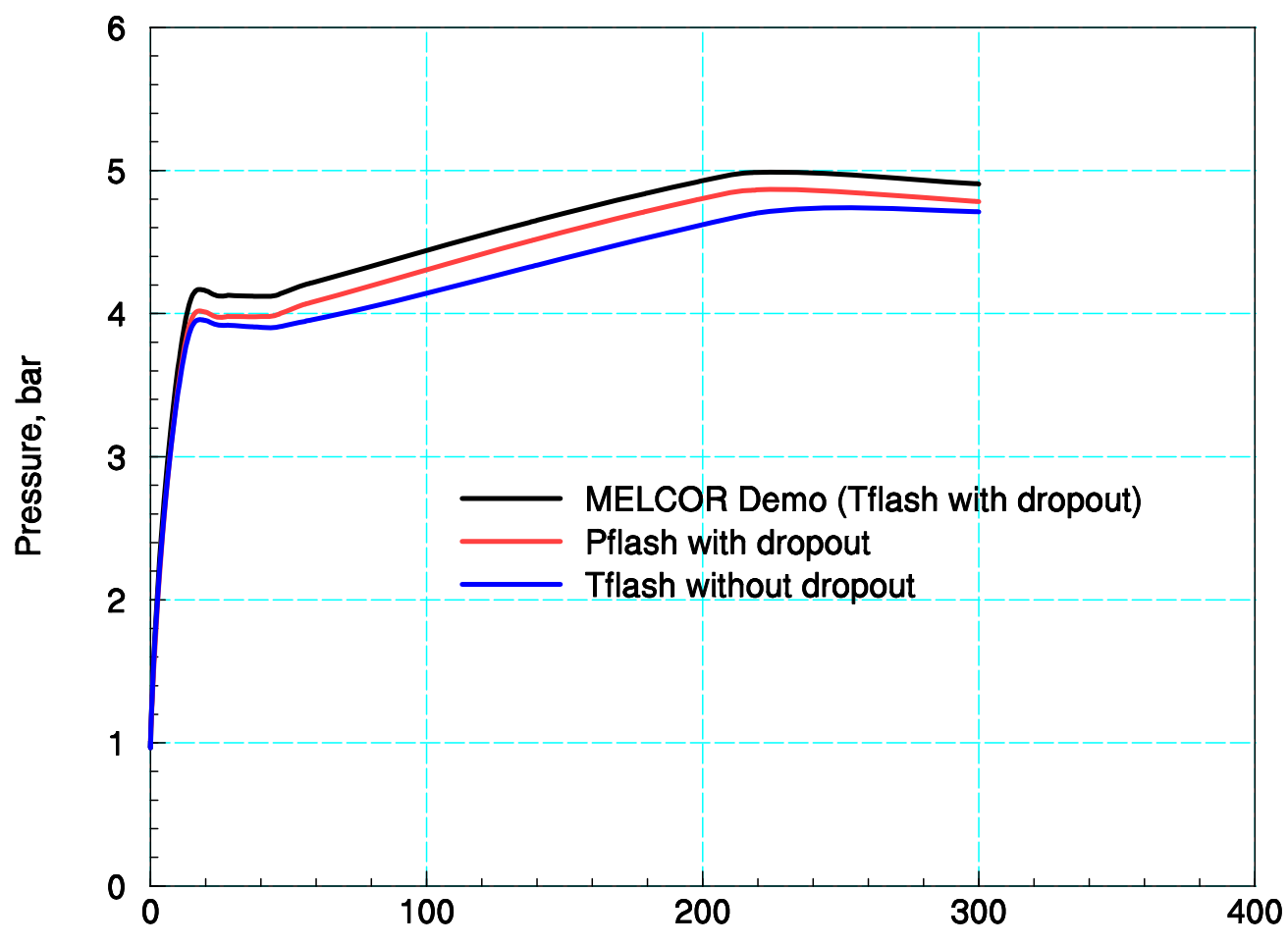

Time, seconds

Figure 2.26 MELCOR-calculated pressure sensitivity to determination and treatment of unflashed liquid water from LOCA scenario in large dry PWR plant. 


\section{AP1000 Containment Analysis (Advanced Light Water Reactor)}

In the AP1000, active containment mixing systems are not incorporated in the design, therefore local temperatures and gas/steam mixture concentrations need to be better resolved for more accurate pressure predictions. As such, the containment volume is subdivided into compartmental regions. Accordingly in this section, methods used to analyze containments with multi-cell representations are discussed for investigating the variation of local parameters (temperature, gas concentration, etc.) during a DBA event. The representations focus on modeling heat and mass transfer in 1-D ducts (passive containment cooling system [PCS]) and the more complex issue of mixing in 3-D space. User caution is urged for those cases where momentum driven jets may direct flows or when buoyant transitional plumes are dominating the flow regimes within either coupled 2- or 3-D cells in open geometries. In a number of cases, however, the multi-cell representations can provide important information on parameter variation throughout a containment space during DBA-type events, and the calculations may be of use in a number of applications, e.g., determining temperature profiles for equipment qualification or establishing accident management strategies. It is noted that there is a significant volume of assessment literature, accumulated in recent years, addressing issues such as stratification and mixing within containment spaces. Some of these assessment documents specifically focus on validation tests analyzed with the CONTAIN code, and most recently with MELCOR [Til08]. Because lumped-parameter codes like MELCOR are often listed among those codes that tend to over-mix during periods of small driving forces (i.e., during times when natural buoyancy driven flows dominate), it is important to benchmark such a code with other codes that specifically have models that have been developed to limit this tendency to over-mix. Consequently, the MELCOR code is compared here in detail with the CONTAIN code that includes a hybrid flow solver which has been shown to provide improved prediction of local parameters for situations where over-mixing is normally believed to be problematic.

The AP1000 containment analysis focuses on two important phenomena for determining peak pressure and temperature loads on the containment structure: 1) liquid film tracking on the containment outer dome and vertical wall as part of the PCS; and 2) the mixing of steam/air within the containment for two events with pipe break injections of varying elevation-the LOCA event has a low elevation break and the MSLB event is presented as a high elevation break.

Containment Model. Figure 3.1 shows a sketch of the AP1000 containment and Figure 3.2 presents the containment nodalization scheme. Table 3.1 provides a listing of the various compartments that divide the containment. A unique feature of the AP1000 plant is the PCS. During an accident event, the outer steel shell of the containment is flooded with water along the exterior surface; the flooding provides cooling of the containment shell by water evaporation into a natural circulation air flow along the outer shell surface. The nodalization of the PCS ductwork and containment was derived from previously performed CONTAIN assessments, which included the large-scale facility testing program for this containment type. The MELCOR input (CVH, FL, and HS packages) for the AP1000 containment is essentially a direct translation of the CONTAIN AP1000 input deck that was applied for confirmatory analysis during the Westinghouse AP1000 certification process. In this report, the only difference between the CONTAIN and MELCOR input decks is an elimination of paint resistance on interior heat structures of the MELCOR input. The elimination of paint simplifies the MELCOR structure 
input, and does not significantly affect the parameter comparisons for otherwise painted structures. For the painted containment shell, the paint specification indicates a high conductivity paint, which also effectively eliminates any concern for paint resistance in modeling the containment shell.

The analyses presented in the following subsections also follow the licensing specifications extracted from the Westinghouse AP1000 certification submittal; these specifications include the mass and energy sources to the containment during an accident event, PCS operation parameters (flood rates and coverage), and various assumptions regarding containment modeling to assure a conservative DBA calculation for containment loads. The conservative assumptions or biases important for the calculations are as follows:

- exclusion of floor surfaces as heat sinks;

- air gap (20 mils) between all steel-lined concrete heat sinks;

- no heat transfer to selected structures in dead-ended compartments after the blowdown injection;

- reduced mass and heat transfer coefficients on inner containment shell surface, multiplied by factor of 0.73 ;

- reduced mass and heat transfer coefficients on outer containment shell surface, multiplied by factor of 0.84; and

- PCS air flow loss coefficients increased by $30 \%$ above the experimental determined coefficients.

A summary of the calculated peak containment conditions in response to postulated DBA events can be found in the AP1000 Final Safety Evaluation Report (FSER) (see reference US04).

Listings of CONTAIN and MELCOR AP1000 inputs for both the LOCA and MSLB calculations used to generate the containment responses discussed above are not included in this report due to proprietary information that is likely embedded with these input decks.

\subsection{LOCA Accident Analysis}

The injection sources for the LOCA double-ended cold leg (DECLG) break are located below the operating deck within the steam generator compartments. The sources are: 1) the initial subcooled water injection to the east steam generator compartment (No. 4) from the RCS vessel side of the cold leg break with a post-blowdown liquid water injection (Figure 3.3); and 2) high temperature, post-blowdown steam from the steam generator side of the break and subsequent steam injection from ADS relief valves that open at 1500 seconds into the accident event (Figure 3.4), divided equally between each steam generator compartment. ${ }^{3}$ The water flow rate for flooding the containment outer shell is shown in Figure 3.5. The flooding is introduced at the top of the shell, and through a weir setup is distributed in a near uniform manner to the shell with a wetted coverage of $90 \%$. Full-term calculations are carried out to 10000 seconds, which is sufficient time to reveal the peak pressure period and a substantial portion of the subsequent depressurization period.

\subsubsection{Single vs. Multi-cell Models}

In the previous discussions of primary and secondary system breaks (LOCA and MSLB), the containment volume was modeled as a single containment volume. Multi-cell models introduce two important issues that need to be addressed: 1) the treatment of two-phase water injection,

\footnotetext{
${ }^{3}$ All steam injections for each code are input according to a temperature-flash setting with dropout of all liquid formed in the atmosphere.
} 
and 2) the mixing of gases within the containment. (Note: Representation of the containment as either single volume or multi-cell refers only to the containment; the PCS is modeled similarly in both the single volume and multi-cell containment cases.)

Two-phase blowdowns. As noted in the single volume analysis for large dry PWR containments, the temperature flash option ${ }^{4}$ is selected as the recommended method for treating phase separation, and the associated dropout of liquid water in the atmosphere assures the conservative prediction of pressure and temperature. In the scenarios dealing with single volume calculations, atmospheric conditions during the LOCA blowdown are observed to be saturated, a consequence of the modeling approach where the equilibrium temperature is the saturation temperature if sufficient liquid water is available to saturate the atmosphere during calculation time-step.

For multi-cell calculations where a distinct break room region exists (e.g., steam generator compartment), the dynamics of the pressure and temperature response for the containment can be quite different from an equivalent single containment volume representation. The difference is the result of what is calculated to occur in the break room during the blowdown. In the break room, the temperature equilibrium calculation forces saturation conditions, and the dropout of liquid water in the break room effectively filters out water that otherwise would be in the vapor state for a single volume representation of the containment. Because the break room is rapidly purged of non-condensible gases, the break room total pressure is essentially also the saturation pressure. Consequently, the multi-cell calculation with dropout more closely represents a single volume pressure flash approach for the LOCA event. This behavior is discussed more fully in Appendix A. Heat and mass transfer will tend to mitigate the variations that may be anticipated for the global or pressure response between single and multi-cell cases, but local effects will be observed due to a large degree of superheating that can occur in regions removed from the break room.

Figure 3.6, for example, shows the blowdown pressure profile calculated by MELCOR for single and multi-cell containment nodalization. The pressures are essentially identical for this LOCA event. However, the temperature profiles obtained using the two containment representations are different, as shown in Figure 3.7, where the local temperatures calculated in the above operating deck region are compared to the single containment volume temperature. In the comparison, the above operating deck region is observed to be highly superheated, resulting in a higher gas temperature compared to the single volume temperature that follows the saturation curve, as discussed above. From a licensing review standpoint, i.e., for a reported maximum gas temperature, there is an obvious issue with regard to containment nodalization. In reality, however, the difference is not as significant as implied by the comparisons of local temperature. This is because the potential for heat and mass transfer to equipment (e.g., equipment qualification review) in a single or multi-cell case is nearly the same due to the relatively small amount of energy associated with atmospheric superheat compared to the latent energy transferred by condensation on colder surfaces.

Regional gas mixing. Gas mixing develops under two conditions: mixing resulting from forced flow during periods of imposed pressure differences between containment compartments (i.e., during the blowdown period) and by convection driven by buoyancy forces. Because gas mixing can have a significant effect on condensation heat transfer coefficients, the degree of mixing can have an impact on total energy transfer within the containment and therefore on the global

\footnotetext{
${ }^{4}$ Temperature flash is really not an option in the MELCOR code, rather the temperature equilibrium model is the default model approach for external mass and enthalpy (M\&E) sources. The dropout of liquid water at the end of a time-step is by input parameter setting (see Table 2.6).
} 
energy balance in the atmosphere, i.e., pressure. Because the blowdown period is quite short, heat and mass transfer effects are relatively minor during this period compared to the rate of energy addition to the atmosphere by the injection source. Consequently, the mixing issue in terms of predicted containment loads is of greater concern for slow pressurization scenarios where both pressure driven and buoyant forces may be equally important. In the case of LOCA events where the injection elevation is low in the containment, buoyancy forces tend to create a well-mixed containment above the injection, as has been observed in numerous separate and integral effects tests (e.g., HDR E11.4 [Til02b]).

For the AP1000 certification, the issue of regional gas mixing affecting passive heat sink energy transfer was important due to the absence of any active ESF. Gas mixing importance is demonstrated for maximum pressure predictions in Figure 3.8, where single and multi-cell containment representations are compared. One multi-cell case shown in the figure is a case without the modeling of passive heat structures in one of the main compartments below the operation deck subsequent to the blowdown period. This case represents a conservative approach to the AP1000 pressure prediction, and has been the conservative approach ultimately adopted for the AP1000 certification submittal; this will be discussed in more detail in the code-to-code comparisons below. The multi-cell representation with all structures modeled could be considered to represent a best-estimate approach to the otherwise single containment volume calculation. The difference between the calculation excluding the below deck structures and the one including the structures demonstrates an approach where a code such as MELCOR might be used to assess the containment loads safety margin due to regional gas mixing, provided that sufficient validation data is available to justify the adequacy of the gas mixing modeling.

\subsubsection{Code Comparisons}

A new model application exercised with the AP1000 containment calculation is the simulation of the PCS performance, where flood water flowing down the outer containment shell is evaporated into an induced natural convective air flow within a downcomer and riser duct configuration adjacent to the containment shell. ${ }^{5}$ To model the phenomena associated with the PCS (film tracking of a cascading flood profile, film evaporation, convective and thermal radiation within the duct space, and the induced buoyant air flows) the MELCOR code input specification includes a number of integrated, mechanistic models, which are unique in this application for design basis accident analysis. The ability to access accurately the containment pressure during maximum loading is, therefore, directly tied to the capability of code to model these coupled processes (i.e., transient film tracking under evaporative conditions derived from a buoyancy driven air flow). The original review of the AP600/1000 containment performance was conducted using the CONTAIN code. To assure the CONTAIN code was adequately validated for the phenomena associated with AP1000 (e.g., PCS modeling), an extensive validation effort was performed using relevant experimental data [Til96]. Additionally, field code comparisons were conducted to show the adequacy of the heat and mass transfer models implemented within CONTAIN for 1-D buoyancy-driven flows in a geometry representative of the AP1000 PCS [Vij99]. Consequently, benchmarking the MELCOR code to CONTAIN for AP1000 application is appropriate and sufficient.

Figure 3.9 shows a comparison of the MELCOR- and CONTAIN-calculated AP1000 containment pressure response to a LOCA event, where again the CONTAIN results are

\footnotetext{
${ }^{5}$ PCS duct is represented by the 12 control volumes (downcomer-cells \#10, 24, 11, 12, and 13; riser-cells \#14, 15, $16,25,17,18$, and 19).
} 
represented as an equivalency band, $+/-5 \%$. The MELCOR pressure calculation (cell \#22) is shown to fall well within the CONTAIN equivalency band (results obtained using the non-ideal EOS for water, see Appendix A). ${ }^{6}$ Table 3.2 lists maximum containment pressure loads for the AP1000 LOCA for the code.

A comparison of local temperatures calculated above the operation deck, where the maximum temperatures occur, are shown during the short-term (blowdown period) and long-term in Figures 3.10 and 3.12, respectively. The temperature comparisons in the critical equipment region (cell \#3) are plotted in Figures 3.11 and 3.13 for the short- and long-term periods. The comparisons indicate that the superheating in regions removed from the break room is calculated somewhat higher with MELCOR during the blowdown period when maximum temperatures above the operating deck occur. Long-term temperatures trend toward saturation for both codes, and are in agreement for showing relatively well-mixed conditions throughout the containment during the post-blowdown period. ${ }^{7}$

Heat removal rate comparisons for the PCS containment shell and equipment region (cell \#3) are shown in Figures 3.14 and 3.15. The differences in the blowdown period heat removal rates in the above and below operating deck regions are due, in part, to a variance between calculations in the steam flow splits between the various pathways exiting the break room during a period of rapid phase separation and disposition in the break room, and the manner in which condensate accumulation on structures is treated within each code. The former variance is addressed here, and the latter, in the context of the single cell PWR large dry containment calculations, was previously discussed in Section 2. Here we note that two-phase flow modeling for the drains in the break room can affect steam flows to regions below the operating deck. For example, Figure 3.16 shows the calculated steam/gas flow exiting the break room through drains modeled by each code's pathway specification-the plot frequency is identical for each code calculation with plot output every 0.01 second. For the CONTAIN input, the drain elevation is at the break room floor elevation. The MELCOR input also include drains on the break room floor, but the extension of the assumed vertical pathway is set at $10 \mathrm{~cm}$, with the mid-elevation at $5 \mathrm{~cm}$ above the break room floor. These specifications appear nearly identical, but the predicted gas flow by each code is noticeably different. In the CONTAIN flow modeling, pathway flows are single phase; therefore, gas and liquid (pool) water transfers are modeled as separate pathways. A gas pathway is shut off when the liquid level reaches the specified elevation of the pathway. Therefore, when a gas pathway elevation is set very near the floor elevation, large sources of liquid water dropped onto the floor (during a two-phase blowdown) can intermittently block gas flow exiting the compartment from the bottom drain. This method for treating two-phase flow is not followed in the MELCOR code; rather, two-phase flow modeling in the MELCOR code allows simultaneous gas and liquid to flow in a single pathway. In this case, the composition of the flow in terms of gas versus liquid (i.e., void) is determined by liquid level in the pathway, based on the vertical height of the pathway. In this case, if the pathway vertical opening is specified as having the bottom at the floor level and extending $10 \mathrm{~cm}$ above the floor, some gas will flow in the pathway until the liquid level rises above $10 \mathrm{~cm}$. The pathway (or pipe) void is therefore used to determine the relative mixture of gas and liquid flowing in the pathway. As can be observed in Figure 3.16, the CONTAIN input specification and flow modeling effectively inhibits gas flow

\footnotetext{
${ }^{6}$ Previous CONTAIN confirmatory calculations provided for AP1000 certification were performed using the default equation-of-state (ideal) for water-peak pressure results obtained for that application were about one psi higher than the results reported here.

${ }^{7}$ This is a common outcome relative to mixing due to the low elevation of the injection source for the LOCA event.
} 
during significant time periods when only liquid water exits through the drains, whereas for the MELCOR-calculated drain flow, the gas flow is represented as a more continuous stream exiting the through the drains. The potential importance of a larger integrated gas flow exiting through the drains is that this flow passes directly through the cavity region and enters cell \#3 where there is a large exposed mass of steel. Consequently, the higher steam injection into cell \#3 during the blowdown results in a greater amount of condensation on relatively cold structures in cell \#3 compared to the CONTAIN modeling. While the difference is not significant to the containment pressure loads, the differences in recorded maximum temperatures predicted in critical regions (such as cell \#3) may not be similarly dismissed, as indicated in Figure 3.11. Because either code has a two-phase drain model that could be defendable as a best-estimate approach, a conservative or biased methodology may be suggested in some applications, and this biased approach is discussed in the subsection below on user guidance.

Turning to the longer-term containment performance (1000-2000 seconds) where the maximum pressure loading is dependent on the heat removal from the PCS, we present a comparison of buoyancy induced duct air/vapor flow and transient evaporative film mass on the containment shell due to exterior flooding. A comparison of exit air flow velocity from the PCS duct for each code is plotted in Figure 3.17, and the agreement is shown to be very good. Figure 3.18 shows each code's prediction of evaporative film mass for specific area locations along the shell exterior surface. Film mass is plotted for two structures along the shell: structure s1_17w lies just above the spring-line (contained within cell \#17) and structure s1_14aw is at the base of the containment shell (contained within cell \#14). Flooding of the shell begins at 336.5 seconds. The flooding predicted by both codes is in good agreement, indicating there is $100 \%$ evaporation of PCS flood water at the time ( 1500 seconds) when the maximum containment pressure load occurs.

\subsection{MSLB Accident Analysis}

The injection source for the MSLB event is located at an elevated region above the operating deck in cell \#7, as shown in Figure 3.2. Figure 3.19 plots the superheated steam release rate into the containment. As with the LOCA event, the region below the operating floor containing the majority of structural mass is assumed adiabatic after the injection for the reference multi-cell case, which for these calculations is for times after 850 seconds. Flooding rates and water temperature and coverage are the same as in the calculation for the AP1000 DECLG LOCA event. The calculations are run out for one hour following the steam line break.

Because the steam injection from the secondary system is superheated steam as opposed to the high pressure liquid water injection during the LOCA blowdown, there is no issue regarding phase separation and disposition as in the case of the LOCA analysis. An important focus for the MSLB, apart from the global concern for maximum pressure loading, is the prediction of local temperatures. The reason for the concentration on local response is that the location of the secondary system break occurs at an elevated location in the containment, typically some distance above the operating deck (see Figure 3.2). Above the break location, the containment is generally well mixed, however below the break, a region where the temperature and steam stratification is significant can be observed from near prototypical experiments (CVTR). Because the area of stratification is more likely a region where critical equipment may be located, knowledge of the stratification profiles for temperature and steam concentration can be important for accessing equipment performance and safety margins for equipment qualification. For the LOCA event, with a break location lower in the containment, a reduced stratified containment is 
typical; therefore, the importance of multi-cell containment modeling is somewhat diminished compared to the MSLB case.

From a code comparison standpoint, the issue of stratification is also emphasized more for the MSLB event. This is due to the substantial amount of validation literature that exists for the CONTAIN code, with its hybrid flow solver model, to address a common fault of control volume codes, i.e., a tendency to over-mix containment regions during periods of reduced injection rates. Consequently, the comparison of MELCOR local temperature predictions with CONTAINgenerated results takes on special significance.

\subsubsection{Single vs. Multi-cell Models}

The AP1000 MSLB event is compared in this subsection for both single and multi-cell models, where the model descriptions refer to the segmentation of the containment interior space. For all models, the PCS remains segmented, as indicated in Figure 3.2. Additionally, for direct comparison purposes, the elimination of passive heat sinks below the operating deck as recommended in the AP1000 certification audit is ignored, unless specifically noted.

The prediction of pressure is dependent on the timing and degree that injected steam energy is removed from atmosphere-to-structure mass and heat transfer processes. ${ }^{8}$ A single cell model represents a model approach that has two competing heat removal processes that are inherent to such a simple and approximate representation of the containment: 1) over-prediction of the dilution of steam concentration in the containment; and 2) immediate contact of all structural material with a steam supply available for condensation. Depending on which process dominates, the single cell model may be predicted to produce a pressure loading that is either higher or lower than an equivalent multi-cell model where the two competing processes are more appropriately treated with some capability to address stratification processes (forced and buoyancy-induced gas flows). Figure 3.20, for example, shows a comparison of the single and multi-cell pressure profile prediction for the AP1000 MSLB event. During the rapid pressure phase that occurs during the first $\sim 100$ seconds, both single and multi-cell models produce similar pressure responses, as also observed for the LOCA event; at the reduced injection phase, however, the multi-cell model trend is to generate a higher peak pressure than the single cell model. This response, with respect to peak pressure prediction, is seen to be a reverse from that noted with the LOCA event. Therefore, for this type of containment and system break specifications, it would not be accurate to refer to a single cell model as a model that will provide the most conservative prediction of containment pressure.

For the prediction of maximum temperature profile for equipment qualification, the situation with respect to the impact that containment nodalization has on results is even more significant. Figure 3.21 shows the maximum temperature profile calculated by MELCOR for both single and multi-cell models during the MSLB event. Here, the multi-cell model shows that the single cell model predicts a maximum temperature profile that is slightly lower than the multi-cell model; however, in the likely region where critical equipment may exist (i.e., below the operating deck, cell \#3), the single cell model significantly over-estimates the temperature profile with which equipment will be in contact. Numerous integral tests of containment responses to elevated injections have validated the trends that are predicted here with MELCOR for temperature stratification.

\footnotetext{
${ }^{8}$ For the AP1000 plant, there are no active systems (sprays or fan coolers) that are rated as safety equipment for the purpose of limiting atmospheric pressure and temperature response to primary or secondary system breaks.
} 
The issue of superheating within the containment atmosphere during an MSLB event is addressed by a nodalization choice (single vs. multi-cell) in Figures 3.22 and 3.23. In both models, the timing and degree of superheat is similarly predicted, where the maximum superheating occurs at the end of the rapid pressurization phase ( 100 seconds) at $\sim 60 \mathrm{~K}$. Saturation conditions during the MSLB event are calculated with either nodalization model to begin $~ 300$ seconds following the termination of the steam injection.

\subsubsection{Code Comparisons}

Figure 3.24 shows the pressure comparisons between CONTAIN and MELCOR for the multicell model applied to the AP1000 MSLB audit calculation. Figure 3.25 shows a similar comparison for the maximum temperature profile calculated in the region above the operating deck. Table 3.3 lists the peak pressure and temperature calculated with the various codes (including Westinghouse's WGOTHIC code used to prepare the AP1000 certification submittal). The MELCOR-calculated peak values are observed to be in good agreement with the CONTAIN predictions (within the $+/-5 \%$ equivalency band). However, during the period when the steam source is terminated, there is a tendency for the MELCOR results to trend to the CONTAIN equivalency band boundary or outside the band in the case of pressure. This tendency on the part of the MELCOR modeling is caused primarily by a trend of the MELCOR code to over-mix the containment atmosphere compared to the CONTAIN model (which includes a corrective methodology to reduce over-mixing during periods dominated by buoyant flows driven by gas density variations using the hybrid flow solver). It is important to note that this noticeable variance in the code-to-code result occurs subsequent to the peak containment loads and, therefore, is relevant primarily for situations where local temperature profiles may be required to assess issues related to equipment qualification.

The relative tendency to over-mix is demonstrated by each code's prediction of temperature stratification within the containment. Calculated temperature stratification for each code is shown in Figure 3.26. The high temperature profile plotted in the figure represents the region above the operating deck near the injection source (cell \#7), whereas the lower temperature profile represents the region below the operating deck where critical safety equipment is likely to be located. Note that for late-time behavior for MELCOR predictions, there is the trend for the temperatures to converge (mixing). The CONTAIN resulting profile, on the other hand, shows a stratification that remains relatively the same as time proceeds, indicating that mixing is noticeably reduced as compared to the equivalent MELCOR calculation.

Furthermore, noting the observed trends for late-time MELCOR pressure and temperature responses in Figures 3.24 and 3.25, containment energy removal is dominated by mass and heat transfer above the operating deck region of the PCS. Over-mixing during this period tends to lower the gas (saturation) temperature. Consequently, a reduced temperature is predicted by MELCOR compared to CONTAIN. The higher CONTAIN calculated temperature at late time translates to slightly higher energy transfers on a global basis. (The higher temperatures translate to higher steam concentration and, therefore, higher condensation heat transfer coefficients along the containment shell above the operating deck.)

As indicated above, superheating within the containment may be significant for an MSLB event. The prediction of superheating for both MELCOR and CONTAIN in the region above the operating deck is shown in Figure 3.26. The timing and degree of superheating calculated with each code is observed to be in relatively good agreement. 
It is of interest to consider what the comparisons between MELCOR and CONTAIN models would reveal if the below operating deck structures were not effectively removed from the calculation following the injection at 850 seconds. Figures 3.27 and 3.28 show pressure and maximum temperature comparison for MELCOR and CONTAIN assuming no energy removal biasing due to structural removal in the below operating deck region; Figure 3.29 shows the temperature stratification profiles for each code. Including the below operating deck structures for the entire calculation period changes the previous comparisons only slightly, however some noticeable trends can be perceived. First, the added below operating deck structures effectively increase global energy removal for the MELCOR calculation in the lower regions of the compartment due to the added tendency for this calculation to mix the atmosphere at late times. This effect tends to balance the reduced energy transfer to the upper containment shell above the operating deck. The consequence of the compensating energy transfers is that the pressure calculation is now in slightly better agreement with the CONTAIN results (within the $+/-5 \%$ equivalency band for the entire calculation period) compared to the cases without below operating deck structures for times after the injection. However, the situation with respect to maximum temperature comparison is not improved. In this case, the above operating deck temperature calculated by MELCOR at late time is observed to fall below the CONTAIN equivalency band at late times. Stratification comparisons (Figures 3.26 and 3.29) are slightly improved with the addition of below operating deck structures. The added structures increase condensation in the lower regions of the containment causing an enhancement of the stratification effect. Consequently, mixing attributed to the MELCOR over-mixing tendency during periods of reduced steam injection is reduced.

\subsection{User Guidance for Multi-cell Containments}

\subsubsection{Containment Model Building}

To build a detailed multi-cell containment model, sufficient design information must be made available from the plant vendor or applicant's design documentation, which typically will include general arrangement drawings of the containment, detailed drawings of specific areas of special interest, other supporting material that defines interconnecting pathways between compartments, and a listing of structural information (concrete, steel-lined concrete, and steel) by location. In some cases where information is not explicitly listed in design documents, input for build-a-model may be extracted from an applicant's own multi-cell input deck for whatever code they are using to calculate the containment response to an accident event. However, some independent checking of those processed inputs should be considered throughout the model building process.

A choice for the nodalization scheme is often dependent on the physical divisions of the containment, where each physical compartment may be associated with a control volume or cell. In some cases, however, large open regions may be divided to allow a best-estimate or what could be considered a more conservative representation of regional/local temperature or concentration. For example, in the AP1000 plant, the region above the operating deck was divided into seven regions (Figure 3.2). The general scheme for division of open regions bounded by a cylindrical side wall and upper dome region is to set up a number of stacked cells comprising an inner cylinder region surrounded by an annulus region of equal number of stacked cells, with a cap cell that spans the top cylinder and annulus regions. Such a scheme allows sufficient pathways for circulation loops to develop (dead-ended regions should be avoided in this case). Pathway lengths for interconnected compartments, unless connected by a specified 
pipe length, have their lengths estimated as $l=\sqrt[3]{V_{\min }}$, where $V_{\min }$ is the smaller compartment volume attached to the pathway. The pathway length determines the inertia of the pathway contents, and the length is therefore only important typically for subcompartment analysis, where the timeframe of interest is a few seconds after the injection. For DBA application where peak containment loads are the focus, the pathway lengths are not so critical and this can be verified through sensitivity calculations.

Sufficient design information must be available to specify compartmental flow pathways. Required information includes path area, irreversible loss coefficient (form loss), length of pathway, elevation of the pathway for both donor and receiver cells, as well as data on pathway orientation, and opening and exit pathway heights (mainly for horizontal pathways). Specification of opening heights may or may not be available and may have to be estimated based on plant drawings. Only in regions where both liquid and gas are expected to flow in the pathway will the opening heights possibly have some affect on pathway flows. Opening heights derived from MELCOR default settings should however be reviewed carefully because nonphysical pathway geometry can be generated in some cases where the pathway areas are large. In such cases, direct specification of opening top and bottom elevation is preferred. Uncertainty with respect to the height parameter may also be evaluated through judicial sensitivity calculations. Special attention should be focused on the irreversible loss coefficients, where the flow equation is the basis for how coefficient values are translated from one code to another, or from values defined otherwise as discharge coefficients. For example, tabulated CONTAIN irreversible loss coefficients are related to MELCOR by $K_{M E L C O R}=2 * C_{\text {CONTAIN }}$, based on the relative formulations of the flow equations. Note that friction losses are generally not modeled in containment applications because pathways most resemble orifices (e.g., door openings, breakout panels, etc.). Consequently, the frictional losses are effectively zeroed by setting the pipe or pathway segment length (SLEN) to a small value (e.g., 1.0e-10). In most cases, critical flow is not important for DBA analysis as pathway areas are relatively large, and therefore the MELCOR choke flow discharge coefficient can remain at the default setting, $\mathrm{CDCHKF}(\mathrm{R})=1$.

The amount and distribution of short-term heat sinks (metal from equipment, components, and structures) in the containment are based on an estimate of steel mass derived from an occupied volume percentage of the free space in the containment or in a specific compartment of the containment. Uncertainty in these steel mass amounts should be ascertained for follow-up analysis via sensitivity calculations because the amount of short-term heat sinks can have a significant impact on the predicted peak containment loads. This is indicated for the AP1000 LOCA calculation where heat removal in cell \#3 (core makeup tank [CMT], chemical and volume control system [CVCS], accumulator room) is shown to dominate heat removal predicted for other regions of the containment, such as the entire region above the operating deck (e.g., compare Figures 3.14 and 3.15). Clearly, any modeling assumption that influences heat removal from critical regions must be scrutinized and considered for investigation in sensitivity calculations. Containment short-term heat sink mass is a candidate for a targeted review of uncertainty, along with model assumptions that impact exposure of structures to condensing steam environments.

It is important, generally, that wall, floor, and roof structure descriptions include the following information: material type, 1-D thickness by material type from surface to back side, containment region adjacent to surface and back side, surface paint resistance, orientation of the structure (vertical/horizontal), elevation of structure (bottom), and height of structure. Most modern code input will include this data, but in some cases the general arrangement drawings 
may be needed to obtain information on elevation and structure heights. Characteristic lengths for structures are often based on the structure height in the case of vertical walls. Structures representing suspended equipment within a compartment may have a characteristic length representative of the compartment vertical dimension, but also should be described with an associated physical dimension. The physical dimension in the vertical plane can affect how the film tracking is performed and therefore what film resistance is calculated for the structure. For most equipment this dimension should be small in relation to the compartment height. Because film resistance generally is not an important parameter for atmosphere-to-structure heat transfer, the accuracy that is required in modeling film tracking on miscellaneous steel is low for DBA analysis. For specific applications, uncertainty related to input can be addressed through sensitivity calculations based on equipment physical dimension. For horizontal surfaces such as floors or roofs, the effective characteristic length may be derived from $L=A / P$, where $A$ is surface area and $\mathrm{P}$ is the perimeter of the surface. Uncertainty, however, with respect to flooding and horizontal heat transfer correlations, has prompted a conservative treatment of floors where horizontal structures are eliminated from the list of included structures in a containment model.

Stratification in the AP1000 plant can develop as a result of buoyancy-induced flows or elevated release injections. The tendency to stratify can be further driven by localized heat and mass transfer that may develop within the dome region as a result of the initial PCS flooding of the upper containment shell. For the MSLB scenario, the steam injection is elevated within the open region above the operating deck (cell \#7), and preferential heat and mass transfer occurs predominately in the upper dome region above the spring line. These conditions favor a higher steam concentration in the regions above the injection. These conditions may be captured partially with segmentation of the open region; however, as mentioned previously, the MELCOR flow modeling is representative of many lumped-parameter flow models that tends to over-mix containment cells where flows are driven primarily by gas density variation. Nodalization of the containment may be only partly successful, therefore, in developing actual stratification profiles, with success depending on the containment model and scenario. This observation is demonstrated in the MSLB event where the steam mole fractions in the above deck region are calculated with MELCOR (Figure 3.30) and CONTAIN (Figure 3.31). The CONTAIN code with the hybrid flow solver, which corrects for over-mixing by flows driven by vertical density differences, shows a significant degree of stratification in vapor concentration in the open region, whereas the MELCOR code shows essentially no stratification except near the very bottom of the region. The relatively good agreement in pressure prediction between the codes is due, in part, to the compensating nature of the heat removal rates along the containment shell, which tends to result in a total regional heat removal rate that is approximately equal for either code model. Nonetheless, stratification can be a significant feature for some types of scenarios, even though the global effect may not be sensitive to a more accurate representation of open region temperature or concentration profiles.

To minimize the tendency to over-mix, some nodalization schemes may bias containment input to effectively reduce circulation flows, and therefore to force stratification. This can be accomplished by significantly increasing the forward loss coefficients for pathways in the regions where stratification is expected, for example for the AP1000 MSLB in the pathways connecting cells \#7 and \#8 with lower cells \#22 and \#23. While this method for biasing input to produce a stratification effect may be useful for exploring conservative or non-conservative responses to phenomenon, the approach should be used with caution. Biasing input to produce stratification should be considered useful when 1) a user has an argument that stratification is occurring, and 2) an under prediction of the stratification produces a non-conservative 
containment response for peak loads. Suspected over-mixing can be investigated either by independent calculations using a code that has a validated model for predicting similar stratification profiles (e.g., see CONTAIN assessments for thermal hydraulic phenomena, reference Til02b), or by obtaining information from prototypical facility test programs.

\subsubsection{Code Default Settings}

Various default settings are included for MELCOR model options. For DBA analysis, the more important settings deal with the heat transfer correlations used in the HMTA method. Table 2.6 lists an important setting which is changed via sensitivity coefficient 4110(1), where the leading coefficient for a vertical plate natural convection correlation is changed from 0.1 to 0.14 . The rationale for making this change is by investigating parameter settings for a number of separate and integral test analyses conducted with the MELCOR code.

A unique feature for the AP1000 plant is the PCS that includes an internal vertical channel where a relatively high air velocity $(3-4 \mathrm{~m} / \mathrm{s})$ is induced by buoyancy forces within the duct. The duct flow rates are essentially in the transition region that defines the mixed natural and forced convective regime for a vertical wall. The MELCOR code has a mixed convective equation that attempts to predict the Nusselt number for this regime, but is not referenced. Other codes, such as CONTAIN (and WGOTHIC), use a simple mix convective correlation where the larger of either the natural or forced convective Nusselt numbers are used to represent heat transfer in the mixed convective regime [Mur97]. Validation studies using experimental tests in this flow regime, and referenced in the CVTR report [Til08], suggest that the CONTAIN prescription for mix convection is preferred over the MELCOR default treatment. Consequently, a set of sensitivity coefficients are used to force the MELCOR mix convection equation for the Nusselt number to the CONTAIN correlation; this is accomplished by setting the first value for coefficients 4060 and 4061 to -1.0 .

As noted in the introduction to the AP1000 calculation, the calculation is biased conservatively by eliminating floor structure heat and mass transfer. This biasing reflects on the uncertainty attributed to horizontal heat transfer correlations for confined surfaces. In the single cell calculations discussed in Section 2 and listed in Table 2.6, a similar set of biased prescriptions was applied with pool surface heat transfer eliminated via sensitivity coefficient 4407 (see Table 2.6). The AP1000 plant calculations discussed above did include pool surface heat transfer because this original calculation model was used in a confirmatory manner where it was assumed that pool heat transfer was included in the applicant submittal calculations (similar argument is made for the inclusion of atmosphere-to-structure thermal radiation in this demonstration calculation). No specific guidance (as in Table 2.6) for pools to be excluded can be given in the case of multi-cell DBA applications because pool geometry is generally more accurately represented in multi-cell nodalizations and, therefore, more properly included. For single cell representations, pool geometry may be considerably distorted by the inability to adequately establish flooding profiles and, therefore, biasing the pool heat transfer is thought to be appropriate and elimination is shown to be conservative. The effect of biasing the calculation in relation to pool surface heat and mass transfer may be explored via sensitivity calculations in determining the impact on margins of safety. For the AP1000 plant calculations for example, excluding pool surface heat transfer increases the MELCOR peak pressure for the LOCA event by $\sim 1$ psi, which is a relatively small effect on pressure at $\sim 57$ psig, but possibly of some interest given the slight margin of safety. The point is that sensitivity calculations are an integral part of most DBA analyses, and their relevance and ultimate value depends on the specific licensing decision under review. 


\subsubsection{Comments on Input Format \& Output Processing}

Structuring the MELCOR input according to the various model packages (CVH, HS, FL, etc.) and logical geometric division has advantages for simplifying changes to large input streams. Using the AP1000 input as an example, the MELGEN input for the AP1000 containment calculation is divided among the following input files that are sequentially read by the MELGEN processor using the redefined input file $(\mathrm{r} * \mathrm{i} * \mathrm{f})$ directive:

$\begin{array}{ll}\mathrm{r}^{*} \mathrm{i} * \mathrm{f} & \text { mp.txt } \\ \mathrm{r} *^{*} \mathrm{f} & \text { cont.txt } \\ \mathrm{r} *^{*} \mathrm{f} & \text { fl_cont.txt } \\ \mathrm{r} *^{*} \mathrm{i} f & \text { fl_pcs.txt } \\ \mathrm{r} *^{*} \mathrm{i} f & \text { below_struc.txt } \\ \mathrm{r} *^{*} \mathrm{f} & \text { above_struc.txt } \\ \mathrm{r} *^{*} \mathrm{f} & \text { dc_struc.txt } \\ \mathrm{r} *^{*} \mathrm{i} f & \text { riser_struc.txt } \\ \mathrm{r} *^{*} \mathrm{i} f & \text { film_trk.txt } \\ \mathrm{r} *^{*} \mathrm{i} f & \text { pcs_rad.txt }\end{array}$

*material properties

$* \mathrm{CVH}$ input for containment volumes

*FL input for containment pathways

*FL input for PCS pathways

*HS input for below operating deck structures

*HS input for above operating deck structures

*HS input for PCS downcomer structures

*HS input for PCS riser structures

*HS input for containment shell film tracking

*HS input for PCS structure-to-structure thermal radiation

The AP1000 MELCOR calculations required an ability in real time to eliminate a number of local heat sinks in the containment following the termination of the blowdown injection. To accomplish this task, a series of restart times were set up to approximate the times at which the blowdown injection terminated for either the LOCA or MSLB scenario. A number of restart times were set up for the MSLB scenario as there was some uncertainty regarding the appropriate point at which the extended steam injection source might be considered terminated. In MELCOR Version 1.8.6, heat structures could not be added or deleted on a restart. Therefore, heat sinks (below the operating deck) were effectively removed by modifying boundary surface data for specific structures. In this case, the MELCOR restart input stream was set up to change the heat and mass transfer scaling factors for the selected heat sinks on the boundary surface data input (HSCCCCC400). Therefore, to effectively eliminate these heat sinks, the scaling factors XHTFCL and XMTFCL were changed from 1.0 to 1.0E-10 in the MELCOR restart input stream. Figure 3.8 shows the effect of either retaining the original scaling factor or changing the factors on restart for the LOCA scenario.

Figure of merits for DBA containment analysis are pressure and gas temperatures. However, the analysis of the DBA event involves more than reporting only these quantities; investigation of many different containment response quantities, such as presented above in the numerous figures, can be anticipated. One set of important outputs are those variables that reveal how much energy is being removed and where the energy is being removed from the containment atmosphere during the accident event. This type of information is significant in order to assign relative importance to various regions of the containment that may dominate by passive heat removal during the calculation of containment pressure. Typically needed is a compartment-bycompartment assessment of total energy transfer to surrounding heat sinks, i.e., the sum of the surface integrals of all energy transfer processes from the atmosphere caused by the presence of structures within a compartment. In MELCOR, this information is not available directly and 
therefore some additional processing of plot output variables is required. ${ }^{9}$ There can be some confusion regarding the terminology used to identify various plot variables with energy transfers from the atmosphere. For example, ENERGY refers only to energy transfer due to vapor condensation or evaporation (latent plus liquid energy), and QTOTAL refers only to sensible heat removal (by convection and radiation). Furthermore, there is no surface integral variable for energy transfer; only the energy transfer flux is provided via plot variable. On the other hand, the sensible heat transfer has both the flux and surface integral components represented by plot variables. To extract the total energy transfer from the atmosphere to all structures within a compartment, the user must post-process: 1) calculate the surface integral calculation for energy transfer by multiplying the ENERGY flux and structure area; 2) sum surface integrals over all compartment structures; and 3) combine integral energy transfers with the total sensible heat integrals also summed over all compartment structures. Of course, if a region of the containment must be processed, all compartments within that region must be included in the summation process. Additionally, if transfer rates (MW) are desired, the total integral quantities must also be differentiated with respect to time. Figures 3.14 and 3.15 show an example of the result of this type of post-processing, where total energy transfer rates are plotted for a region (Figure 3.14) and a compartment (Figure 3.15).

Another issue related to atmospheric energy transfer, although not reported on specifically in the DBA analysis discussed above, is the matter of condensate run-off and the associated energy transfer removed from a structure surface via film flow. Energy transfer to a surface area composed of a number in a stacked structure, such as the containment shell in the AP1000 plant (and riser portion of the PCS) requires not only information on atmospheric energy transfers directed to a specific structure located within a vertical stack, but also the energy transfers due to film advection, as condensate flows to the structure from above and away from the structure at the bottom. The time-dependent process involved with condensate flow in the film tracking model is treated in a pseudo-steady state manner in the MELCOR code; therefore rapid changes in film flow cannot be resolved precisely. Nevertheless, DBA processes of interest for evaluation of PCS systems like the AP1000 plant are processes that have time constants that are on the order of minutes; under these conditions the pseudo-steady state treatment of film flow is appropriate with segmentation of the containment shell into a number of smaller structures. Unfortunately, a direct assessment of structure surface heat transfer cannot be obtained from the MELCOR output variables as the energy transfer associated with film flow is not provided. Estimates of these transfer rates for film flow can be obtained by post-processing using available plot variables in the case of networks consisting of a single structure (default film tracking). For these cases, the film drainage rate can be obtained by performing a mass balance using the time rate-of-change of film mass (derivative of film mass, plot variable HS-FILM-MASS) and condensate/evaporation rate (derivative of mass transfer, plot variable HS-MASS-FLUX). Film energy transfer is subsequently determined by multiplying the derived drainage rate by the film enthalpy (plot variable HS-FILM-ENTH). Energy transfer to the structure is then calculated as the atmospheric energy transfer rate minus the film energy transfer due to condensate drainage. The importance of this discussion rests with DBA analyses that focus on the condensation heat transfer coefficients calculated among various codes or in relation to measurements obtained in separate or integral tests. In these cases, the heat transfer coefficients are always derived in relation to the energy transfers at the surface of the structure, i.e., at the interface between film

\footnotetext{
${ }^{9}$ All energy transfer quantities are available as plot variables but not as control function arguments; therefore, processing energy transfer information is accomplished in a post-calculation procedure where the input variables are extracted from the MELCOR plot file (via Excel worksheets).
} 
and structure, and therefore the energy transfer by condensation is the latent energy associated with condensation, not the energy transfer due to vapor mass flow to the atmosphere-to-film interface.

Table 3.1. Nodalization for the AP1000 MELCOR Model.

\begin{tabular}{|c|c|}
\hline Compartment No. & Description \\
\hline \multicolumn{2}{|l|}{ Below Deck: } \\
\hline 1 & Reactor cavity (including steam generator connecting tunnel) \\
\hline 2 & Refueling room \\
\hline 3 & CMT, CVCS, and accumulator room SE and NE \\
\hline 4 & Steam generator room* (break room for DECLG) \\
\hline 5 & Steam generator room west* \\
\hline 6 & IRWST room \\
\hline \multicolumn{2}{|l|}{ Above Deck: } \\
\hline 7 & Top cylindrical center \\
\hline 8 & Top annulus \\
\hline 9 & Dome \\
\hline 20 & Bottom cylindrical center \\
\hline 21 & Bottom annulus \\
\hline 22 & Mid-cylindrical center \\
\hline 23 & Mid-annulus \\
\hline \multicolumn{2}{|l|}{ PCS: } \\
\hline 10 & Downcomer plenum \\
\hline 24 & Top downcomer \\
\hline 11 & Upper downcomer \\
\hline 12 & Mid-downcomer \\
\hline 13 & Bottom downcomer \\
\hline 14 & Bottom riser \\
\hline 15 & Mid-riser \\
\hline 16 & Upper riser \\
\hline 25 & Top riser \\
\hline 17 & Dome riser \\
\hline 18 & Lower chimney \\
\hline 19 & Upper chimney \\
\hline \multicolumn{2}{|l|}{ Environment: } \\
\hline 26 & Reference compartment for the environment \\
\hline
\end{tabular}


Table 3.2. Calculated peak pressure for LOCA (DECLG) event in the AP1000 plant.

\begin{tabular}{|l|l|l|}
\hline \multicolumn{1}{|c|}{ Code } & \multicolumn{1}{|c|}{ Peak Pressure, psig } & \multicolumn{1}{c|}{ Available margin*, \% } \\
\hline MELCOR & 56.8 & 3.1 \\
\hline CONTAIN** & 58.3 & 1.0 \\
\hline WGOTHIC $* * *$ & 57.8 & 1.7 \\
\hline
\end{tabular}

* Design pressure is 59 psig-Margin determined by absolute pressure

** with non-ideal equation-of-state (EOS)

*** AP1000 FSER; NUREG-1793, Volume 1

Table 3.3. Calculated peak pressure and temperature for MSLB event in the AP1000 plant.

\begin{tabular}{|l|l|l|l|}
\hline \multicolumn{1}{|c|}{ Code } & \multicolumn{1}{|c|}{ Peak Pressure, psig } & \multicolumn{1}{c|}{ Available margin*, \% } & \multicolumn{1}{c|}{ Peak Temperature, K } \\
\hline MELCOR & 56 & 4.2 & 461 \\
\hline CONTAIN $* *$ & 57.3 & 2.3 & 461 \\
\hline WGOTHIC $* * *$ & 57.3 & 2.3 & 463.1 \\
\hline
\end{tabular}

* Design pressure is 59 psig-Margin determined by absolute pressure

** with non-ideal equation-of-state (EOS)

*** AP1000 FSER; NUREG-1793, Volume 1 


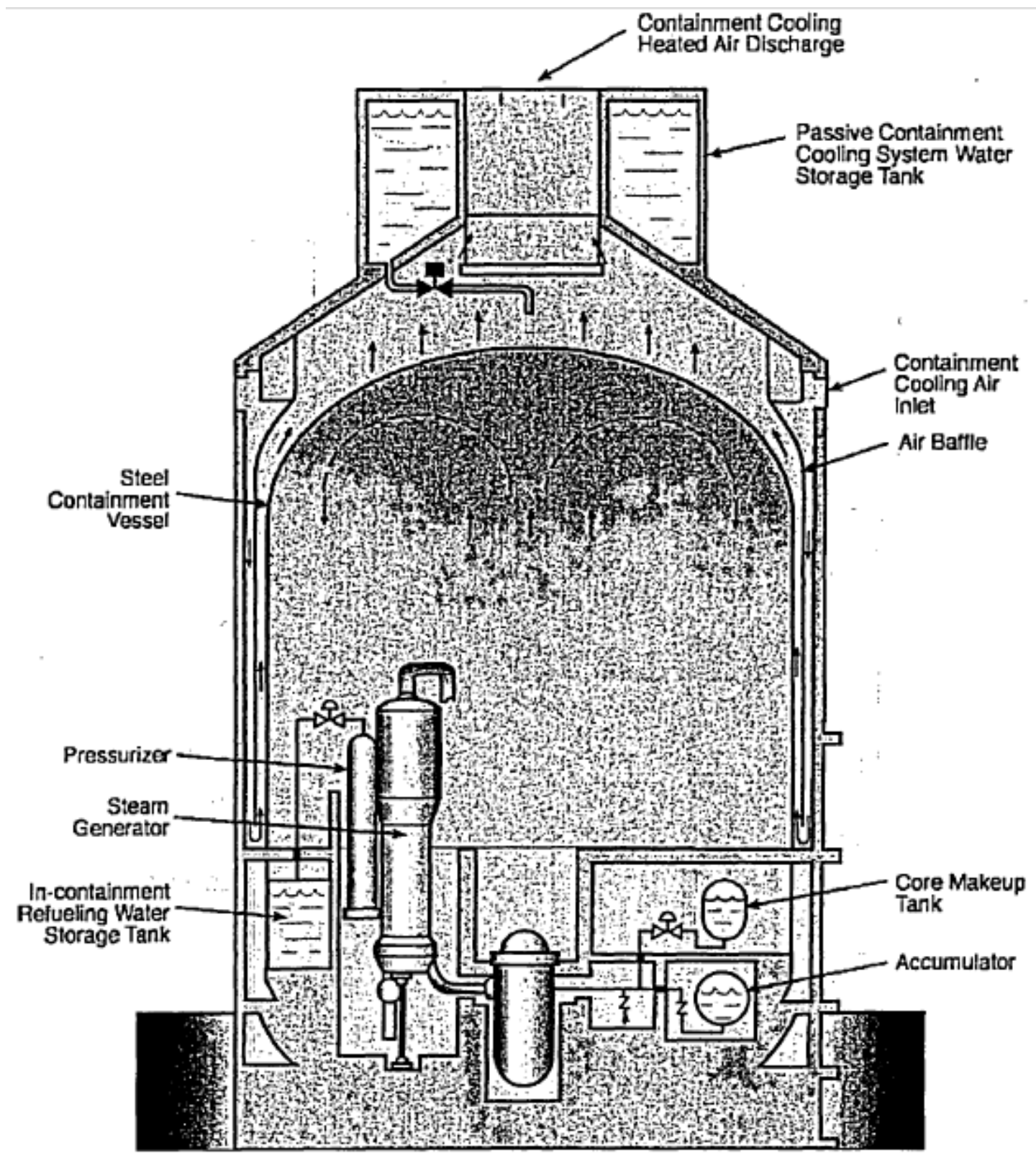

Figure 3.1 AP1000 Containment [US04]. 


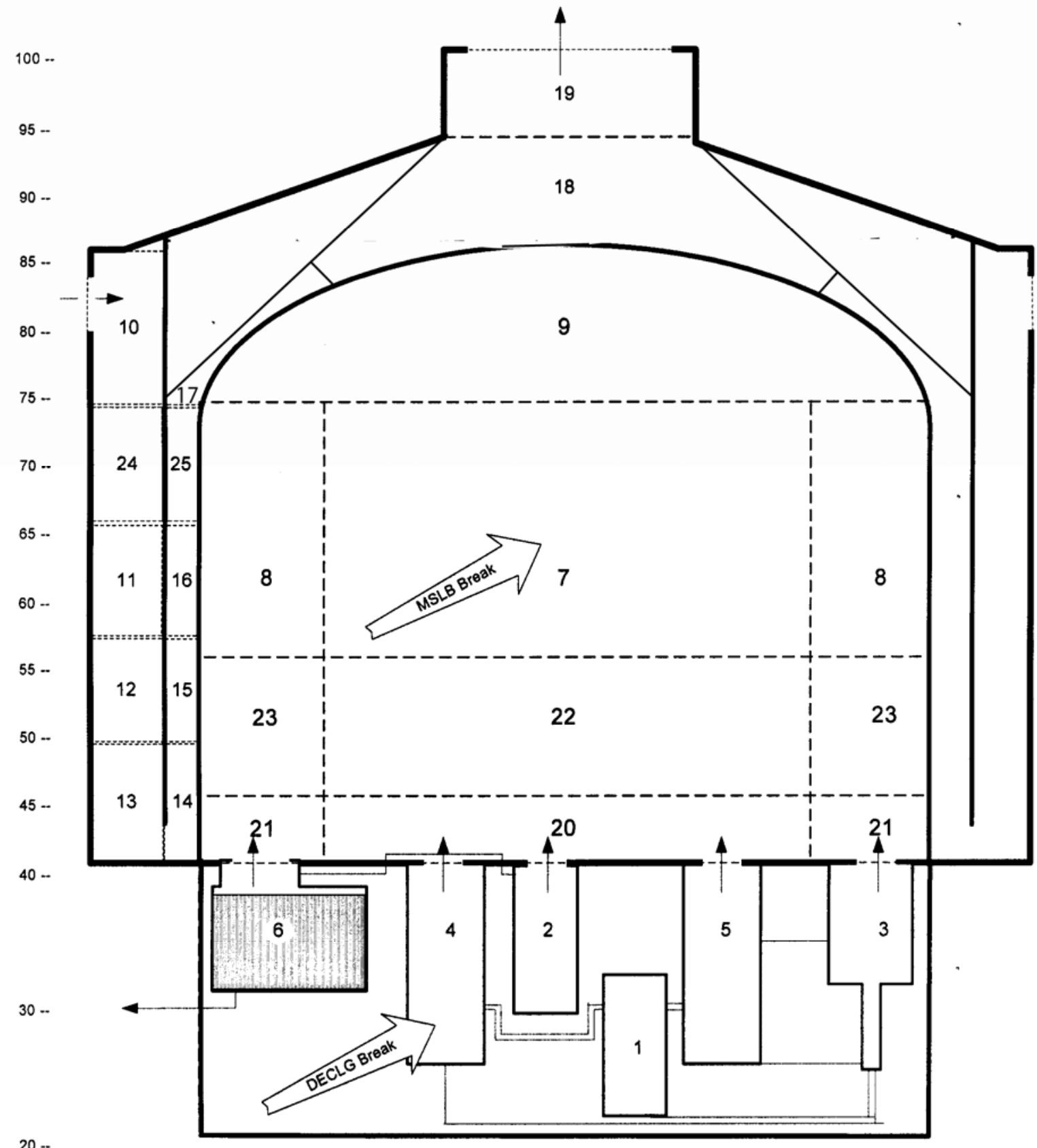

Figure 3.2 AP1000 Containment Nodalization Model. 


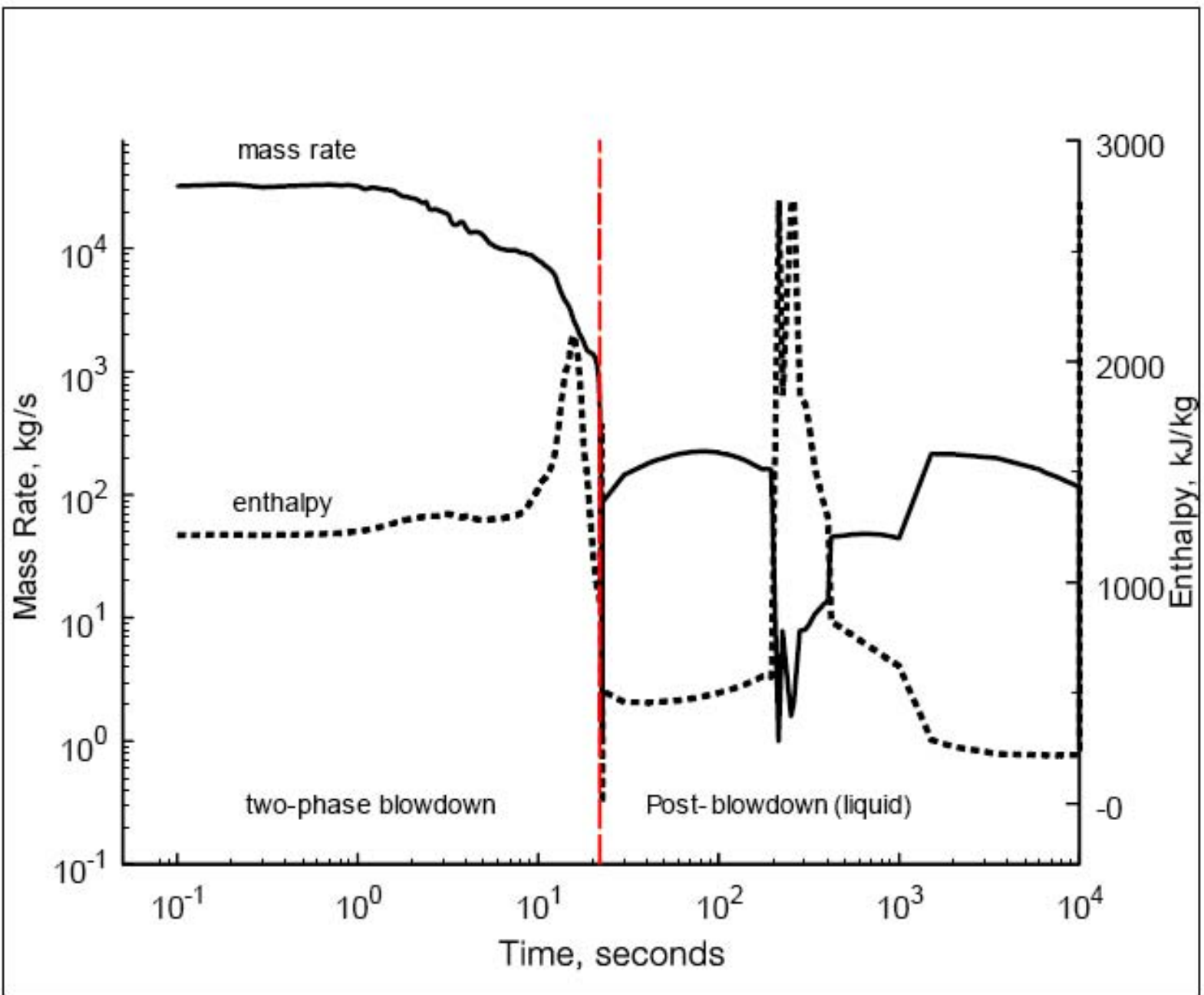

Figure 3.3 Two-phase water injections for DECLG LOCA (vessel side break flow). 


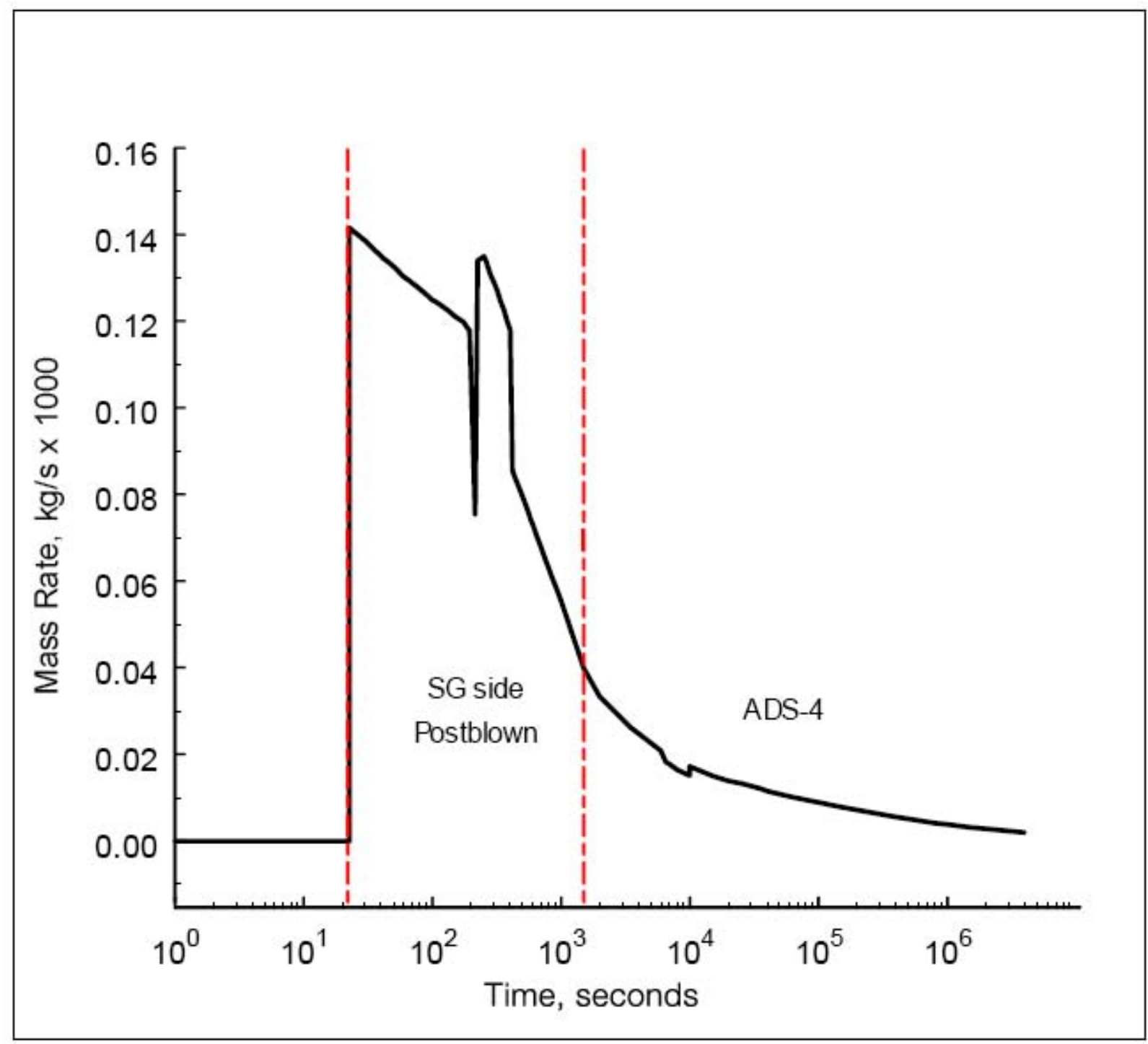

Figure 3.4 Steam injections into the AP1000 steam generator compartments, post-blowdown and ADS-4. 


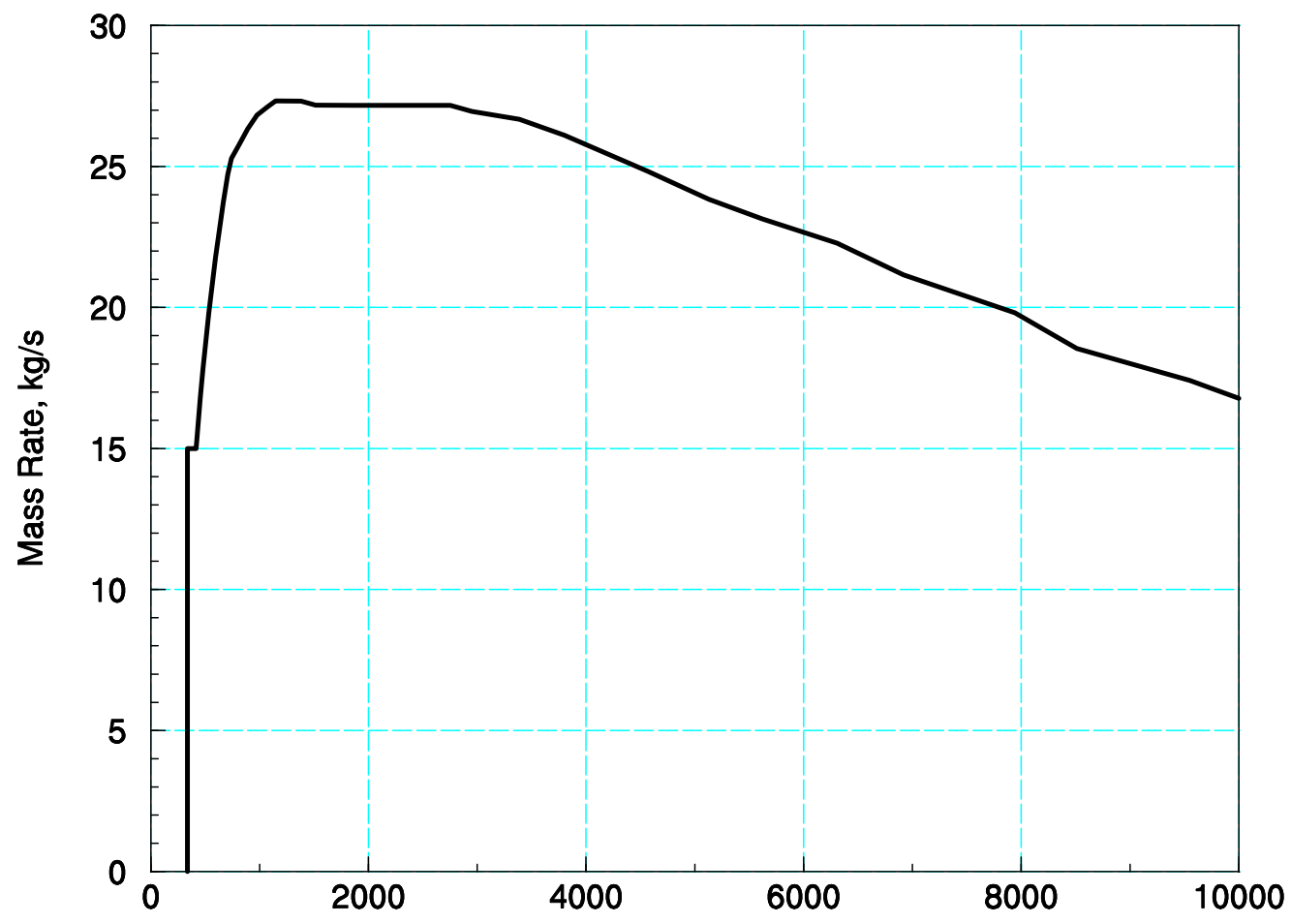

Time, seconds

Figure 3.5 Outer containment shell water flood rate for PCS (both LOCA and MSLB events). 


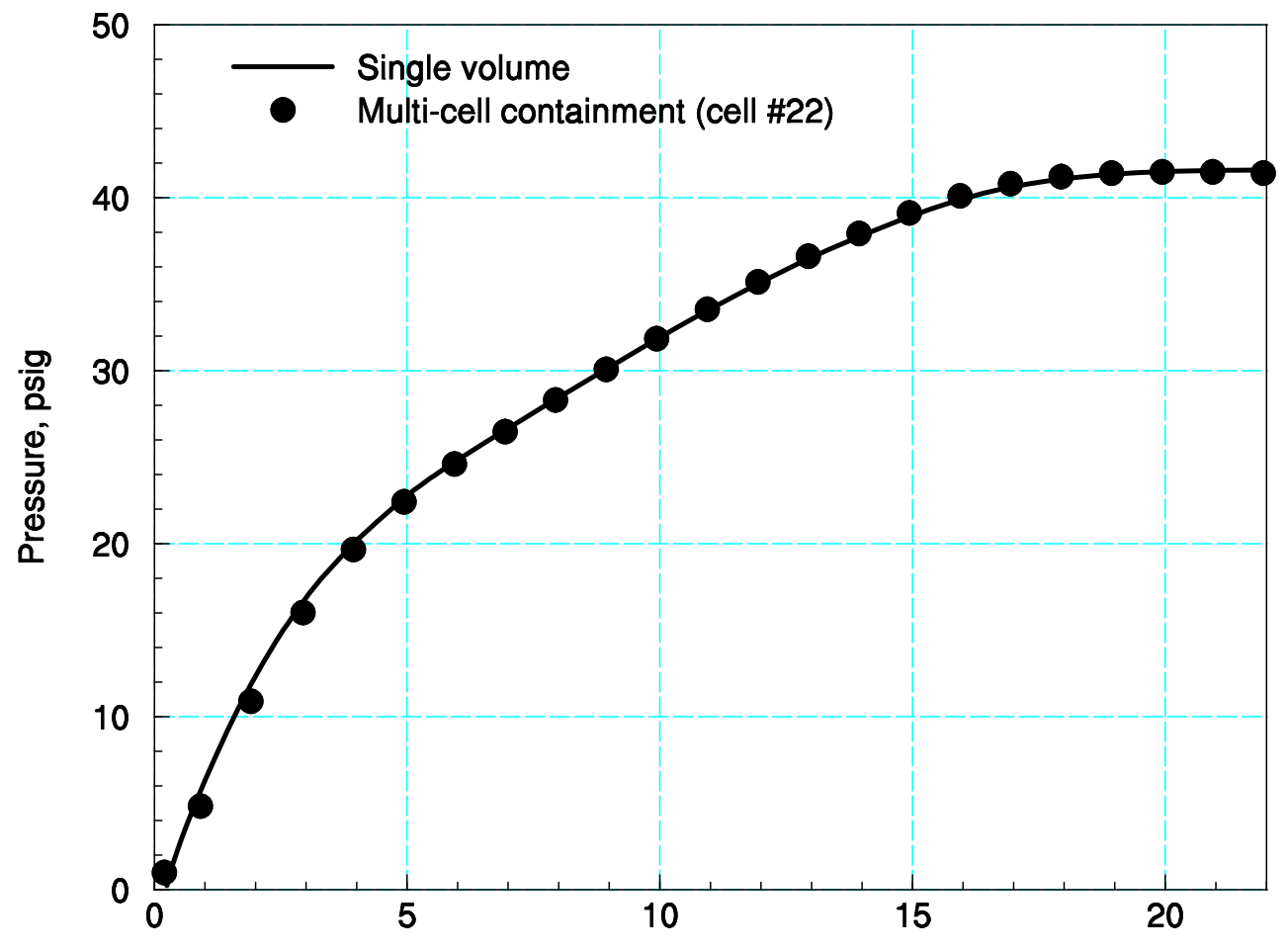

Time, seconds

Figure 3.6 Comparison of MELCOR-calculated pressure during the AP1000 LOCA event, single vs. multicell representations. 


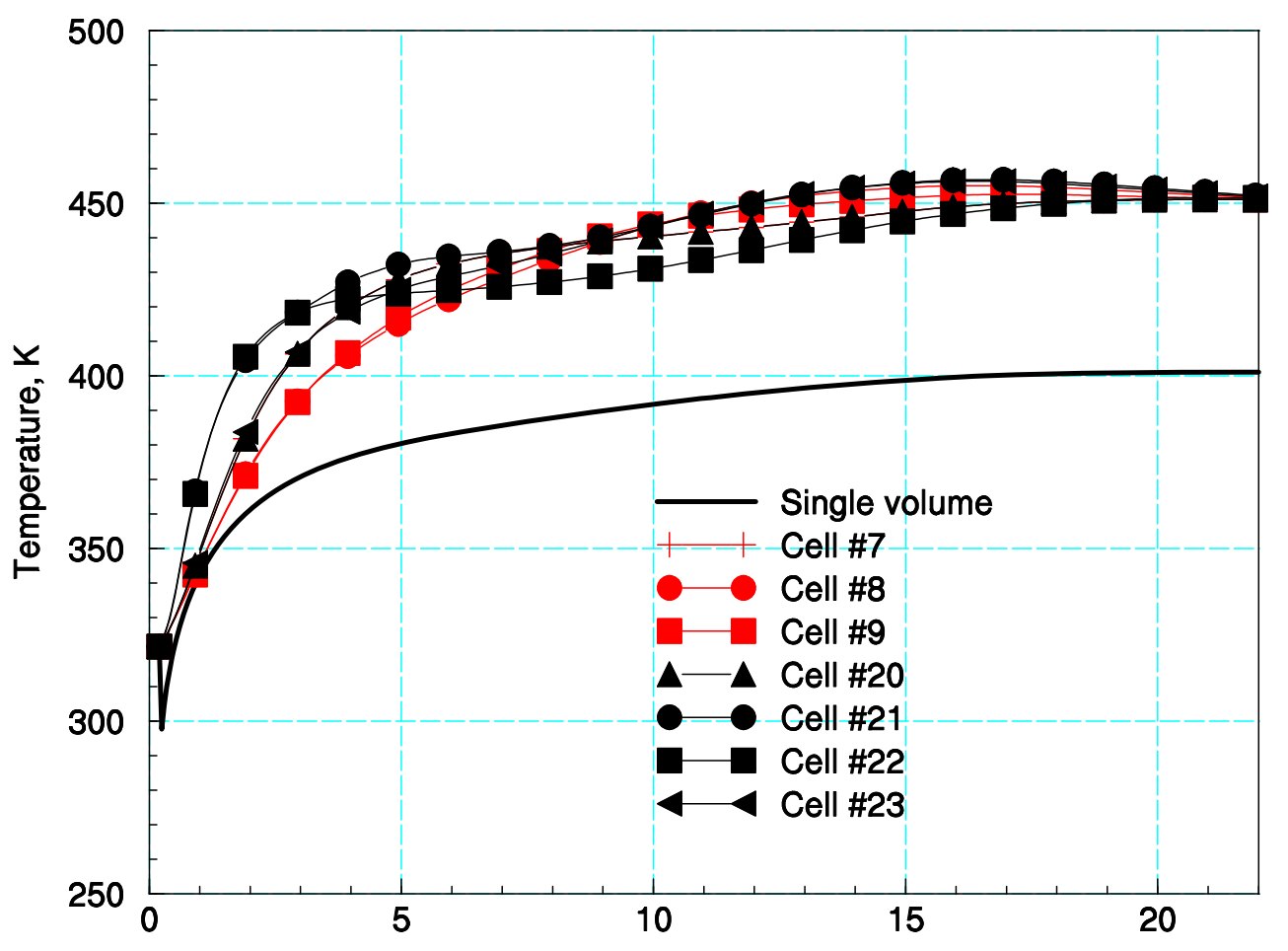

Time, seconds

Figure 3.7 Comparison of MELCOR-calculated gas temperatures during the AP1000 LOCA event, single vs. multi-cell representations. 


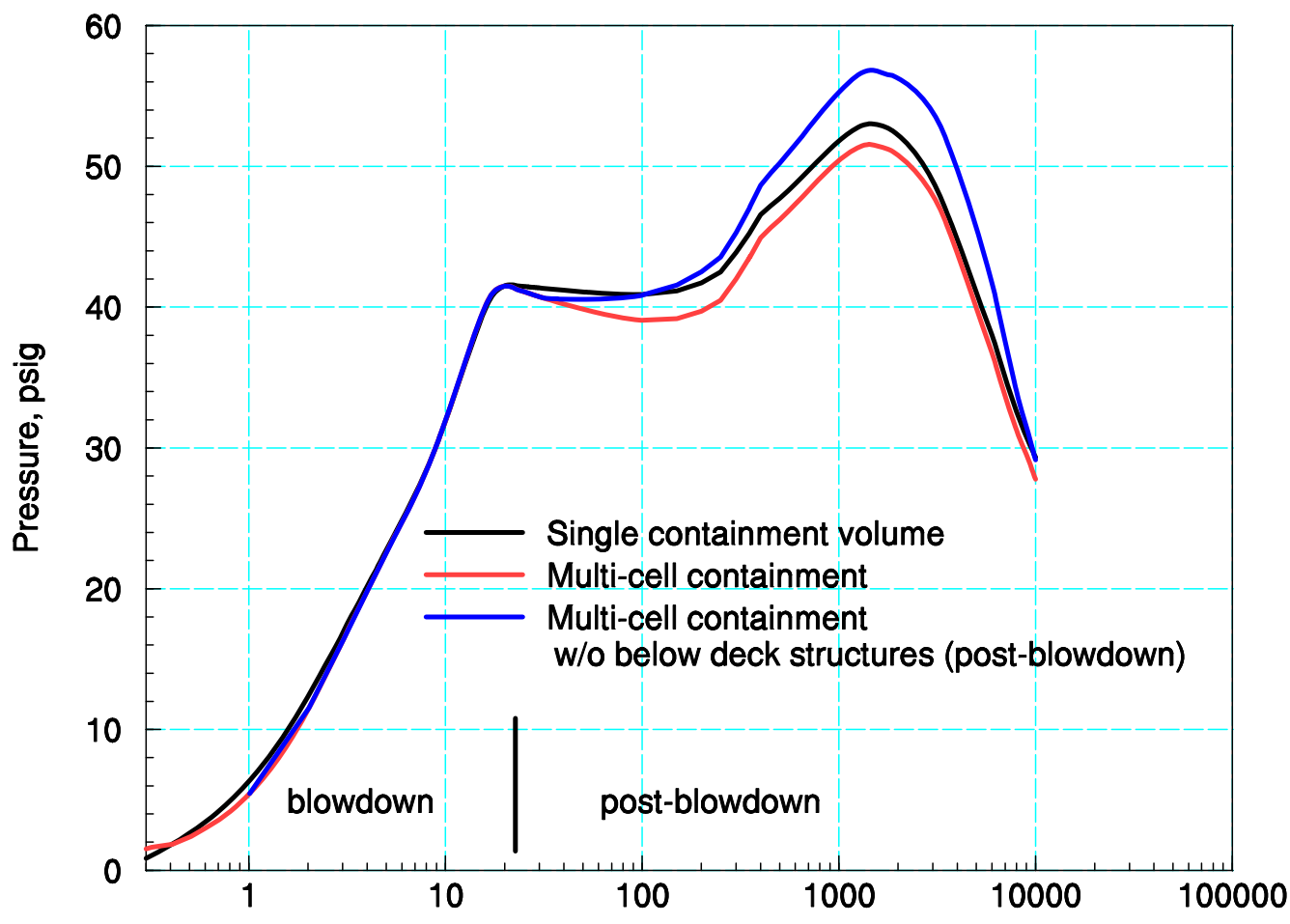

Time, seconds

Figure 3.8 Comparison of MELCOR-calculated long-term pressure profiles during the AP1000 LOCA event, single vs. multi-cell representations. 


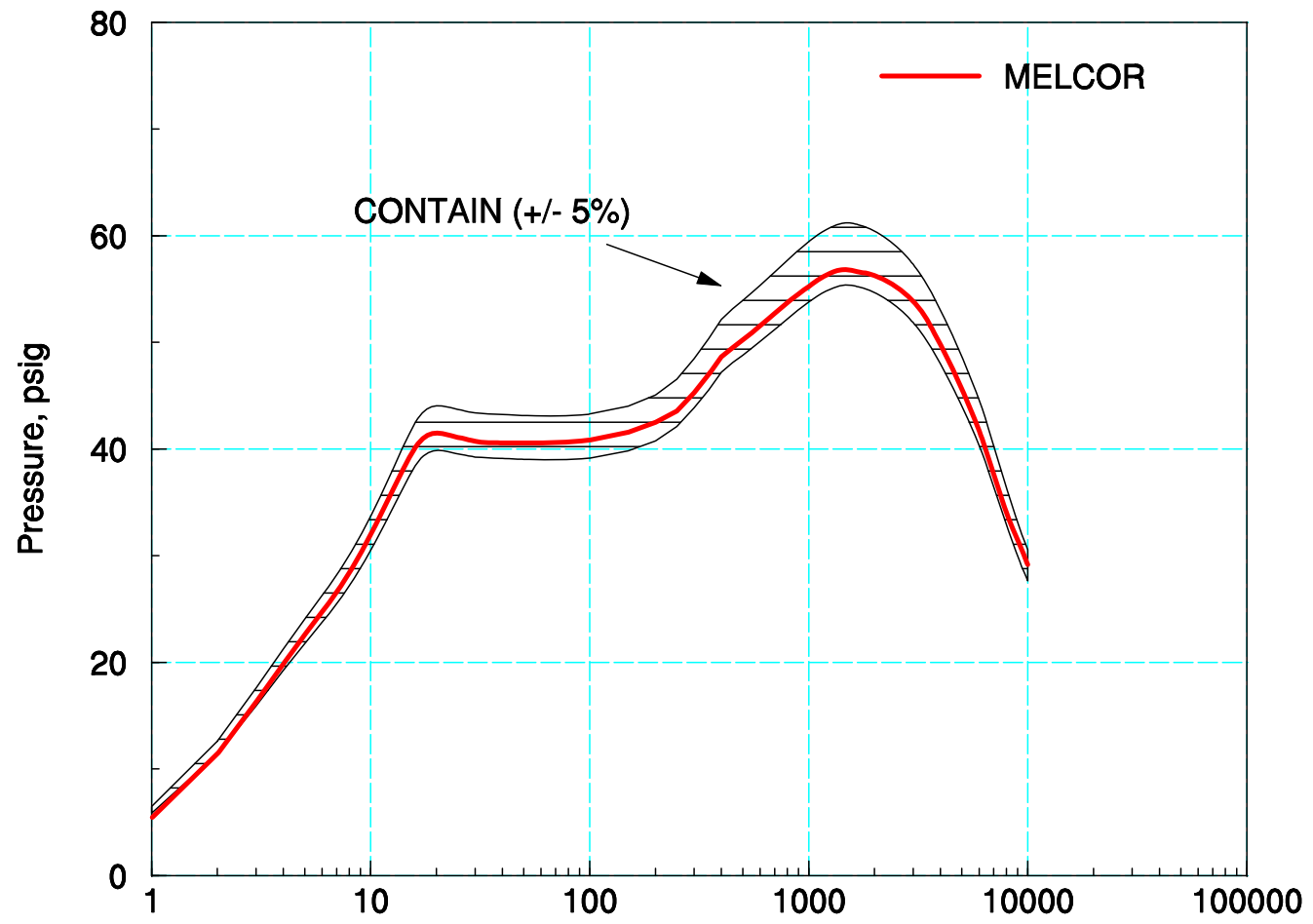

Time, seconds

Figure 3.9 Comparison of MELCOR- and CONTAIN-calculated containment pressure response for the AP1000 DECLG LOCA event. 


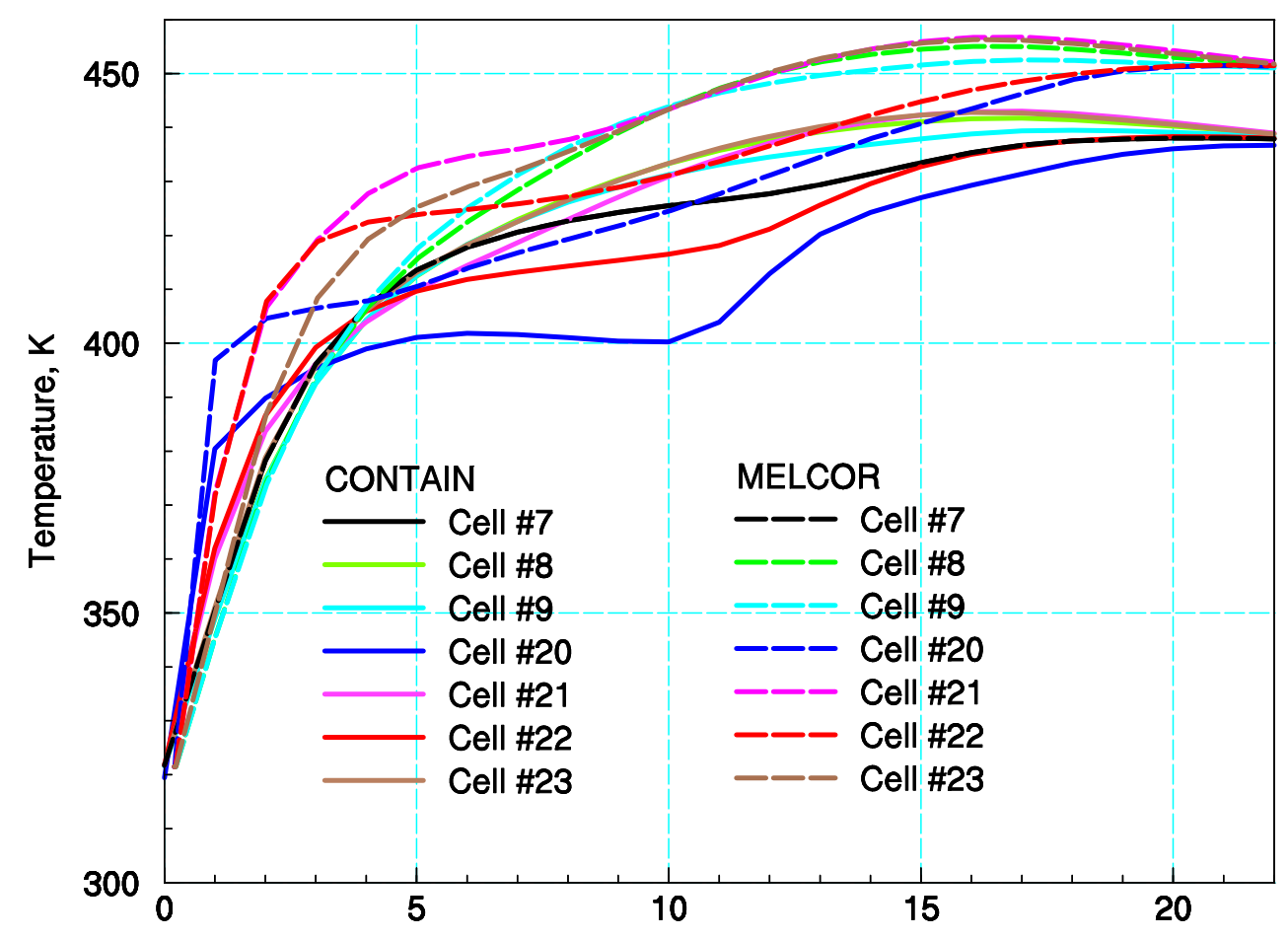

Time, seconds

Figure 3.10 Comparison of MELCOR- and CONTAIN-calculated short-term gas temperature response in the region above the AP1000 operation deck during the DECLG LOCA event. 


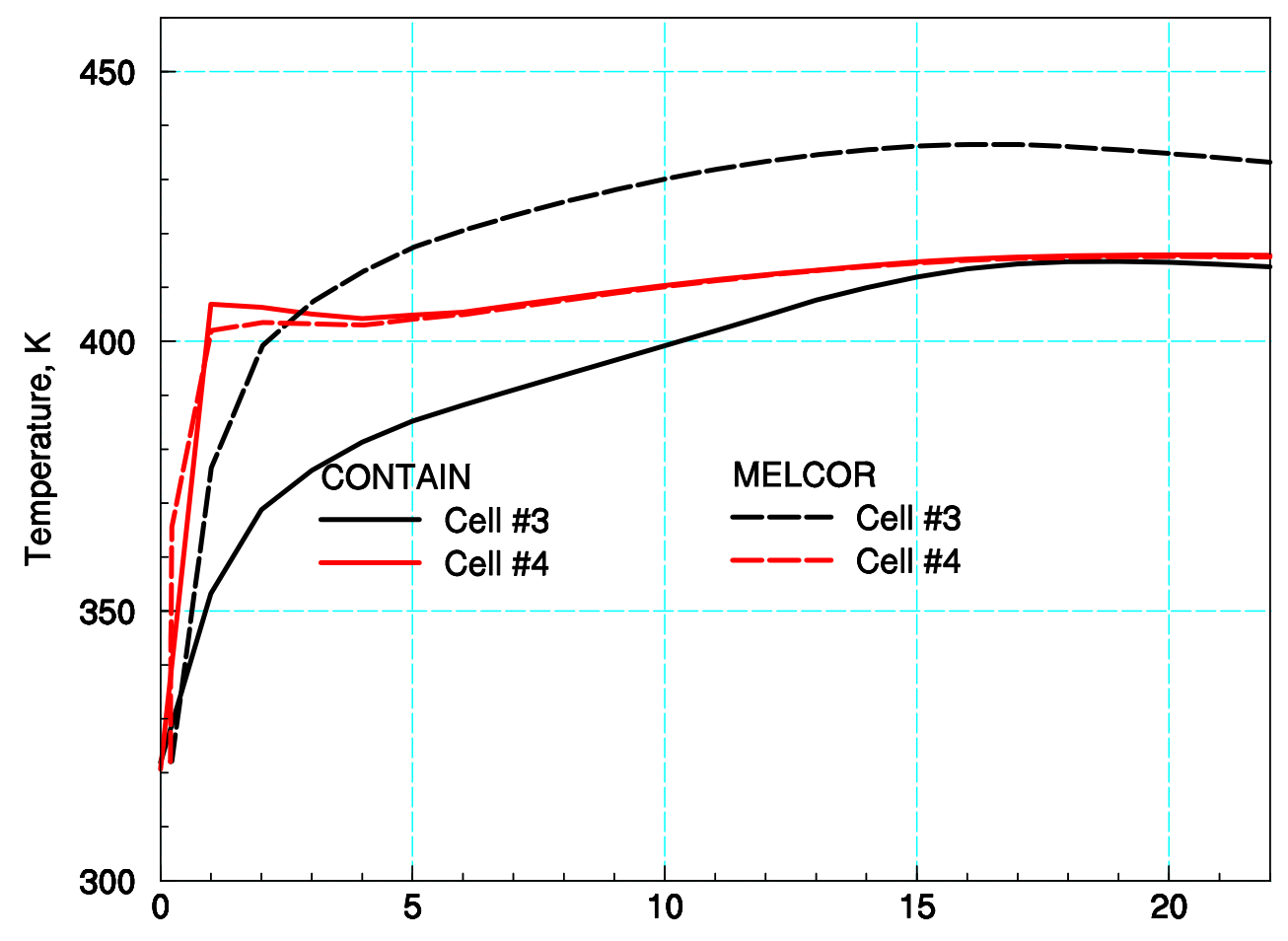

Time, seconds

Figure 3.11 Comparison of MELCOR- and CONTAIN-calculated short-term gas temperature response in the region below the AP1000 operation deck during the DECLG LOCA event. 


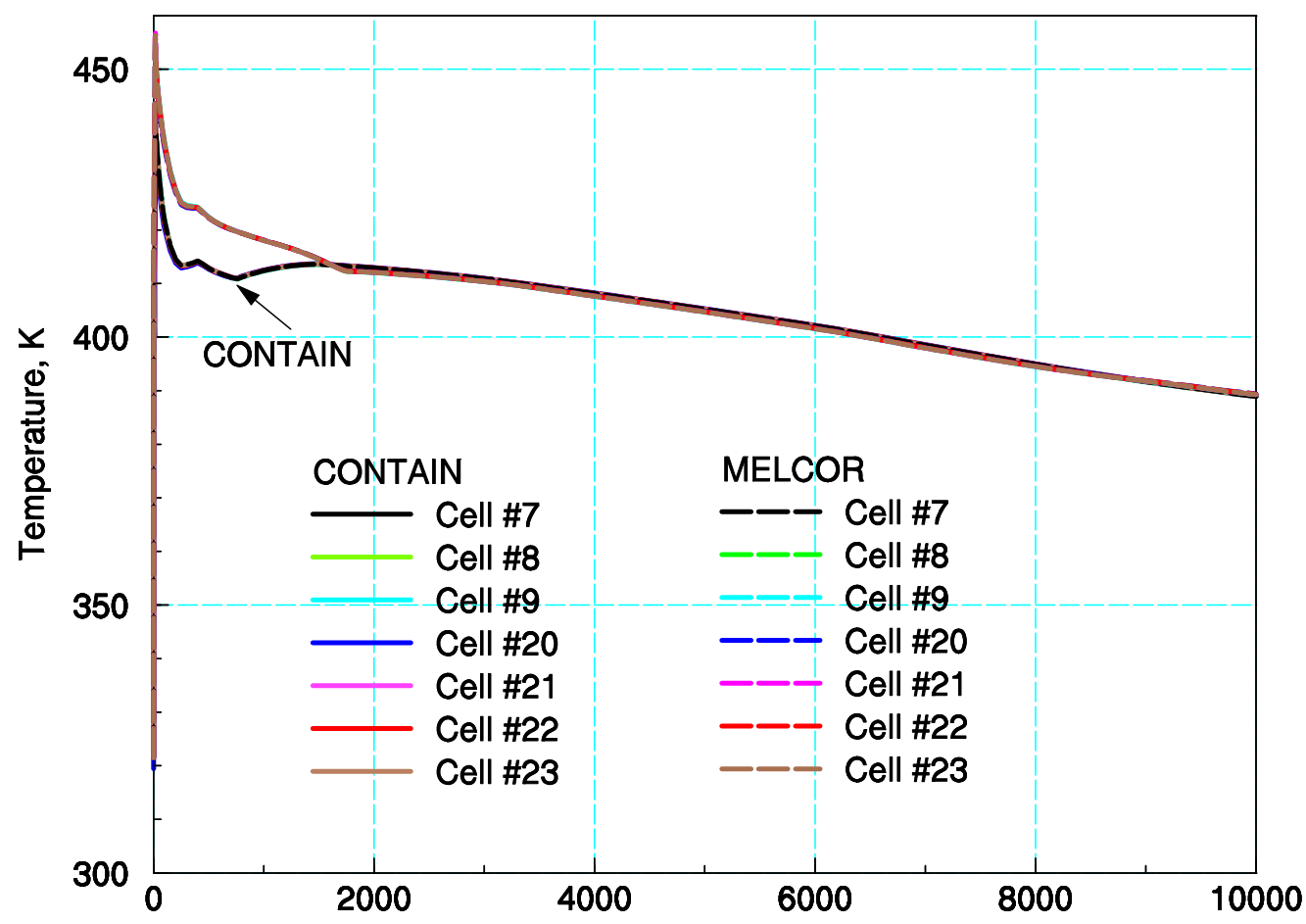

Time, seconds

Figure 3.12 Comparison of MELCOR- and CONTAIN-calculated long-term gas temperature response in the region above the AP1000 operation deck during the DECLG LOCA event. 


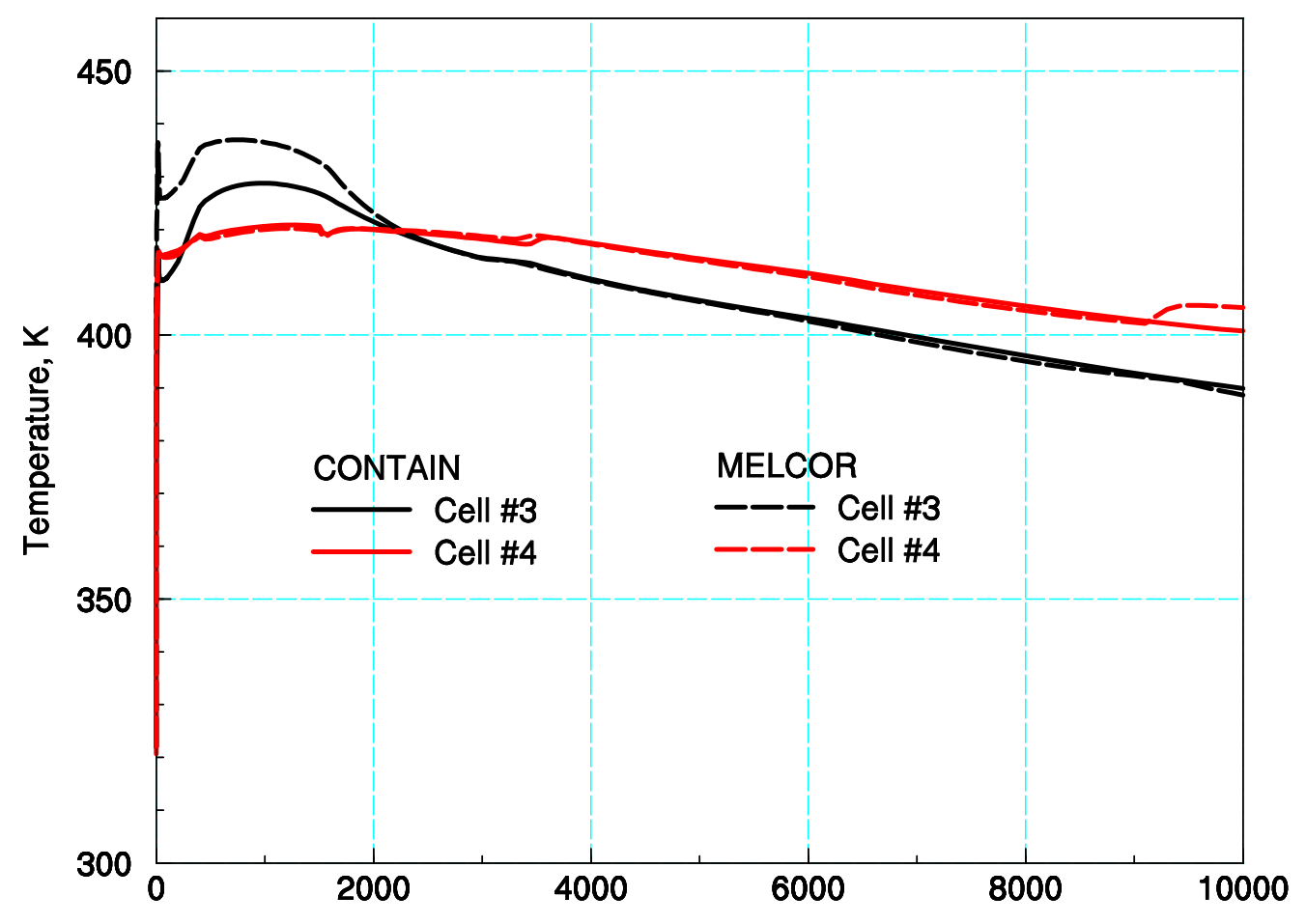

Time, seconds

Figure 3.13 Comparison of MELCOR- and CONTAIN-calculated long-term gas temperature response in the region below the AP1000 operation deck during the DECLG LOCA event. 


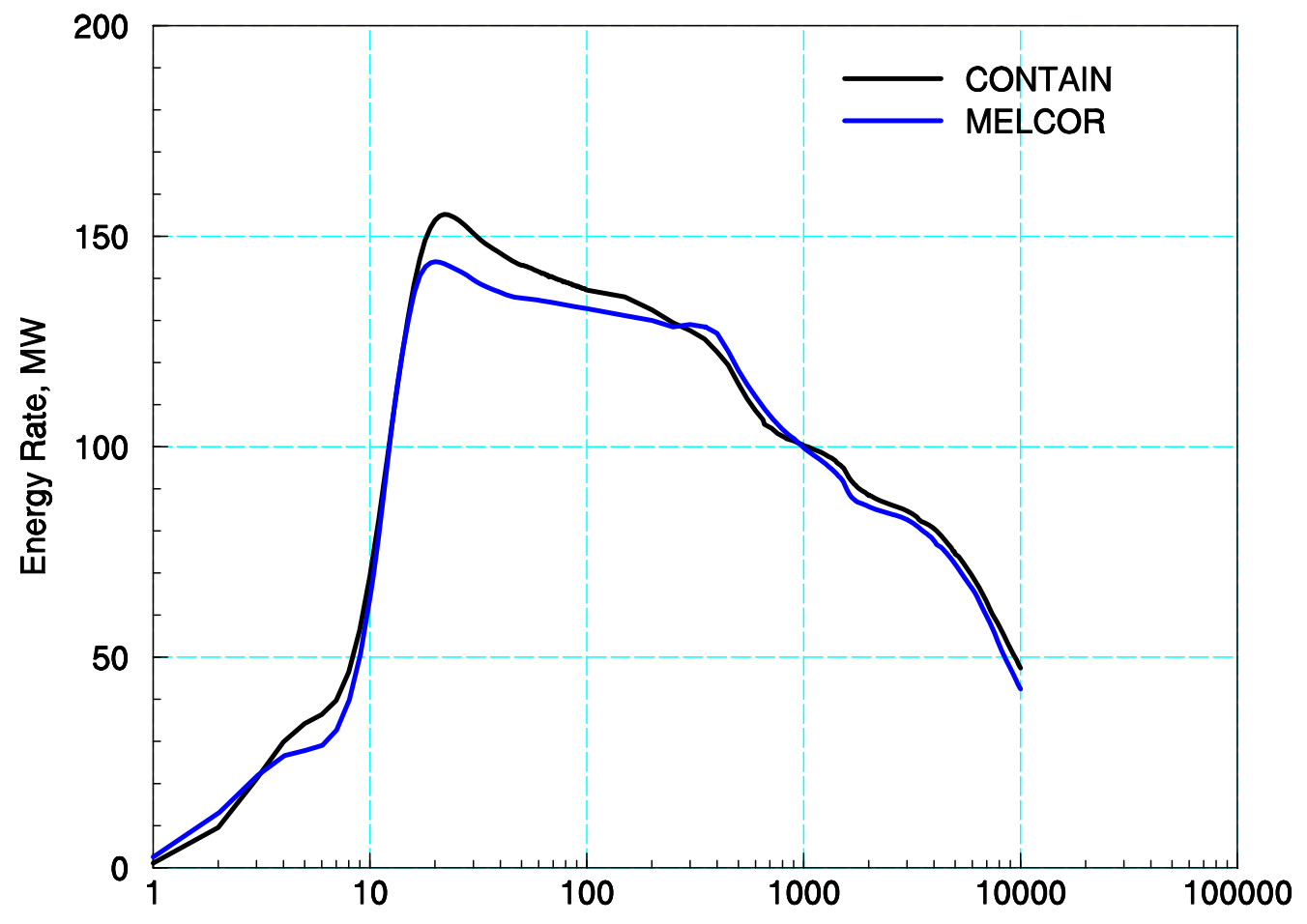

Time, seconds

Figure 3.14 Comparison of CONTAIN- and MELCOR-calculated heat removal rates for the AP1000 containment shell above the operating deck during the DECLG LOCA event. 


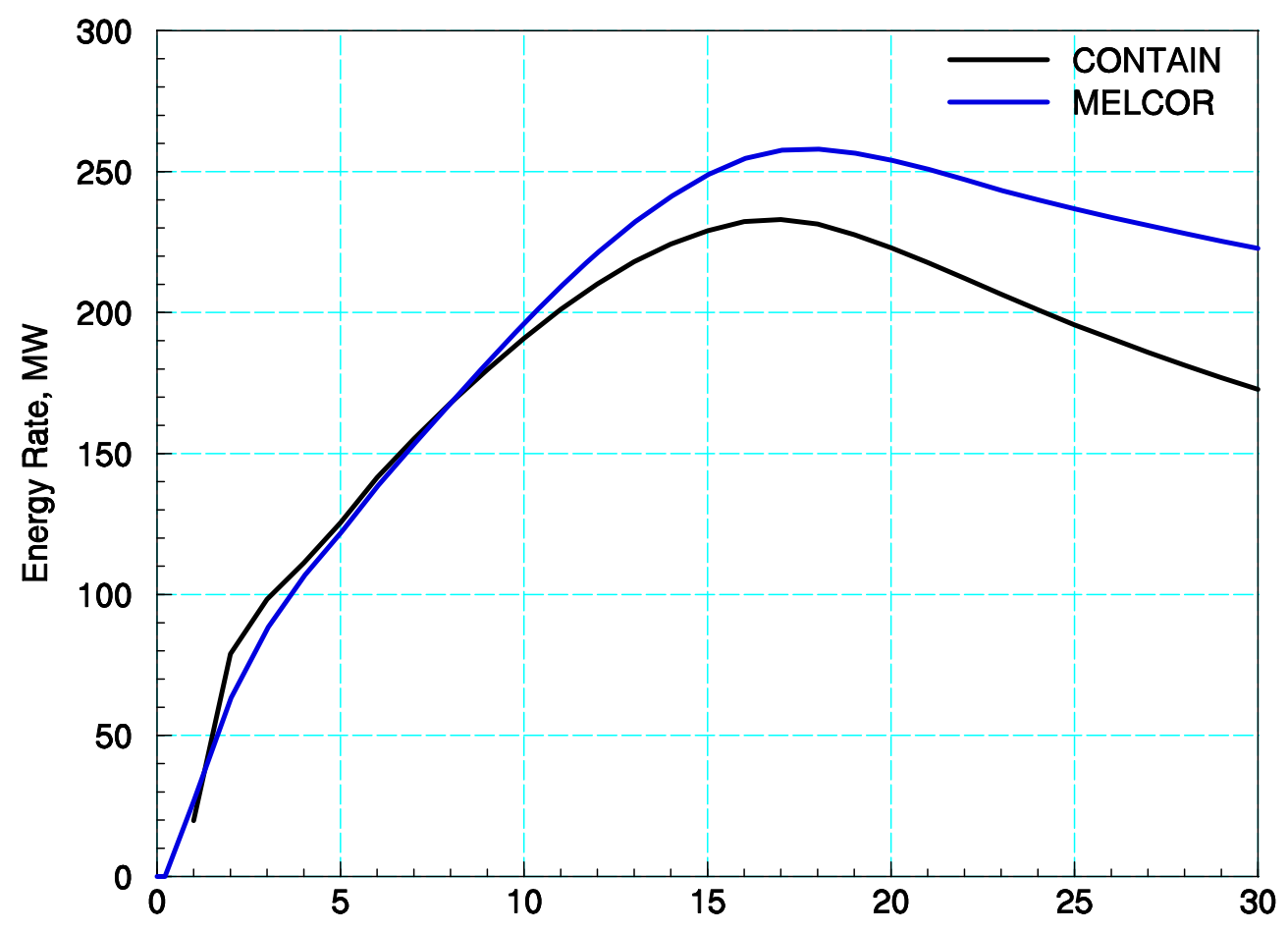

Time, seconds

Figure 3.15 Comparison of CONTAIN- and MELCOR-calculated heat removal rates for the AP1000 containment cell \#3 (CMT, CVCS, and accumulator room SE and NE) below the operating deck during the DECLG LOCA event. 


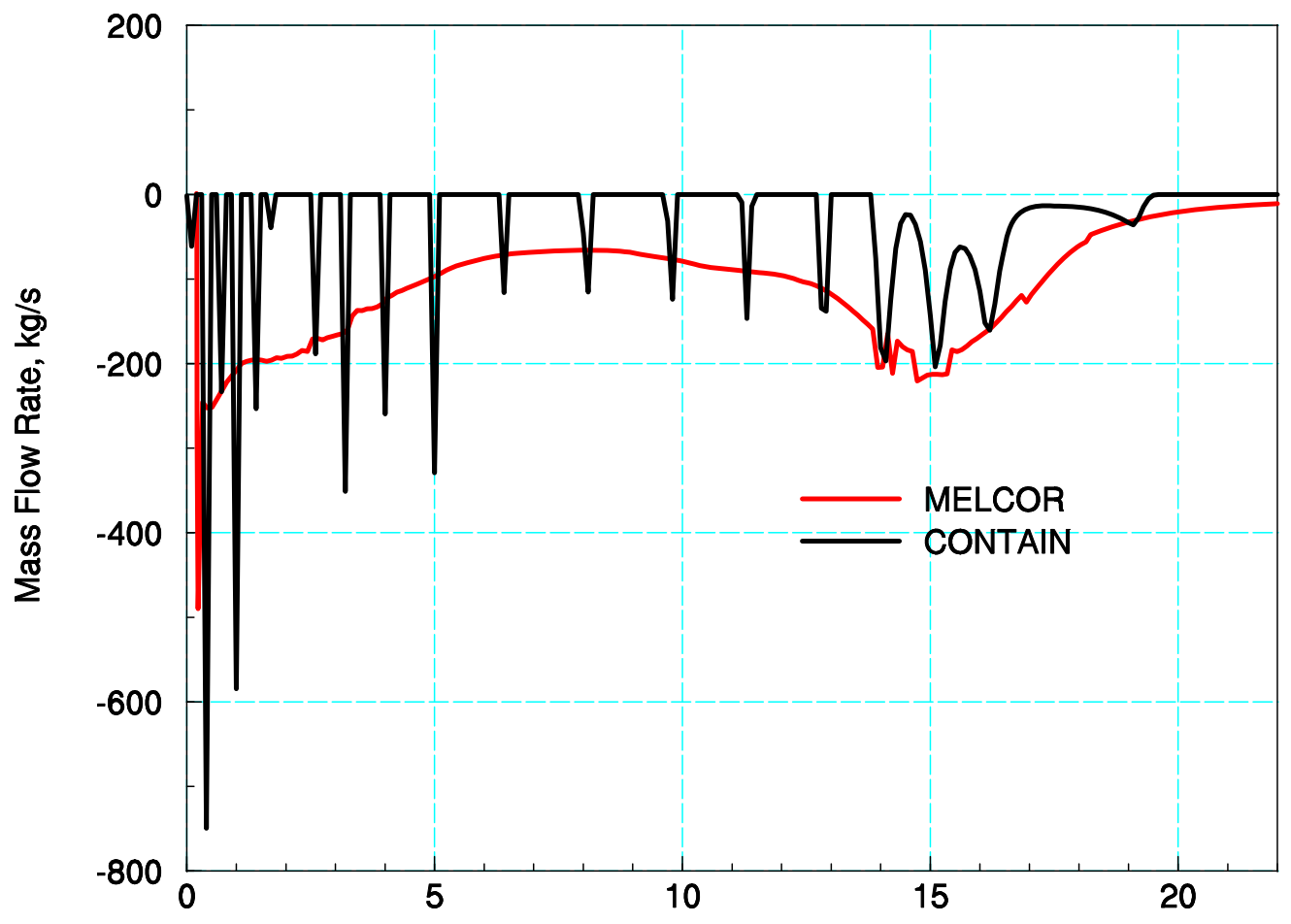

Time, seconds

Figure 3.16 Comparison of CONTAIN- and MELCOR-calculated air/steam flow from the reactor cavity compartment (cell \#1) to break room (cell \#4). 


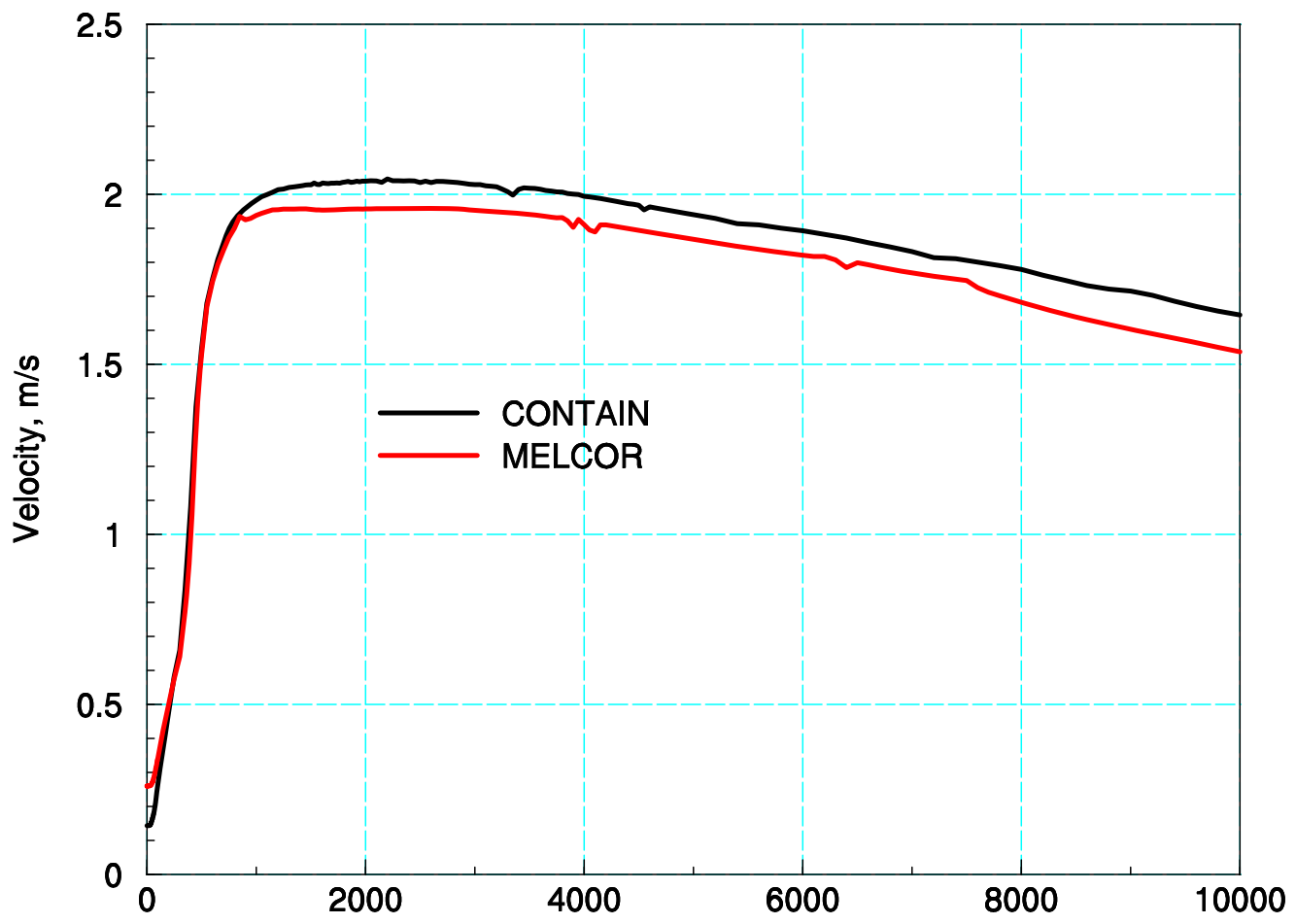

Time, seconds

Figure 3.17 Air velocities in the PCS riser exit during AP1000 DECLG LOCA event. 


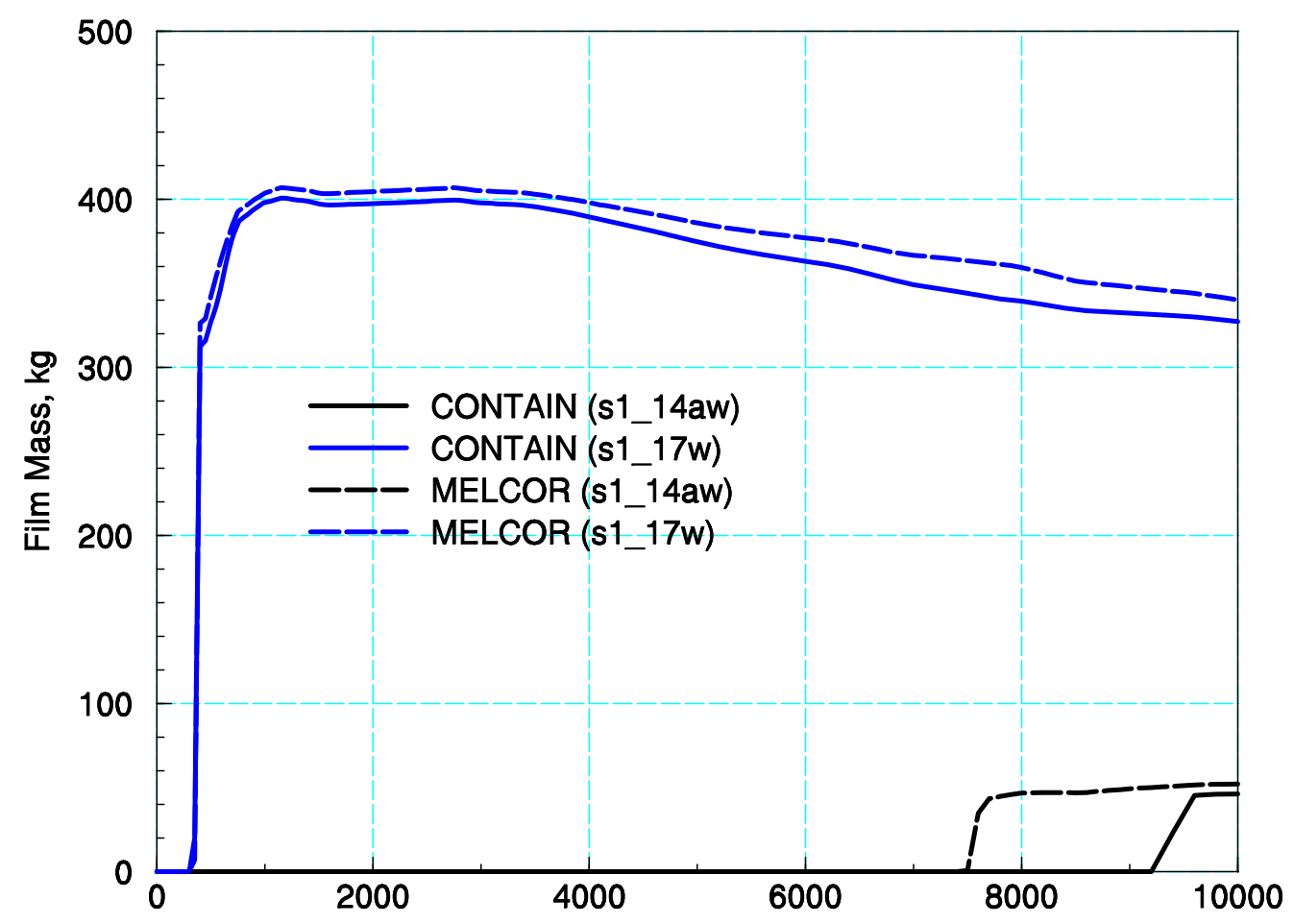

Time, seconds

Figure 3.18 Transient exterior film mass at locations above the spring-line (s1_17w) and near the bottom of the PCS riser (s1_14aw) during the AP1000 DECLG LOCA event. 


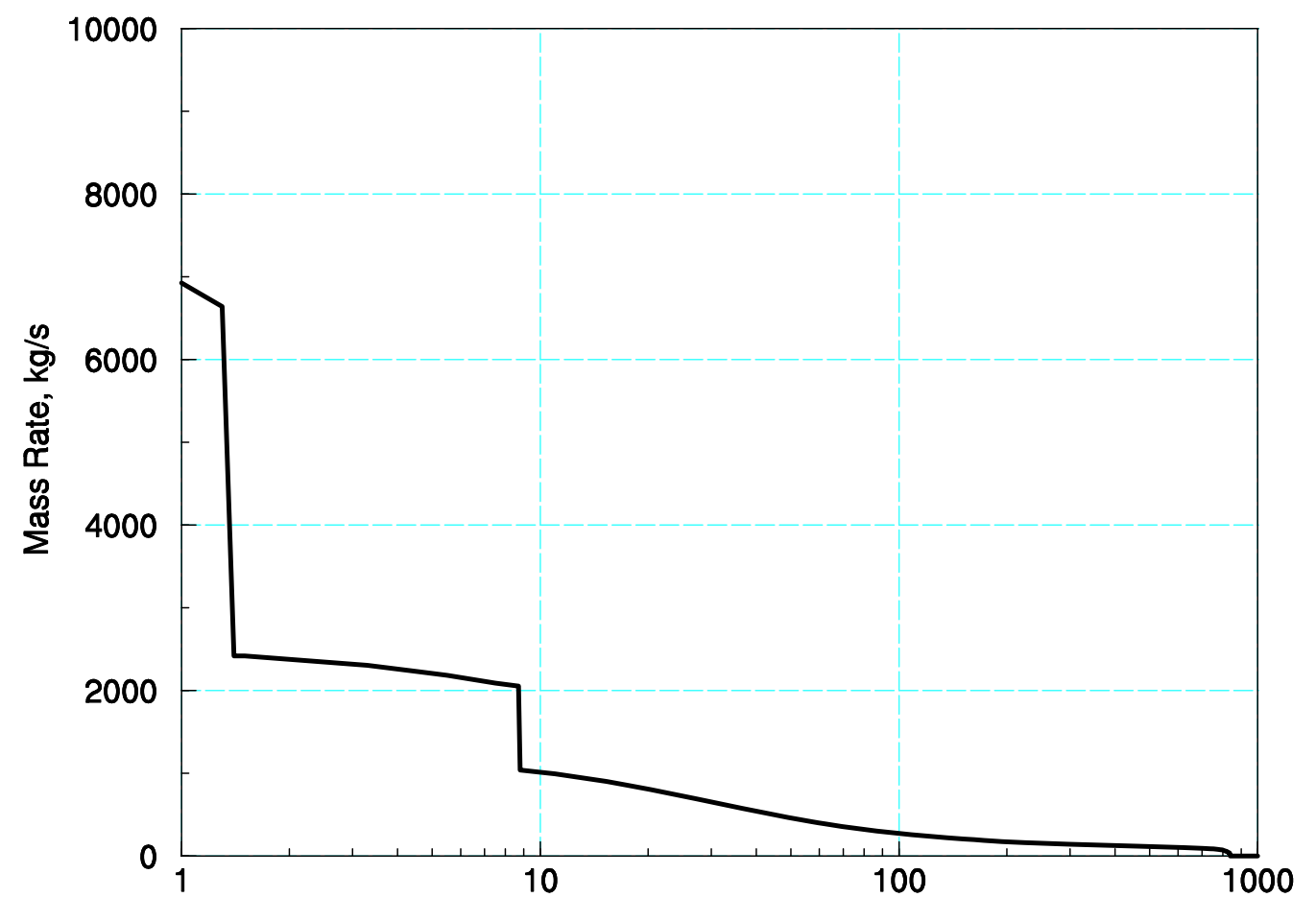

Time, seconds

Figure 3.19 Steam injection mass rates for the AP1000 MSLB event. 


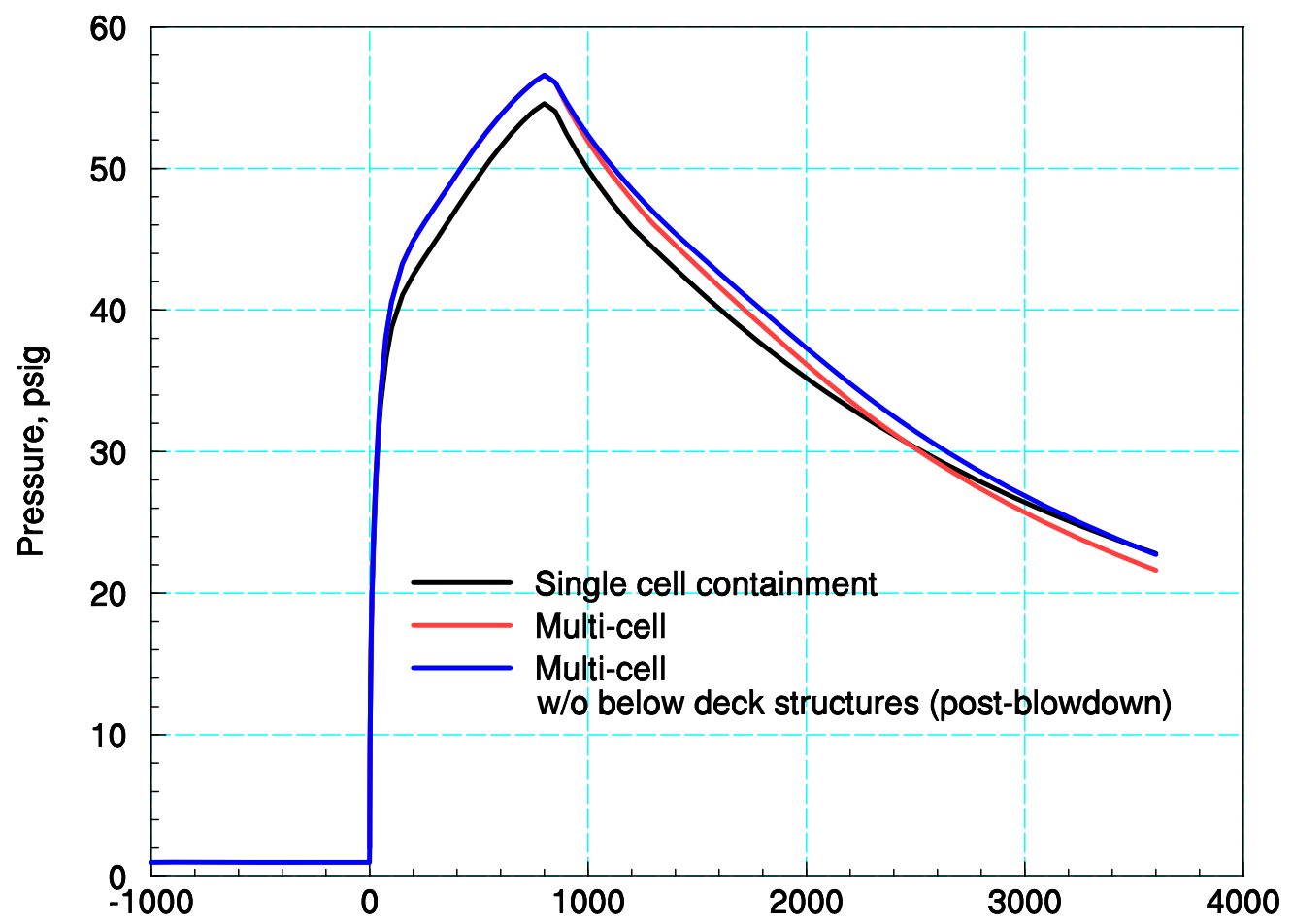

Time, seconds

Figure 3.20 Comparison of MELCOR-calculated containment pressure for single and multi-cell models of the AP1000 plant during an MSLB event. 


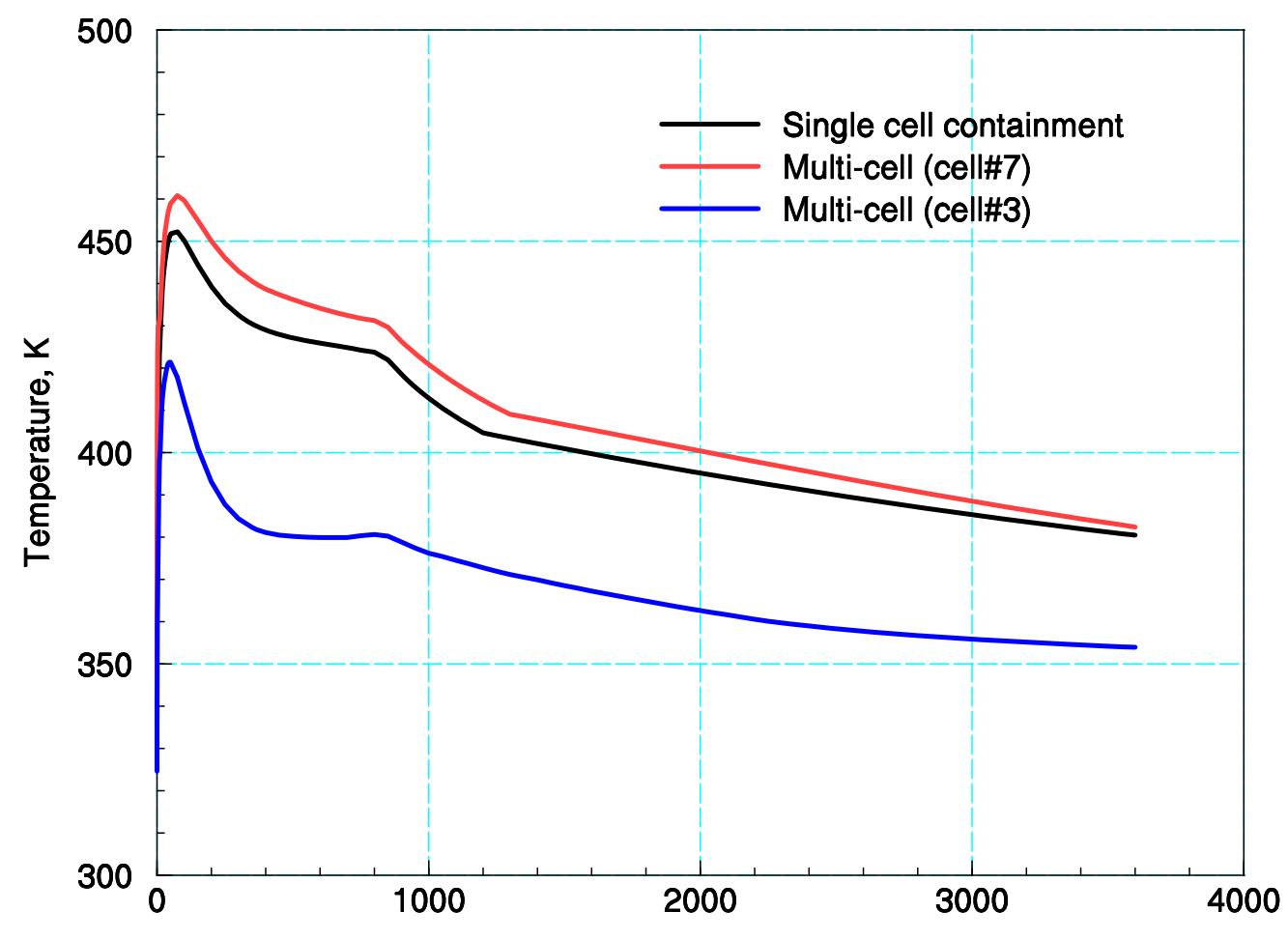

Time, seconds

Figure 3.21 Comparison of MELCOR-predicted temperature profiles using the single and multi-cell models for the AP1000 MSLB event. 


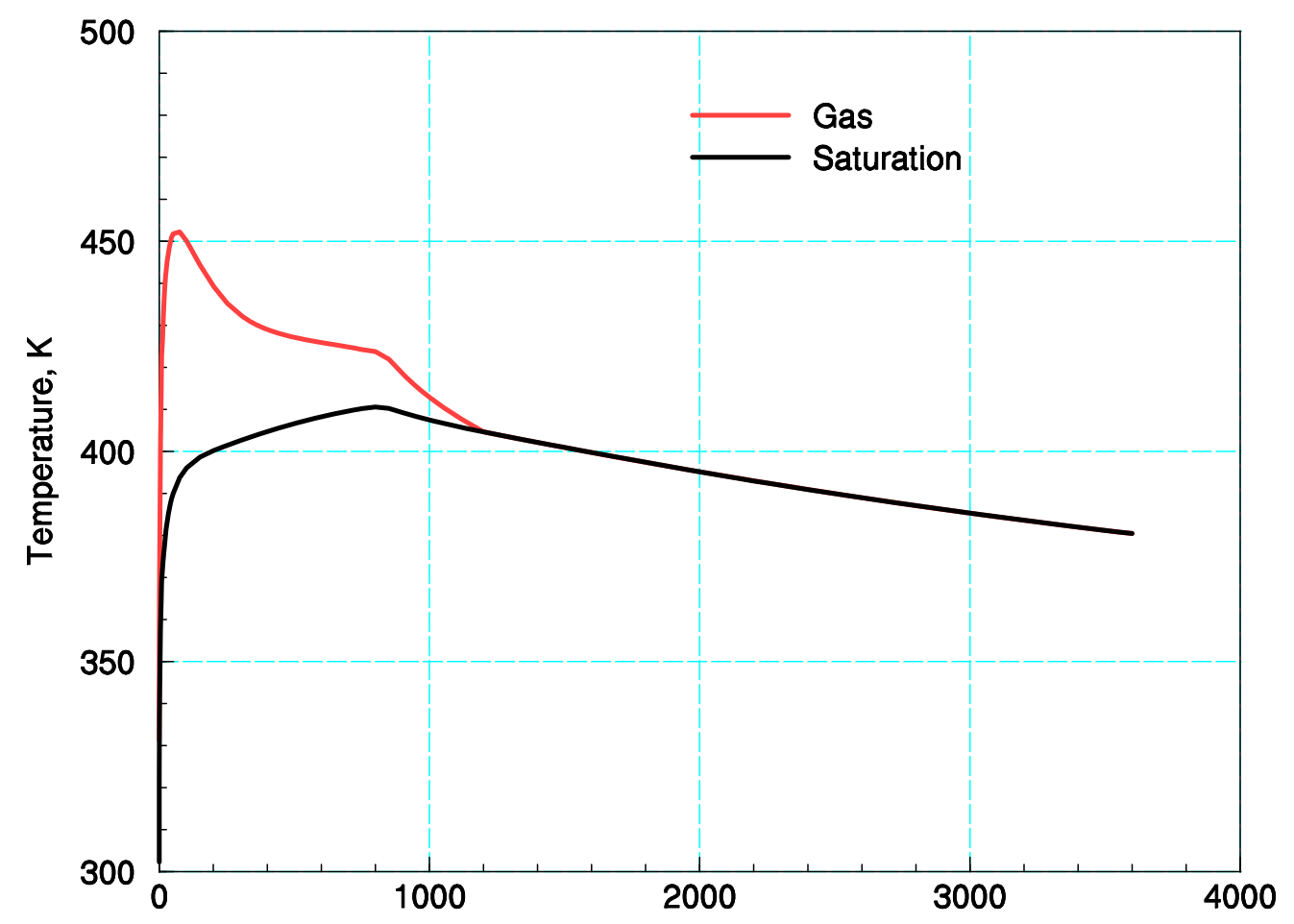

Time, seconds

Figure 3.22 MELCOR-calculated maximum temperature profile showing the degree of superheat predicted using the single cell containment model. 


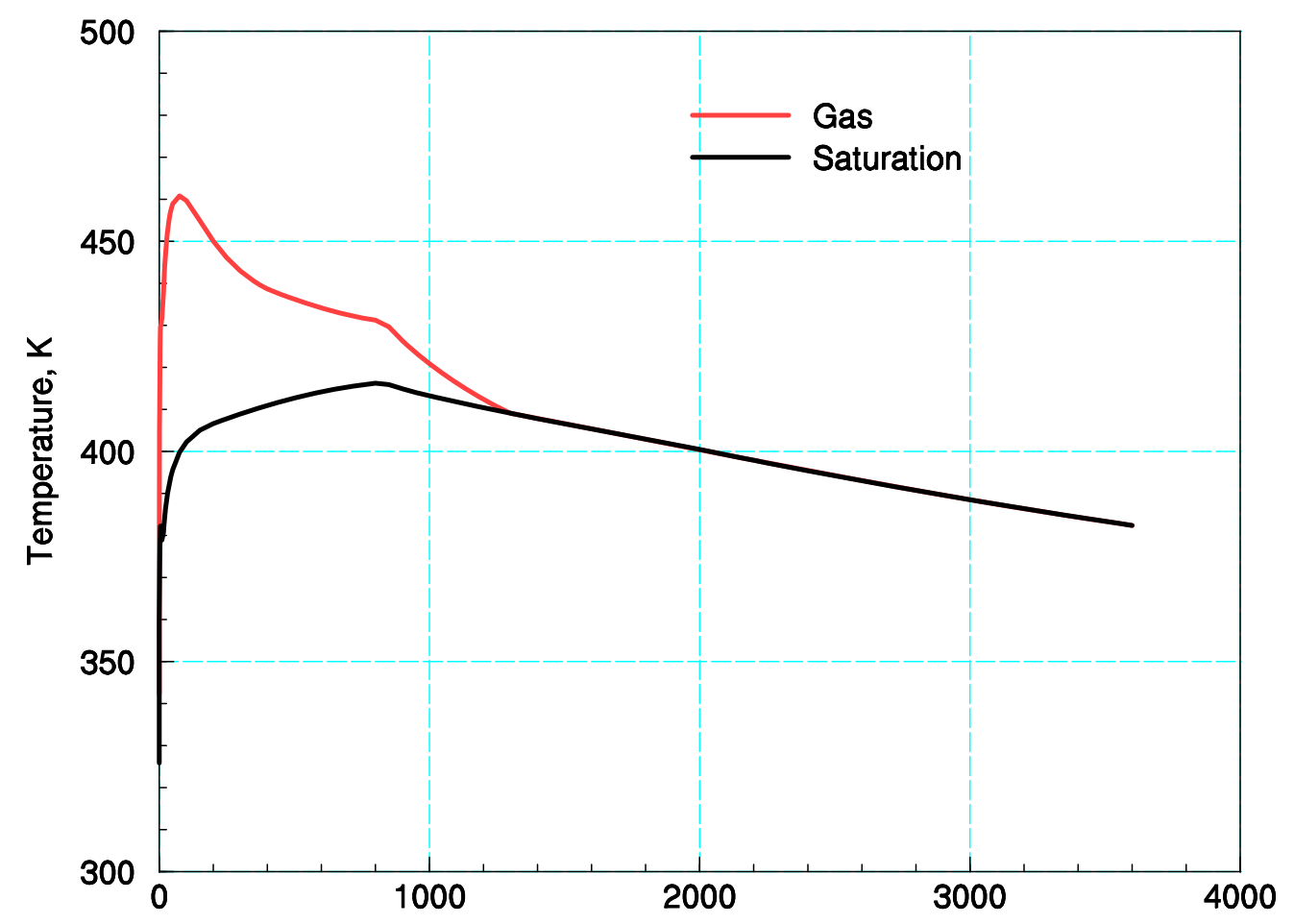

Time, seconds

Figure 3.23 MELCOR-calculated maximum temperature profile showing the degree of superheat predicted using the multi-cell containment model for cell \#7. 


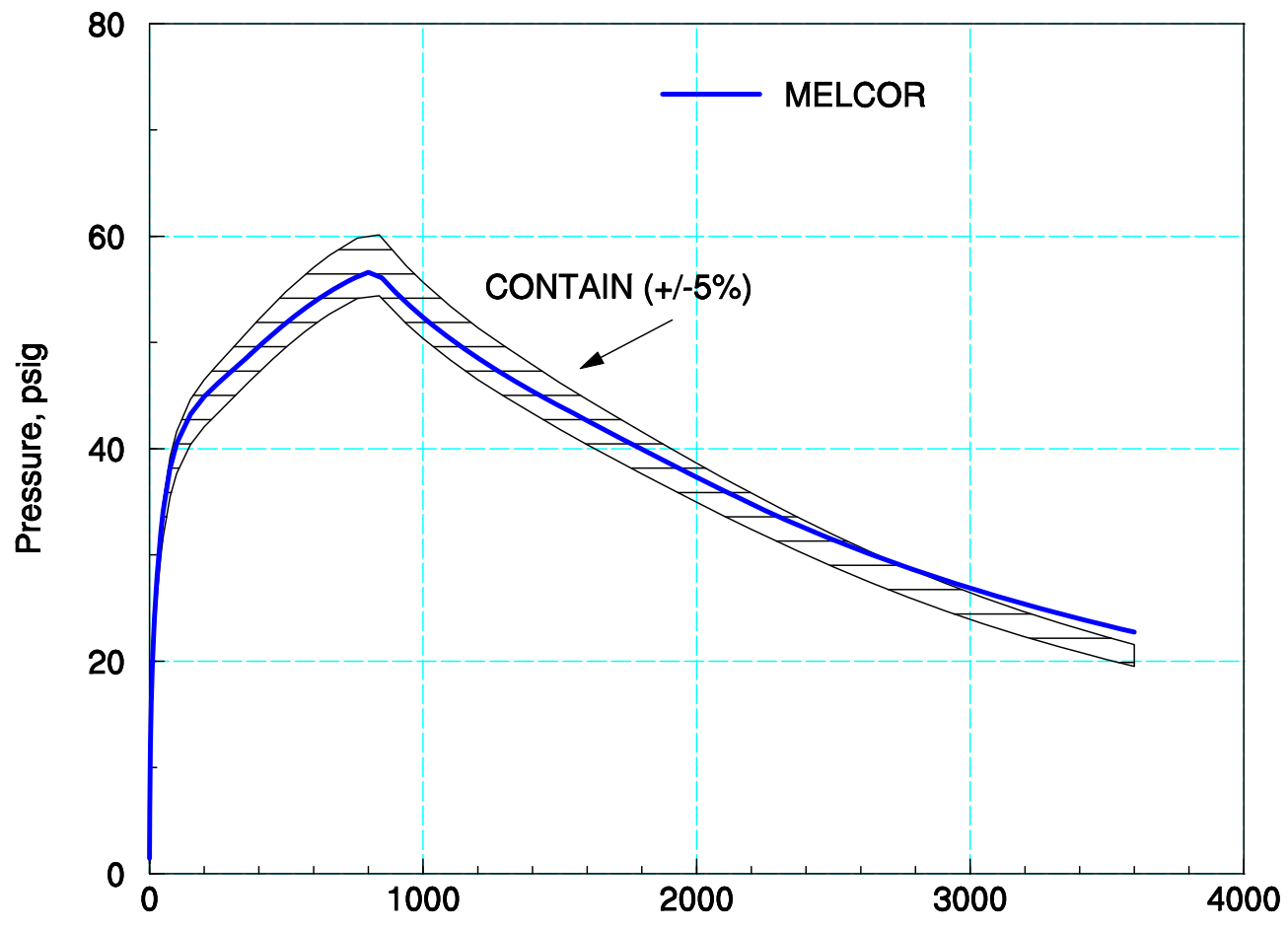

Time, seconds

Figure 3.24 MELCOR-calculated containment pressure response compared to the CONTAIN equivalency band for the AP1000 MSLB event (cell \#22 pressure plotted). 


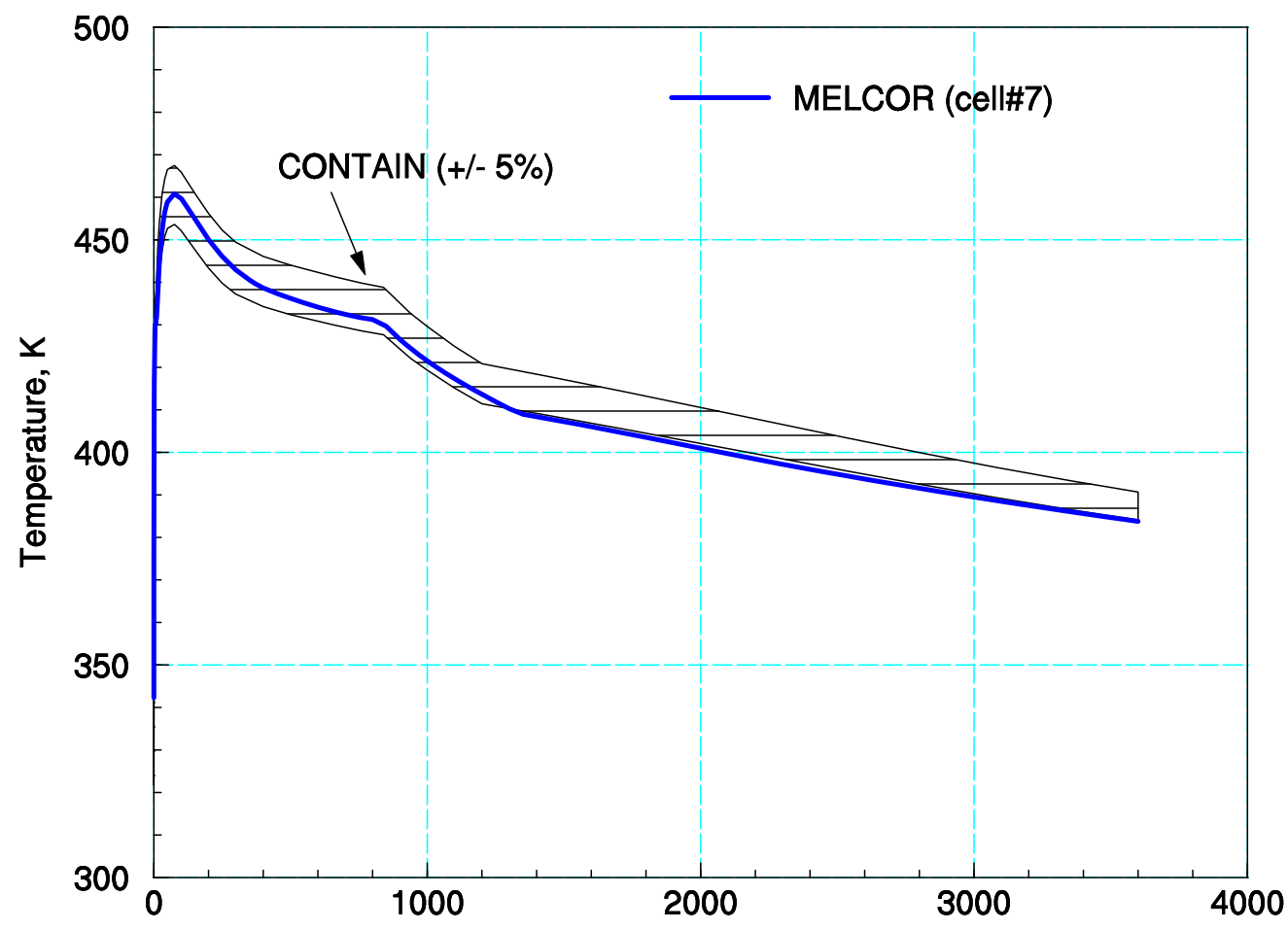

Time, seconds

Figure 3.25 MELCOR-calculated containment maximum temperature response compared to the CONTAIN equivalency band for the AP1000 MSLB event (cell \#7 gas temperature plotted). 


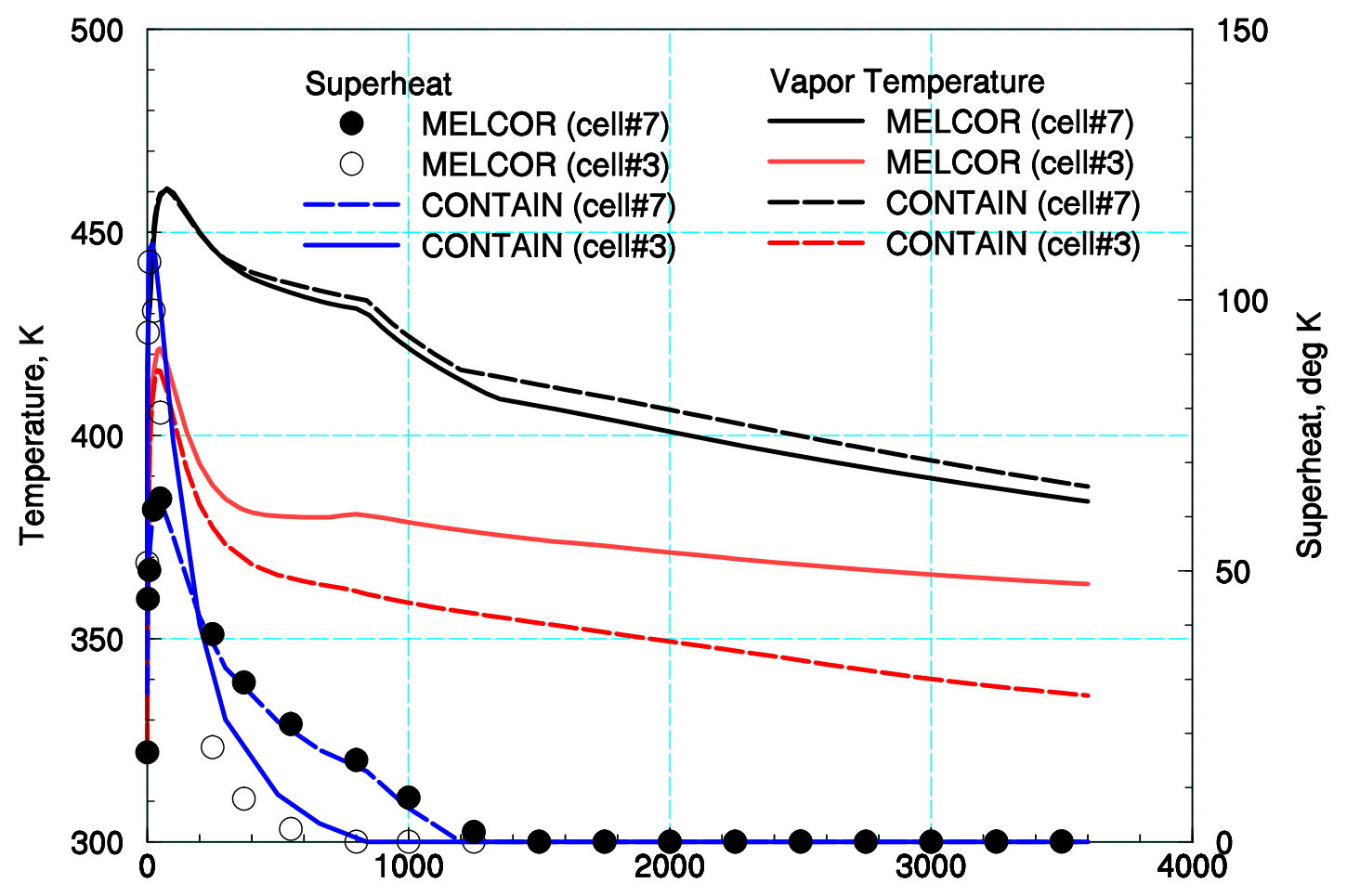

Time, seconds

Figure 3.26 Comparison of MELCOR- and CONTAIN-calculated gas temperature stratification within the AP1000 containment for the MSLB event. 


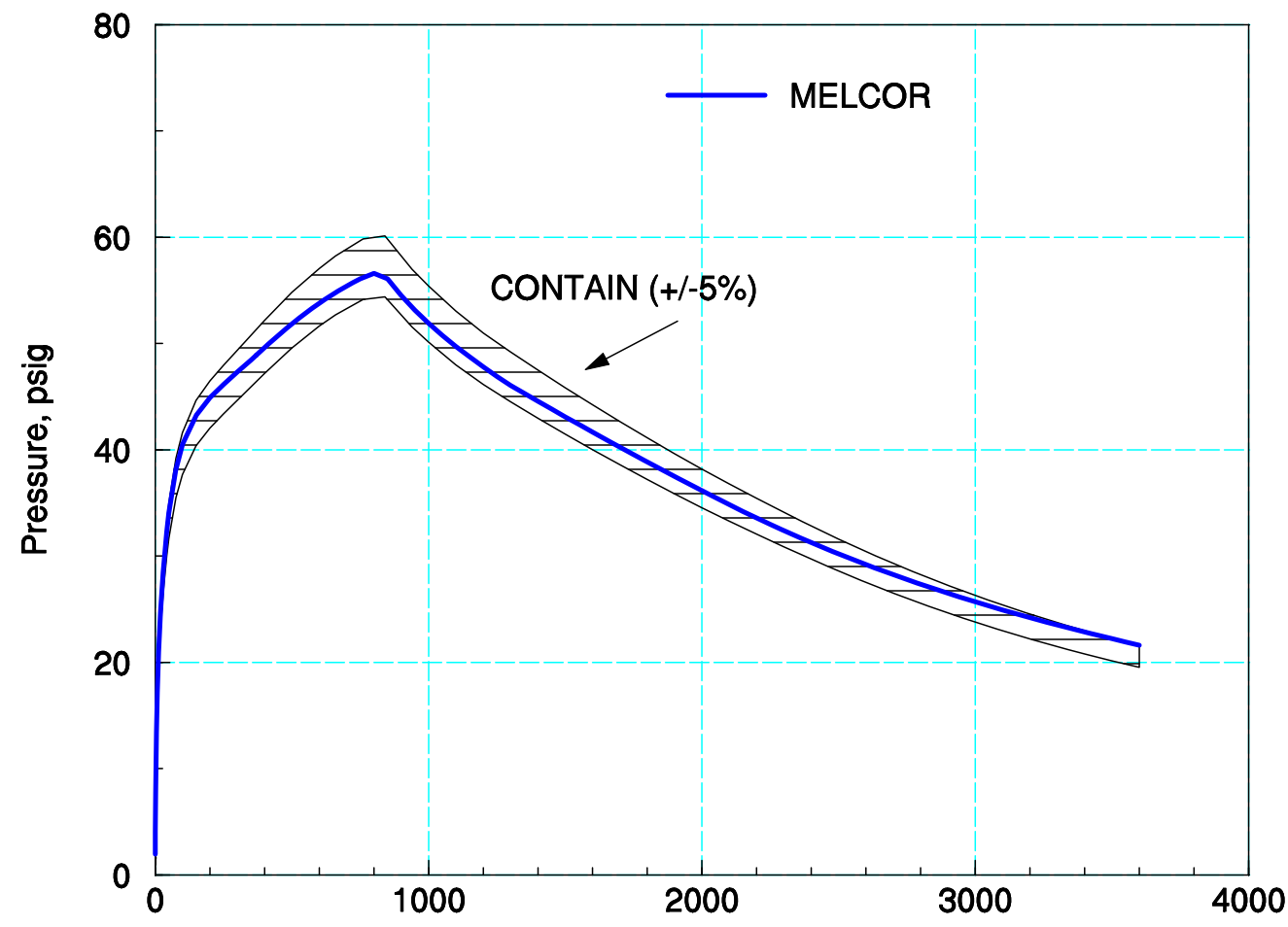

Time, seconds

Figure 3.27 MELCOR-calculated containment pressure response compared to the CONTAIN equivalency band for the AP1000 MSLB event (cell \#22 pressure plotted), where the calculations retain below operating deck structures for the entire calculation period. 


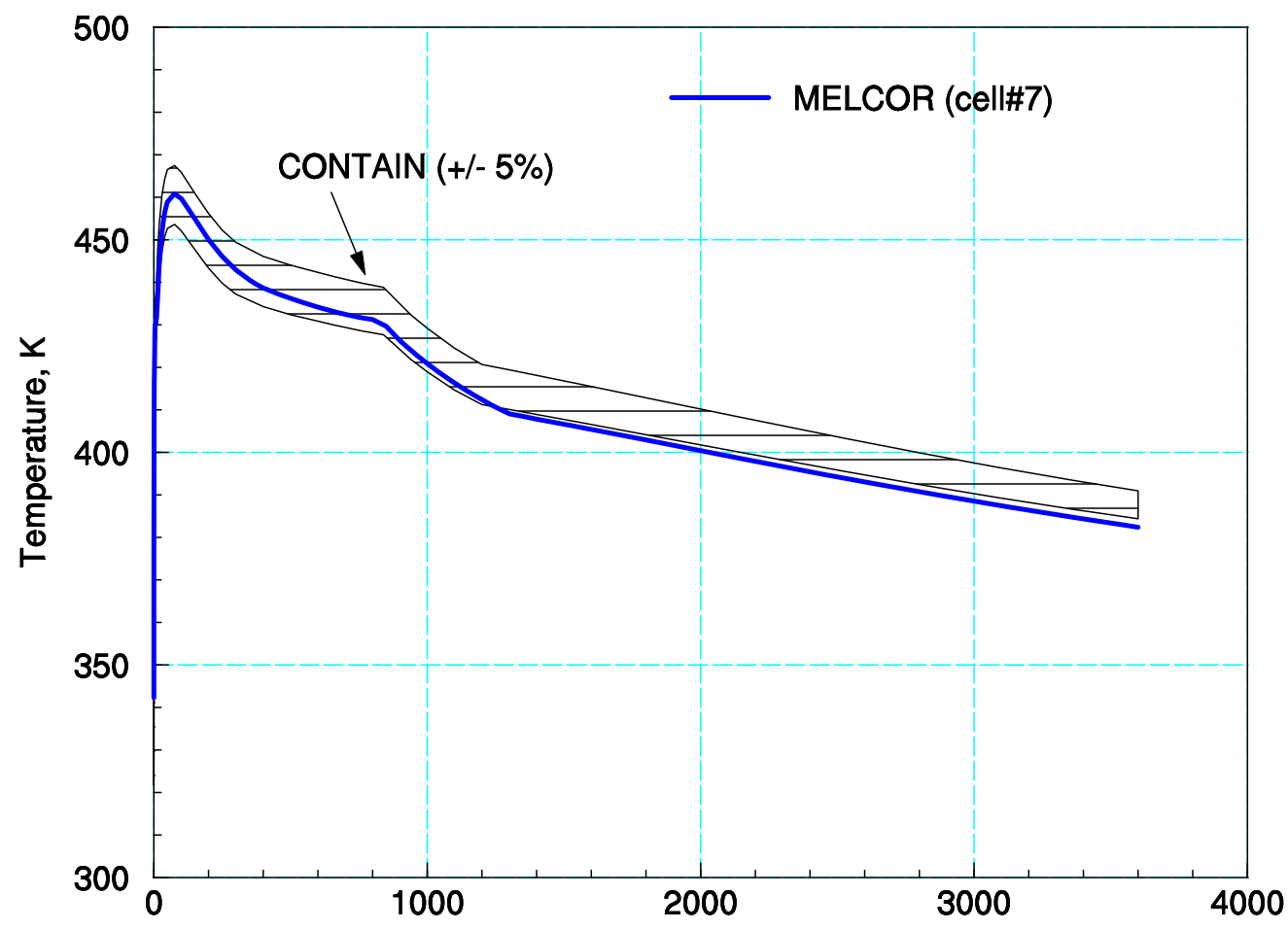

Time, seconds

Figure 3.28 MELCOR-calculated containment maximum temperature response compared to the CONTAIN equivalency band for the AP1000 MSLB event (cell \#7 gas temperature plotted), where the calculations retain below operating deck structures for the entire calculation period. 


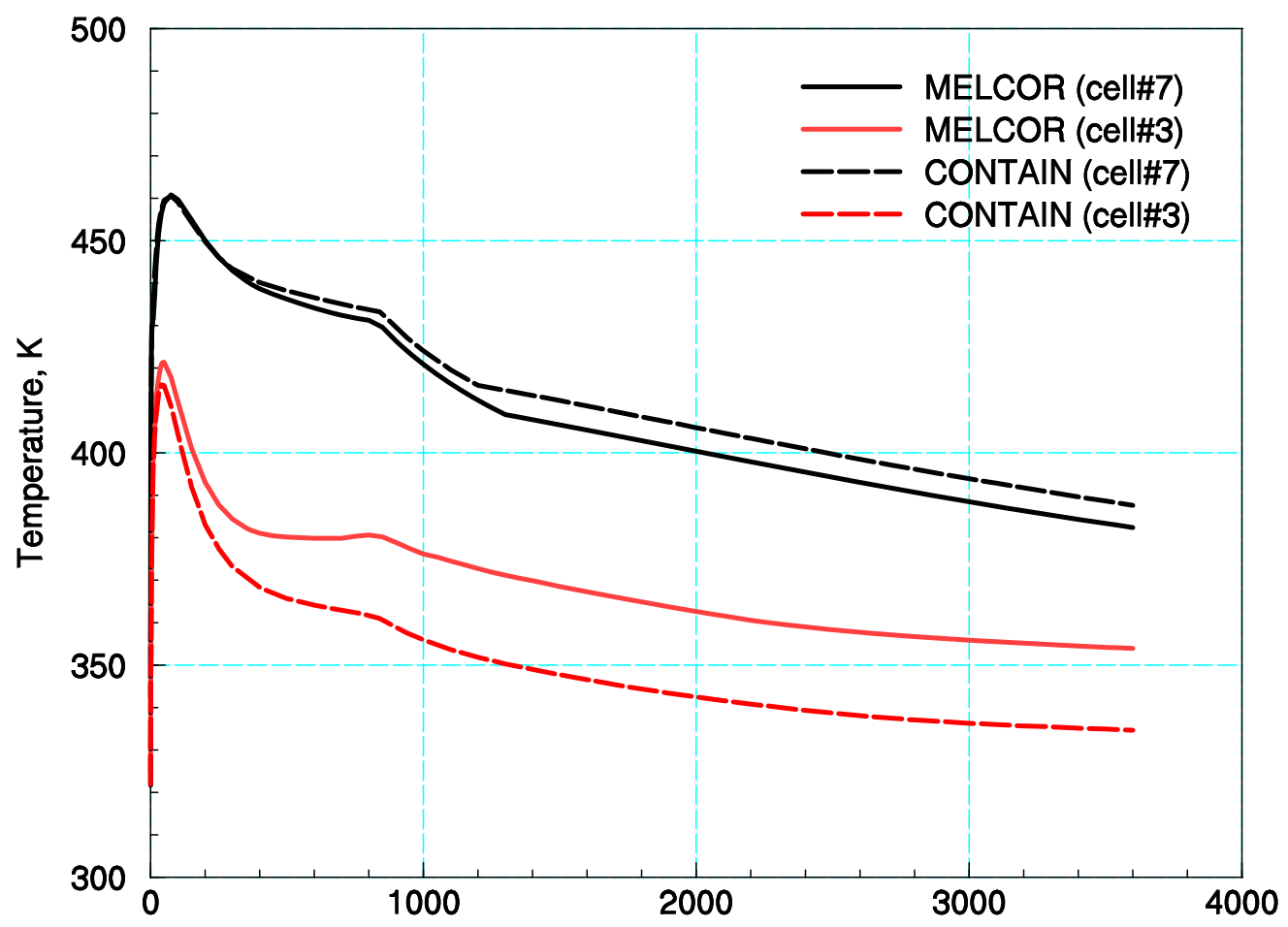

Time, seconds

Figure 3.29 Comparison of MELCOR- and CONTAIN-calculated gas temperature stratification within the AP1000 containment for the MSLB event, where the calculations retain below operating deck structures for the entire calculation period. 


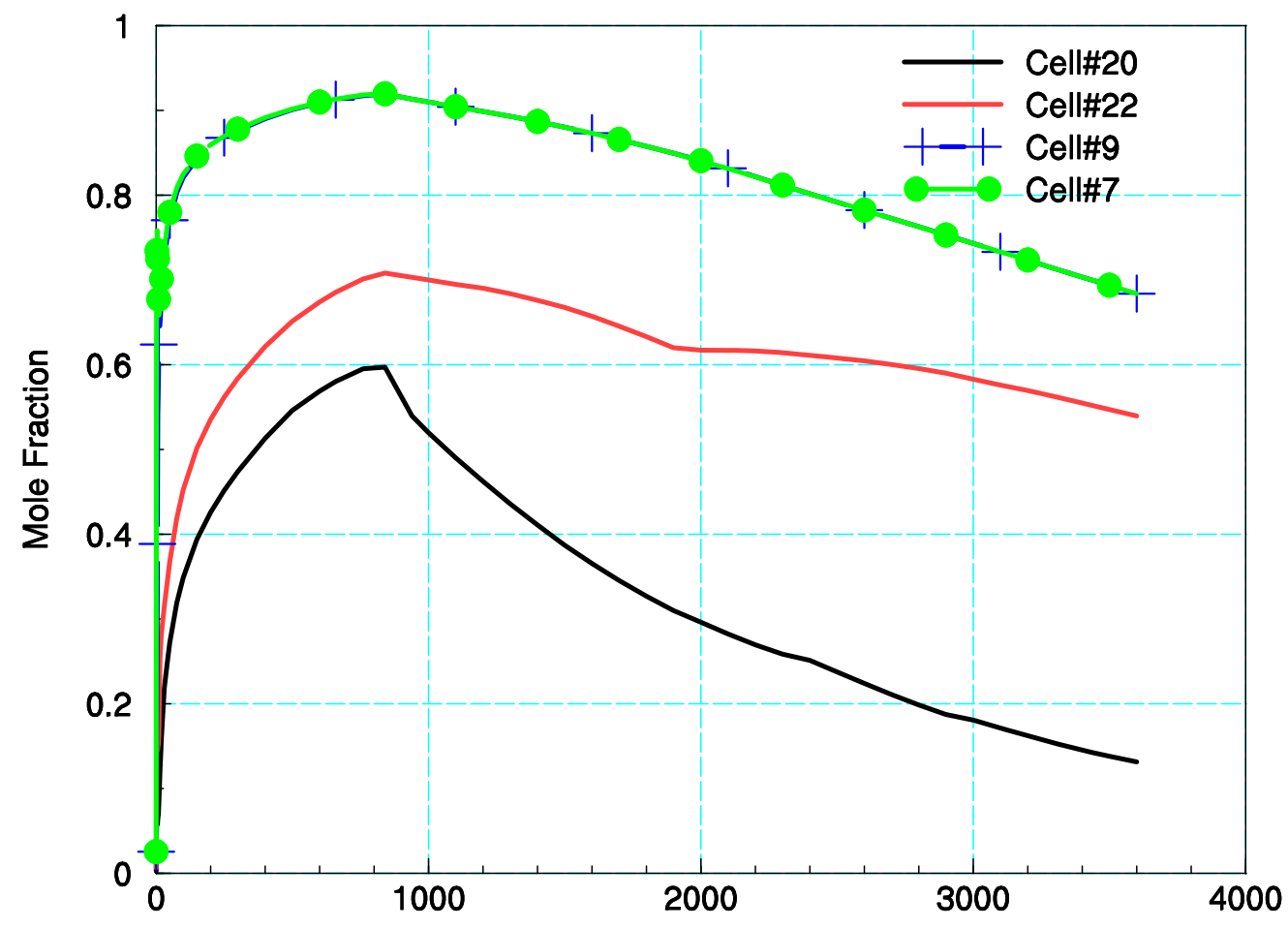

Time, seconds

Figure 3.30 CONTAIN-calculated steam mole fractions for the above operating deck region for the AP1000 MSLB event (steam injection location is cell \#7). 


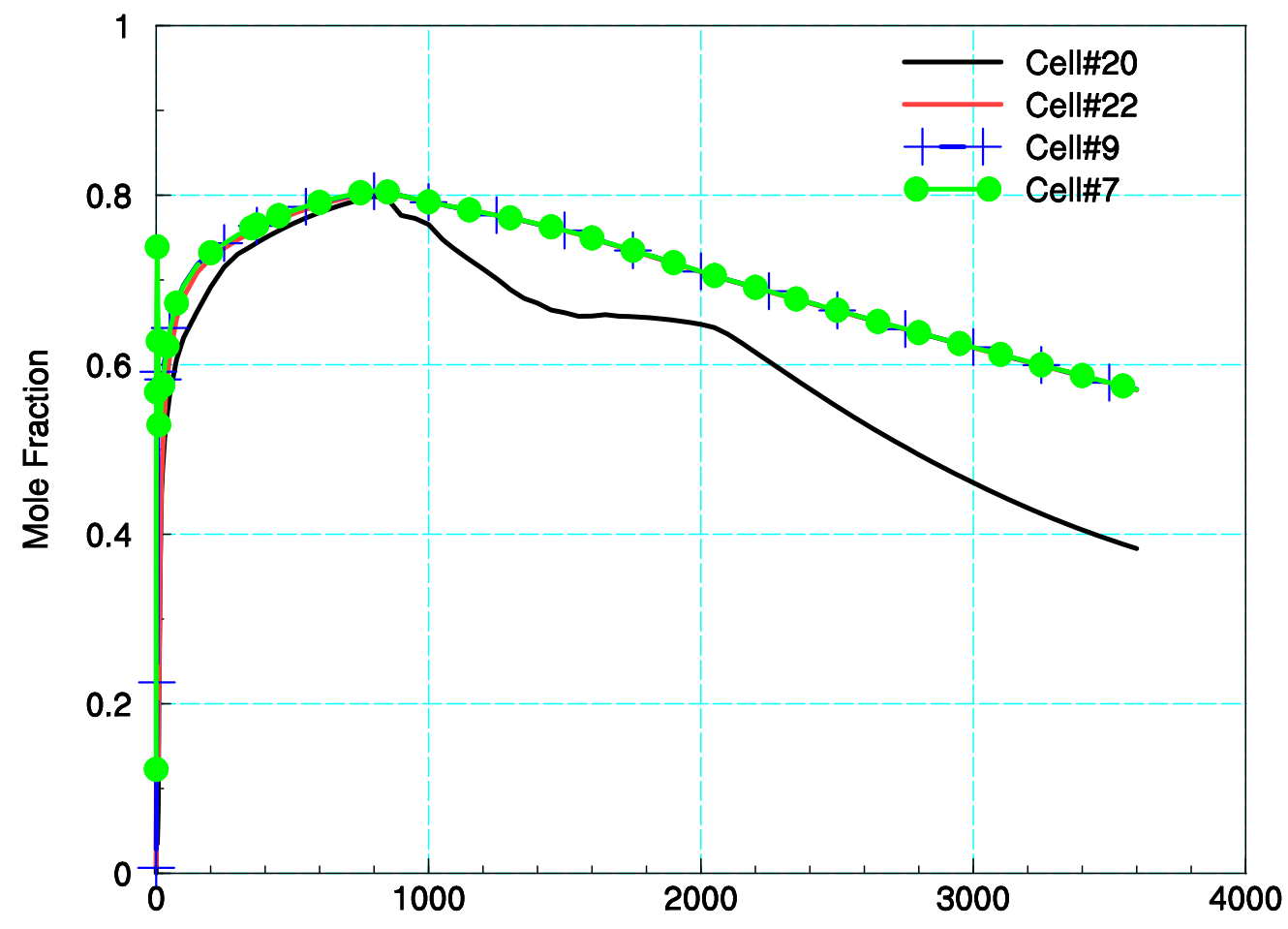

Time, seconds

Figure 3.31 MELCOR-calculated steam mole fractions for the above operating deck region for the AP1000 MSLB event (steam injection location is cell \#7). 


\section{Summary and Conclusions}

The main objective of this report was to present a critical assessment of the MELCOR code for application as a containment analysis code within a licensing venue; specifically, as an audit code for the review of DBA calculations that have been submitted in accord with NRC regulatory guides and standard review procedures. An assessment has been based on typical PWR plant LOCA and MSLB scenarios for current and advanced containment designs. The criterion for acceptable performance was the ability of the MELCOR code results to match another validated and qualified containment analysis code, CONTAIN. Consequently, assessment of the MELCOR code was a matter of benchmarking or determining the equivalency of code results for figure-of-merit quantities (maximum pressure and gas temperature) to similar calculations performed with the CONTAIN code for DBA scenarios.

For the containment types considered, the DBA assessment focused on the calculations of maximum containment loads during rapid and slower pressurization phases of accidents initiated by either a primary or secondary system blowdown. For either scenario, the key phenomena affecting the containment response were 1) expansion and transport of high mass/energy releases, 2) heat and mass transfers to structure passive heat sinks, and 3) containment pressure reduction due to ESFs (i.e., sprays). It was noted that key phenomena simulated in both CONTAIN and MELCOR codes were modeled in a similar manner. For example, in general the important heat and energy transfer processes (condensation of structures and spray droplets) were modeled using a mechanistic approach using the HMTA methodology for simulating mass transfers from atmosphere to condensate or droplet. A CONTAIN code "equivalency band" for assessing adequate code-to-code agreement was established for each scenario and plant type. The band was centered on the CONTAIN calculated pressure or gas temperature results with a variation of $+/-5 \%$ (based on the appropriate gauge or temperature rise above an initial value).

\subsection{Large Dry Containment Analysis (Single-cell Short-term Comparisons)}

The traditional approach for determining short-term containment loads in a large dry PWR containment, with ESFs active, dictated that the containment be modeled as a single volume. Using representative containment geometry, with a typical ESF system design (sprays and fan coolers) and conventional blowdown injection, MELCOR and CONTAIN DBA containment analyses were compared based on containment pressure and gas temperature time history profiles. For both LOCA and MSLB scenarios, the MELCOR code results for pressure and gas temperature were shown to lie within CONTAIN's +/-5\% equivalency band for rapid and slow pressurization phases of the accident. There was a tendency for the MELCOR predicted gas temperature to trend outside the equivalency band during the slow pressurization phase of the LOCA scenario; however, this trend was corrected through a small adjustment in spray droplet size. The size adjustment was well within the typical range of mean spray droplet diameters for representative spray nozzles, and therefore was not considered significant. Maximum pressure and gas temperatures were consequently equivalently predicted by each code. A table of general guidance was presented as an aid in constructing MELCOR input for DBA analyses, applicable to the current class of large dry PWR containments in the United States. 


\subsection{AP1000 Containment Analysis (Multi-cell Short- and Long-term Calculations)}

The single-cell calculations for large dry PWR were intended as a bridge back to the more traditional containment analyses performed during the 1970s and 1980s for the current fleet of PWR plants. For the advanced PWR plants that have either just been certified (AP1000) or are in the process of certification (U.S. EPR), a concern over steam/air mixing in the containment has surfaced due to an emphasis (through the design process) on passive heat removal to limit containment loads during DBA events (excluding active ESFs). Consequently, more recent containment analyses include multi-cell representations of the containment to simulated stratification of steam concentration and gas temperature within the containment. A comparison of single- and multi-cell calculations for the AP1000 containment has been conducted for LOCA (two-phase, low elevation injection) and MSLB (single-phase, high elevation injection) events using the MELCOR code. That comparison indicated the following:

- Global response (pressure) is calculated nearly identical during the rapid pressurization phase of an accident for LOCA and MSLB events. During the slower pressurization phase, where maximum loads are predicted, differences between the containment models are revealed: LOCA events calculated with the multi-cell model predict maximum pressure slightly lower than the single-cell model; and MSLB events calculated with the multi-cell model predict maximum pressure slightly higher than the single-cell model.

- Local response (gas temperature) calculated with the multi-cell model for a two-phase, LOCA event indicated significant superheating for regions downstream of the break room. The superheating effect is due to the preferential dropout of suspended liquid water in the break room. The single-cell model, with a similar flashing model (temperature flash), produced no superheating, and therefore produces short-term gas temperatures that are noticeably lower than the equivalent multi-cell model.

- Local response (gas temperature) calculated with the multi-cell model for the singlephase, MSLB event indicated that the single-cell model slightly under-predicts maximum temperature in the containment. Both single- and multi-cell models predicted superheating in the containment.

Choosing whether a containment model is more appropriately described as a single- or multi-cell model may be determined according to the type of containment design and function during an accident event; for example, whether the design is based on passive or active (ESFs) heat removal processes may indicate a well-mixed (single-cell) or stratified (multi-cell) containment. Without sprays and/or fan coolers operating, mixing of steam and air can be inhibited especially for events involving high elevated injections. Therefore, for containment designs that rely solely on passive heat removal processes (e.g., condensation on heat sinks) to limit maximum containment loads, a multi-cell representation of the containment is often considered an appropriate modeling approach.

To benchmark the MELCOR multi-cell modeling capability, the pressure and local temperature results for LOCA and MSLB events in the AP1000 containment (designed with a PCS to limit containment loads) were compared to CONTAIN code results obtained using an identical nodalization scheme. These comparisons showed the following:

- Global response (pressure) calculated with MELCOR during rapid and slow pressurization periods was equivalent to the CONTAIN results for LOCA and MSLB events. 
- Both codes predicted the maximum temperature occurring during the heat-up phase of the MSLB event. Maximum temperatures were obtained during the MSLB event, and in this case the MELCOR and CONTAIN code results were equivalent.

- Long-term gas temperature stratification predicted for the LOCA event was minimal, and this trend was similarly indicated using either code.

- Long-term steam concentration and gas temperature stratification for the MSLB event was significant using either code. The degree of stratification calculated with MELCOR code, however, was noticeably smaller than that calculated with CONTAIN code, which, by default, used the code's hybrid flow solver to minimize over-mixing. Consequently, a reduced degree of stratification in the MELCOR calculation indicated a greater tendency of the MELCOR code to over-mix a containment atmosphere during post-blowdown periods.

In summary, concerning maximum containment loads with a multi-cell containment representation, both the MELCOR and CONTAIN codes were found to be equivalent. Long-term results (post-blowdown) for stratification of steam concentration or local gas temperature indicated an over-mixing tendency for the MELCOR code that was not as apparent in the CONTAIN simulation for the same MSLB scenario.

Finally, concluding the section on the AP1000 containment analysis, a user guidance subsection was included for the modeling of containments with multi-cell schemes. Guidance was given on geometry input preparation and format, code default settings, and output processing. 


\section{References}

Gau05a Gauntt, R.O., et al., “MELCOR Computer Code Manuals - Vol.1: Primer and User’s Guide, Version 1.8.6 September 2005,” NUREG/CR-6119, Vol. 1 Rev 3, SAND 20055713, Sandia National Laboratories, Albuquerque, New Mexico, September 2005.

Gau05b Gauntt, R.O., et al., "MELCOR Computer Code Manuals - Vol.2: Reference Manuals, Version 1.8.6 September 2005,” NUREG/CR-6119, Vol. 2 Rev 3, SAND 2005-5713, Sandia National Laboratories, Albuquerque, New Mexico, September 2005.

Har79 Hargroves, D.W., et al., “CONTEMPT-LT/028 - A Computer Program for Predicting Containment Pressure -- Temperature Response to a Loss-of-Coolant Accident,” NUREG/CR-0255, TREE-1279, R4, Idaho National Engineering Laboratory, Idaho Falls, Idaho, March 1979.

Mur97 Murata, K. K., et al., “Code Manual for CONTAIN 2.0: A Computer Code for Nuclear Reactor Containment Analysis,” NUREG/CR-6533, SAND-1735, Sandia National Laboratories, Albuquerque, NM, December 1997.

Til02a Tills, J., Notafrancesco, A., and Murata, K., "CONTAIN Code Qualification Report/User Guide for Auditing Design Basis PWR Calculations,” SMSAB-02-03, USNRC ADAMS Accession Number ML022490381, August 2002.

Til02b Tills, J., Notafrancesco, A., and Murata, K., “An Assessment of CONTAIN 2.0: A Focus on Containment Thermal Hydraulics (Including Hydrogen Distributions), SMSAB-02-02, USNRC ADAMS Accession Number ML022140438, July 2002.

Til08 Tills, J., Notafrancesco, A., and Longmire, P., “An Assessment of MELCOR 1.8.6: Design Basis Accident Tests of the Carolinas Virginia Tube Reactor (CVTR) Containment (Including Selected Separate Effects Tests), SAND2008-1224, Sandia National Laboratories, Albuquerque, NM, February 2008.

Til96 Tills, J., "Calculations and Analyses for the Large-Scale Passive Containment Cooling System (PCS) Tests,” SAND96-1089, Contractor Report, Sandia National Laboratories, Albuquerque, NM, May 1996 (Proprietary).

US04 U. S. Nuclear Regulatory Commission, NUREG-1793, "Final Safety Evaluation Report Related to Certification of the AP1000 Standard Design,” September 2004.

Vij99 Vijaykumar, R. and Khatib-Rahbar, M., “Applicability of the CONTAIN Code Heat and Mass Transfer Models to Asymmetrically Heated Vertical Channels,” Nuclear Technology, Volume 128, No. 3, pp. 313-326, December 1999. 


\section{Appendix A. Simulation of the Blowdown Containment Response to a Loss-of-Coolant Accident}

\section{A.1 Introduction}

A loss-of-coolant accident (LOCA) is often characterized in the short term as a blowdown or discharge of highly subcooled and, shortly, two-phase water from a reactor primary system into a low pressure environment composed of dry air. The injection into the containment during the first few seconds is entirely subcooled liquid water; the injection then transitions rapidly to a mixture of steam and liquid with a quality less than one. The specific enthalpy of the injected water begins as representative of liquid water at system pressure and then increases somewhat as the discharge becomes two-phase. In most containment response simulations, the blowdown injection is simply described in terms of total water mass rate $(\mathrm{kg} / \mathrm{s})$ and either specific enthalpy $(\mathrm{kJ} / \mathrm{kg})$ or integrated energy rate $(\mathrm{kJ} / \mathrm{s})$ for the discharge stream. In such cases, the representation of the discharge at the break in terms of pressure, temperature, and quality is unknown. As a result, some methodology for determining phase separation for the discharge must be assumed. The modeling of the actual phenomena that determines, in reality, the dispersion and separation of water phases is beyond verification ability for state-of-the-art system or field codes due to the uncertainties associated with pipe break and surrounding geometry and instrumentation limitations.

A reasonable analytical approach to describing the dispersion and separation phenomena, therefore, is to characterize the blowdown in terms of a known phenomenon for phase separation, i.e., flashing. Flashing refers to the evaporation of high pressurized liquid water when the water expands into a low temperature and pressure surrounding. In the flashing process, excess latent heat is liberated in the discharge process and made available to evaporate some portion of the injected liquid water entering the containment. The path from subcooled liquid to separation of phases that determines the quantity of latent heat available for evaporation is open to some debate, i.e., whether the flashing occurs as an adiabatic or isenthalpic process, or whether the process occurs in a mixed or unmixed state. Depending on the type of assumptions made in the flashing model, different containment responses can occur. The most widely applied flashing model assumes an isenthalpic expansion, such that the percentage of flashed or evaporated water is determined as

$$
\text { Flash } \%=\frac{\boldsymbol{h}_{\text {blowdown }}-\boldsymbol{h}_{f}(x)}{\boldsymbol{h}_{g}(x)-\boldsymbol{h}_{f}(x)} * 100
$$

where

$\boldsymbol{h}_{\text {bitowdown }}=$ specific enthalpy of water entering containment

$\boldsymbol{h}_{f}(\boldsymbol{x})=$ saturation enthalpy of liquid water

$\boldsymbol{h}_{\boldsymbol{g}}(\boldsymbol{k}) \quad=$ saturation enthalpy of steam

In the above functional relationships for saturation enthalpies, the independent variable $x$ may be represented either as temperature or pressure. When maximum containment loads are to be evaluated, the so called "temperature flash" or thermal equilibrium model is often preferred. This model is known, in most cases, to produce the highest containment energy during the blowdown process and, therefore, generally the highest atmospheric pressure and temperature, assuming saturation conditions. In this case, the saturation enthalpies are evaluated at the equilibrium 
temperature, such that $x$ 뜬 $\boldsymbol{T}_{s a t}=T_{m b x}$. Another model, typically used for containment analyses where a minimum pressure is desired, is the "pressure flash" model that finds utility for conservative emergency core cooling system (ECCS) backpressure predictions. This model replaces the independent variable in the enthalpy function by the saturation pressure, which is taken as the total containment pressure, i.e., $x$ 程 $P_{\text {got }}=P_{\text {total }}$. Figures A-1 and A-2 show the calculated flashing percentages for various water injections based on flashing temperature or pressure. For most two-phase blowdowns (LOCAs), the water injection enthalpy lies between $1200-1800 \mathrm{~kJ} / \mathrm{kg}$, and therefore the amount of flashed steam ranges from approximately $40 \%$ to $60 \%$ under typical containment conditions.

For each modeling approach, the subsequent location of unflashed liquid also requires a method for dealing with liquid suspension subsequent deposition processes. Transferring all or a portion of the unflashed water to a liquid region or pool must be calculated for each flashing model. Again, the modeling of the actual process of liquid distribution is complicated and is therefore treated using two extremes, where the real process is believed to fall somewhere in between. The extremes typically assumed are that either unflashed liquid is removed from the atmosphere immediately and transferred into a pool region (dropout option), or the liquid is assumed to be entirely retained in the atmosphere. As with the flashing model, the liquid transfer assumptions selected in the blowdown simulation can be of some importance to both short- and long-term predictions for containment atmospheric pressure and temperature.

Although recommendations for conservatively biased assumptions can be made in general (as discussed below), it is recommended to apply a range of assumptions for any accident scenario with unique features to determine the most appropriate choice, and to ascertain sensitivity of the figure of merits, such as atmospheric pressure or temperature. The importance of this recommendation is demonstrated in the analyses discussed. The assumptions associated with flashing (temperature or pressure) are discussed below with methods used to distribute unflashed water, and demonstrated for adiabatic boundary conditions (without heat sinks or engineered safety features [ESFs] activated). These modeling choices are presented for both single and multi-cell representations of containments. The basis for the primary system discharge characterizations (mass and energy sources) are derived from the plants' safety analysis reports. Comparisons of results from two system analysis codes, CONTAIN and MELCOR, are presented for investigation of variance based on differences in the implementation of modeling for temperature and pressure flash methods during LOCA-type injections (Table A-1).

\section{A.2 Single Adiabatic Containment Configuration}

\section{A.2.1 Temperature Flash Model}

During the blowdown process, the fluid injected into the atmosphere enters at a very high velocity, near sonic speed for either a single or two-phase fluid. Consequently, it is reasonable to assume that the fluid will be dispersed uniformly throughout the containment volume with very good contact between gas (air/steam) and suspended droplets of liquid water. As a result of the intimate contact, thermal equilibrium is rapidly established, and a mixture temperature $T_{\text {mix }}$ based on the mass and energy balance is evaluated. This mixture temperature defines the surrounding environment where flashing can then occur. The amount of unflashed liquid is determined from the saturated condition of the atmosphere where the saturation temperature is the mixture temperature calculated with the assumption that there is thermal equilibrium between phases at all times. 
When the prediction of maximum containment pressure is a goal of the analysis, the unflashed liquid water is immediately removed from the atmosphere and placed into a pool region at the end of a calculation time-step. Removal of unflashed water reduces the total heat capacity of the containment atmosphere during the transient, and therefore increases the predicted mixture temperatures determined from the fluid injection.

Figure A-3 shows a sketch of a reactor primary and containment system that is typical of a design-basis accident simulation. The containment is represented as a single volume into which the primary system discharges a high pressure stream of water. The blowdown mass and enthalpy injection profile for a typical LOCA event is plotted in Figure A-4. The containment and pressure and temperature response for this injection, where there is an immediate dropout of unflashed water, is shown in Figures A-5 and A-6, respectively. The two codes represented in the plots are CONTAIN 2.0 and MELCOR 1.8.6 ${ }^{10}$. Each code is run in a 64-bit configuration, i.e., compiled with double precision. MELCOR uses steam/liquid properties that are equivalent to properties determined by Keenan and Keyes [Kee78]. CONTAIN, on the other hand, uses, by default, a water equation-of-state (EOS) that is based on an ideal gas formulation for the vapor [Van78] and saturation properties of liquid water [Tou79]. A non-ideal EOS can also be used in CONTAIN, however, and this setting is also based on Keenan and Keyes equations. ${ }^{11}$

Activation of the non-ideal EOS equations is made by including keyword HIPRWATR in the CONTAIN input. In Figures A-5 and A-6, both the CONTAIN default setting for ideal EOS and non-ideal EOS for water are plotted. In these calculations, the containment is adiabatic in the sense that there is no heat transfer to structures, pool surface, or interaction with any ESFs (fan coolers or sprays). The time-steps for each code are essentially identical and chosen to eliminate any progression of pressure variation when time-steps are reduced. As shown in the containment response figures, both codes predict essentially identical results for gas pressure and temperature when equivalent water properties are used. CONTAIN default water properties are seen to produce slightly higher pressure and temperature responses than indicated for the MELCOR calculation.

Figure A-7 shows a comparison between MELCOR-calculated pressure with temperature flash where the unflashed liquid water is either removed immediately during the flashing period or retained in the atmosphere. ${ }^{12}$ Removing the liquid water slightly increases pressure during the blowdown period and therefore represents a more conservative assumption regarding the distribution of unflashed liquid when maximum containment loads are required.

\section{A.2.2 Pressure Flash Model}

The pressure flash model is similar to the temperature flash method, but differs in how the final thermodynamic states of the vapor and liquid regions are determined. For pressure flashing, the saturation temperature for the final liquid state corresponds to the total atmospheric pressure

\footnotetext{
${ }^{10}$ MELCOR 1.8.6 YN+thrm+64 is a 1.8.6 version updated by two modification files, YN and thrm. The "64" designation indicates that the version is compiled as double-precision.

${ }^{11}$ The CONTAIN non-ideal EOS for water was added to the code to improve predictions involving high pressure water conditions (at about reactor system pressure) occurring during direct containment heating (DCH) events. Essentially all low pressure cases, containment related non-DCH cases such as DBA events, have been calculated using the default, ideal EOS for water.

${ }^{12}$ Removal of liquid water (fog) is activated in MELCOR by setting parameter IPFSW=2 on the CVnnn01 input line. Retention of liquid water (fog) is accomplished in MELCOR by setting parameter IPFSW=0 (default) and setting the sensitivity coefficient $4406(1)$ to a high value $=50$ that is above the maximum expected fog density before liquid water is removed to the pool.
} 
against which the liquid boils. Additionally, two alternative assumptions regarding mixing are considered: 1) assume complete mixing and saturation of the steam/air mixture during the flashing process, followed by immediate removal of unflashed liquid; or 2) assume that unflashed liquid does not mix with the atmosphere and is immediately removed from the atmosphere following flashing. Complete mixing infers a saturation condition if enough water is available, whereas the case with no mixing removes a constraint that the gas temperature will follow the saturation curve. Complete mixing with the attending saturation condition has been assumed for previous auditing codes such as CONTEMPT, and this assumption is also retained for the MELCOR code for both temperature and pressure flash in a single volume. For CONTAIN, however, complete mixing is not assumed. As discussed below for the multi-cell cases, one can argue that the unmixed assumption is more appropriate for a flashing method driven by a "boiling" process where the unflashed liquid is assumed isolated from the bulk of containment volume.

Using the pressure flash method, with complete mixing of unflashed water, the flashing percentage is determined based on the process of boiling at the total pressure of the containment, as discussed above. The containment temperature, which is also the saturation temperature in this case, is in turn derived from the vapor density for the completely mixed atmosphere. When complete mixing is not assumed for the final thermodynamic state of the atmosphere, gas temperature is determined by a thermal equilibrium calculation where the steam addition is the flashed steam that, after unflashed water is removed, completely mixes in the atmosphere. In both cases, the flashing percentage is calculated in a similar manner, but only in the case with unflashed water mixing in the atmosphere is the containment gas temperature constrained to be the saturation temperature. ${ }^{13}$ The difference between the MELCOR and CONTAIN treatments of pressure flashing can be significant for near adiabatic conditions (blowdown periods) because the CONTAIN treatment will typically result in some superheating of the atmosphere. Consequently, using the CONTAIN pressure flash method can result in gas pressures and temperatures that tend to be higher than responses calculated with an alternative temperature flash method. The opposite generally occurs for the pressure flash method implemented in the MELCOR code. For MELCOR, the pressure flash method results in pressures and temperatures that are lower than the loads calculated by temperature flash because the unflashed water is removed from a saturated air/steam mixture at a higher temperature corresponding to the boiling pressure (i.e., total pressure) of the water.

Figures A-8 and A-9 show the pressure and temperature profile comparisons for the MELCOR and CONTAIN codes using the pressure flash method with immediate removal of unflashed liquid to the pool region. Due to a lack of mixing for the unflashed water in the CONTAIN pressure flash modeling, there is a significant degree of superheating calculated in the CONTAIN results (Figure A-10). The saturation temperature, however, calculated with CONTAIN is essentially identical to the MELCOR values (compare Figures A-9 and A-10), and therefore the increased pressure calculated with CONTAIN, compared to MELCOR, is mainly

\footnotetext{
${ }^{13}$ When discussing the pressure flash model implementation in MELCOR or CONTAIN, it should be noted that the flashing or partitioning of water as steam or liquid is the only process modeled appropriately as "flashing." However, in the case of CONTAIN, removal (to the pool region) of unflashed water without mixing in the atmosphere is also an integral part of the "flashing model." MELCOR, on the other hand, by default retains unflashed water as fog, and fog removal occurs separately from the "flashing modeling." We draw a distinction in terms of mixing or not mixing unflashed water between the codes on this basis. For MELCOR's flashing model implementation, the presence of fog (even for a short time period) implies atmospheric saturation, whereas removal of liquid without mixing assumes atmospheric conditions not constrained to the saturation line.
} 
the result of superheating by the CONTAIN treatment. Because the amount of energy associated with the sensible heat is still relatively small compared to latent heat in the atmosphere, nonadiabatic boundary conditions and activation of ESFs (sprays and fan coolers) can efficiently eliminate much of the superheating and reduce pressures obtained by the CONTAIN pressure flash method. As shown in Figure A-11, the pressure flash method results in a pressure profile that is below an equivalent temperature flash treatment. In the case of MELCOR, with an assumed mixing of unflashed water in the atmosphere prior to dropout, the common conclusion [Sla70] that pressure derived from pressure flashing is less than temperature flashing is confirmed (Figure A-12).

\section{A.3 Multi-cell Adiabatic Containment Configuration}

To examine the effects of the various blowdown modeling options in multi-cell containment configurations, a simple two-cell representation is shown in Figure A-13: the break room is that volume consisting of the steam generator compartment that contains the cold leg break, and the rest of the containment volume is included as an adjoining volume connected to the break room by gas and liquid pathways. In a similar approach as discussed above, the simulations of temperature and pressure flash phase separation treatments that affect containment loads are calculated with MELCOR and CONTAIN for the two-cell containment geometry.

Unflashed water dropout. In the following calculations, the CONTAIN results are calculated using only non-ideal EOS for water, and all calculations assume removal of unflashed water from the atmosphere. Figures A-14 and A-15 show the break room and containment pressure comparisons for each code, using a temperature flash treatment to predict phase separation. Figures A-16 and A-17 show plots of gas temperatures in a similar set of comparisons. The early time pressure profiles in the break room pressure show that the results obtained with CONTAIN are somewhat higher than MELCOR, and this behavior is in part the result of a mismatch in the gas and liquid flow from the lower drain path from the break room to containment volume. Here we note that the modeling of simultaneous gas and liquid or liquid-only transport is treated differently in each code. For example, closing off the drain pathway to gas flow when sufficient liquid is draining will tend to increase the break room pressure, whereas when both gas and liquid are allowed to flow (generally, in the case of MELCOR) the break room pressure is somewhat reduced. The pressure difference observed during the early time period is, however, more an issue related to subcompartment analysis and therefore is not further pursued here. More important, however, to the containment pressure analysis are the pressure and temperature comparisons for the containment volume (Figures A-15 and A-17). For these figures, it is clear that both the MELCOR and CONTAIN codes predict nearly identical profiles.

The containment pressure and gas temperature profiles are noticeably higher than the equivalent single cell results reported above. For the multi-cell case, the containment volume is noticeably superheated because unflashed water, in both code calculations, is removed from the atmosphere prior to mixing with the containment volume. A comparison of the multi- and single cell gas pressure and temperature for the containment volume is shown in Figures A-18 and A-19.

Preventing mixing of unflashed water with a large portion of the overall containment atmosphere with the multi-cell configuration and the temperature flash method is similar to the CONTAIN pressure flash method using the single cell configuration. This behavior is indicated in Figures A-20 and A21. At this point, we can see the practical aspect for preventing unflashed water mixing with the entire containment atmosphere during a pressure flash modeling which is implemented in CONTAIN. Furthermore, the procedure for duplicating pressure flashing with 
the CONTAIN single cell configuration can be accomplished by using a simple multi-cell configuration with MELCOR and the temperature flash method.

Unflashed water suspended. In this set of calculations, temperature flash modeling is considered with all unflashed water (as droplets) remaining in contact with the atmosphere. Figures A-22 and A-23 show the MELCOR-calculated results for containment pressure and temperature assuming either dropout or suspension of unflashed water. Retaining the unflashed water in the atmosphere lowers the containment (cell \#1) pressure in comparison to the case where unflashed water is removed from the atmosphere and placed into a pool region. The effect is similar to the case comparisons for dropout and suspension with the single cell nodalization of the containment (Figure A-7). In Figure A-24, the single cell calculations are also shown with the equivalent multi-cell pressure results, where we observe that nodalization has little affect on pressure predictions if unflashed water is assumed to remain suspended in the atmosphere throughout the blowdown period.

\section{A.4 Conclusions}

The investigation of containment response to a typical pressure water reactor (PWR) LOCA-type blowdown using adiabatic boundary conditions has revealed a number of modeling items that can affect the comparisons of CONTAIN and MELCOR for both maximum and minimum containment pressure and temperature analysis. First, an improvement in the containment response comparisons is noted when CONTAIN input includes a keyword that activates the nonideal EOS for water. Without activating the non-ideal EOS for water (i.e., using default setting), the CONTAIN code calculates slightly higher pressure and temperature than the MELCOR code. The improvement with the non-ideal EOS is reasonable considering that CONTAIN non-ideal EOS for water is derived using essentially the same Keenan and Keyes equations used in the MELCOR code.

The second finding in the investigation is that for the MELCOR code, a single cell calculation using the temperature flash method for phase separation results in a higher pressure than an equivalent calculation using a pressure flash method. This behavior was noted to be in agreement with the previous understanding of the differences expected between the two flashing methods as discussed in reference Sla70, where saturation conditions are assumed in both flashing models. However, this observation is not supported when performing the calculations with CONTAIN due to differences in the assumption regarding mixing of unflashed water with the containment atmosphere prior to dropout. The effect of not mixing the unflashed water with the atmosphere, in the case of the CONTAIN treatment for pressure flashing, is to superheat the atmosphere as the flashed water (steam) is injected. It is noted, however, that nonadiabatic conditions and inclusion of ESFs (sprays and fan coolers) can alter these findings relative to CONTAIN, and shows that pressures and temperatures calculated by CONTAIN using the pressure flash method for phase separation generally will be calculated slightly lower than equivalent temperature flash calculations.

A third conclusion involves the multi-cell calculations, where the pressures and temperatures calculated with the MELCOR and CONTAIN codes with temperature flash modeling is essentially equivalent, yet significantly different than the counterpart calculations with a single cell configuration. With either code, the multi-cell pressure and temperature profiles are calculated higher than the single cell cases. The increases in pressure and temperature result from the effective filtering out of unflashed water in the break room prior to mixing in the larger containment volume. The filtering or removal process results in significant superheating of the 
downstream containment atmosphere which is not predicted for single cell cases. This conclusion has a major impact on the reporting of maximum temperature, and a need to distinguish between saturation and superheated conditions when reporting temperature calculations.

The fourth conclusion is that the MELCOR multi-cell configuration with temperature flash modeling was essentially equivalent to a CONTAIN single cell configuration using a pressure flash method for phase separation. This finding is important in showing the physical reasoning behind the CONTAIN implementation of pressure flashing modeling, and providing a procedure for establishing equivalent containment loads calculations using simple variations in the geometric models.

A final conclusion for temperature flashing is that when unflashed water is suspended in the atmosphere throughout the blowdown period, essentially identical pressure will be predicted regardless of the nodalization scheme (single or multi-cell). Difference in pressure predictions based on nodalization is, therefore, observed only when unflashed water is dropped out of the atmosphere during the blowdown period.

\section{A.5 References}

Kee78 Steam Tables, Thermodynamic Properties of Water Including Vapor, Liquid, and Solid Phases (International System of Units - S.I.), J. H. Keenan, F. G. Keys, and J. G. Moore, John Wiley \& Sons, New York, NY, 1978.

Sla70 "Comparison of analytical techniques used to determine distribution of mass and energy in the liquid and vapor regions of a PWR containment following a loss-ofcoolant accident,” Special Interim Report, Idaho Nuclear Corporation, Nuclear Safety Division, Nuclear Safety Development Branch, January 1970.

Tou79 Thermophyiscal Properties of Matter: The TPRC Data Series, Y. S. Touloukian and C. Y. Ho, Plenum Press, 1970-1979.

Van78 Fundamentals of Classical Thermodynamics, G. J. Van Wylen and R. E. Sonntag, $2^{\text {nd }}$ Ed., SI Version, John Wiley \& Sons, New York, NY, 1978. 
Table A-1. Comparison of CONTAIN/MELCOR model inputs for various flashing treatments used to predict short-term containment response for design basis accident loss-of-coolant events.

\begin{tabular}{|c|l|l|l|}
\hline \multirow{2}{*}{ Code } & \multicolumn{1}{|c|}{ Tlashing Model } & \multicolumn{1}{c|}{ Comment } \\
\cline { 2 - 3 } & \multicolumn{2}{|c|}{ Pressure } \\
\hline CONTAIN & $\begin{array}{l}\text { Default; external atmospheric } \\
\text { source for blowdown injection } \\
\text { (SOURCE, ATMOS, etc.); no } \\
\text { dropout of unflashed water; } \\
\text { dropout requires keyword } \\
\text { DROPOUT in FLOWS block }\end{array}$ & $\begin{array}{l}\text { Safety relief valve (SRV) } \\
\text { source used to simulate } \\
\text { pressure flashing; dropout } \\
\text { of unflashed water implied } \\
\text { by SRV model }\end{array}$ & $\begin{array}{l}\text { Pressure flash with SRV } \\
\text { source removes } \\
\text { unflashed water prior to } \\
\text { mixing with atmosphere } \\
\text { (superheating probable } \\
\text { in most cases) }\end{array}$ \\
\hline MELCOR & $\begin{array}{l}\text { Default; blowdown injected as } \\
\text { external atmospheric source using } \\
\text { MASS.3 and ENERGY.A input } \\
\text { on CVnnnCk lines; no dropout of } \\
\text { unflashed water by default } \\
\text { (suspension of water as fog } \\
\text { requires setting sensitivity } \\
\text { coefficient 4406 (1) to large } \\
\text { value); dropout requires setting } \\
\text { parameter IPFSW=2 on CVnnn01 } \\
\text { input line }\end{array}$ & $\begin{array}{l}\text { Enter blowdown source } \\
\text { using WATER-MASS and } \\
\text { input on CVnnnCk lines }\end{array}$ & $\begin{array}{l}\text { Pressure flash assumes } \\
\text { saturation, i.e., mixing } \\
\text { of unflashed water with } \\
\text { atmosphere (perfect } \\
\text { contact) is assumed } \\
\text { during the flashing or } \\
\text { boiling process; } \\
\text { superheating is not } \\
\text { probable for LOCA type } \\
\text { blowdown source }\end{array}$ \\
\hline
\end{tabular}




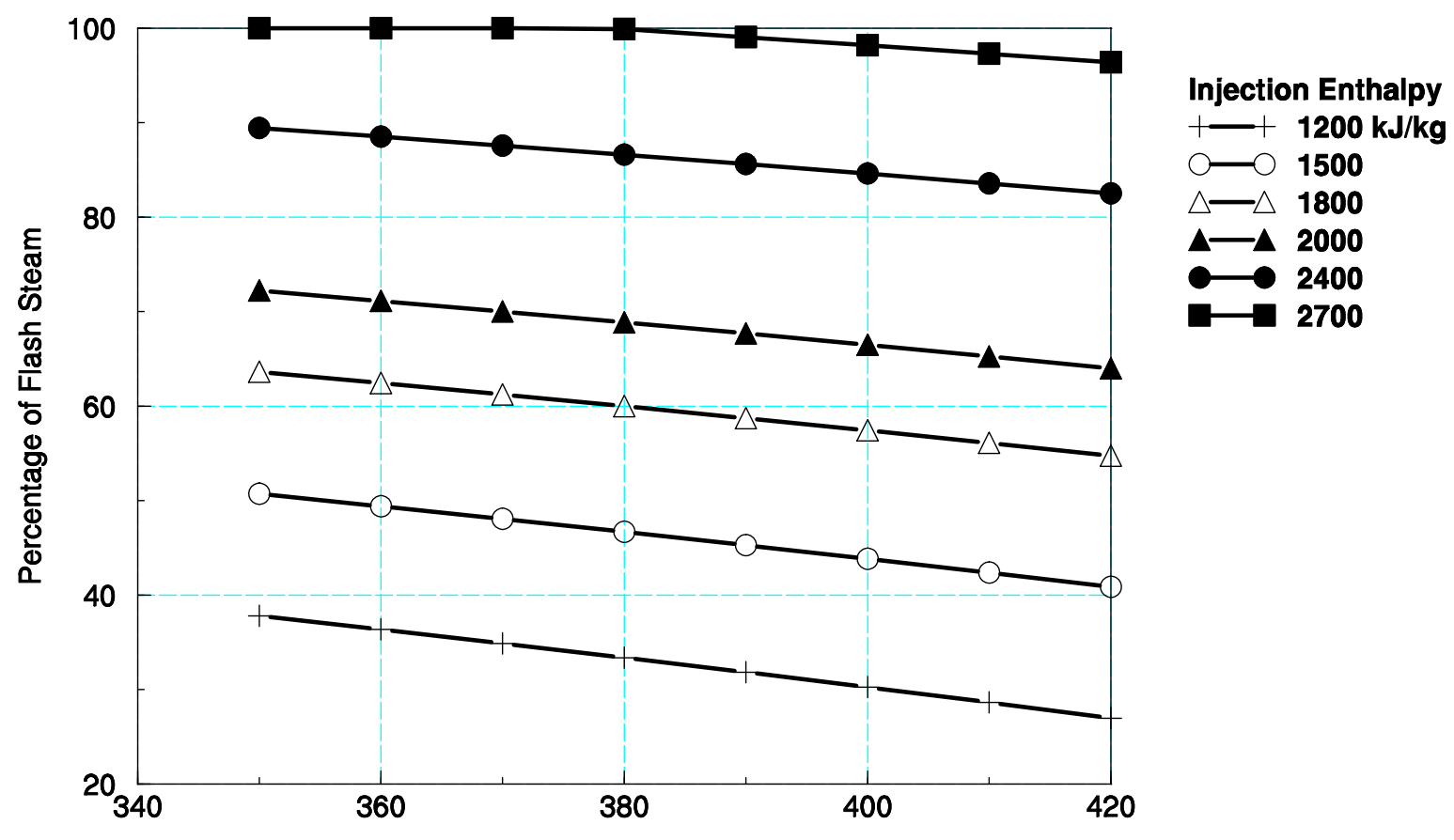

Flash Temperature, $\mathrm{K}$

Figure A-1. Temperature flash model for determining percentage of flashed water for various injection enthalpies. 


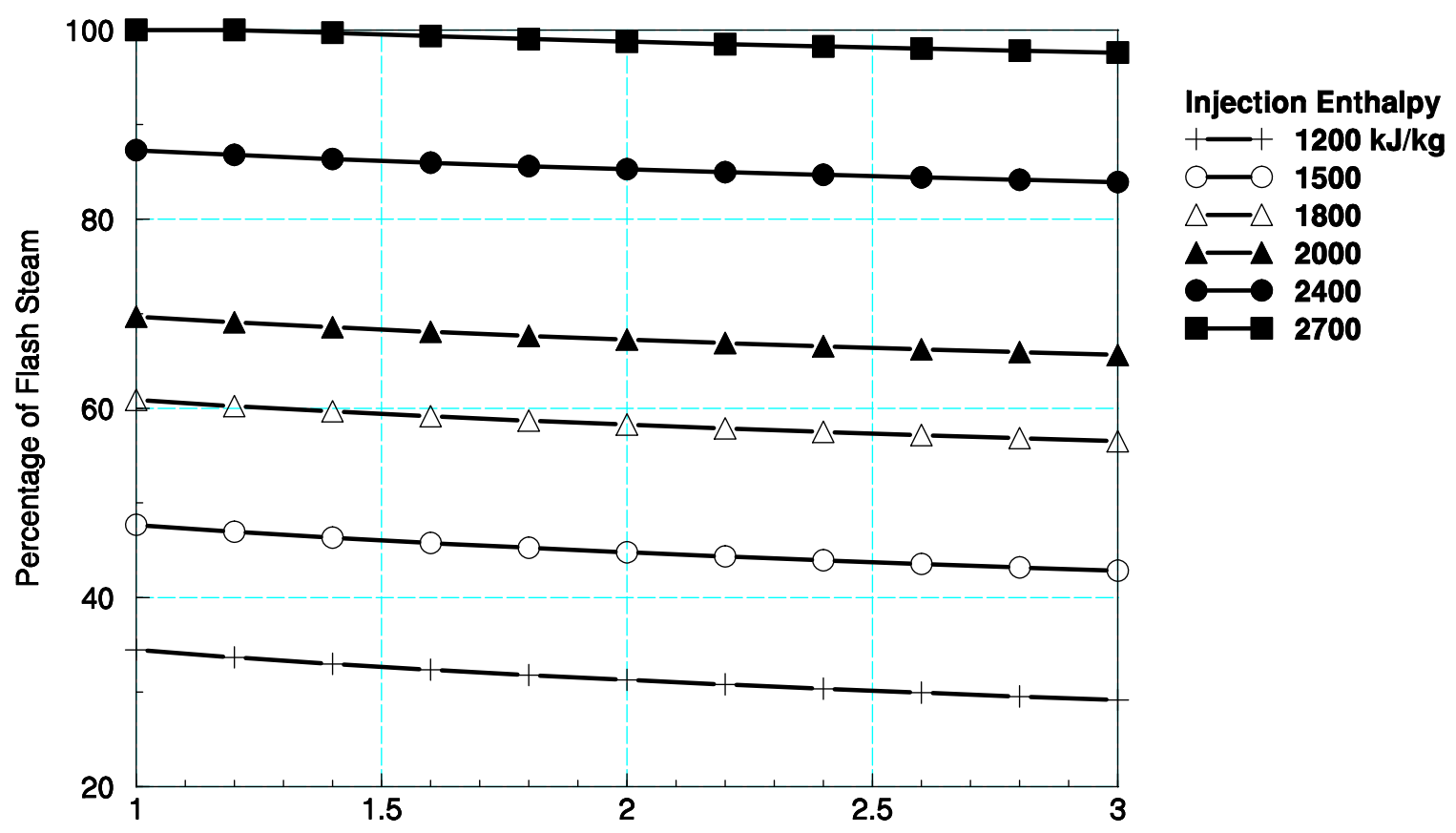

Flash Pressure, bar

Figure A-2. Pressure flash model for determining percentage of flashed water for various injection enthalpies. 


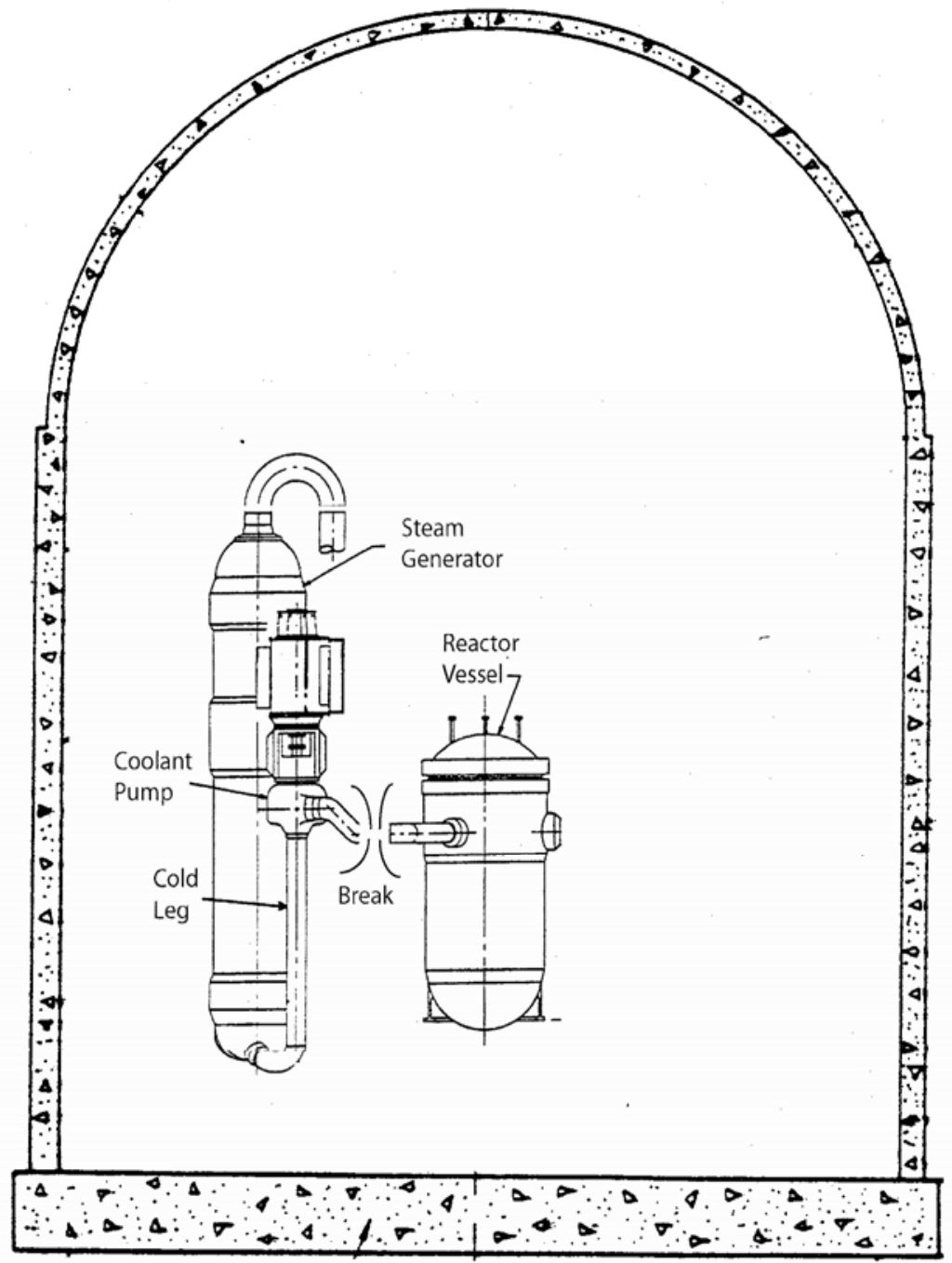

Figure A-3. Sketch of PWR large dry containment represented as a single volume (primary system break in cold leg). 


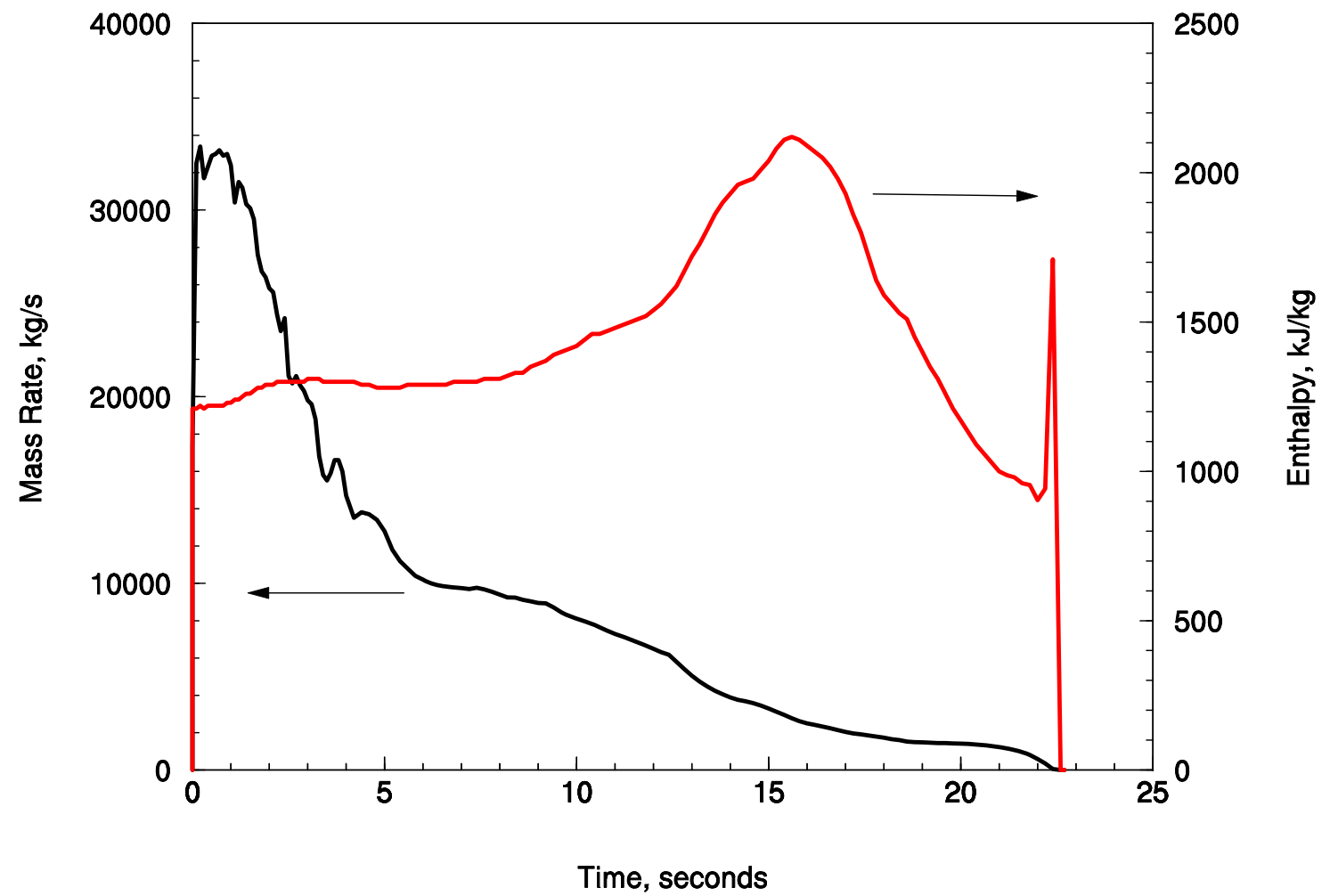

Figure A-4. A typical blowdown injection profile for a PWR double-ended cold leg (DECLG) break. 


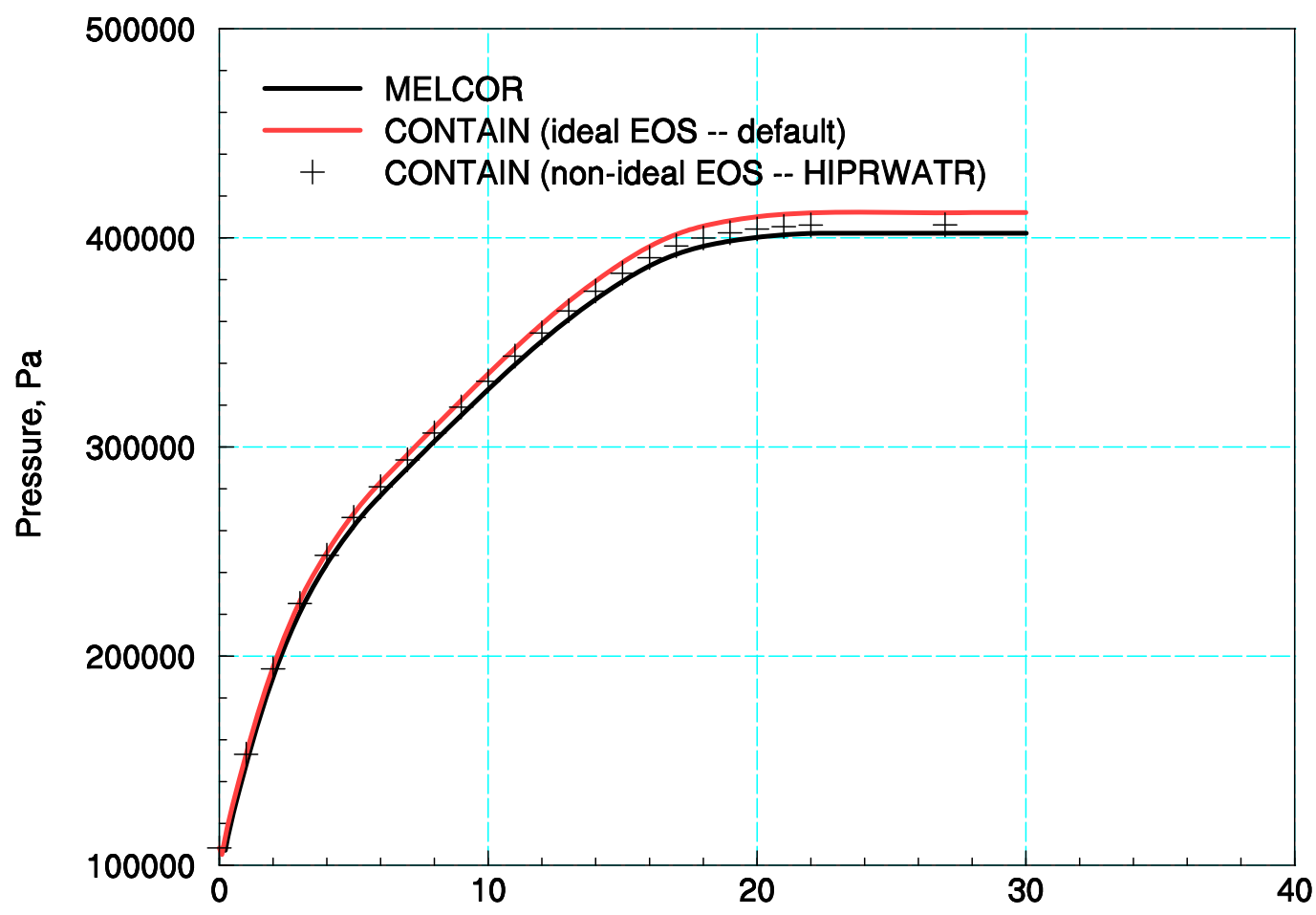

Time, seconds

Figure A-5. Single volume containment gas pressure response for DECLG break using a temperature flash method for treating the two-phase separation, with adiabatic boundary conditions and removal of liquid water to pool region. 


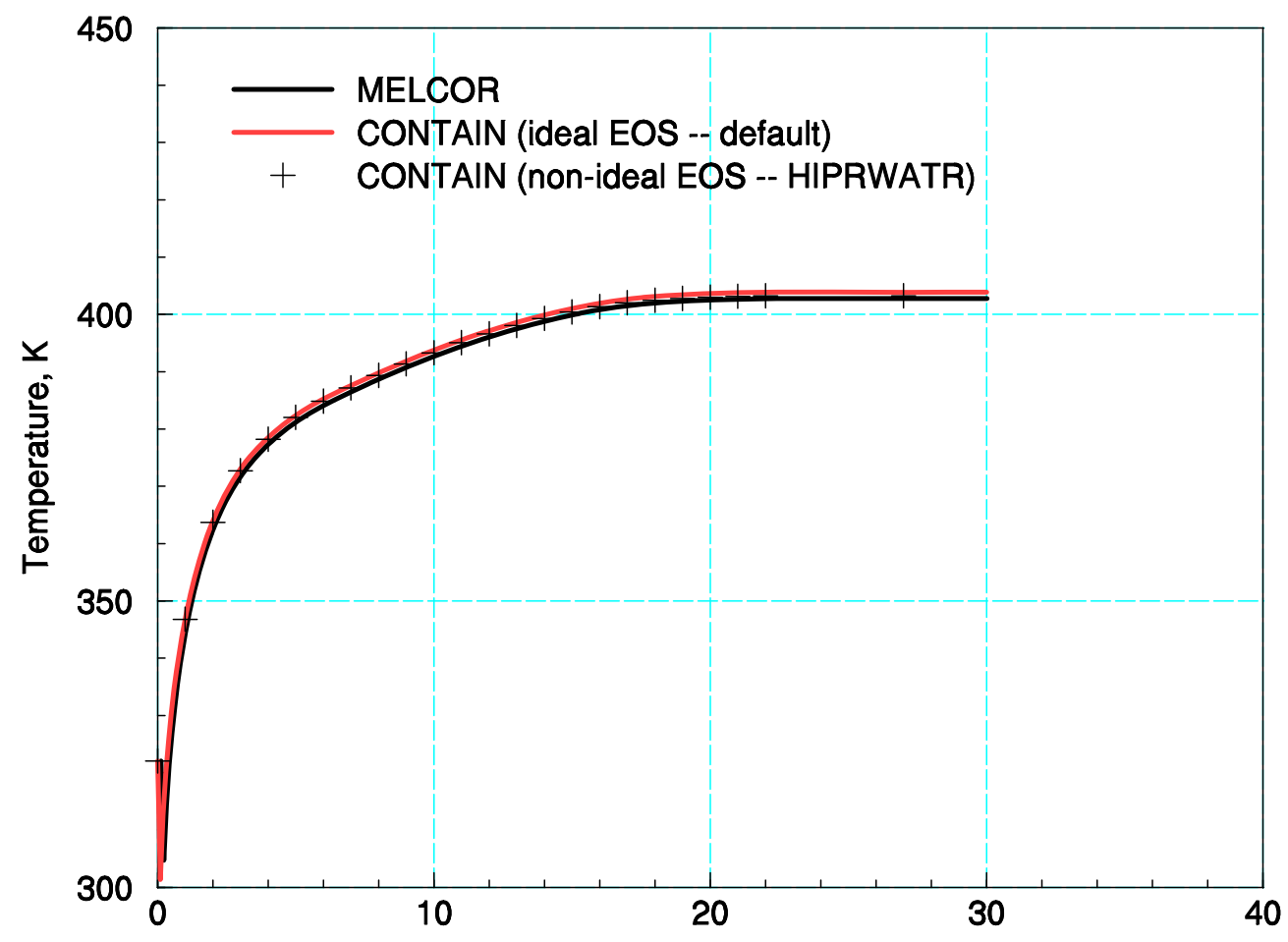

Time, seconds

Figure A-6. Single volume containment gas temperature response for DECLG break using a temperature flash method for treating the two-phase separation, with adiabatic boundary conditions and removal of liquid water to pool region. 


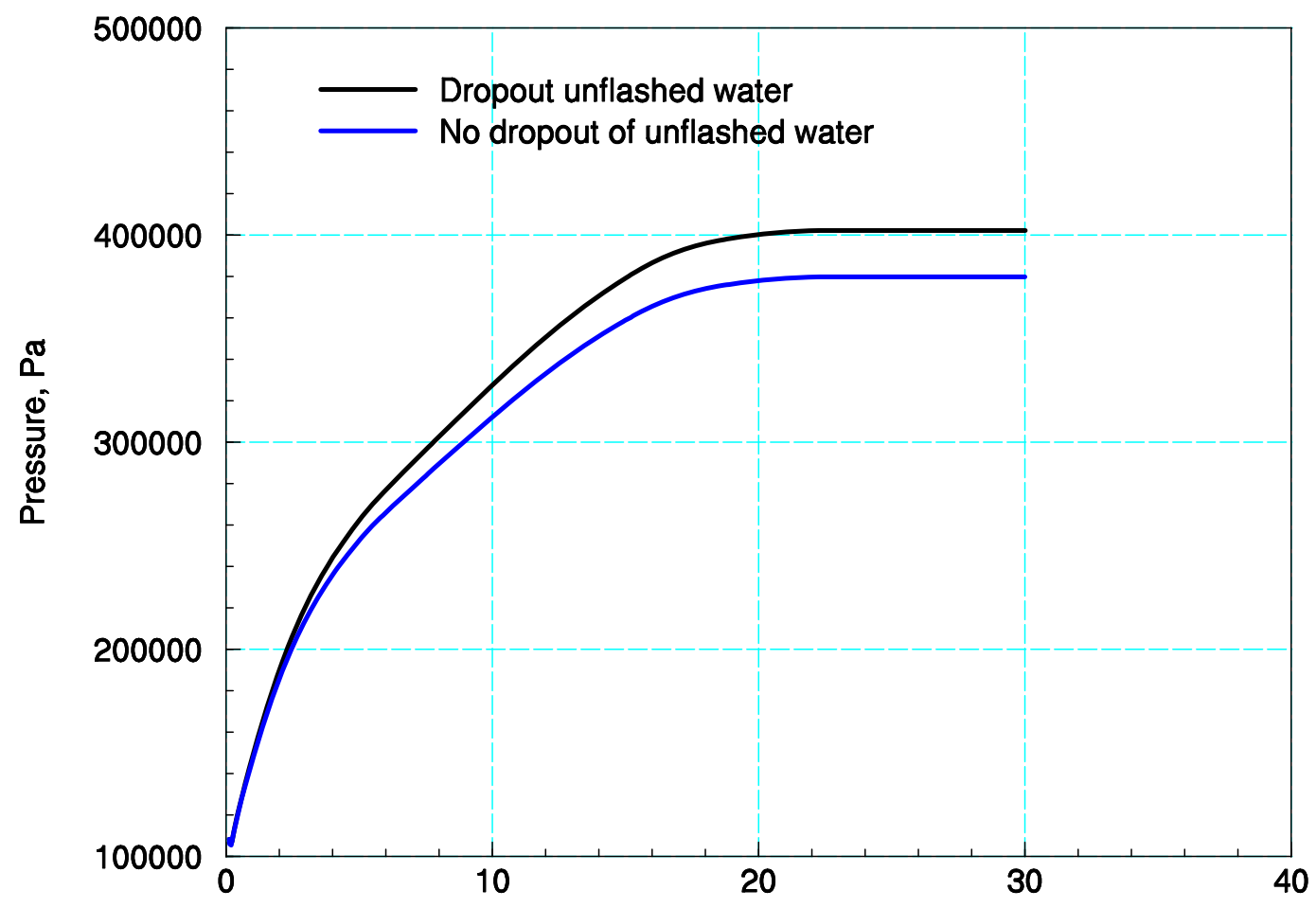

Time, seconds

Figure A-7. Single volume MELCOR containment gas pressure response for DECLG break using a temperature flash method for treating the two-phase separation, with adiabatic boundary conditions with and without removal (dropout) of liquid water to pool region. 


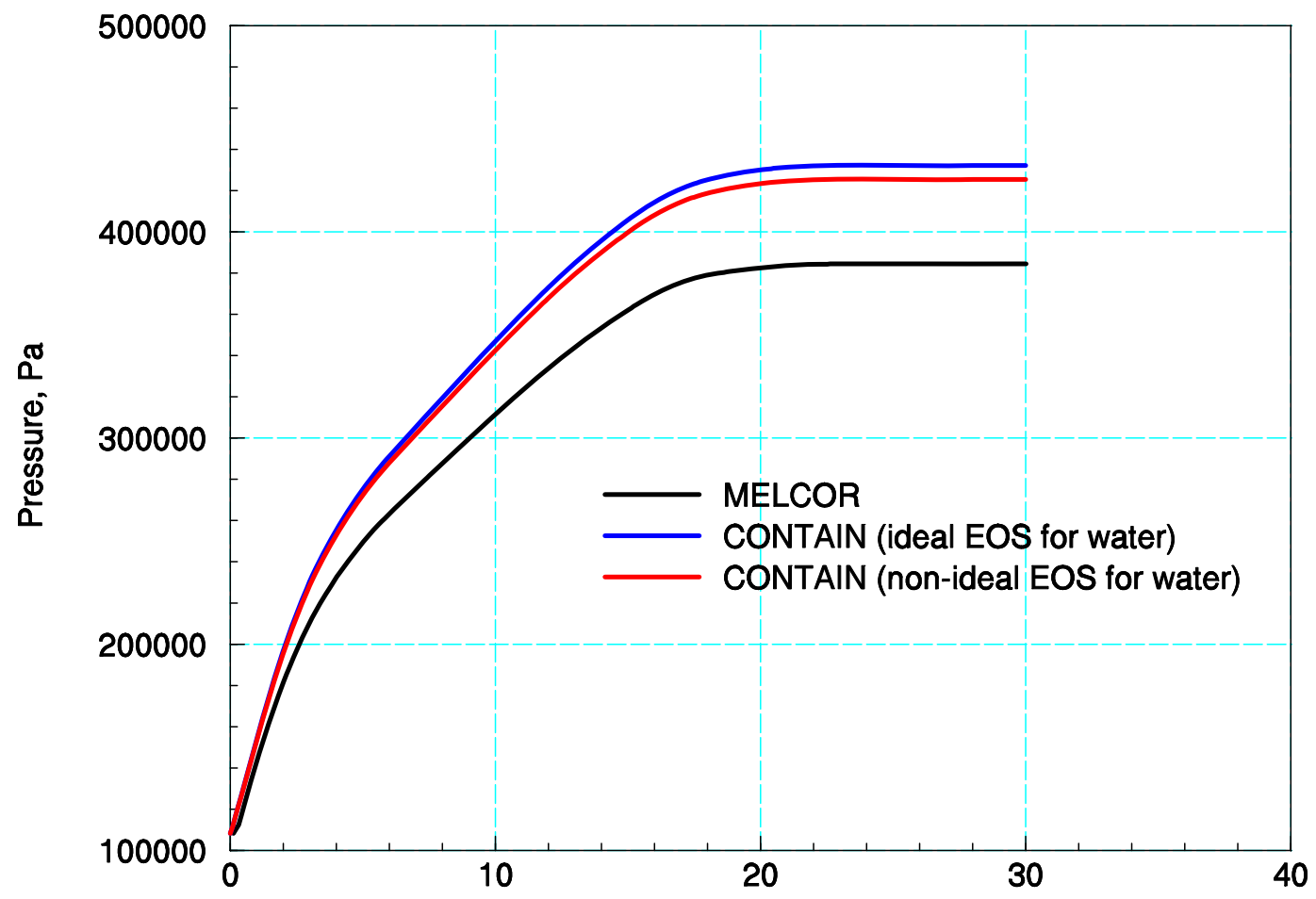

Time, seconds

Figure A-8. Single volume containment gas pressure response for DECLG break using a pressure flash method for treating the two-phase separation, with adiabatic boundary conditions and removal of liquid water to pool region. 


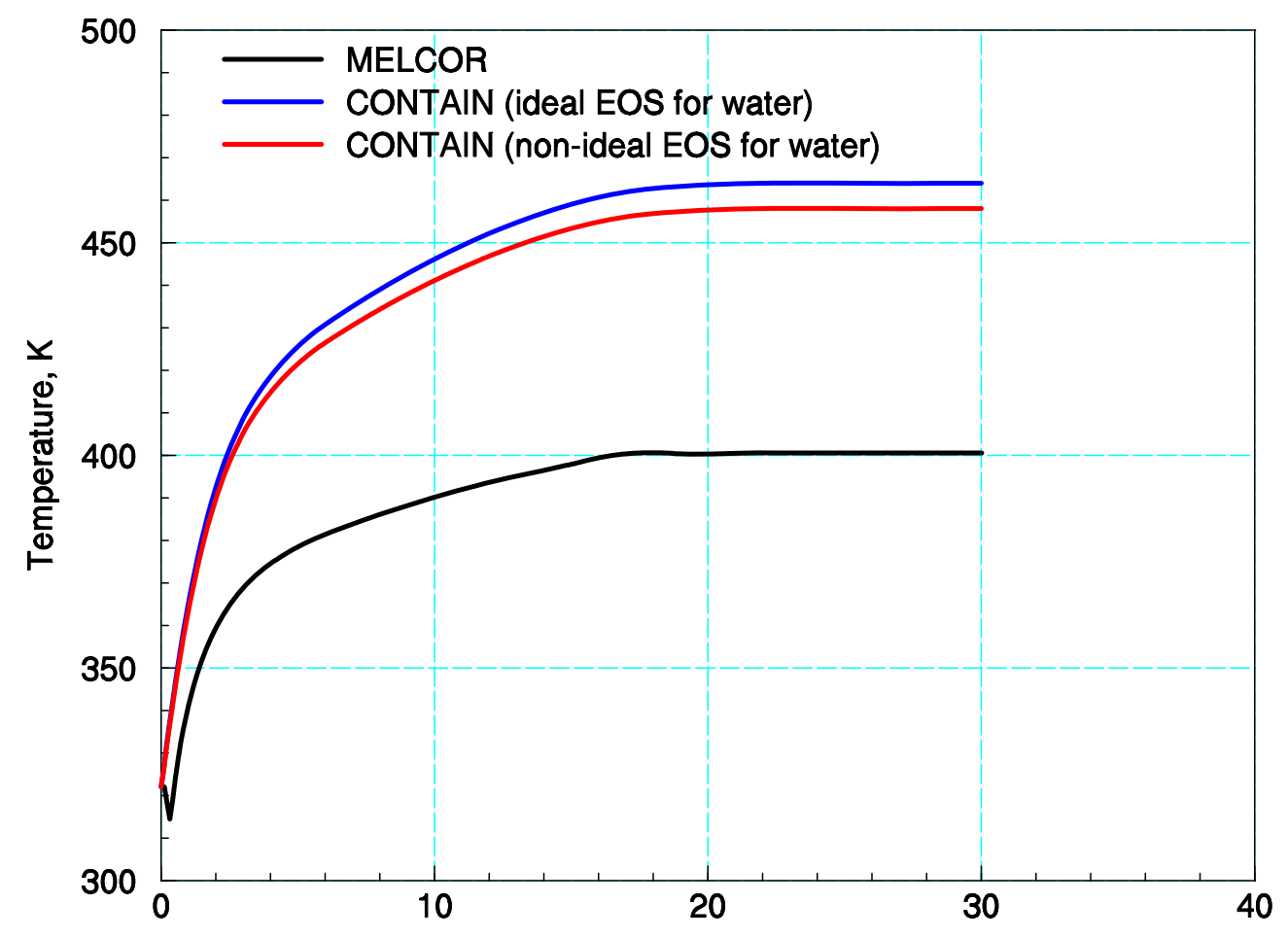

Time, seconds

Figure A-9. Single volume containment gas temperature response for DECLG break using a pressure flash method for treating the two-phase separation, with adiabatic boundary conditions and removal of liquid water to pool region. 


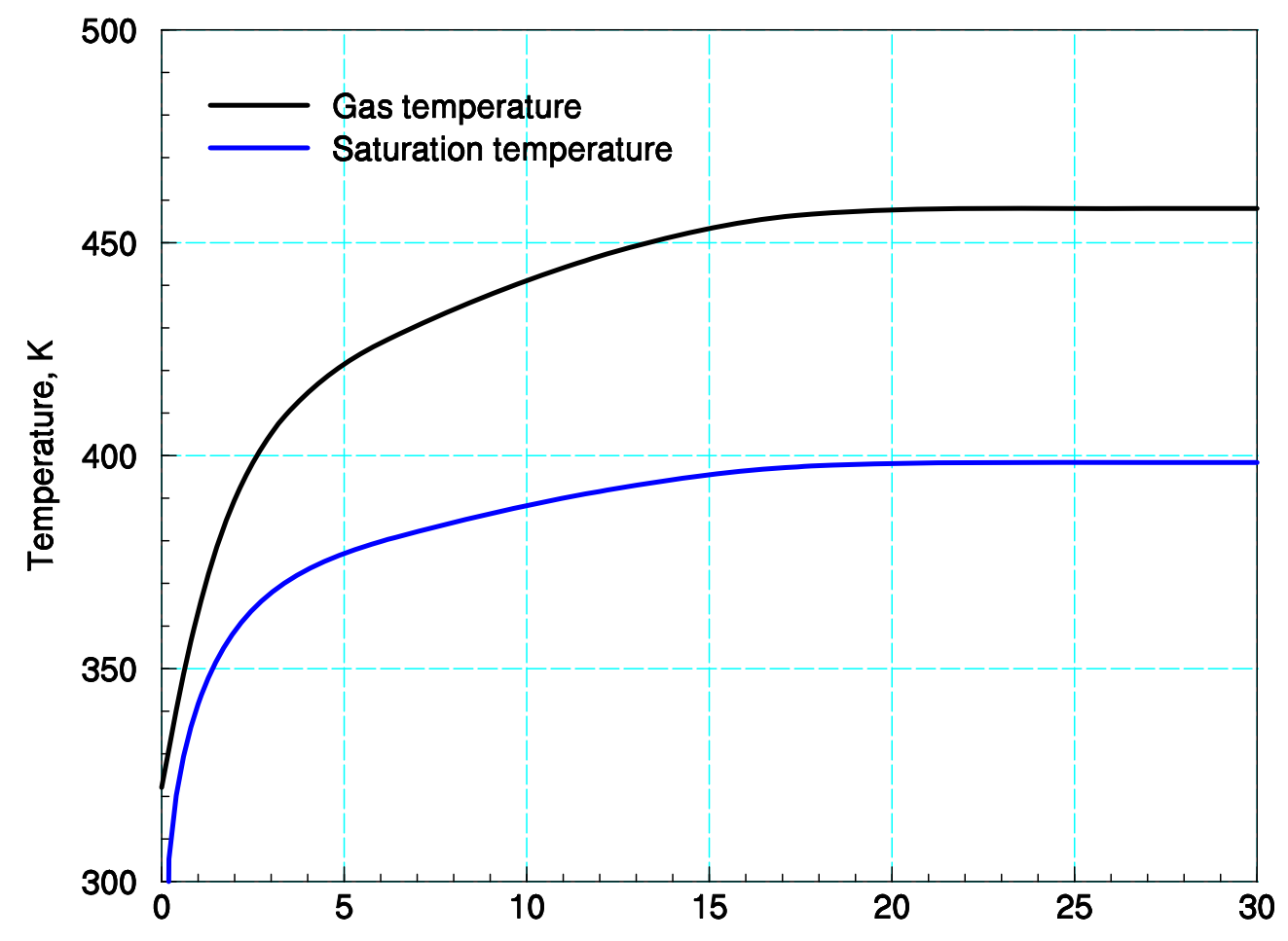

Time, seconds

Figure A-10. Gas and saturation temperature profiles calculated for single volume containment during DECLG blowdown, adiabatic conditions and dropout, by CONTAIN (non-ideal EOS for water) using the pressure flash method for phase separation. 


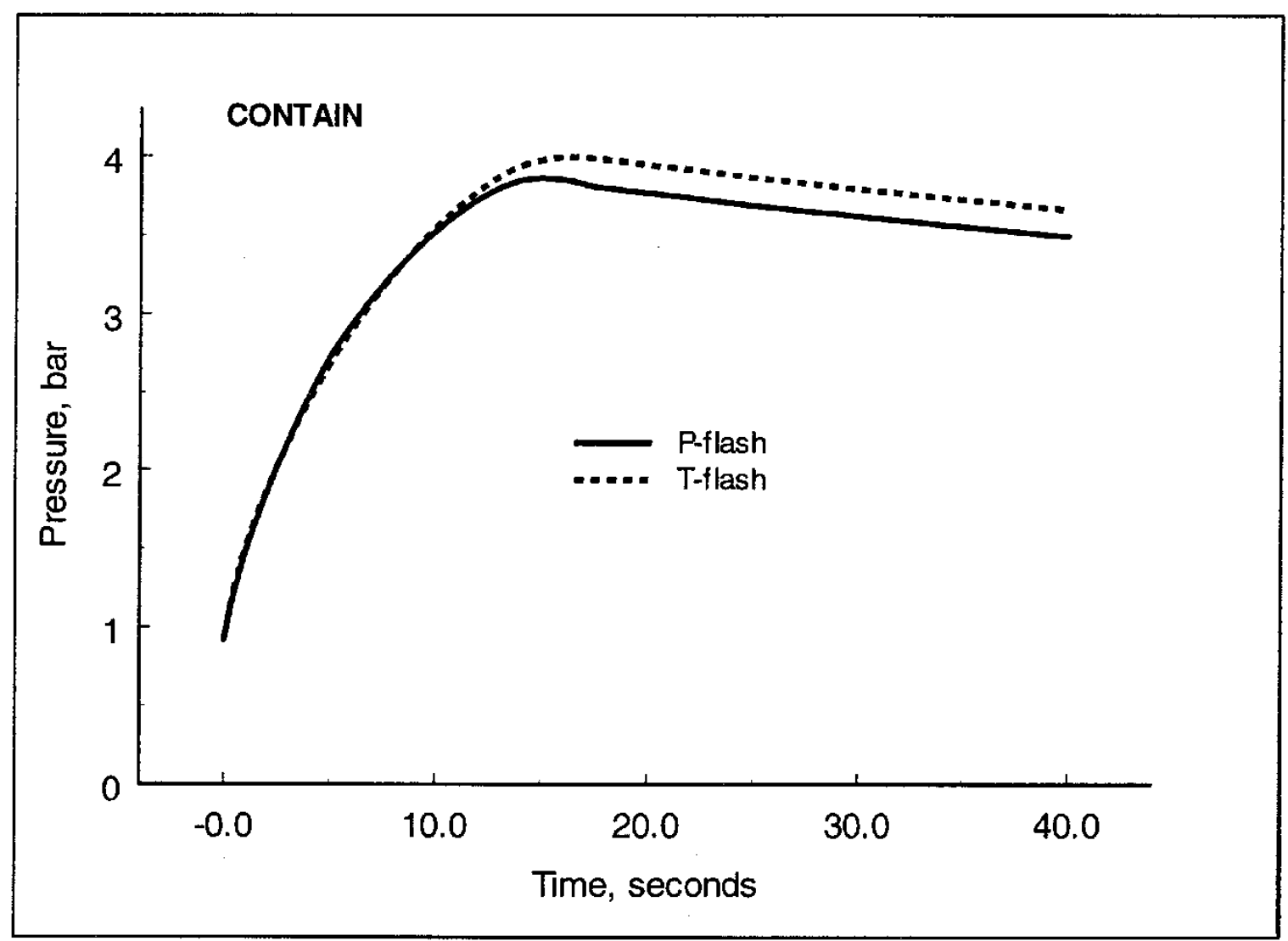

Figure A-11. Comparison of pressure and temperature flash methods for treating the separation of two-phase water injections in the CONTAIN code. The calculations are for a single volume with nonadiabatic boundary conditions and activation of sprays and fan coolers at maximum capacity. Dropout of unflashed water for both calculations is set via keyword DROPOUT in the FLOWS input block. 


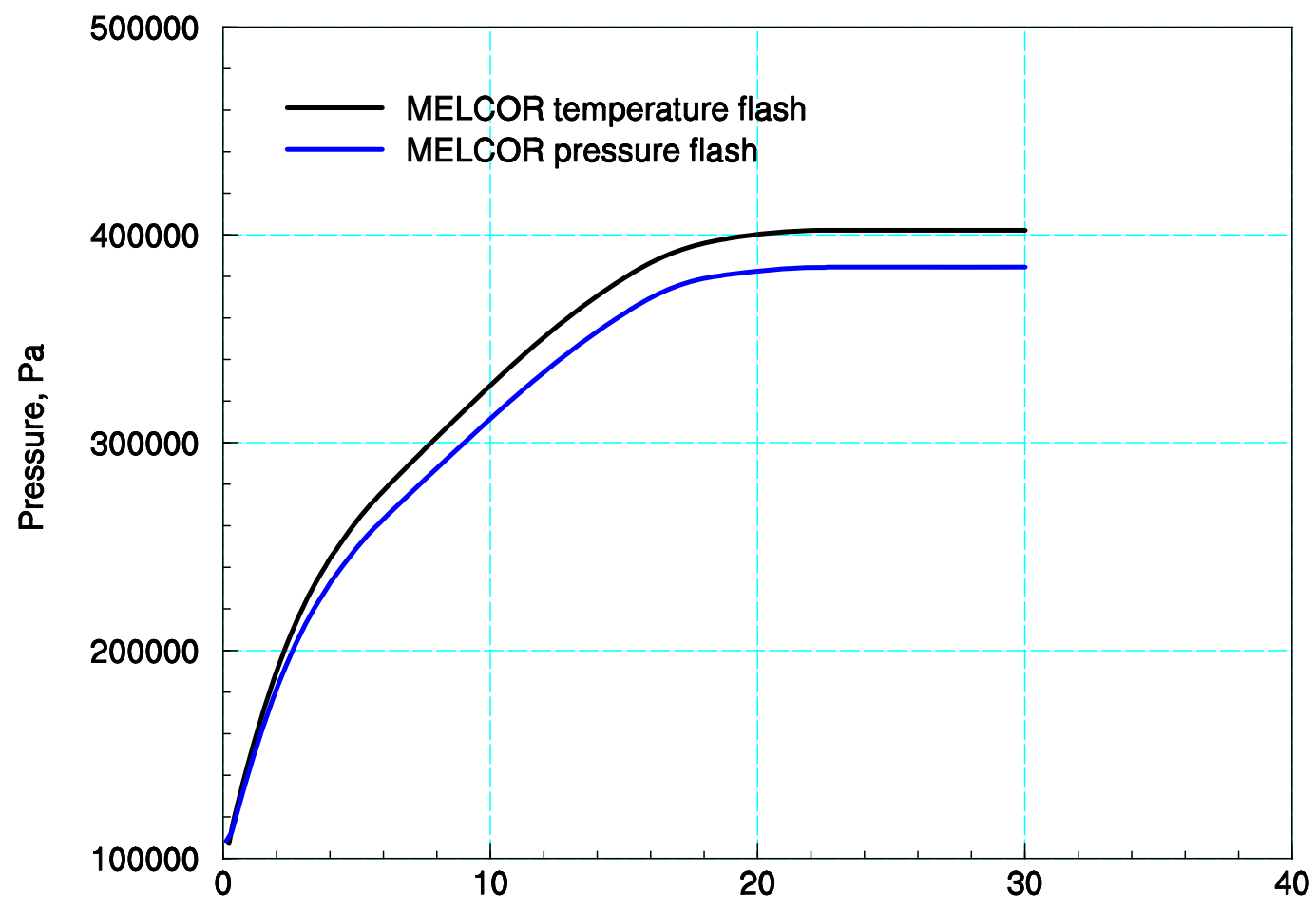

Time, seconds

Figure A-12. Single volume containment gas pressure response for DECLG break using the MELCOR temperature and pressure flash methods for treating the two-phase separation, with adiabatic boundary conditions and removal of liquid water to pool region. 


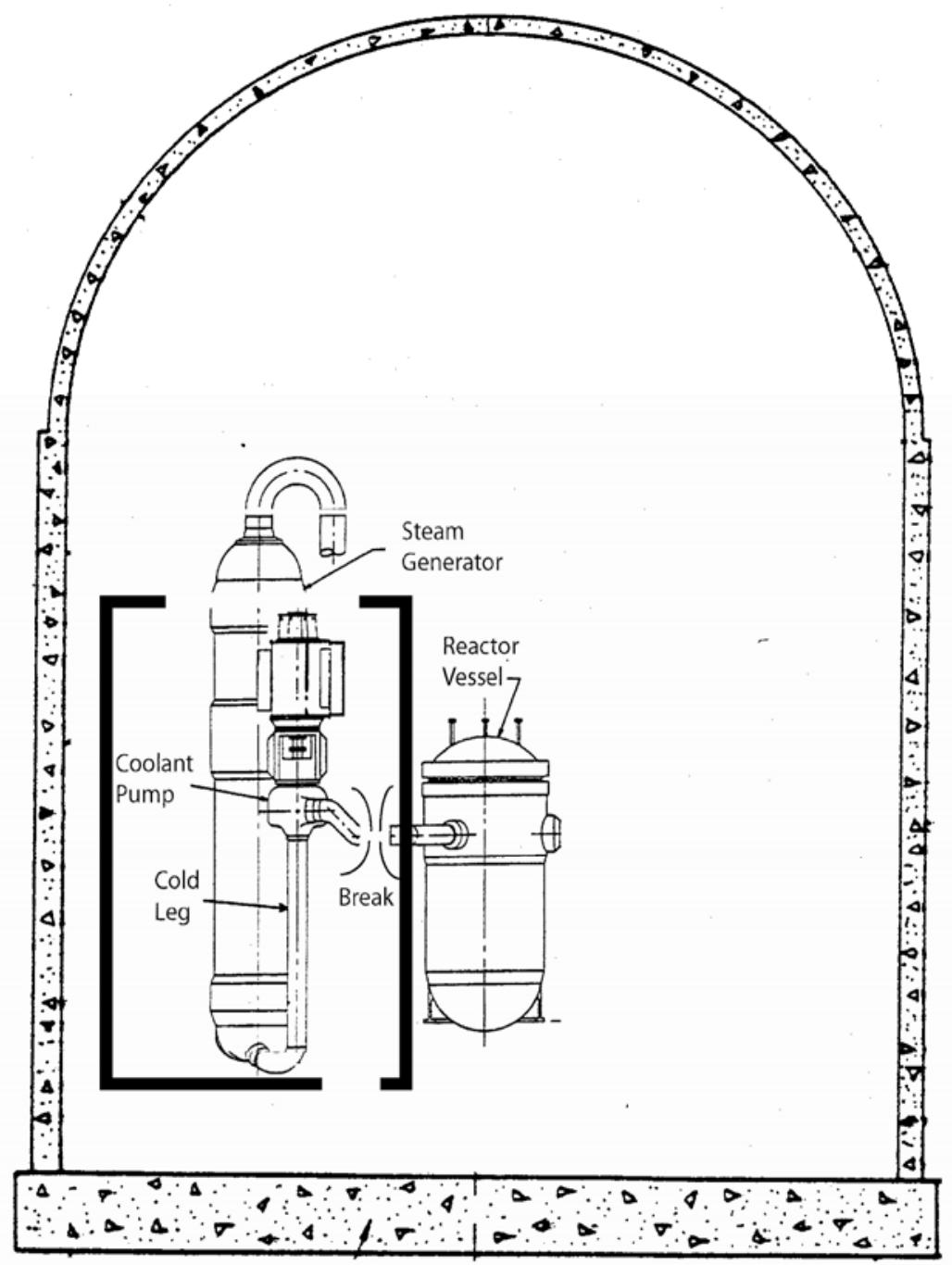

Figure A-13. Sketch of two-volume containment, where the cold leg break is located within the steam generator compartment or break room. The volume outside the break room is included in the containment volume bounded by the containment shell. Two paths leading from the break room are shown: top opening for steam/air exit to containment, and lower opening for the draining of unflashed water to the containment pool region. 


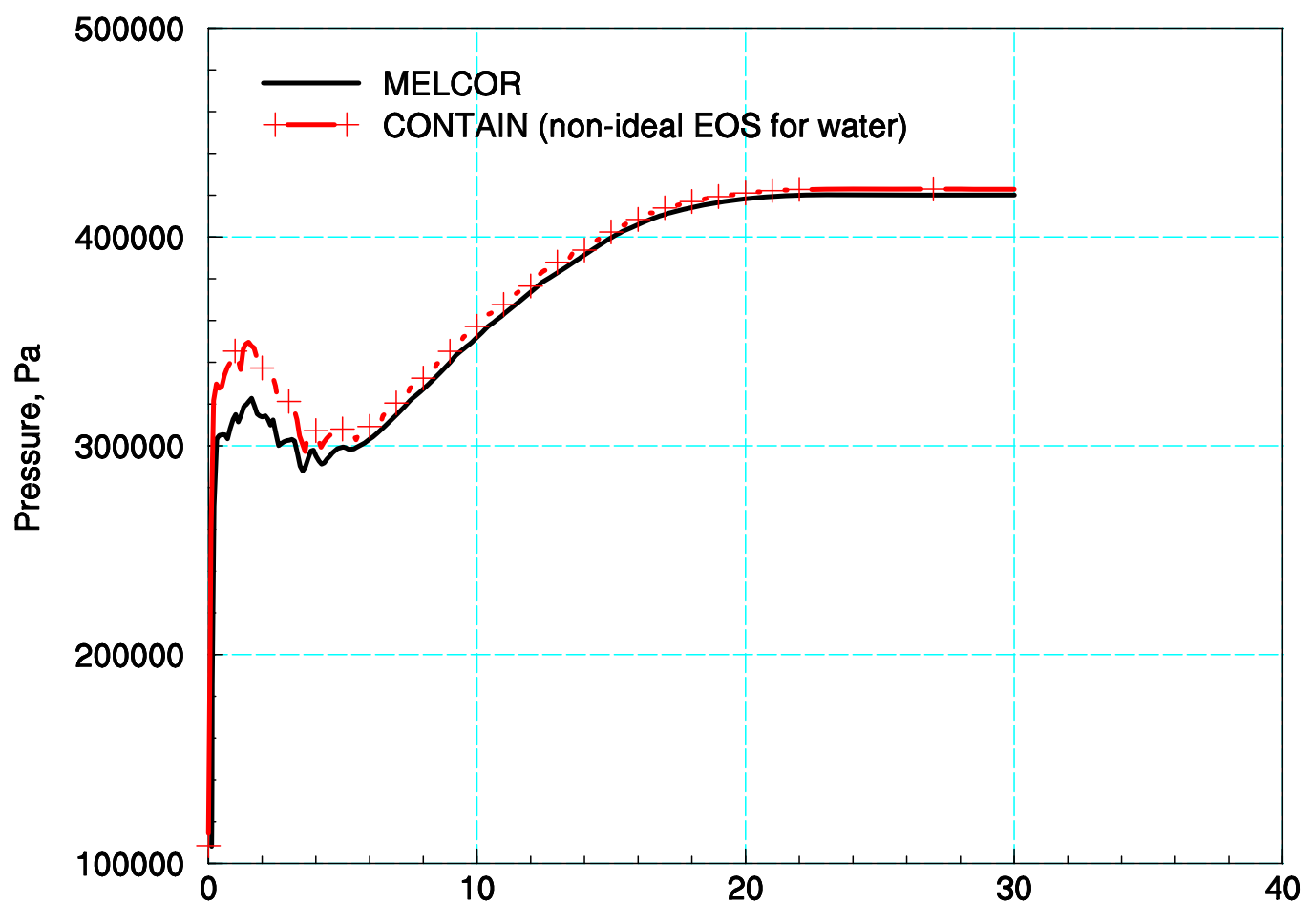

Time, seconds

Figure A-14. Comparison of MELCOR and CONTAIN prediction of break room pressure for DECLG event using a multi-cell nodalization for the break room/containment. The calculations are performed using a temperature flash method to calculate phase separation in the break room. Adiabatic boundary conditions and unflashed water dropout is assumed. 


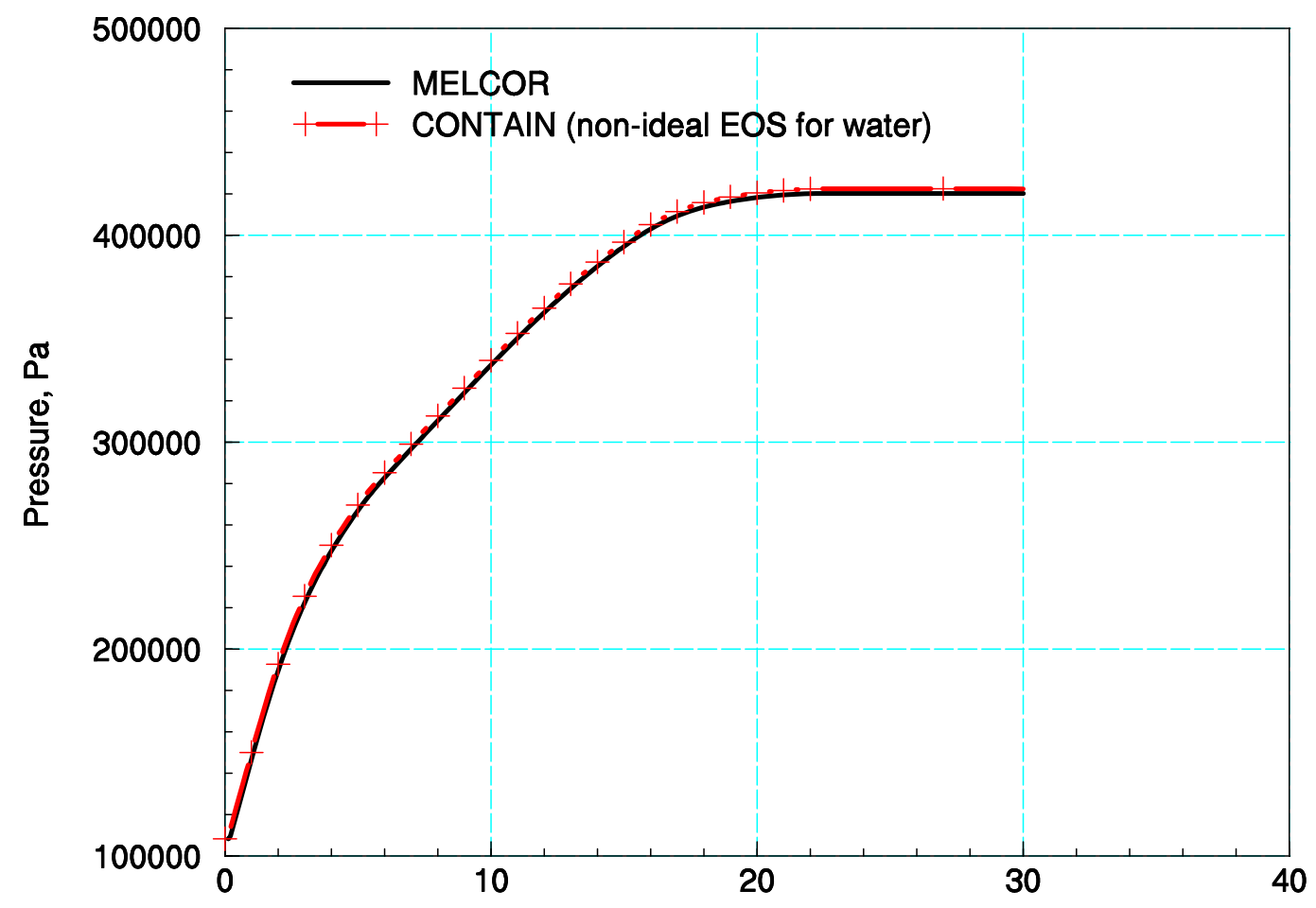

Time, seconds

Figure A-15. Comparison of MELCOR and CONTAIN prediction of containment pressure for DECLG event using a multi-cell nodalization for the break room/containment. The calculations are performed using a temperature flash method to calculate phase separation in the break room. Adiabatic boundary conditions and unflashed water dropout is assumed. 


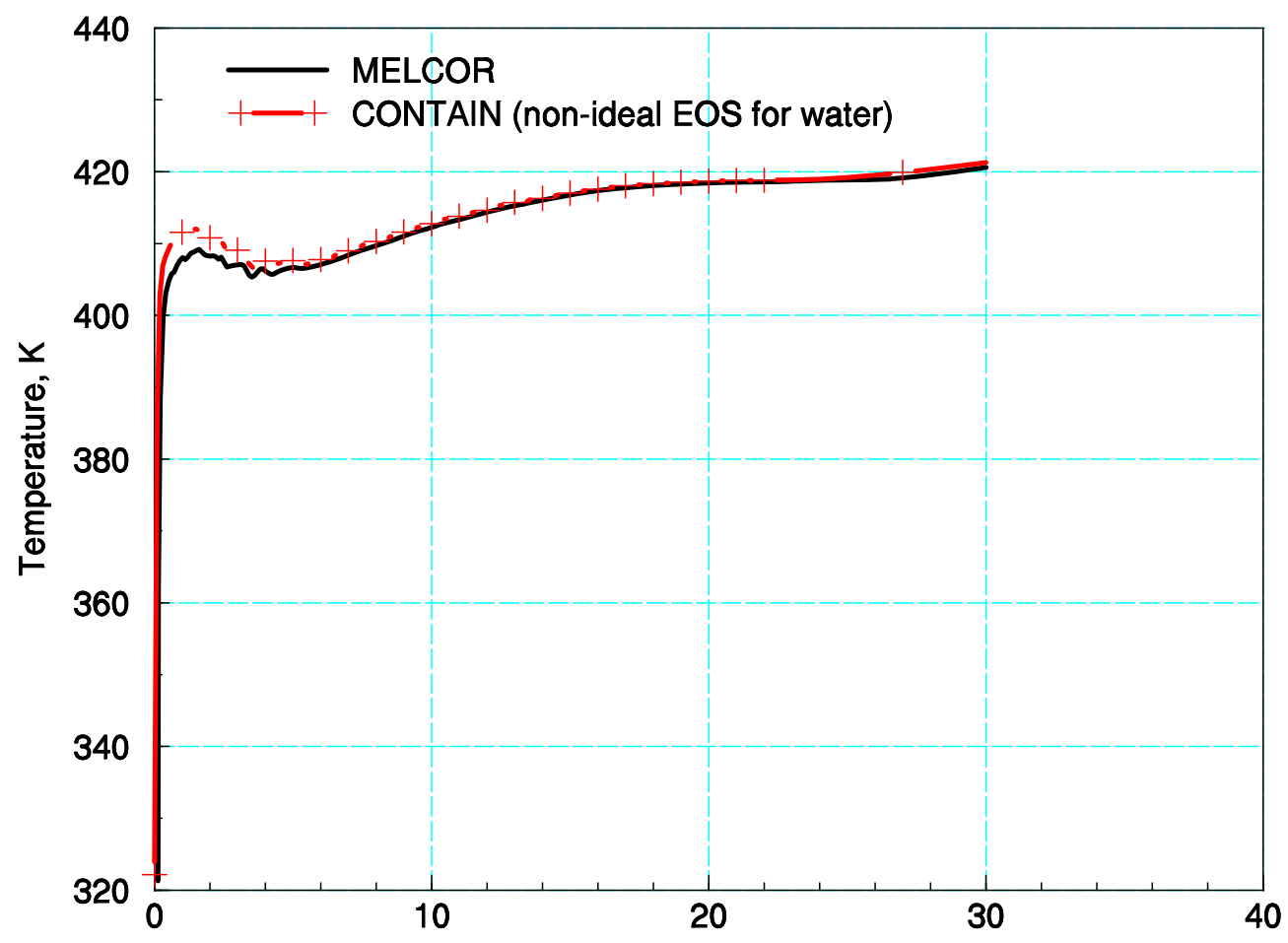

Time, seconds

Figure A-16. Comparison of MELCOR and CONTAIN prediction of break room gas temperature for DECLG event using a multi-cell nodalization for the break room/containment. The calculations are performed using a temperature flash method to calculate phase separation in the break room. Adiabatic boundary conditions and unflashed water dropout is assumed. 


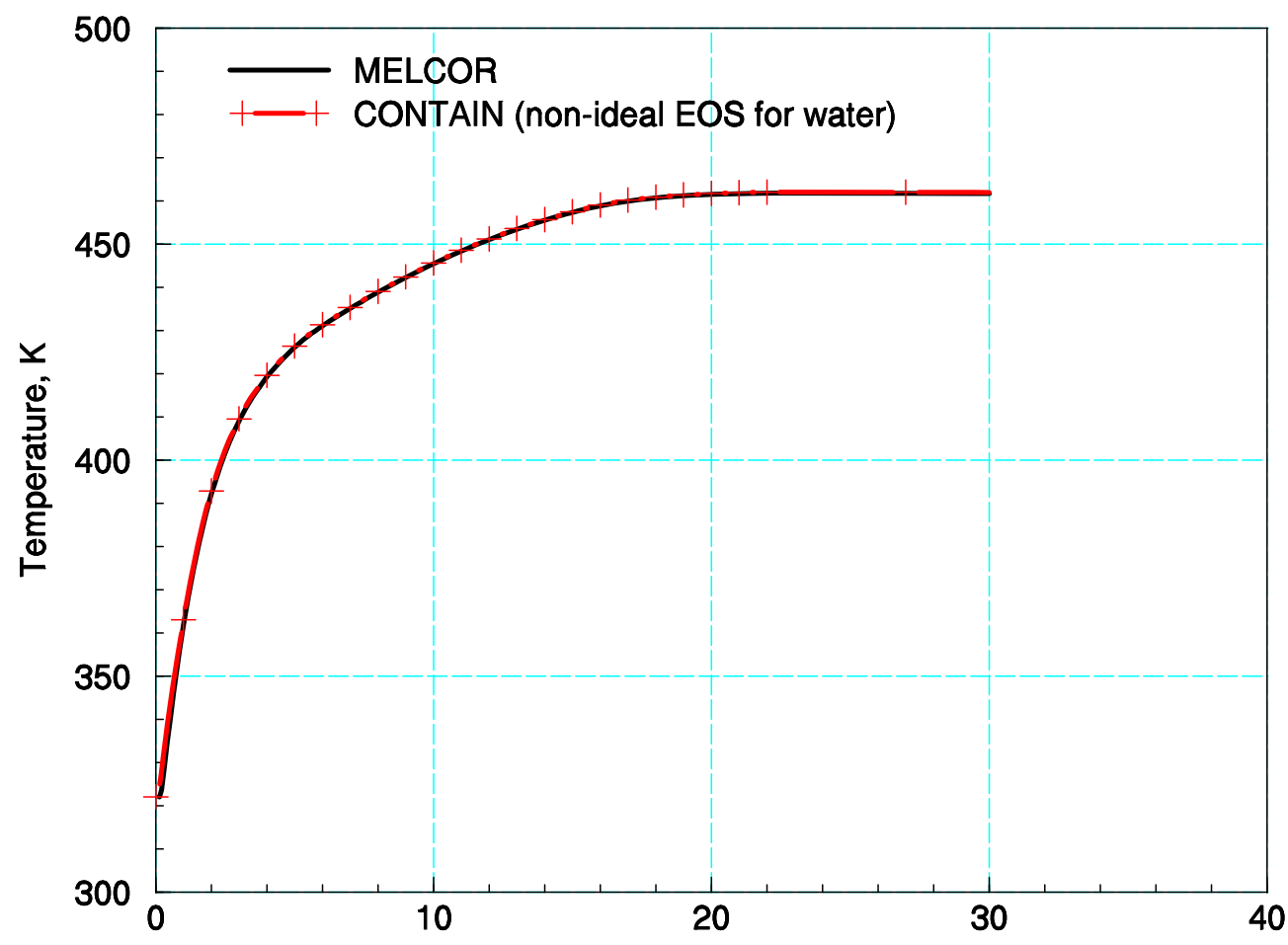

Time, seconds

Figure A-17. Comparison of MELCOR and CONTAIN prediction of containment gas temperature for DECLG event using a multi-cell nodalization for the break room/containment. The calculations are performed using a temperature flash method to calculate phase separation in the break room. Adiabatic boundary conditions and unflashed water dropout is assumed. 


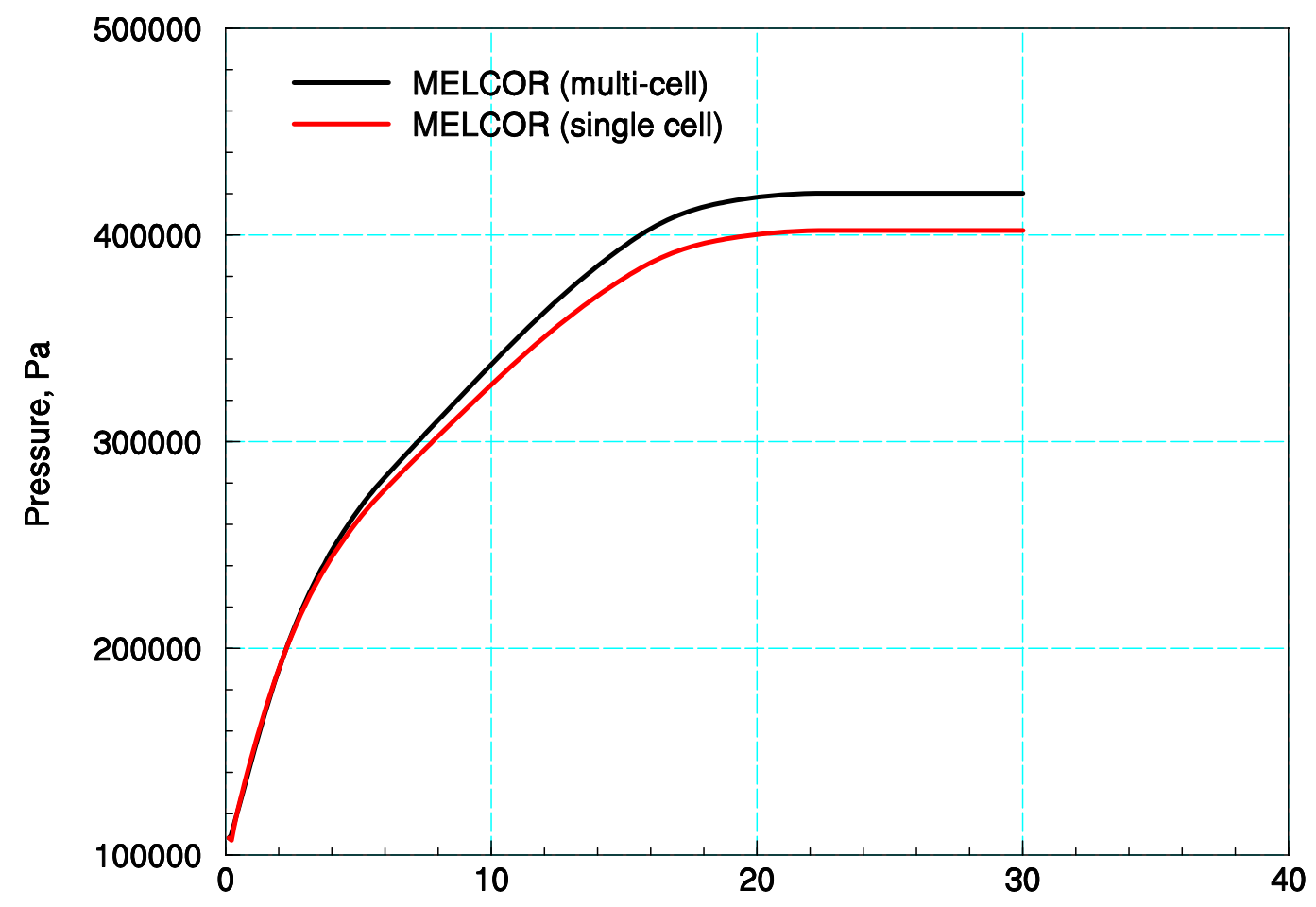

Time, seconds

Figure A-18. Comparison of MELCOR multi-cell and single cell containment pressure response for a DECLG event using the temperature flash method for phase separation. 


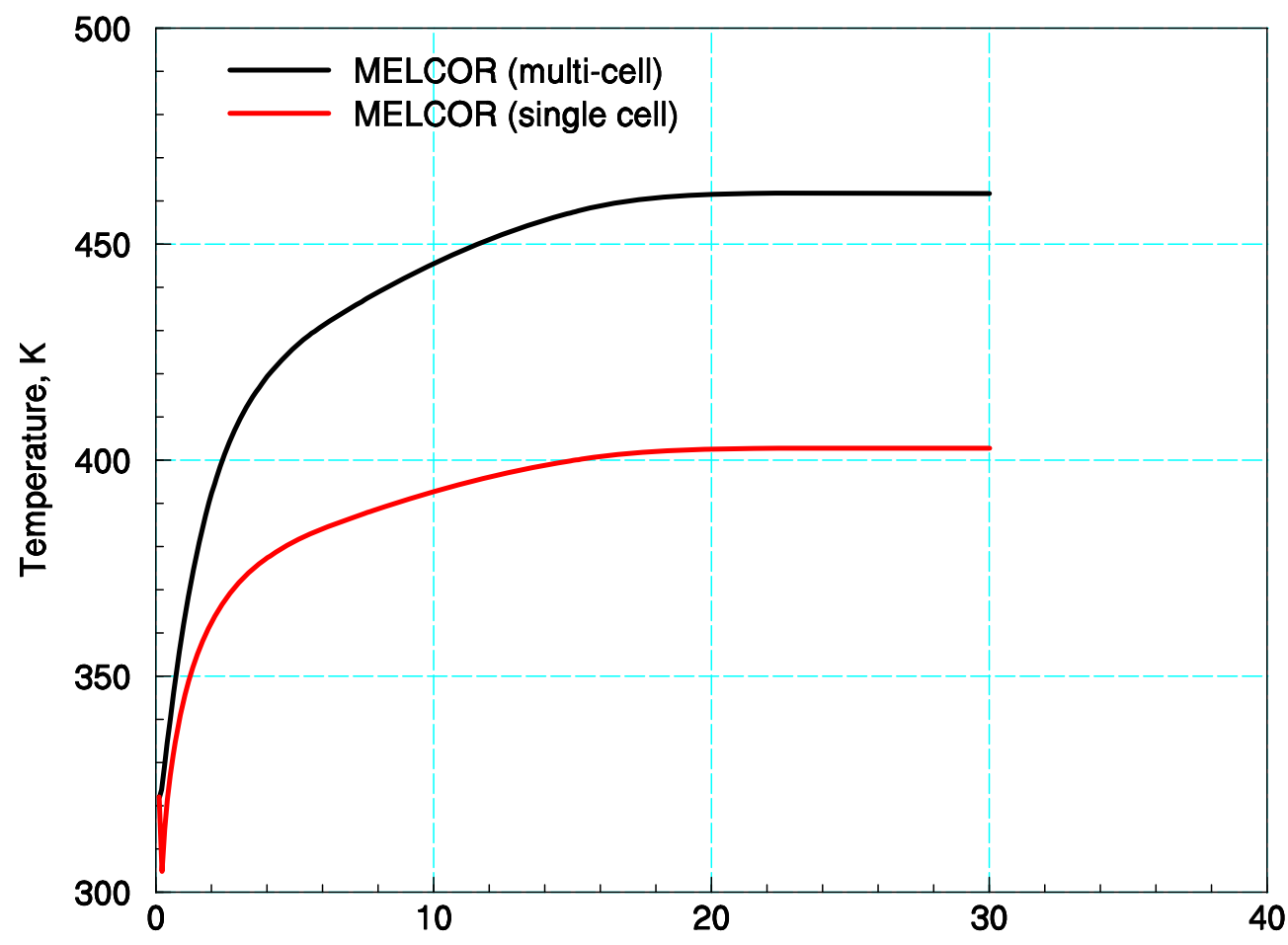

Time, seconds

Figure A-19. Comparison of MELCOR multi-cell and single cell containment gas pressure response for a DECLG event using the temperature flash method for phase separation. 


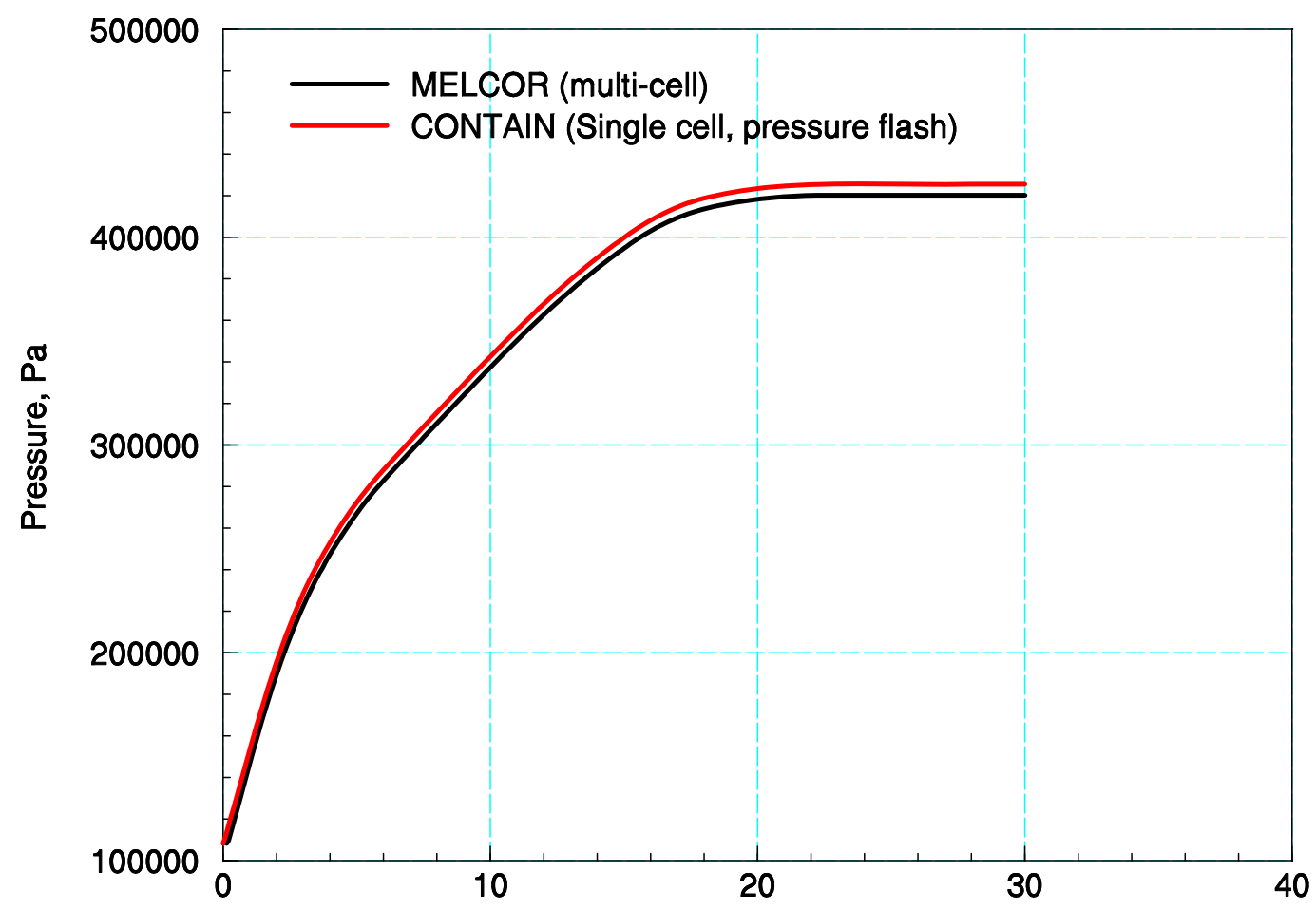

Time, seconds

Figure A-20. Comparison of MELCOR and CONTAIN gas pressure profiles for a DECLG event with adiabatic boundary conditions and dropout of unflashed water. The comparisons show the near identical results obtained using either temperature flash in the MELCOR multi-cell configuration or pressure flash in the CONTAIN single cell configuration. 


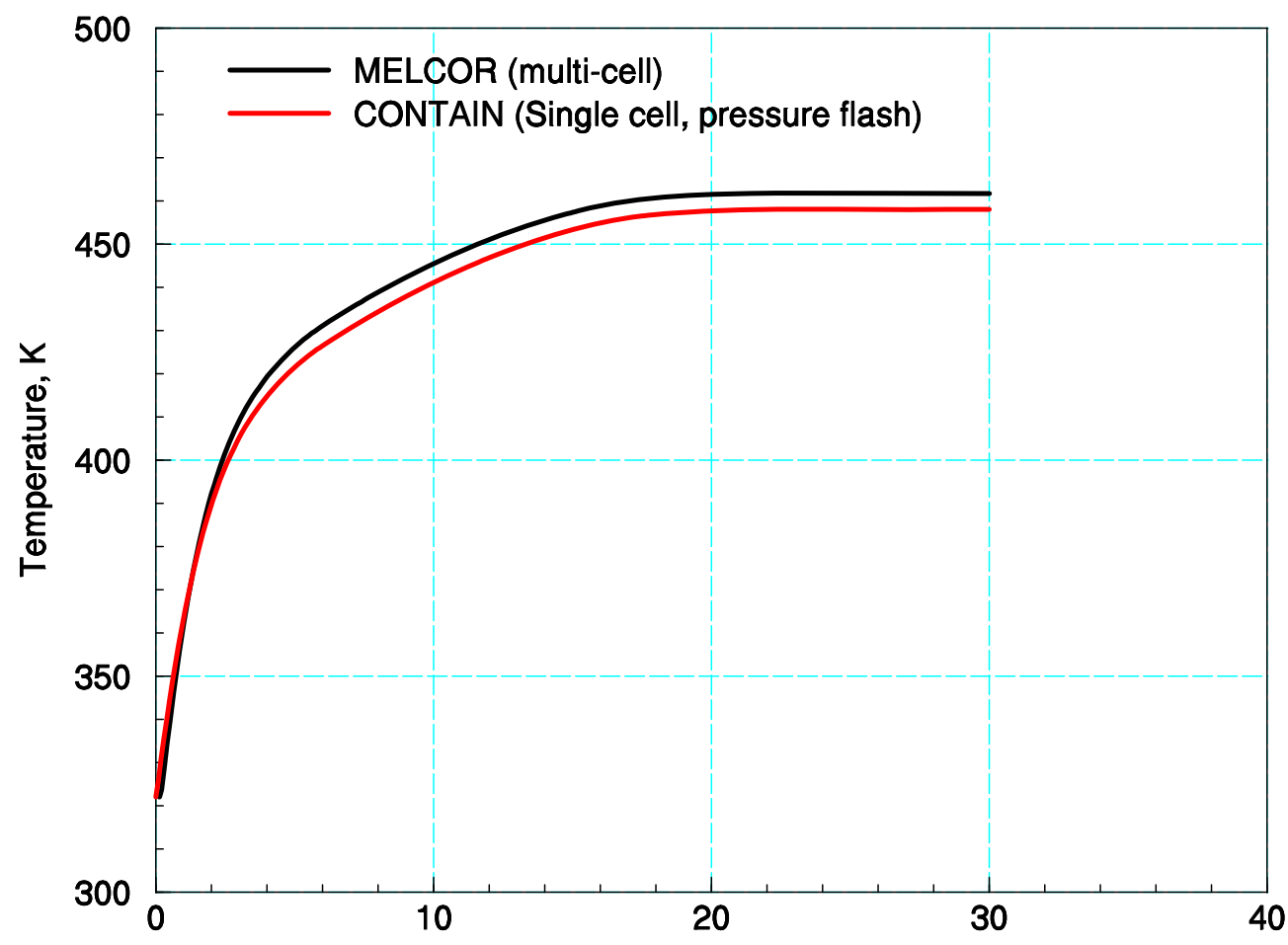

Time, seconds

Figure A-21. Comparison of MELCOR and CONTAIN gas temperature profiles for a DECLG event with adiabatic boundary conditions and dropout of unflashed water. The comparisons show the near identical results obtained using either temperature flash in the MELCOR multi-cell configuration or pressure flash in the CONTAIN single cell configuration. 


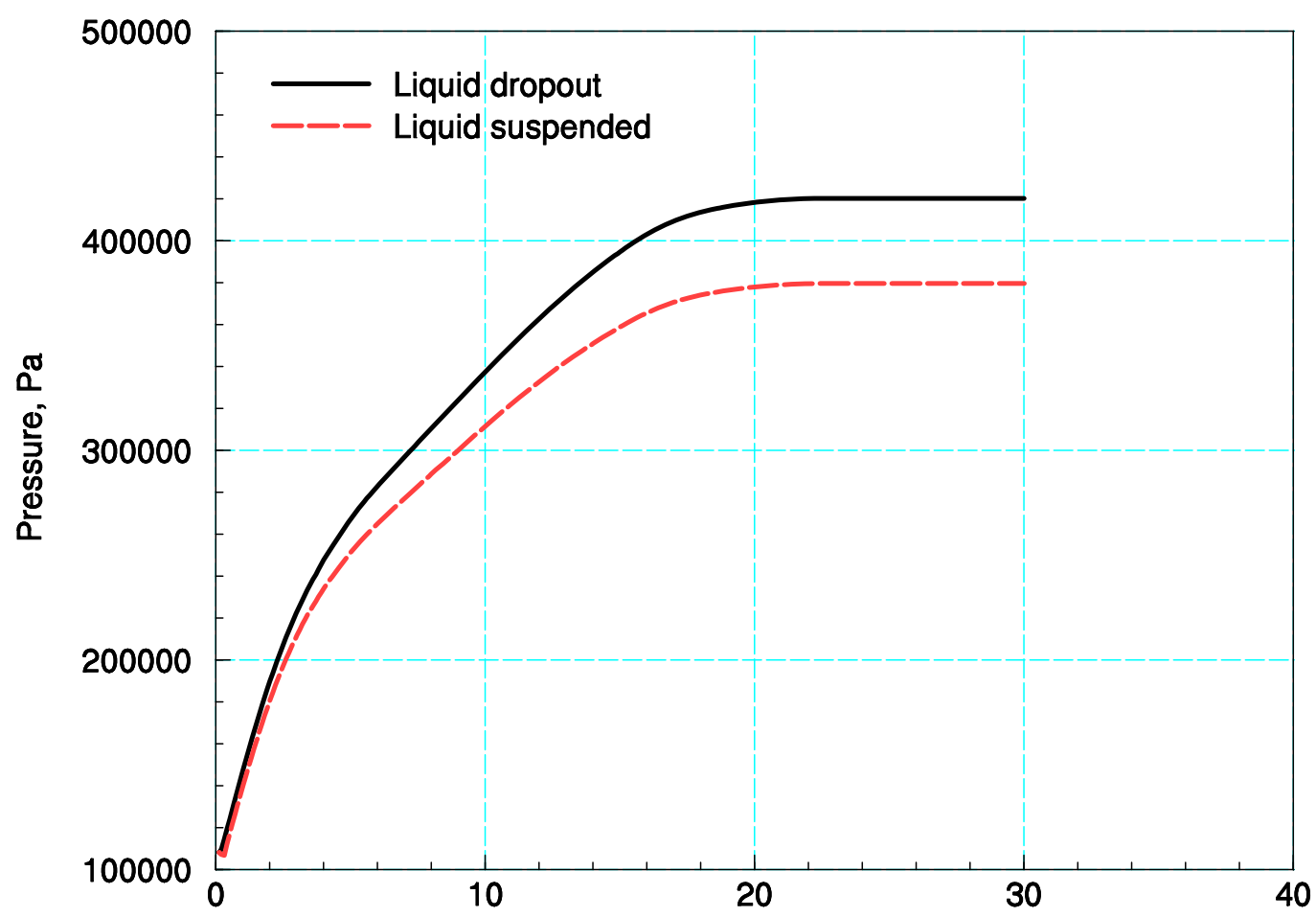

Time, seconds

Figure A-22. Comparison of containment pressure (cell \#1) for a two-cell MELCOR calculation of a DECLG event with adiabatic boundary and temperature flash conditions simulated. 


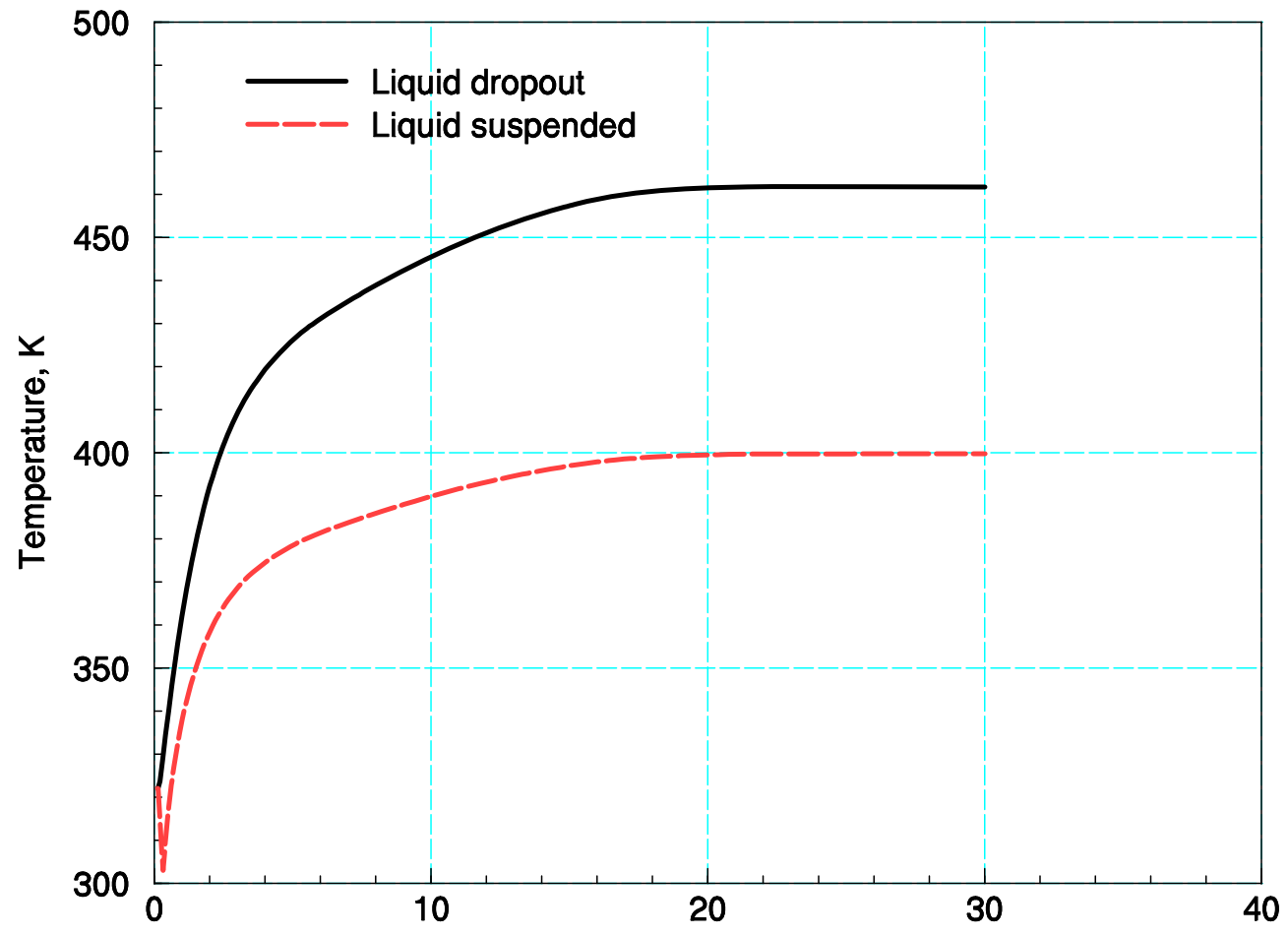

Time, seconds

Figure A-23. Comparison of containment gas temperature for a two-cell MELCOR calculation of a DECLG event with adiabatic boundary and temperature flash conditions simulated. 


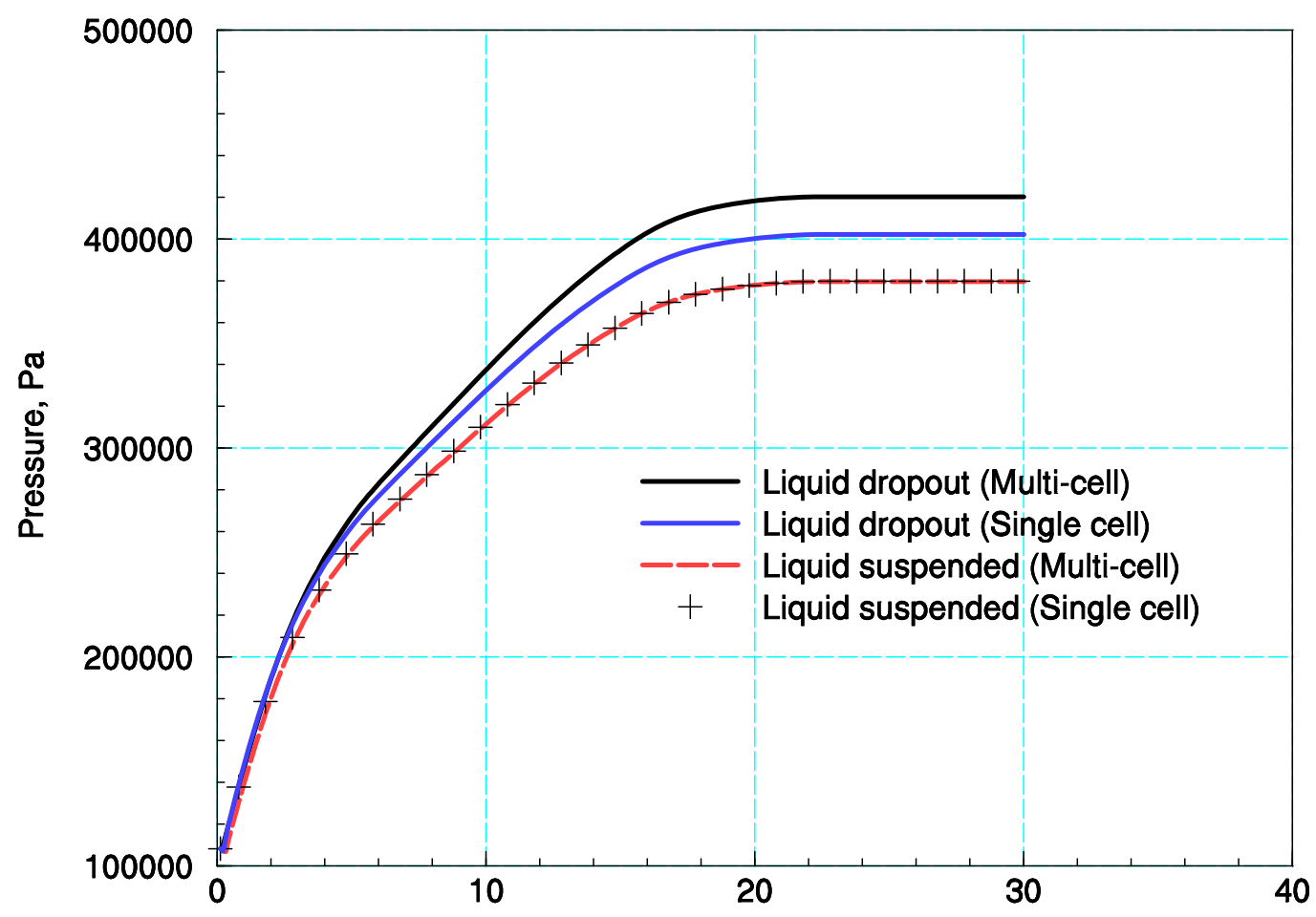

Time, seconds

Figure A-24. Comparison of containment pressure for MELCOR calculation of a DECLG event with adiabatic boundary and temperature flash conditions simulated, showing the affect on pressure due to unflashed liquid water retention in atmosphere and nodalization. 


\section{Appendix B. Modeling Fan Cooler Performance for Design Basis Accident Analysis}

\section{B.1 Introduction}

Active measures that aid in controlling containment gas pressure and temperature during design basis accident (DBA) events include activation of: 1) containment sprays, and 2) the use of fan coolers. Both measures are categorized as being part of the engineered safety features of the plant system. This appendix focuses on the operation of the containment fan coolers during accident events and the modeling approaches for simulating performance as found in various containment analysis codes, most importantly, the MELCOR code. Discussed below, the methods for generating input to fan cooler modeling is addressed and the various assumptions inherent in the models are outlined.

Figure B-1 shows a sketch of a typical fan cooler unit, consisting of banks of coolant tubes (with fins) and a fan unit to force containment air or steam-air flows across the coolant tube bankscross-flow heat exchanger. Units also include a set of inlet filters and outlet moisture separators as part of the design. Unlike containment spray systems, fan cooler units have a dual purpose in that the units are used during both normal operation and accident modes (Table B-1). For normal operation the fan coolers are used to control temperature within the containment, and therefore are operated on demand, as needed, depending on the heat removal requirements to meet operational temperature limits. Under normal conditions, the fan coolers operate as indicated in a high speed mode with a heat removal rate of $\sim 1 \mathrm{MW}$ per unit. In this mode, the heat removal is $100 \%$ sensible heat removal from the containment air. In the accident mode, the fan speed is typically reduced by about 50\%, and the rated performance is ascribed to containment atmospheric conditions approximately at the design limits for the containment. In the case of a typical fan cooler design described in Table B-1, the pressure and temperature design limits for the fan cooler unit are $4.28 \mathrm{e} 5 \mathrm{~Pa}$ and $405.9 \mathrm{~K}$. At this accident mode condition, the rated heat removal is about $24 \mathrm{MW}$, with most of the heat removed as latent heat, i.e., via condensation on the cooling coils. Because the fan coolers are rated in the accident mode for saturated containment atmospheres, the containment temperature is also the saturation temperature and therefore the steam concentration or vapor mole fraction has a one-to-one correspondence with containment temperature; for such a fan cooler unit described here, the accident mode steam mole fraction $X_{\text {vap }}$ is $\sim 0.7$, and the steam mass fraction for inlet steam $\omega_{\text {vap }}$ is $\sim 0.6$. At rated conditions, the steam flow into the fan cooler is $\sim 37 \mathrm{~kg} / \mathrm{s}$. Consequently, the unit has a maximum latent heat transfer capacity of about $80 \mathrm{MW}$, if all the steam entering the unit condenses. Condensing efficiency percentage at rated conditions is, therefore, $\sim 30 \%$.

Fan cooler performance curves are often provided (see Final Safety Accident Reports [FSARs]) to indicate how the fan cooler performs at other-than-rated conditions. For example, for the fan cooler described in Table B-1, the performance curves (heat removal vs. saturation temperature) are shown in Figure B-2 for various inlet coolant temperatures ranging from 305-355 K. Fan cooler models attempt to replicate these sets of performance curves, and in some cases differentiate between sensible and latent heat removal. 


\section{B.2 General Fan Cooler Modeling}

There are three basic approaches used in modeling fan cooler performance: 1) performance curve specification; 2) MARCH code correlation method; and 3) mechanistic models for heat exchanger operation with associated condensation in the primary stream determined using a heat and mass transfer analogy method. The fan cooler modeling for the CONTEMPT code [Har79], serving as a basis for the large dry loss-of-coolant accident (LOCA) and main steam line break (MSLB) events in this report, makes use of the performance curve specification method. In this approach, the heat removal rate versus containment temperature (saturated) is provided by an input table. At a given containment temperature, the heat removal rate is interpolated from the table input and the calculated heat (energy) is removed from the containment atmosphere. For this method, however, only the energy is removed from the atmosphere. Water vapor is assumed to remain in the atmosphere, removed only by bulk condensation as the saturation temperature is lowered. This model trends toward saturation conditions through a non-physical assumption regarding the parsing of heat removal rates (100\% sensible heat removal).

The second approach is the basis for the MELCOR fan cooler model [Gau05a], where the MARCH code correlation for an effective total heat transfer coefficient and transfer area is applied to a changing atmospheric temperature (saturated) during the accident progression. The original MARCH model, as in the performance curve specification, removes energy from the atmosphere only as sensible heat. No condensation within the fan cooler occurs; therefore, local draining of condensate is not modeled. For the MELCOR model, the MARCH correlations are modified to approximately estimate both sensible and latent heat removal amounts. This is accomplished by assuming that the ratio of sensible-to-total heat removal is, in turn, given by the ratio of the sensible (air) and total heat transfer coefficients (steam-air), as determined from the MARCH fan cooler heat transfer correlations. The sensible heat transfer coefficient is approximated using the MARCH heat transfer correlation at pure air conditions. With appropriate scaling factors, the amount of sensible-to-latent heat removal can be adjusted. The method is parametric and can be useful for establishing sensitivity trends related to sensible-tolatent heat removal ratios.

The third approach relies on a physical or mechanistic modeling of the heat and mass transfer process occurring within the fan cooler itself. In this modeling procedure, as used in the CONTAIN code [Mur97], the empirical correlations for heat transfer coefficients experimentally derived for air flow across rows of finned cooling coils are implemented in a heat and mass transfer analogy approach to determine both sensible and latent heat transfer rates from the inlet forced steam-air flow to the fin surfaces on the fan cooler tubes. Because the outlet conditions for coolant temperature, gas temperature, and steam concentration are unknown, the modeling method is iterative and in some cases convergence can be an issue.

\section{B.3 MELCOR Fan Cooler Model Input}

The MELCOR fan cooler model is described in the MELCOR reference manual [Gau05a], FCL package. Input to the fan cooler model package is outlined in the MELCOR user manual [Gau05b]. ${ }^{14}$ Inputs describing the fan cooler performance are:

\footnotetext{
${ }^{14}$ The fan cooler example included in the MELCOR user manual does follow the procedure recommended here (as the inlet parameters are not selected in a consistent manner) and does represent rated conditions for operation in an accident mode.
} 
Rated fan cooler gas volumetric flow rate, $\mathrm{m}^{3} / \mathrm{s}$

Rated fan cooler secondary coolant mass flow rate, $\mathrm{kg} / \mathrm{s}$

Rated fan cooler secondary coolant inlet temperature, $\mathrm{K}$

Rated fan cooler inlet gas temperature, $\mathrm{K}$

Rated fan cooler capacity, W

Steam mole fraction at rated conditions, dimensionless

From these inputs, the effective heat transfer area for the fan cooler $A_{\text {eff }}$ is determined, and then applied in a set of equations for total, sensible, and latent heat removal rates. The key to an appropriate set of inputs is the consistency with which the rated values above are defined. Because fan cooler performance is typically described in terms of both normal and accident modes, it is important that rated inputs correspond to a set of accident mode parameters for use with DBA scenarios. This means, in the case of the typical fan cooler described in Table B-1, the rated inputs in the accident mode are:

$\begin{array}{ll}\text { Gas volumetric flow rate } & =22.18 \\ \text { Coolant mass flow rate } & =125 \\ \text { Coolant inlet temperature } & =324.8 \\ \text { Inlet gas temperature } & =405.9 \\ \text { Capacity } & =2.37 \mathrm{e} 7 \\ \text { Steam mole fraction } & =0.7\end{array}$

Figure B-3 shows the example performance curves generated with the MELCOR fan cooler model compared to an actual performance curve extracted from a plant FSAR. MELCOR calculated performance is presented for input rated capacities of 23.7 and $21 \mathrm{MW}$. The lower capacity rating is observed to represent a good fit to the actual fan cooler performance curve ${ }^{15}$ at the specified coolant inlet temperature of $325 \mathrm{~K}$.

The ratio of sensible-to-total heat removal is determined from a ratio of the sensible-to-total heat transfer coefficient for the fan cooler, as derived from the MARCH fan cooler heat transfer correlation. Because this ratio is not based on a physical model, the ratio may not be representative of the ratio modeled. Consequently, a sensible heat removal multiplier is included in the model, and this multiplier can be set using a sensitivity coefficient input parameter [9001(2)]. The default value for this multiplier is unity. For the fan cooler performance calculations (including the calculations for the effective heat transfer area $A_{\text {eff }}$ at rated conditions) the multiplier $F_{H}$ is changed from 1 to 0.15 . Figure B-4 shows the MELCORestimated sensible-to-total heat removal percentages for the default and changed multiplier. A reasonable estimate for sensible to total heat removal can be derived from a heat and mass transfer analogy (HMTA) for the rated atmospheric conditions and corresponding total heat transfer coefficient. Using the HMTA method, the sensible-to-total heat removal percentage at rated conditions is $\sim 1.7$, which is $\sim 7 \%$ of the default value given in Figure B-4 at the rated vapor mole fraction of 0.7 . We assume some uncertainty in this estimate, and set the ratio at $15 \%$ of default value for the plant demonstration calculations presented in the report.

\footnotetext{
${ }^{15}$ The fan performance curves are analytically derived curves based on the fan cooler supplier's heat and mass transfer calculations. The curves do not represent performance at tested conditions.
} 


\section{B.4 References}

Gau05a Gauntt, R.O., et al., "MELCOR Computer Code Manuals - Vol.2: Reference Manuals, Version 1.8.6 September 2005,” NUREG/CR-6119, Vol. 2 Rev 3, SAND 2005-5713, Sandia National Laboratories, Albuquerque, New Mexico, September 2005.

Gau05b Gauntt, R.O., et al., "MELCOR Computer Code Manuals - Vol.1: Primer and User’s Guide, Version 1.8.6 September 2005,” NUREG/CR-6119, Vol. 1 Rev 3, SAND 20055713, Sandia National Laboratories, Albuquerque, New Mexico, September 2005.

Har79 Hargroves, D.W., et al., “CONTEMPT-LT/028 - A Computer Program for Predicting Containment Pressure -- Temperature Response to a Loss-of-Coolant Accident,” NUREG/CR-0255, TREE-1279, R4, Idaho National Engineering Laboratory, Idaho Falls, Idaho, March 1979.

Mur97 Murata, K. K., et al., "Code Manual for CONTAIN 2.0: A Computer Code for Nuclear Reactor Containment Analysis,” NUREG/CR-6533, SAND-1735, Sandia National Laboratories, Albuquerque, NM, December 1997. 
Table B-1. Typical fan cooler design parameters for normal and accident mode operation.

\begin{tabular}{|l|l|l|}
\hline \multicolumn{1}{|c|}{ Description } & Normal Operation & Accident Mode \\
\hline Speed, rpm & 1200 & 600 \\
\hline Horsepower & 300 & 100 \\
\hline Heat removal, $\mathrm{W}$ & $9.2 \mathrm{e} 5$ & $23.7 \mathrm{e} 6$ \\
\hline Steam-air flow, $\mathrm{m}^{3} / \mathrm{s}$ & 51.91 & 22.18 \\
\hline Steam-air inlet temperature, $\mathrm{K}$ & 322 & 405.9 \\
\hline Steam-air outlet temperature, $\mathrm{K}$ & 307 & 404.8 \\
\hline Total pressure, $\mathrm{Pa}$ & $1.035 \mathrm{e} 5$ & $4.28 \mathrm{e} 5$ \\
\hline Air density, $\mathrm{kg} / \mathrm{m}^{3}$ & 1.1 & 1.1 \\
\hline Steam density, $\mathrm{kg} / \mathrm{m}^{3}$ & 0. & 1.72 \\
\hline Cooling water flow, kg/s & 126 & 125 \\
\hline Cooling water inlet temperature, $\mathrm{K}$ & 305.4 & 324.8 \\
\hline Cooling water outlet temperature, $\mathrm{K}$ & 307.6 & 373.15 \\
\hline
\end{tabular}




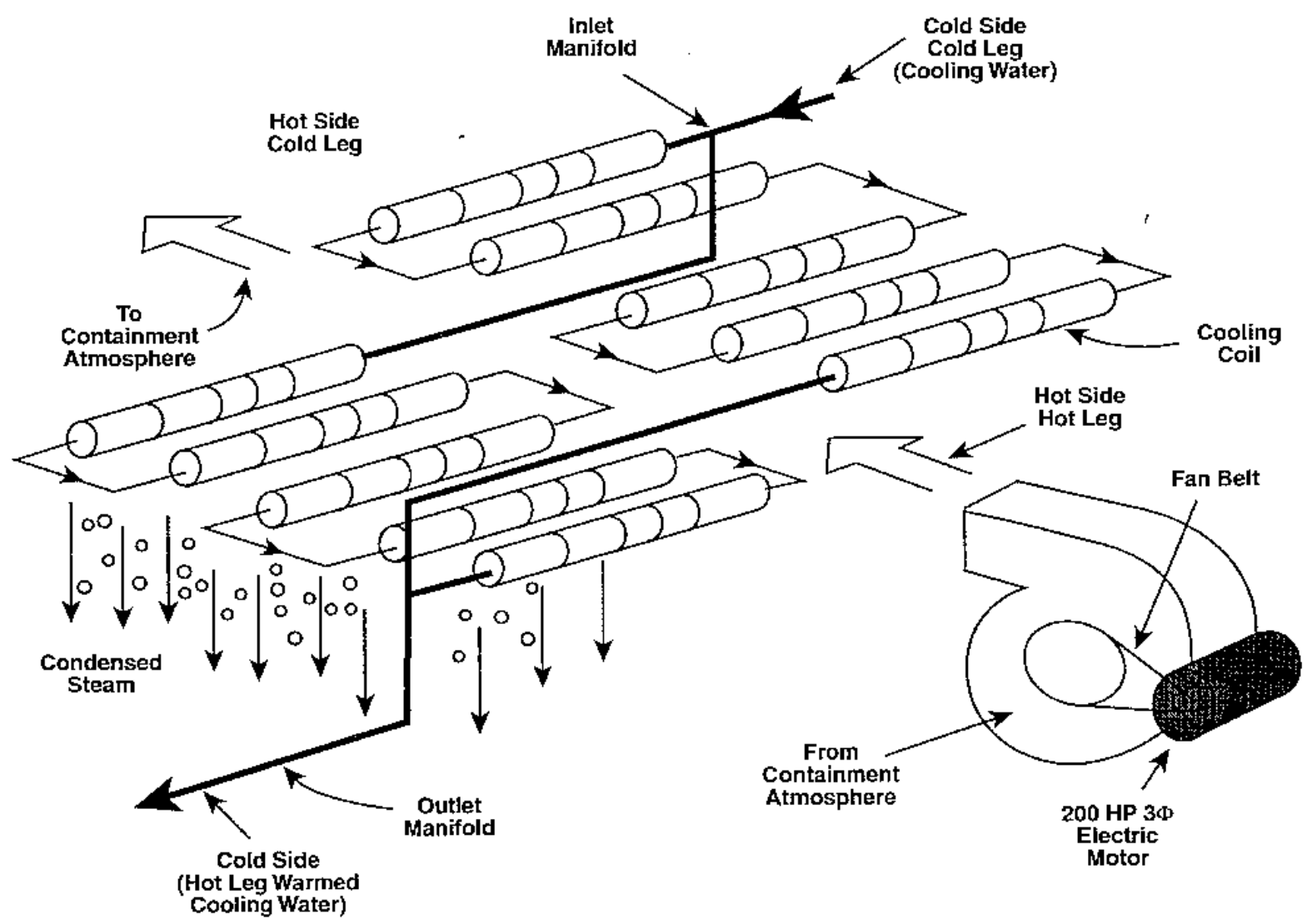

Figure B-1. Sketch of a typical fan cooler unit. 


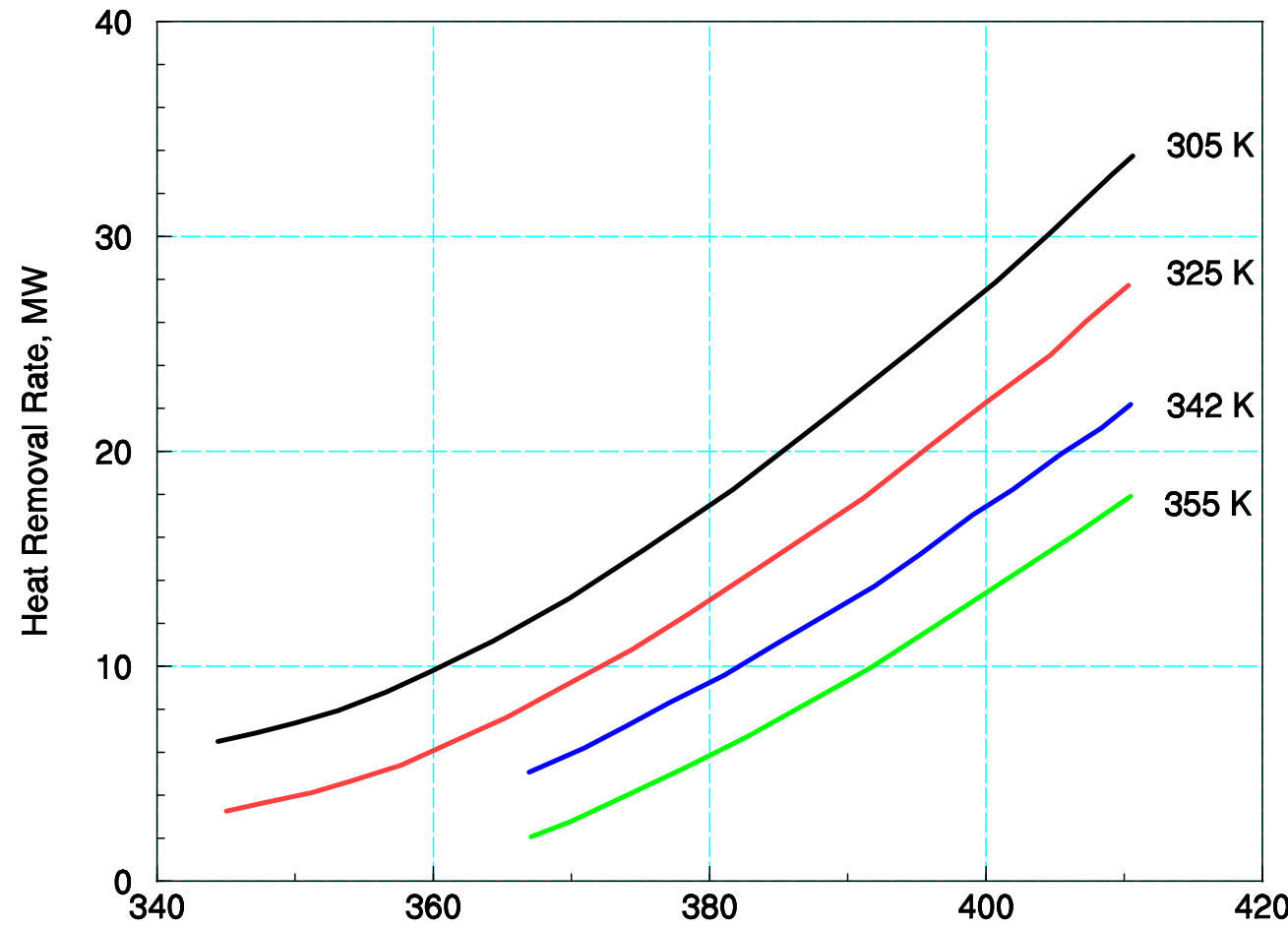

Containment Temperature, $\mathrm{K}$

Figure B-2. Typical fan cooler performance curves as a function of coolant (secondary) inlet temperature. (Note: Containment temperature is the saturation temperature-dry conditions are assumed at the initial air pressure and gas temperature of $1.0135 \mathrm{e} 5 \mathrm{~Pa}$ and $311 \mathrm{~K}$.) 


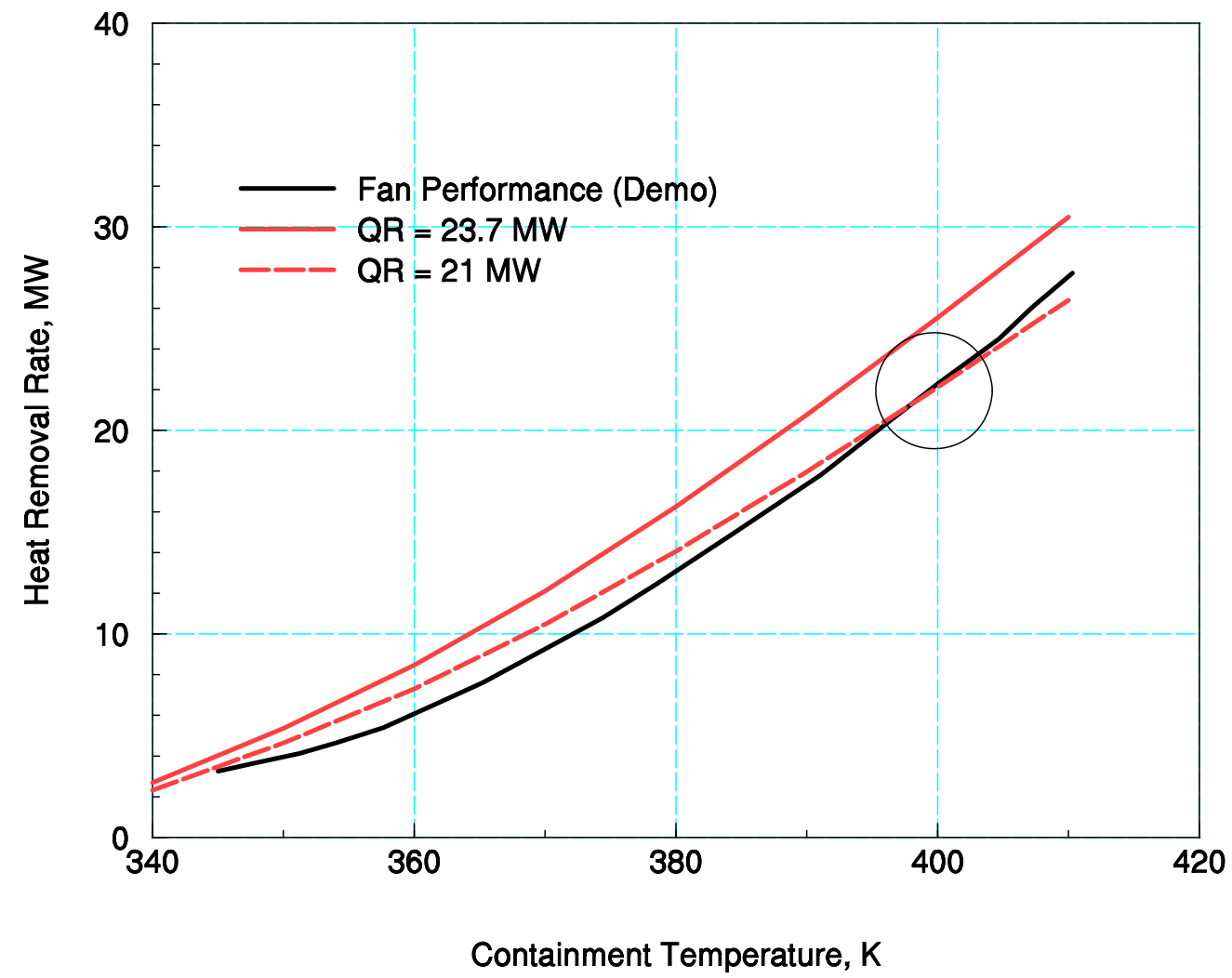

Figure B-3. MELCOR-calculated fan cooler total heat removal for rated heat removal rates of 21 and $23.7 \mathrm{MW}$. Inlet coolant temperature is $325 \mathrm{~K}$, and sensible heat transfer multiplier $F_{H}$ is set equal to 0.15 . 


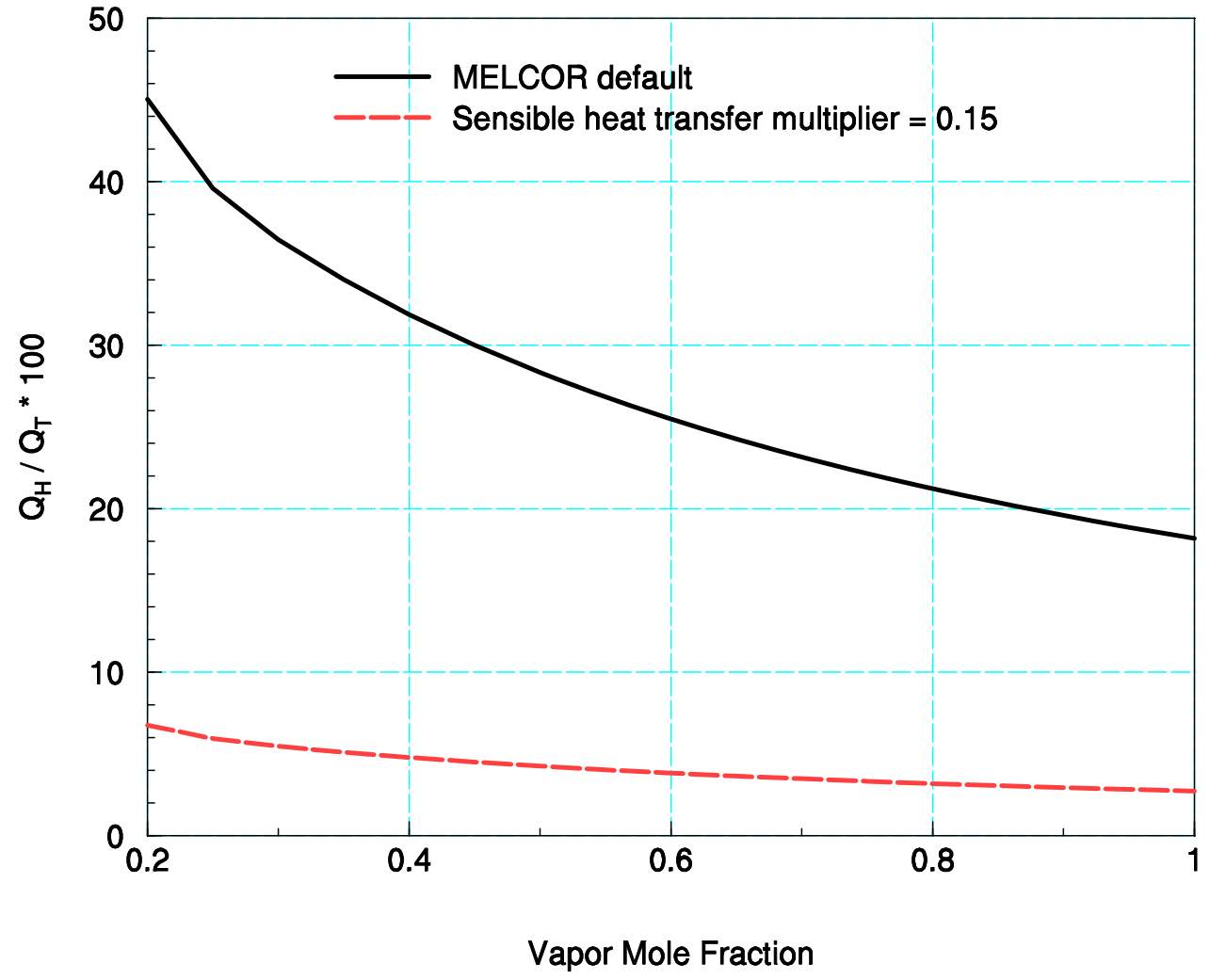

Figure B-4. MELCOR-calculated sensible-to-total heat removal ratio for variations in the sensible heat removal multiplier. A multiplier $F_{H}$ of 0.15 is used throughout the report for the fan cooler model input. 


\section{Appendix C. LOCA CONTAIN and MELCOR Input Files Used for PWR Large Dry Containment Calculations}

\section{C.1 CONTAIN LOCA Input File}

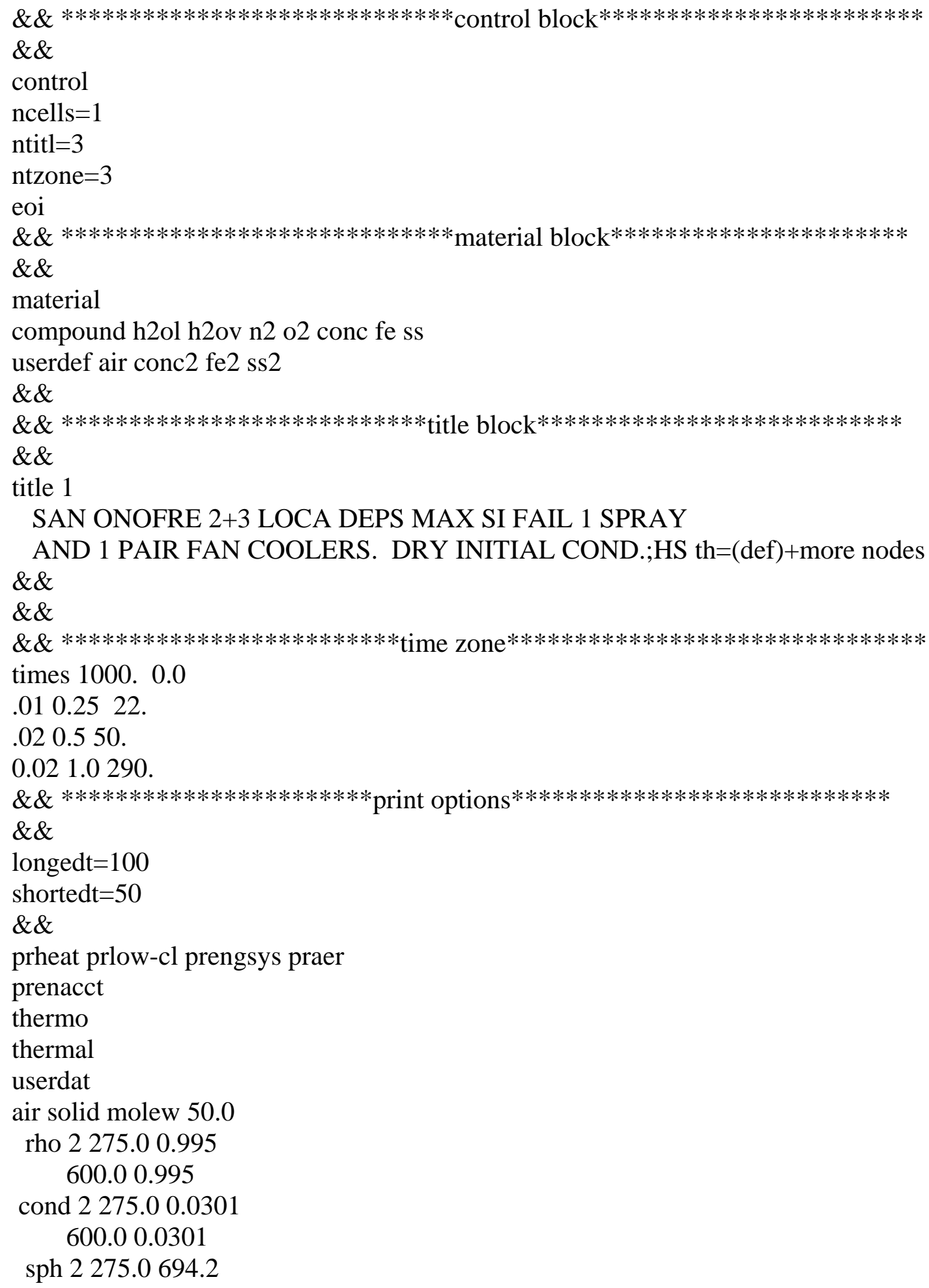




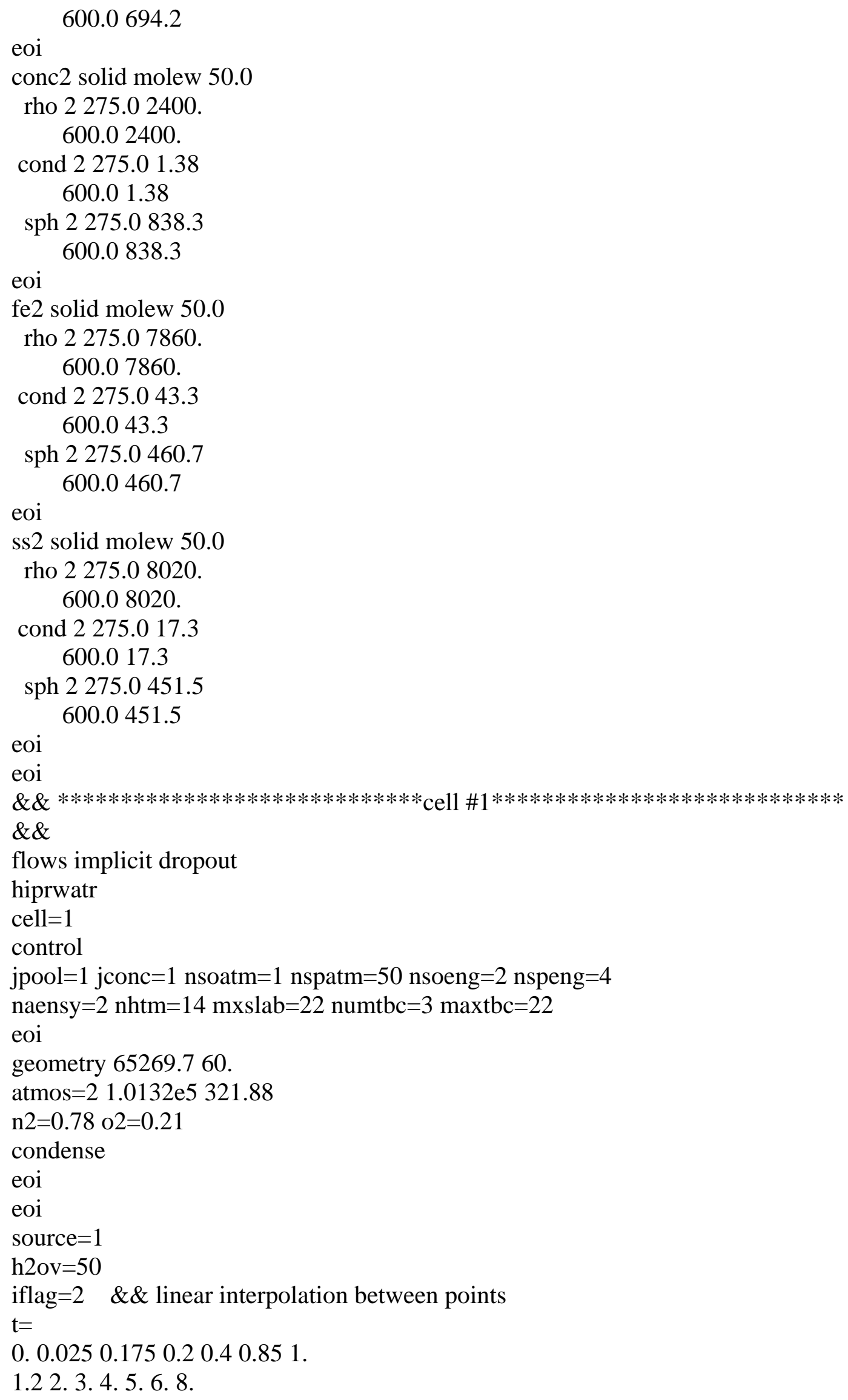


10. 12. 13.515 .17 .117 .318 .5

19.320 .620 .821 .622 .22 .222 .3

24.327 .8 28. 44.544 .8 100. 200.

211. 211.1225 .235 .240 .7245 .5251 .15

262.9281 .6302 .4573 .3600 .1500 .3700 .

10000 .

mass $=$

0.034105 .135352 .942830 .439543 .7

34477.931059 .228410 .126152 .622968 .819866 .6

16701.414272 .911952 .39928 .786861 .114492 .88

3309.441409 .331142 .16775 .1971109 .50525 .719

1280.50223 .170 .00 .073 .4827194 .82

362.061232 .378225 .801352 .626317 .382253 .47

246.394283 .226200 .218159 .167141 .522129 .321

117.3098 .974981 .828972 .121959 .738739 .1182

31.77926 .018319 .3595

enth $=$

$0.01 .27066 \mathrm{e}+061.27578 \mathrm{e}+061.27764 \mathrm{e}+06$

$1.28648 \mathrm{e}+061.30811 \mathrm{e}+06 \quad 1.31020 \mathrm{e}+061.31253 \mathrm{e}+06 \quad 1.31904 \mathrm{e}+06$

$1.33904 \mathrm{e}+061.38859 \mathrm{e}+06 \quad 1.46651 \mathrm{e}+061.53233 \mathrm{e}+06$ 1.56210e+06

$1.59955 \mathrm{e}+061.78190 \mathrm{e}+062.00961 \mathrm{e}+061.67444 \mathrm{e}+061.52512 \mathrm{e}+06$

$1.44511 \mathrm{e}+061.49767 \mathrm{e}+061.07110 \mathrm{e}+061.24391 \mathrm{e}+06771515$.

851992. $0.00 .03 .02372 \mathrm{e}+063.02372 \mathrm{e}+06$

$3.02372 \mathrm{e}+063.02372 \mathrm{e}+06$ 3.02372 +06 3.02372e+06 3.02372e+06

$3.02372 \mathrm{e}+06 \quad 3.02372 \mathrm{e}+062.75973 \mathrm{e}+062.76415 \mathrm{e}+062.76624 \mathrm{e}+06$

$2.7674 \mathrm{e}+062.76834 \mathrm{e}+062.76973 \mathrm{e}+062.77182 \mathrm{e}+062.77368 \mathrm{e}+06$

$2.77322 \mathrm{e}+062.74833 \mathrm{e}+062.74252 \mathrm{e}+062.72554 \mathrm{e}+062.69902 \mathrm{e}+06$

$2.7074 \mathrm{e}+06$

eoi

$\& \& * * * * * * * * * * * * * * * * * * * *$ eng. safety system

$\& \&$ spray starts at $55.08 \mathrm{sec}$ at $100 \mathrm{~F}$

engineer domesp 21120

source $=1$

h2ol=4

iflag $=2$

$\mathrm{t}=0.55 .055 .083697$.

mass $=0.0 .110 .110$.

temp $=310.78310 .78310 .78310 .78$

eoi

spray spdiam $=.0005$

sphite $=50$.

eoi

eoi

\&\& fan cooler start at $33 \mathrm{sec}$

engineer fan 11125

source $=1$

h2ol=4 iflag $=2$

$\mathrm{t}=0.033 .033 .013600$. 


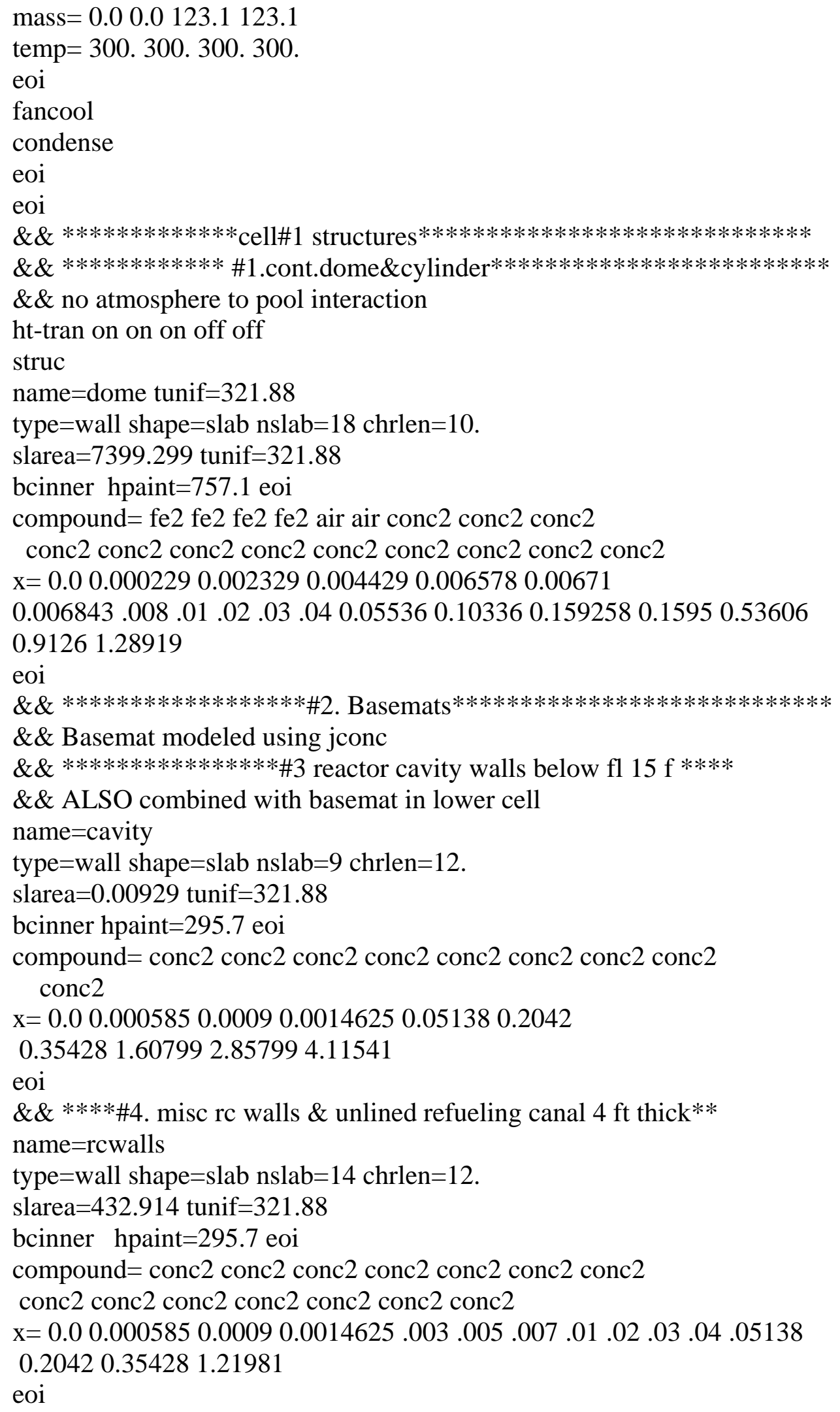




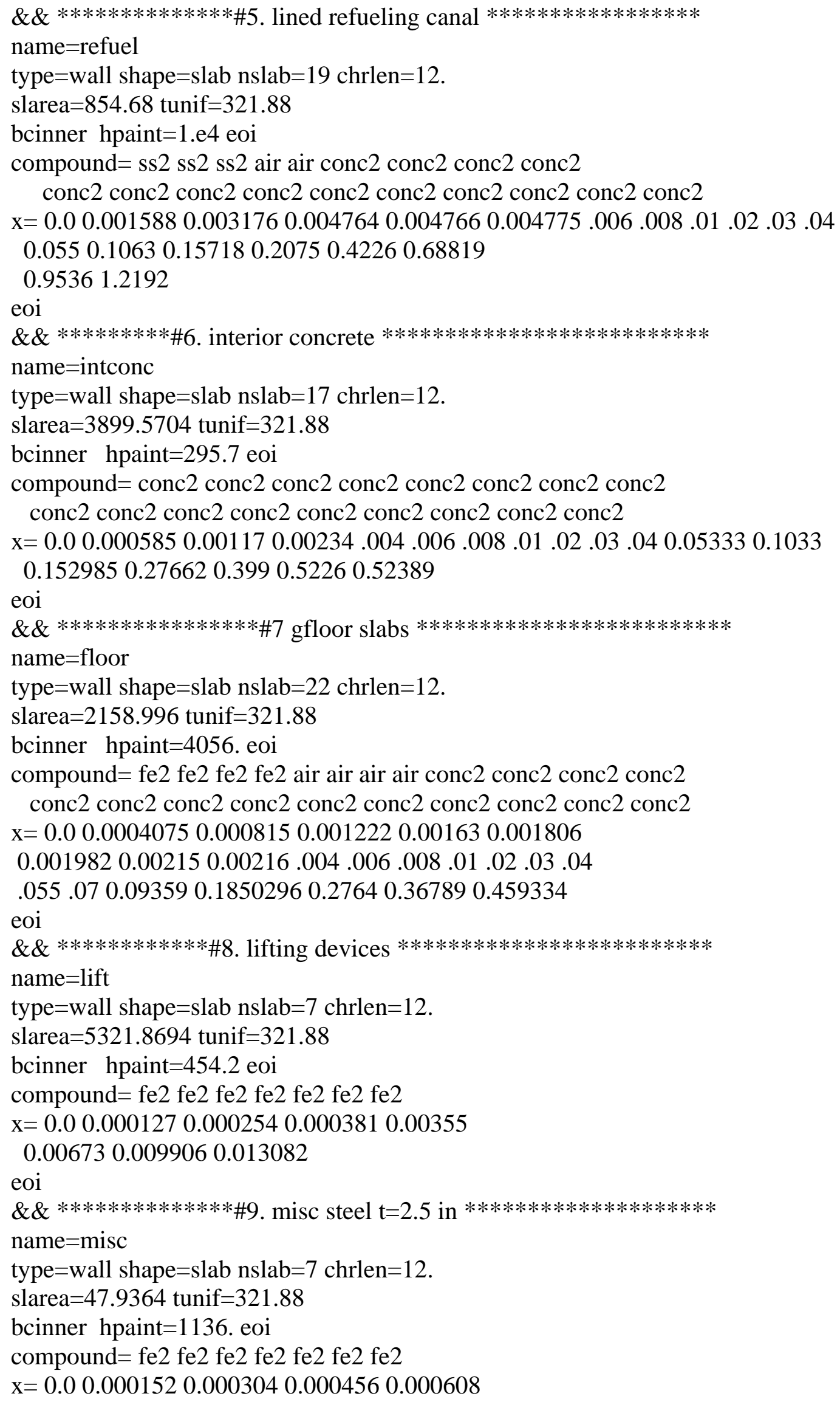




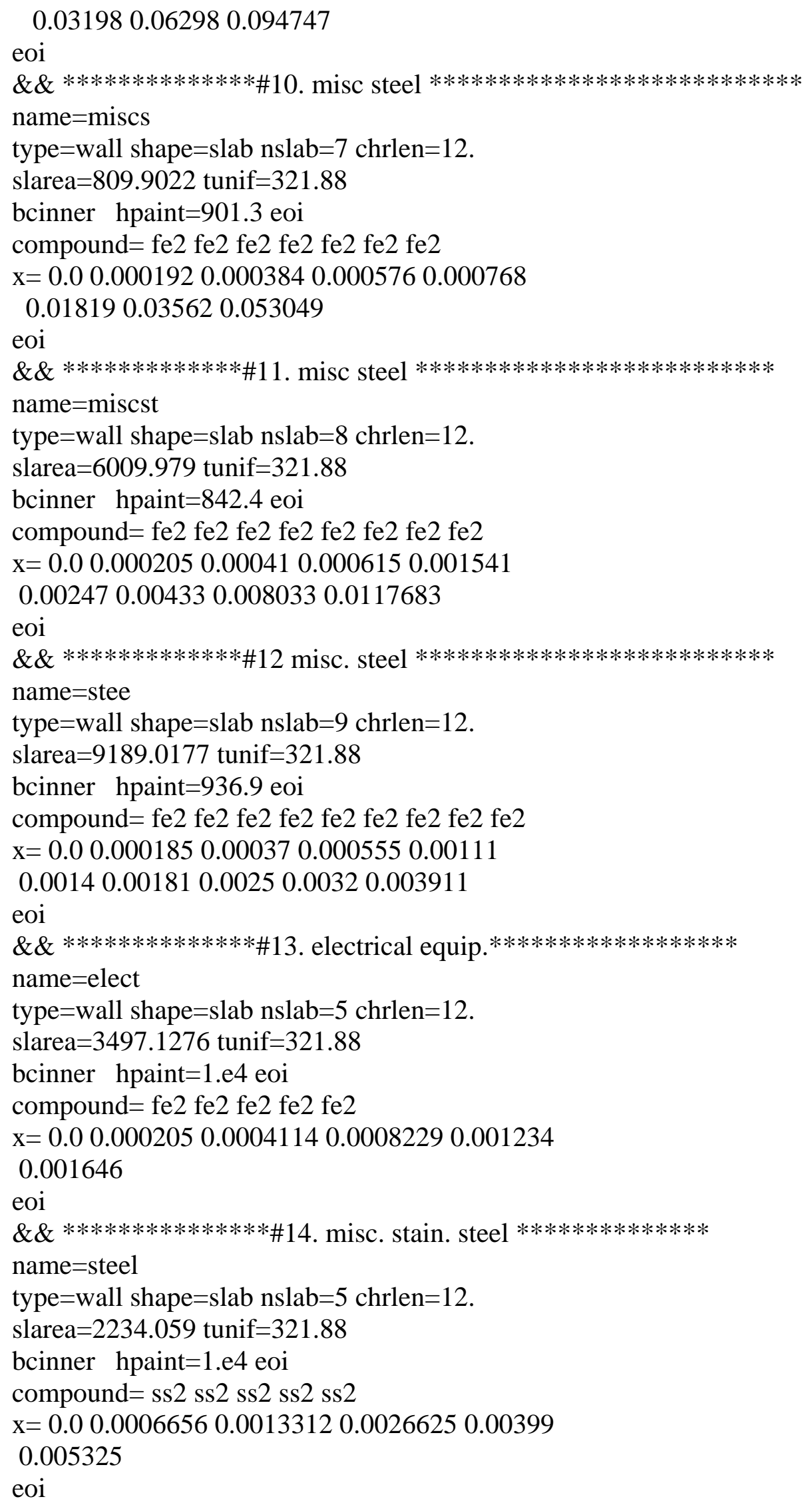


$\& \& * * * * * * * * * * * * \# 15$. cont. wall with stiffness $* * * * * * * * *$

name $=$ stiff

type $=$ wall shape $=$ slab nslab $=10$ chrlen $=12$.

slarea $=147.8039$ tunif $=321.88$

bcinner hpaint $=757.1$ eoi

compound $=$ fe 2 fe 2 fe 2 fe $2 \mathrm{n} 2 \mathrm{n} 2$ conc 2 conc 2 conc 2 conc 2

$\mathrm{x}=0.00 .00022860 .0679620 .1356950 .203429$

0.203694450 .20395990 .523570 .843191 .1628

1.482424

eoi

$\& \& * * * * * * * * * * * * * * * * *$ lower cell

low-cell

geometry $=1490 . \mathrm{bc}=321.88$

concrete

compos $=1$ conc 1 .e 6

temp $=321.88$

eoi

pool

compos $=1$ h2ol 1.0e-4

temp $=321.88$

physics

boil

eoi

eoi

eof

\section{C.2 MELCOR LOCA Input File}

\section{MELCOR Input}

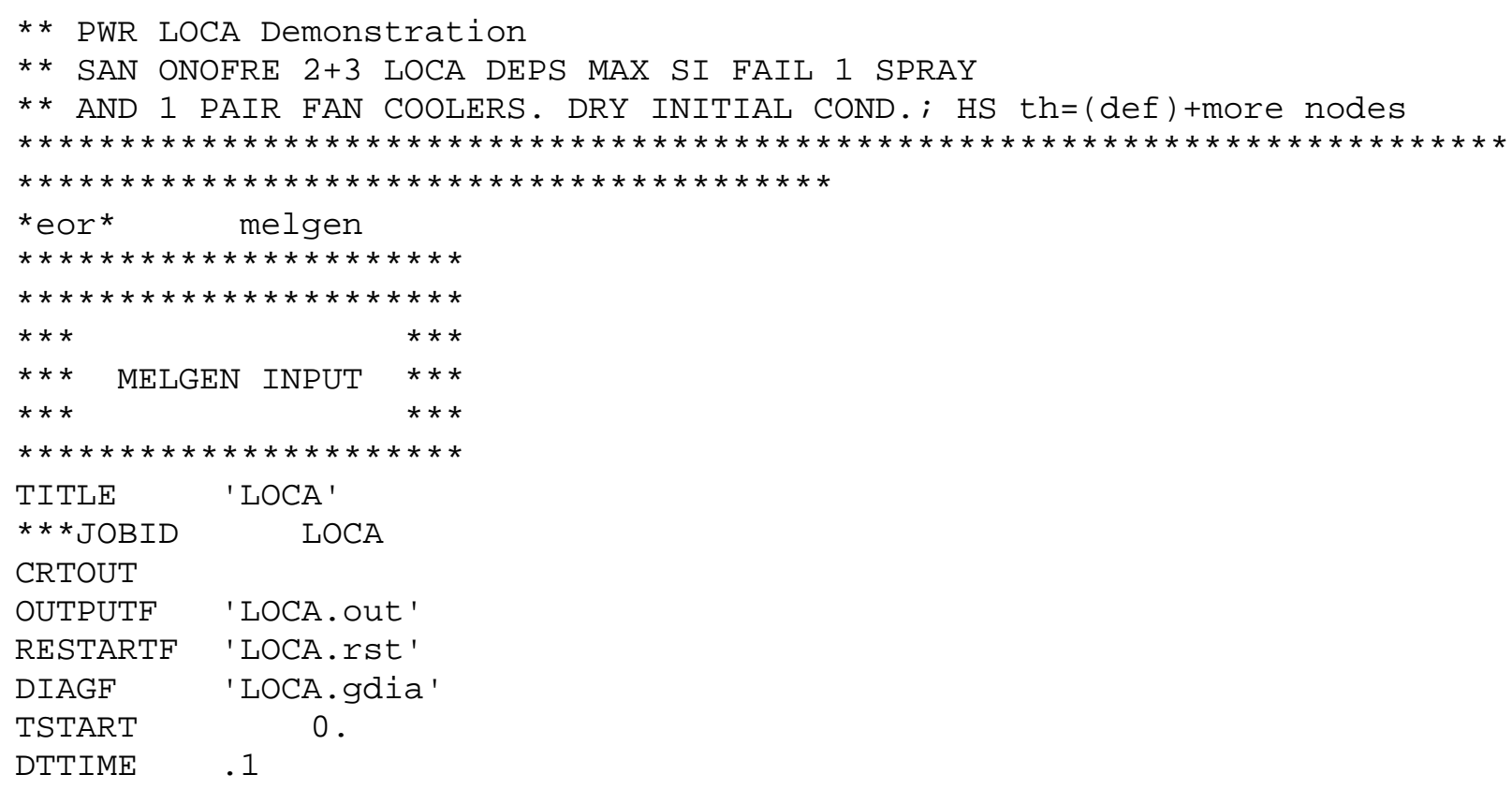




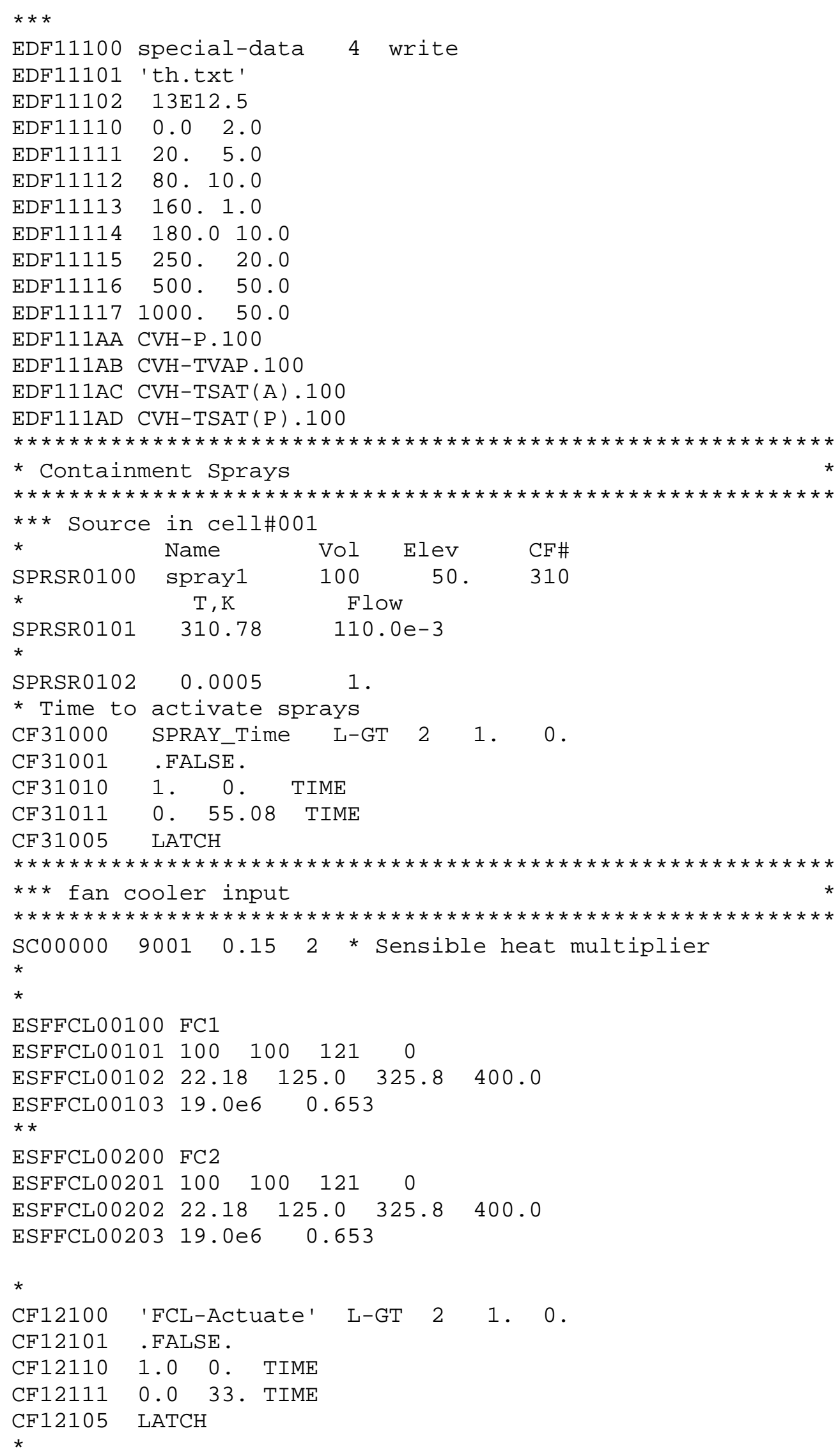




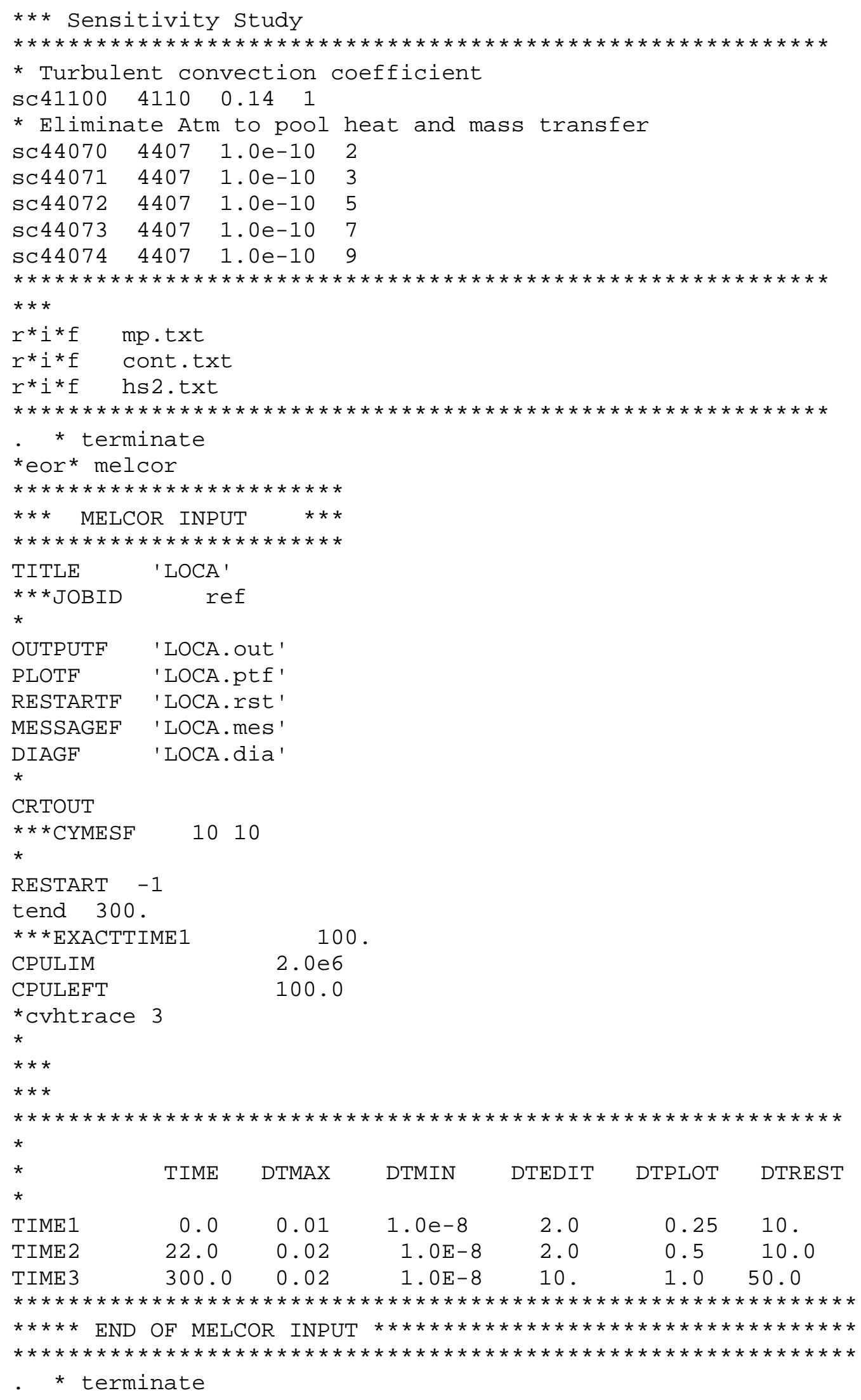




\section{MELGEN CVH Input}

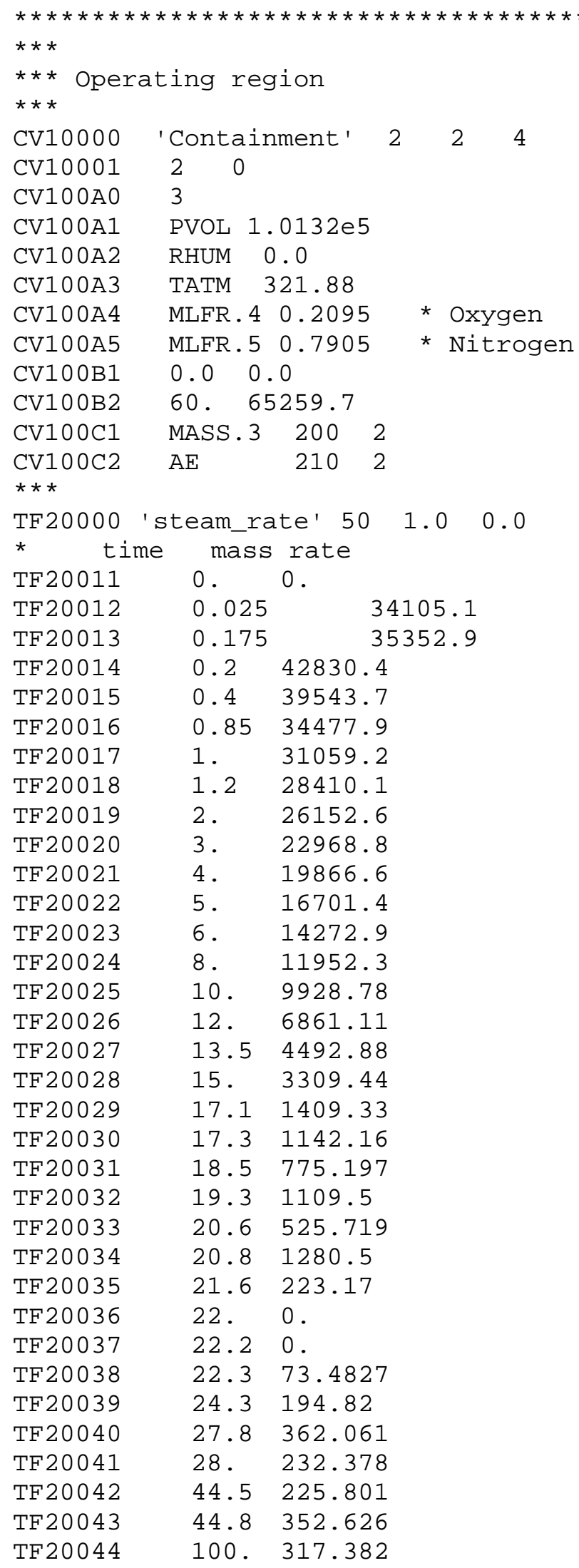




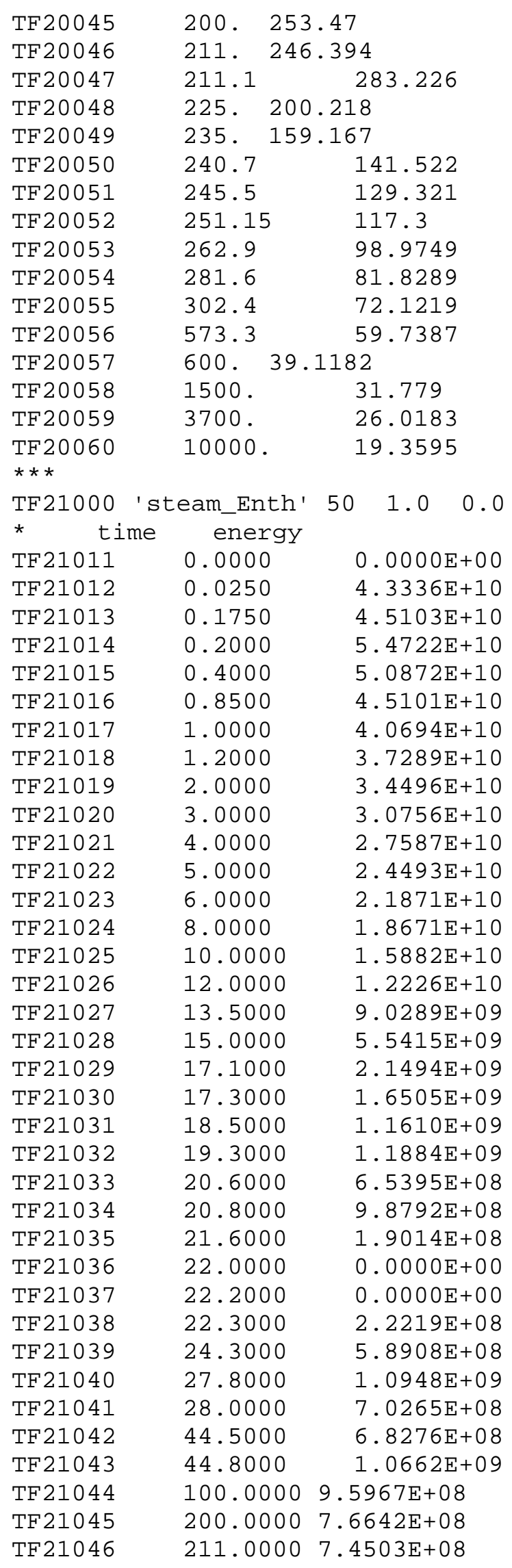




\begin{tabular}{|c|c|}
\hline TF21047 & $211.10007 .8163 \mathrm{E}+\odot 8$ \\
\hline TF21048 & $225.0 \odot \odot \odot 5.5343 \mathrm{E}+\odot 8$ \\
\hline TF21049 & $235.0000 \quad 4.4029 \mathrm{E}+08$ \\
\hline TF21050 & $240.7000 \quad 3.9165 \mathrm{E}+08$ \\
\hline TF21051 & $245.5000 \quad 3.5800 \mathrm{E}+\odot 8$ \\
\hline TF21052 & $251.1500 \quad 3.2489 \mathrm{E}+08$ \\
\hline TF21053 & $262.900 \odot \quad 2.7434 \mathrm{E}+\odot 8$ \\
\hline TF21054 & $281.600 \odot \quad 2.2697 \mathrm{E}+\odot 8$ \\
\hline TF21055 & $3 \odot 2.4 \odot \odot \odot \quad 2 . \odot \odot \odot 1 \mathrm{E}+\odot 8$ \\
\hline TF21056 & $573.300 \odot \quad 1.6418 \mathrm{E}+\odot 8$ \\
\hline TF21057 & $6 \odot \odot . \odot \odot \odot \odot ~ 1 . ๑ 728 \mathrm{E}+\odot 8$ \\
\hline TF21058 & $1500.0000 \quad 8.6615 E+07$ \\
\hline TF21059 & $3700.0000 \quad 7.0224 \mathrm{E}+07$ \\
\hline $\begin{array}{l}\text { TF21060 } \\
\star * *\end{array}$ & $10000.0000 \quad 5.2414 \mathrm{E}+07$ \\
\hline
\end{tabular}

\section{MELGEN HS Input}

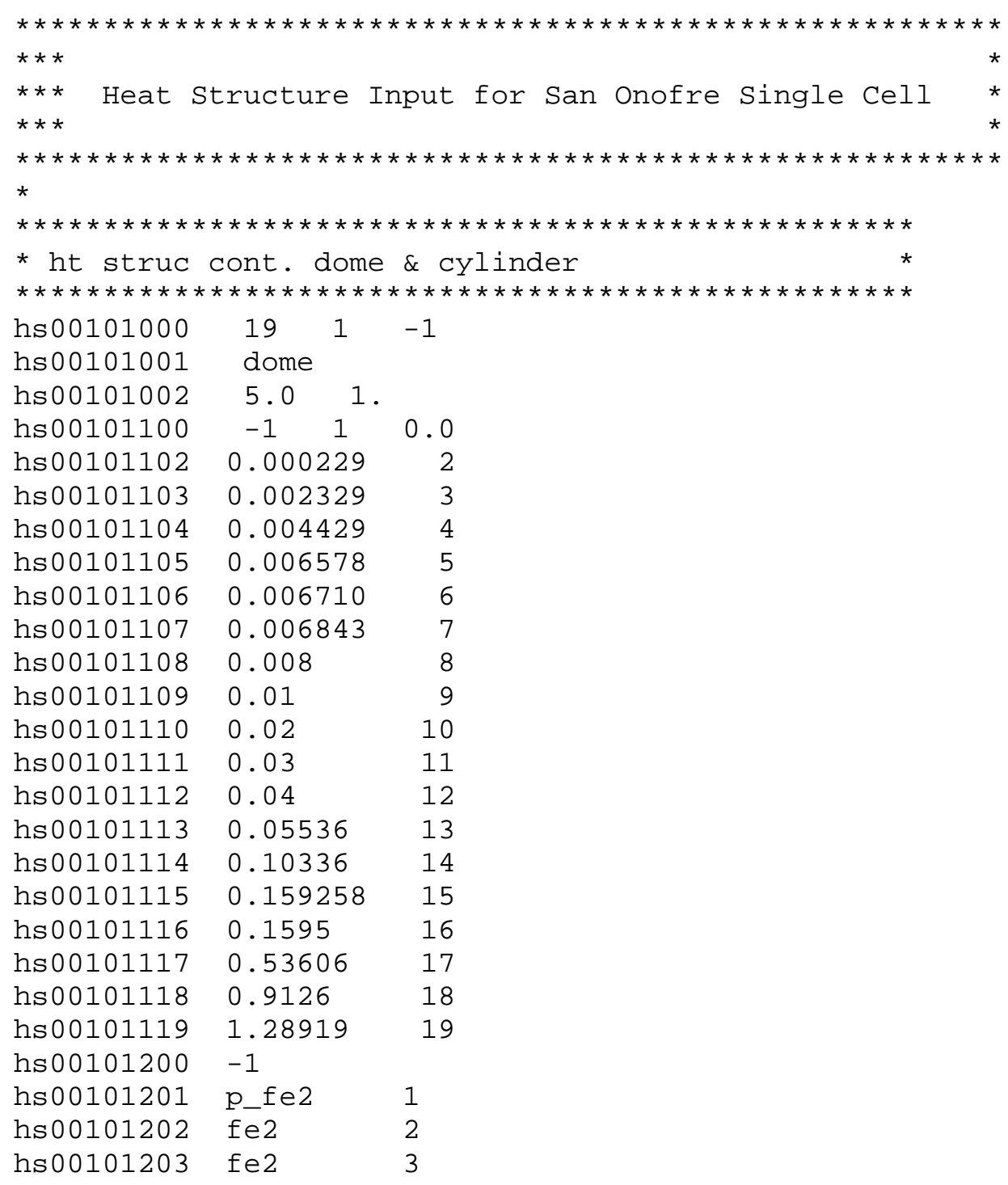




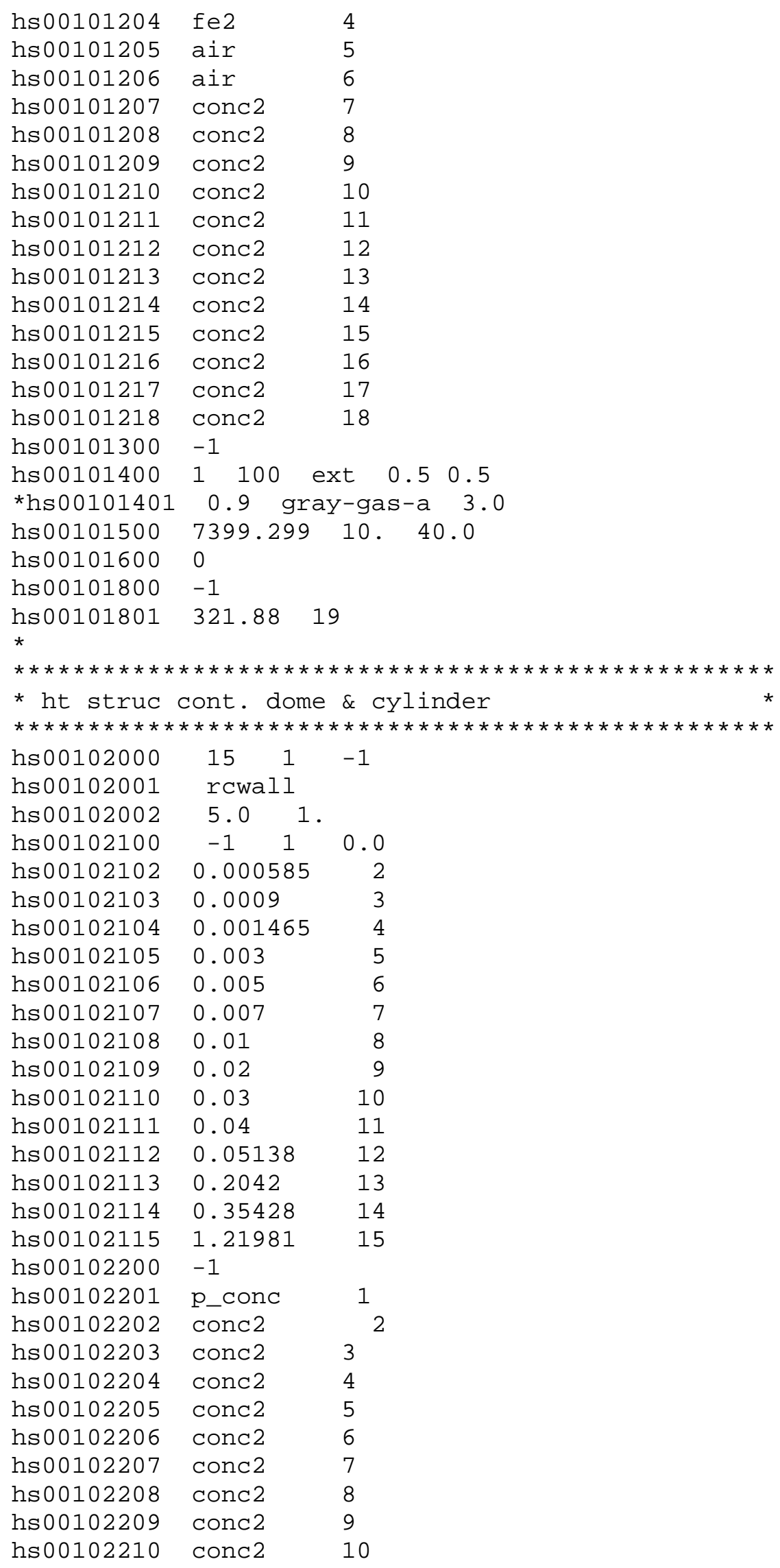




\begin{tabular}{|c|c|c|}
\hline hs 00102211 & conc2 & 11 \\
\hline hs@०1०2212 & conc2 & 12 \\
\hline hs00102213 & conc2 & 13 \\
\hline hs00102214 & conc2 & 14 \\
\hline hs 00102300 & -1 & \\
\hline 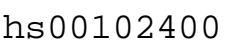 & $1100 \mathrm{e}$ & xt $\quad 0.5 \quad 0.5$ \\
\hline *hs@००102401 & 0.9 gra & $y$-gas-a 3.0 \\
\hline hs@०10250९ & 432.914 & 10. 40.0 \\
\hline hs $\odot \odot 10260 \odot$ & $\odot$ & \\
\hline hs00102800 & -1 & \\
\hline $\begin{array}{l}\text { hs } \\
*\end{array}$ & 321.88 & 5 \\
\hline$* * * * * * * * * * *$ & $* * * * * * * * *$ & $\star * * * * * * * * * * * * * * * * * * * * * * * * * * * *$ \\
\hline 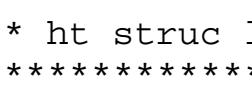 & lined refu & 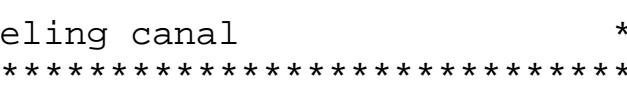 \\
\hline $\begin{array}{l}\text { hs } 00104000 \\
\text { hs } 0 \odot 104001\end{array}$ & $\begin{array}{ll}20 & 1 \\
\text { refuel }\end{array}$ & -1 \\
\hline hs 00104002 & 5. 1.0 & \\
\hline hs 00104100 & -1 & $\odot . \odot$ \\
\hline hs००104102 & 0.00158 & 2 \\
\hline hs๑०1०4103 & $\odot .0 \odot 317$ & 3 \\
\hline hs00104104 & $\odot .0 \odot 4764$ & 4 \\
\hline hs 00104105 & $\odot .0 \odot 4766$ & 5 \\
\hline hs00104106 & $\odot .0 \odot 4775$ & 6 \\
\hline hs 00104107 & 0.006 & 7 \\
\hline 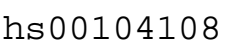 & $\odot . \odot \odot 8$ & 8 \\
\hline hs 00104109 & 0.01 & 9 \\
\hline hs 00104110 & 0.02 & 10 \\
\hline hs 00104111 & $\odot .03$ & 11 \\
\hline hs@०1०4112 & $\odot .04$ & 12 \\
\hline hs 00104113 & 0.055 & 13 \\
\hline hs 00104114 & 0.1063 & 14 \\
\hline hs 00104115 & 0.15718 & 15 \\
\hline hs00104116 & $\odot .2075$ & 16 \\
\hline hs00104117 & 0.4226 & 17 \\
\hline hs00104118 & 0.68819 & 18 \\
\hline hs 00104119 & $\odot .9536$ & 19 \\
\hline hs 00104120 & 1.2192 & 20 \\
\hline hs $\odot \odot 1 \odot 420 \odot$ & -1 & \\
\hline hs00104201 & p_ss2 & 1 \\
\hline hs00104202 & ss2 & 2 \\
\hline hs00104203 & ss2 & 3 \\
\hline hs00104204 & conc2 & 4 \\
\hline hs00104205 & conc2 & 5 \\
\hline hs๑๑1๑42๑6 & conc2 & 6 \\
\hline hs@०1๑42๑7 & conc2 & 7 \\
\hline hs00104208 & conc2 & 8 \\
\hline hs00104209 & conc2 & 9 \\
\hline hs00104210 & conc2 & 10 \\
\hline hs00104211 & conc2 & 11 \\
\hline hs 00104212 & conc2 & 12 \\
\hline hs 00104213 & conc2 & 13 \\
\hline hs@०1०4214 & conc2 & 14 \\
\hline hs@๑1@4215 & conc2 & 15 \\
\hline hs 00104216 & conc2 & 16 \\
\hline
\end{tabular}




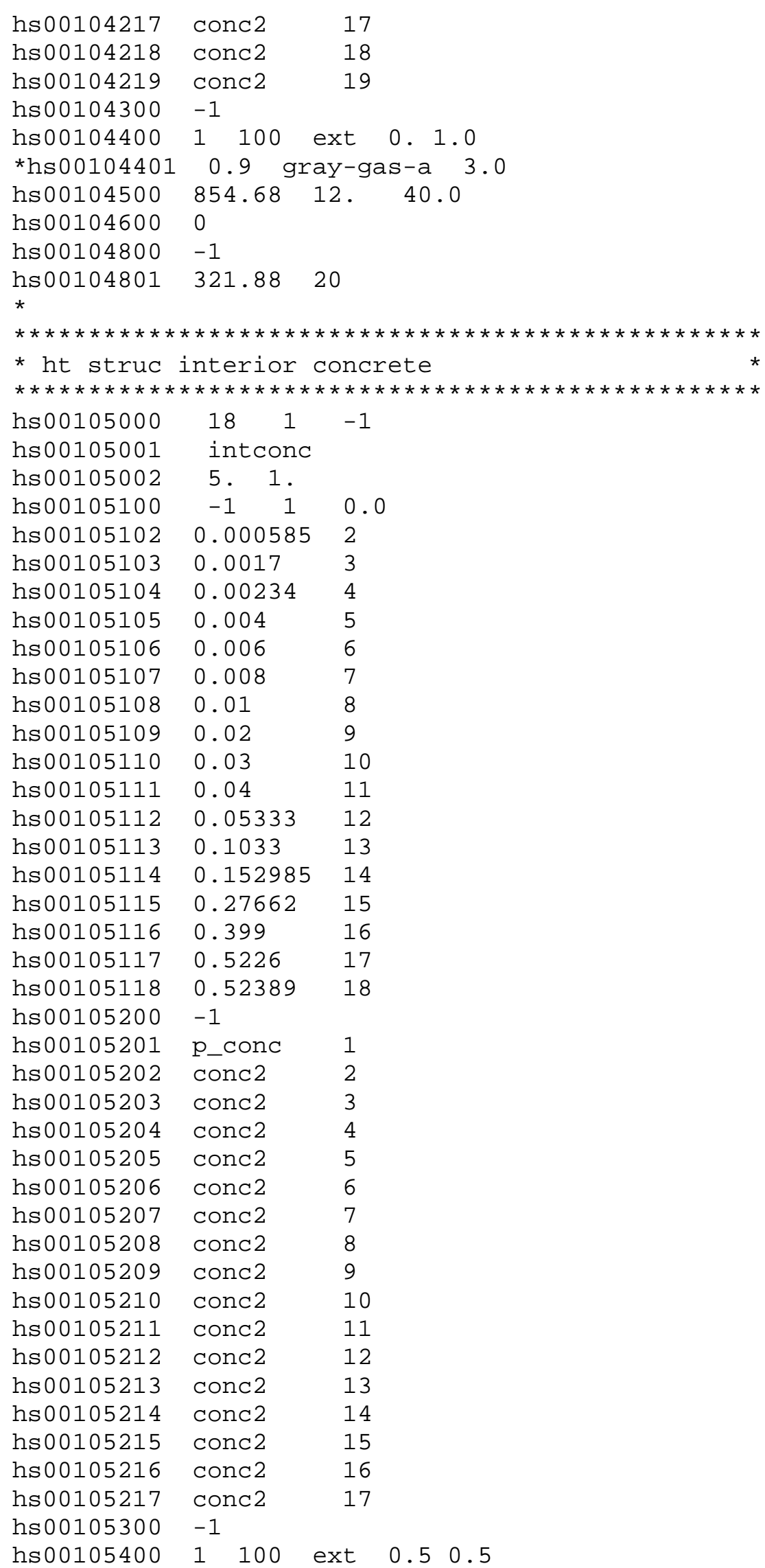




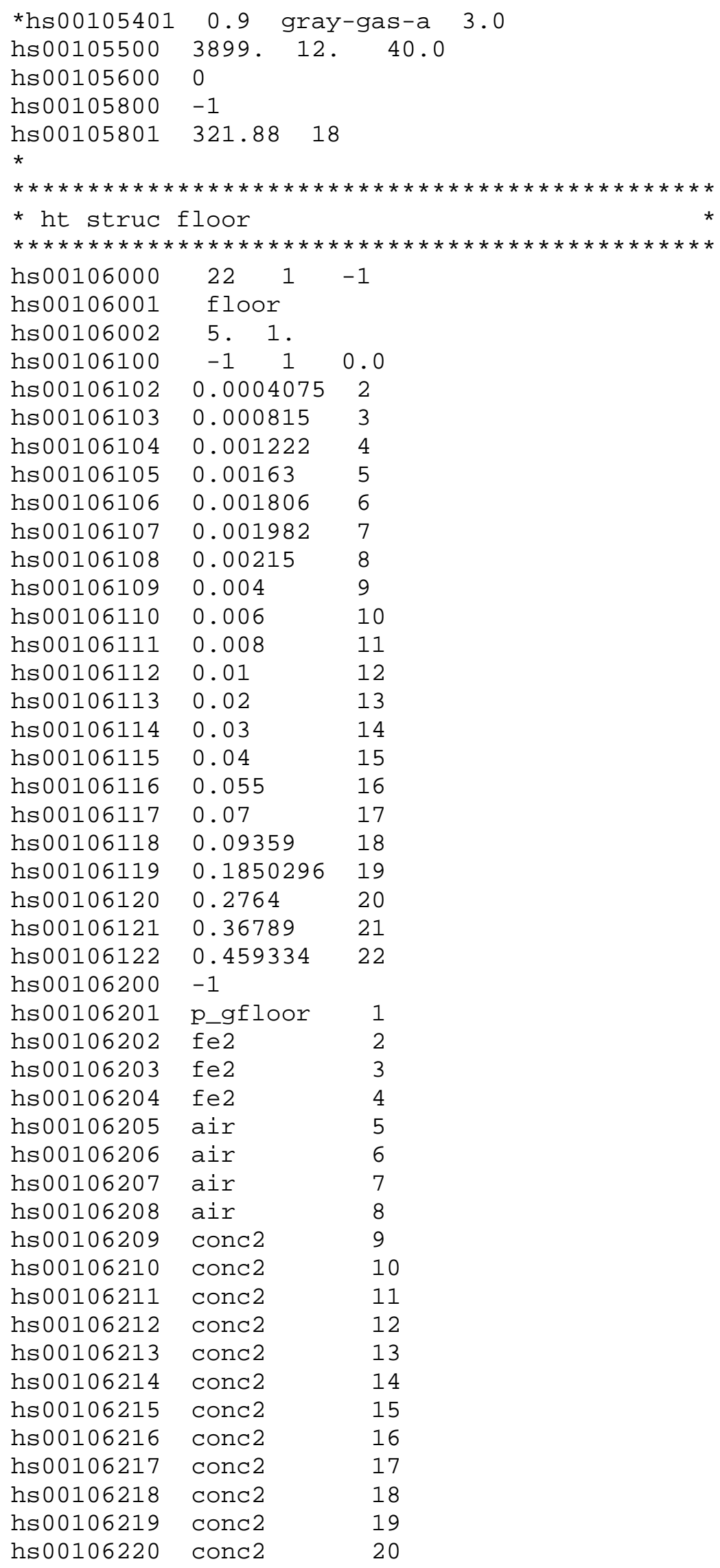




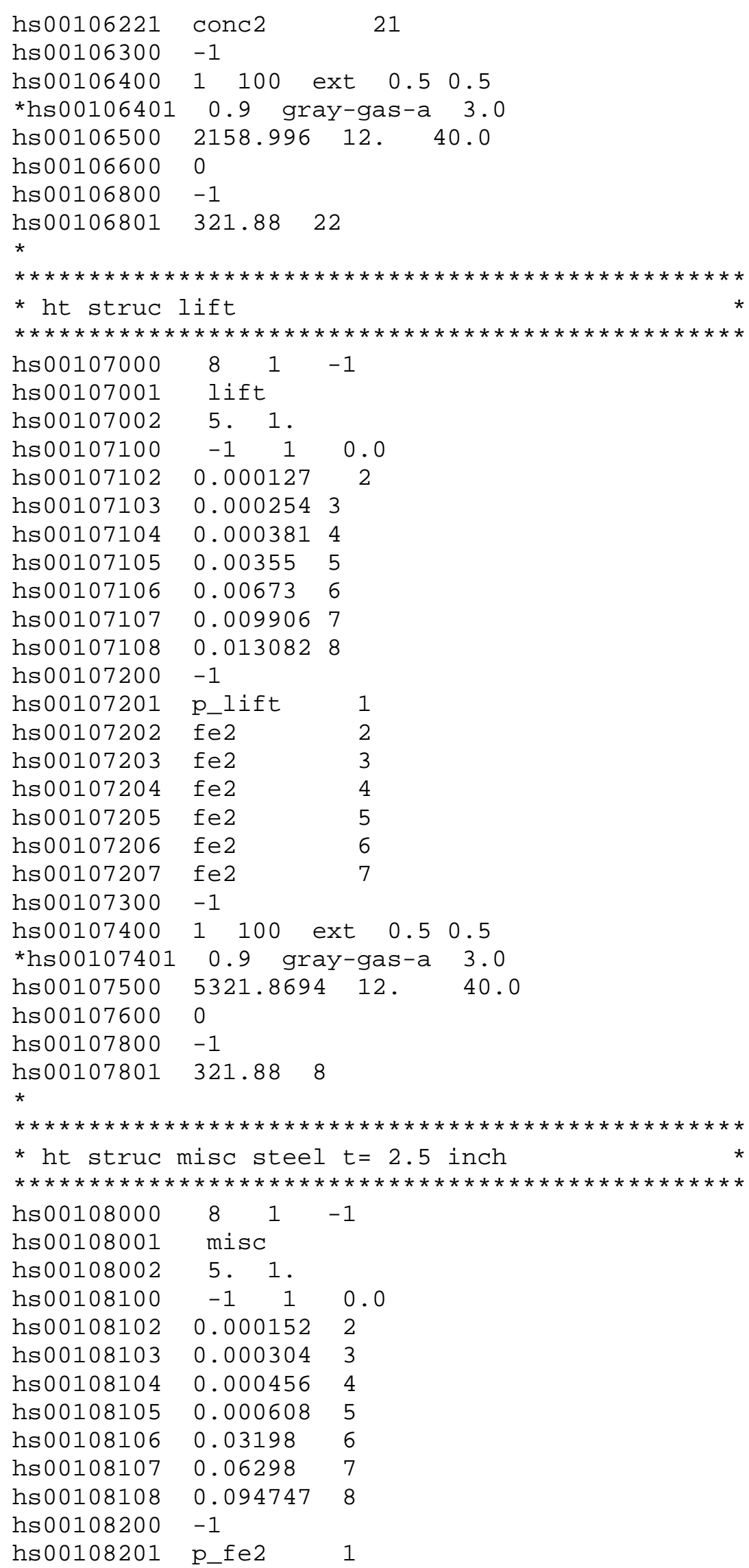




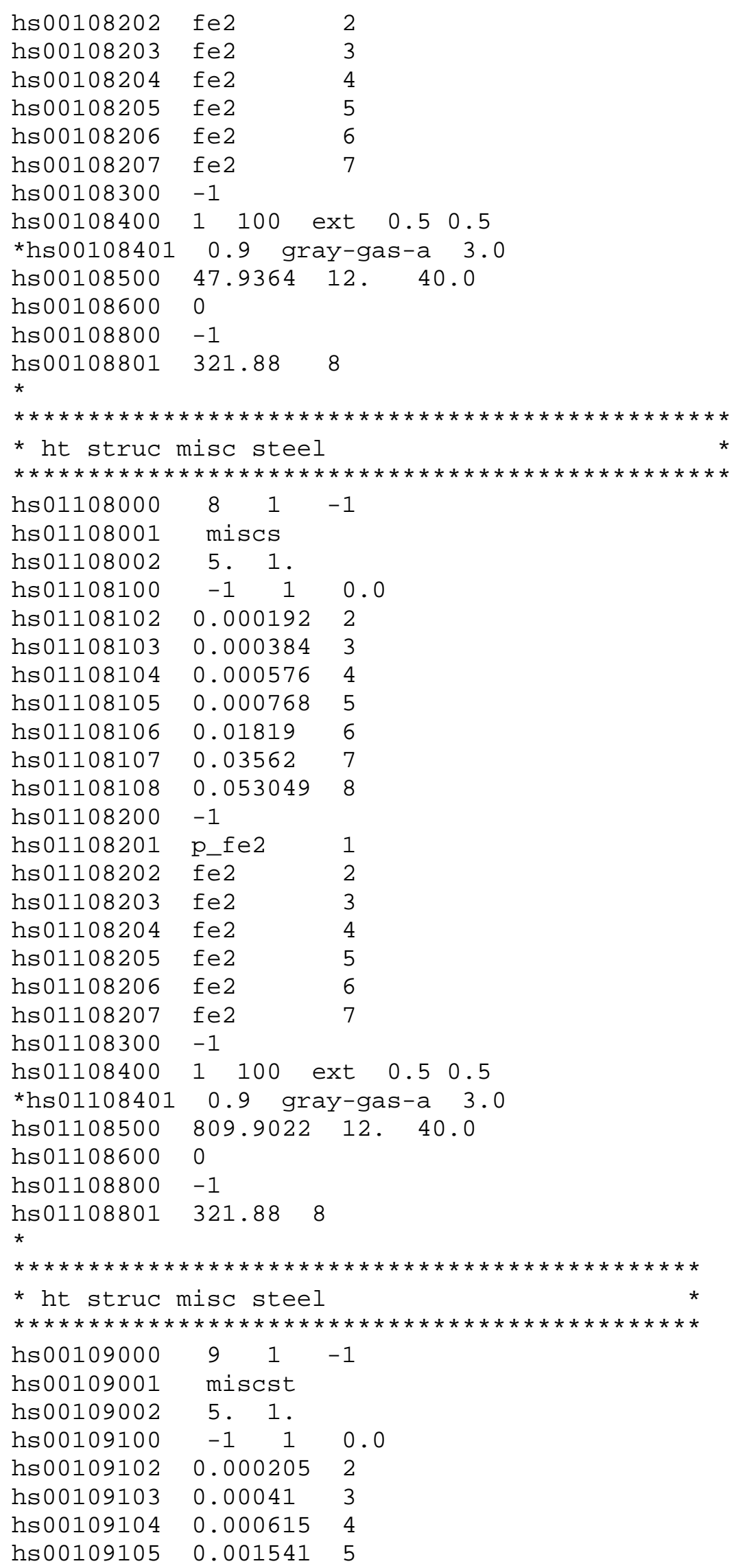




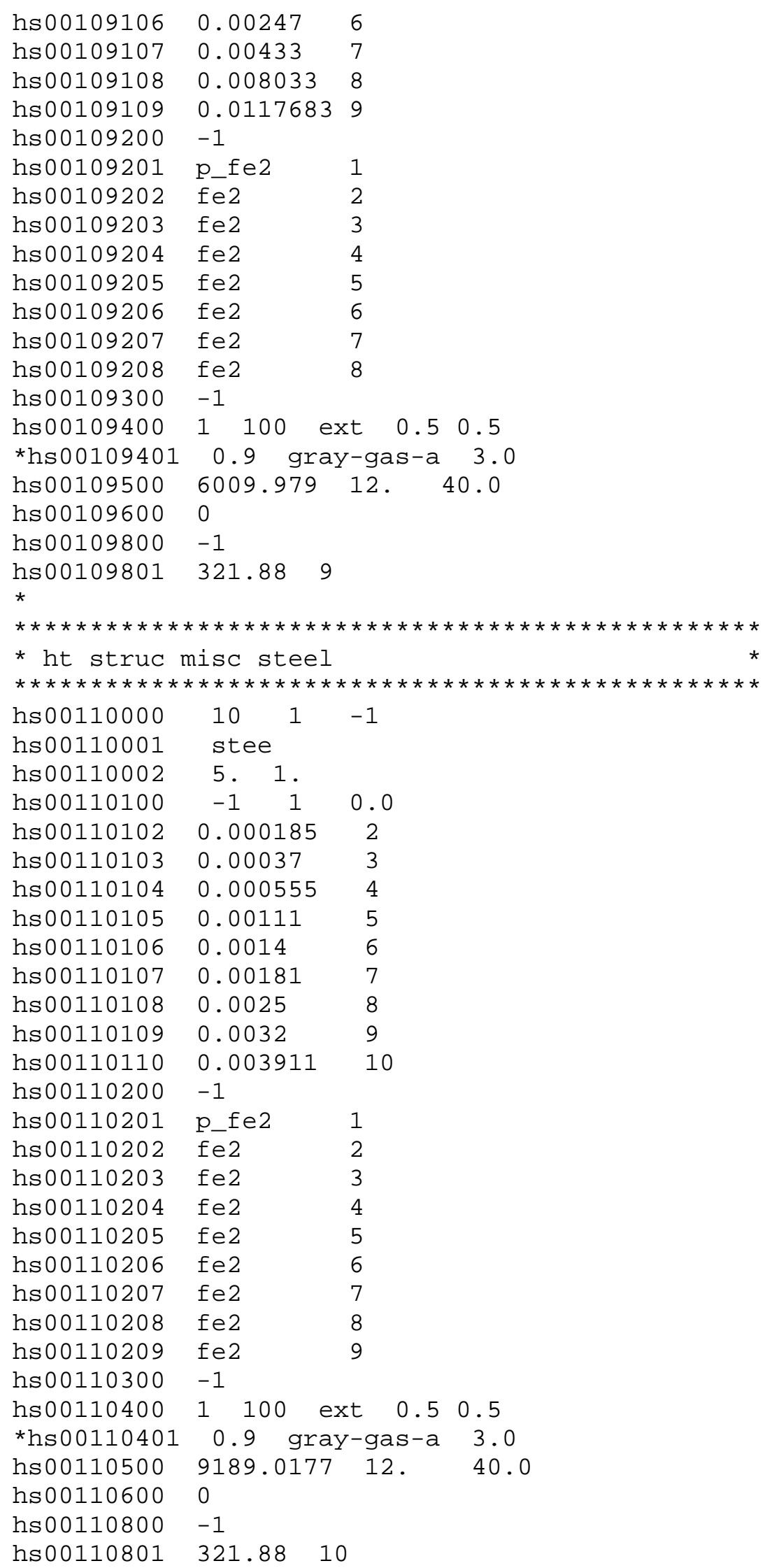




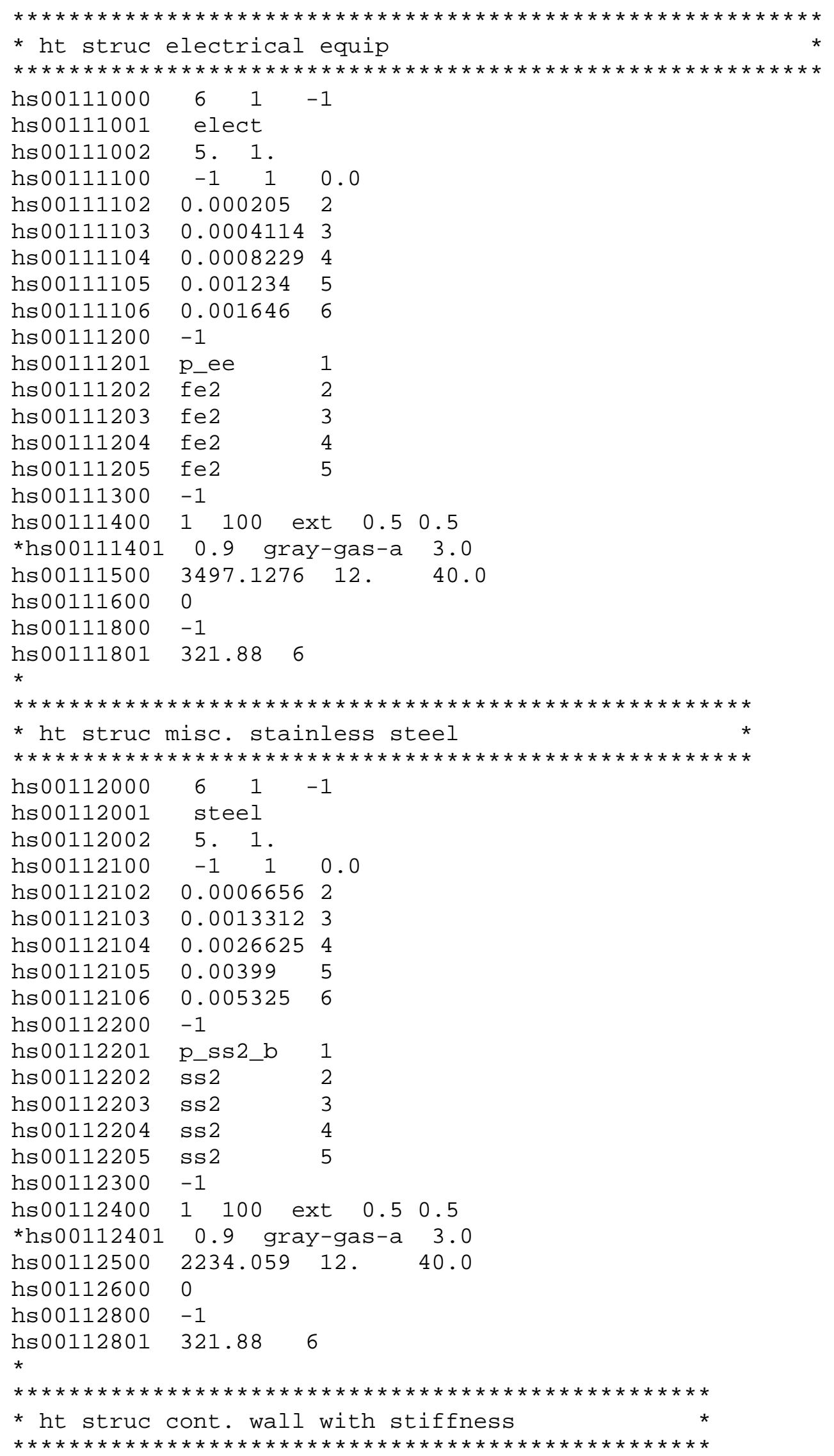




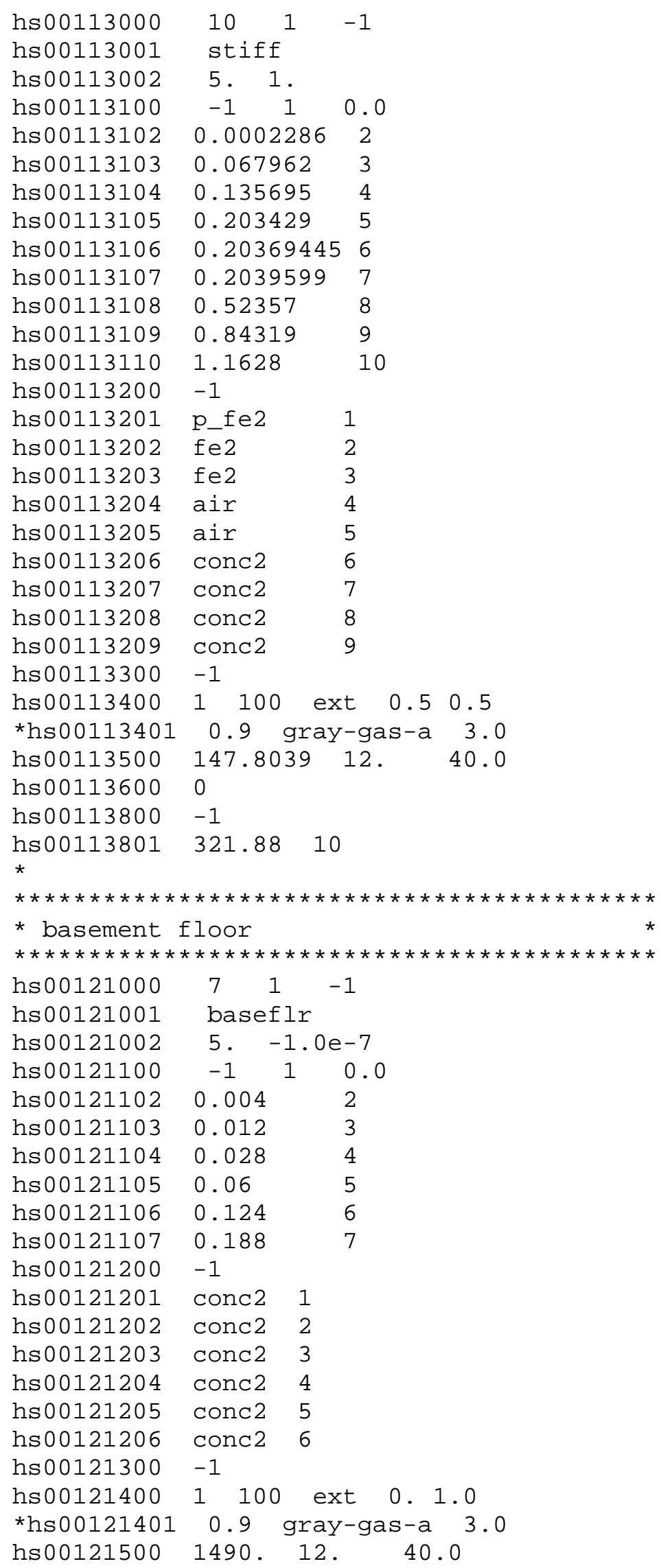




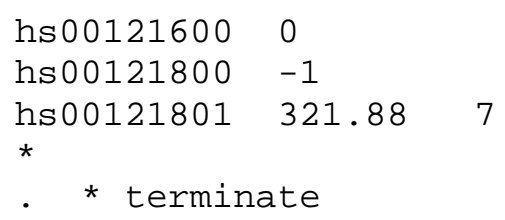

\section{MELGEN MP Input}

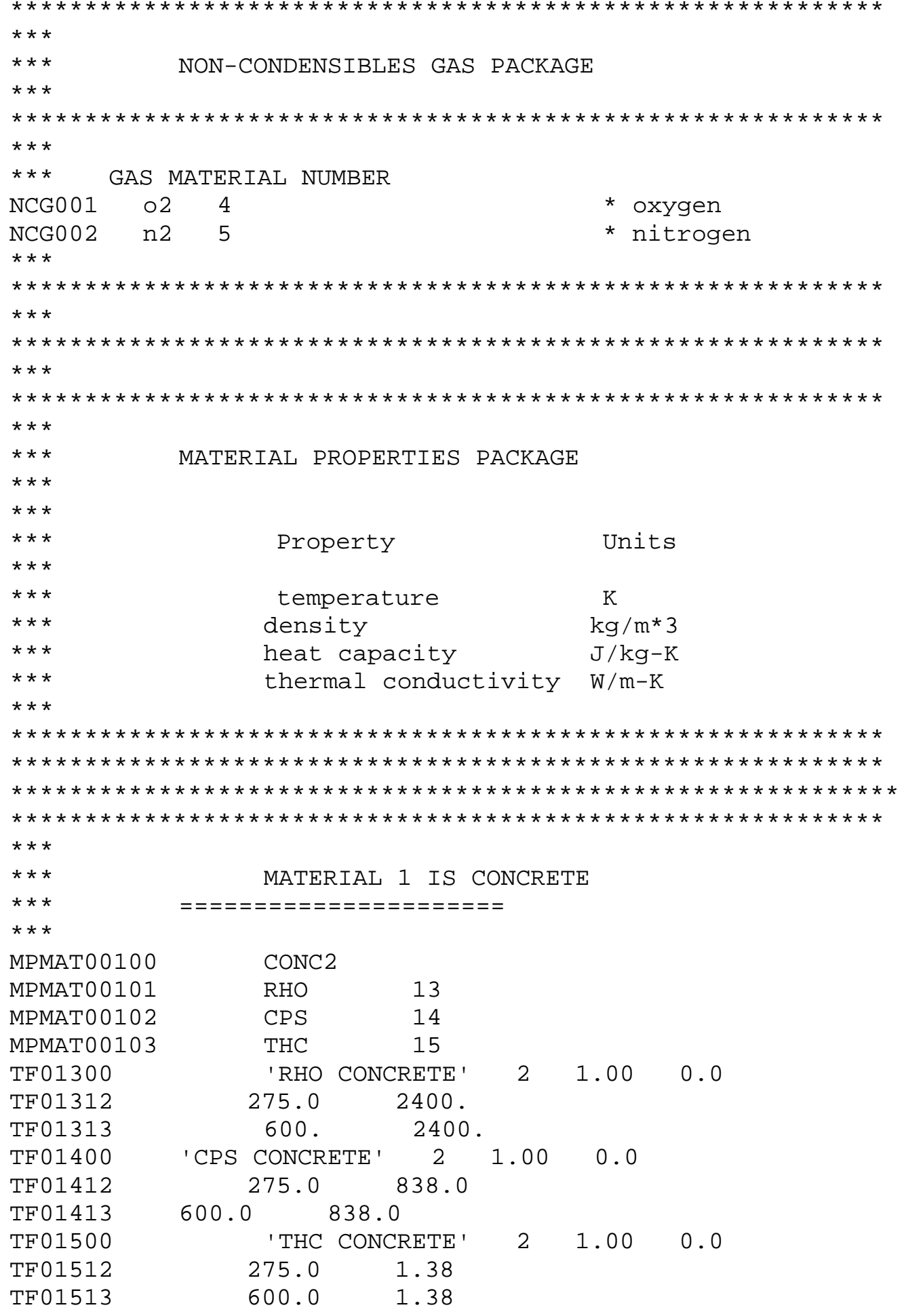




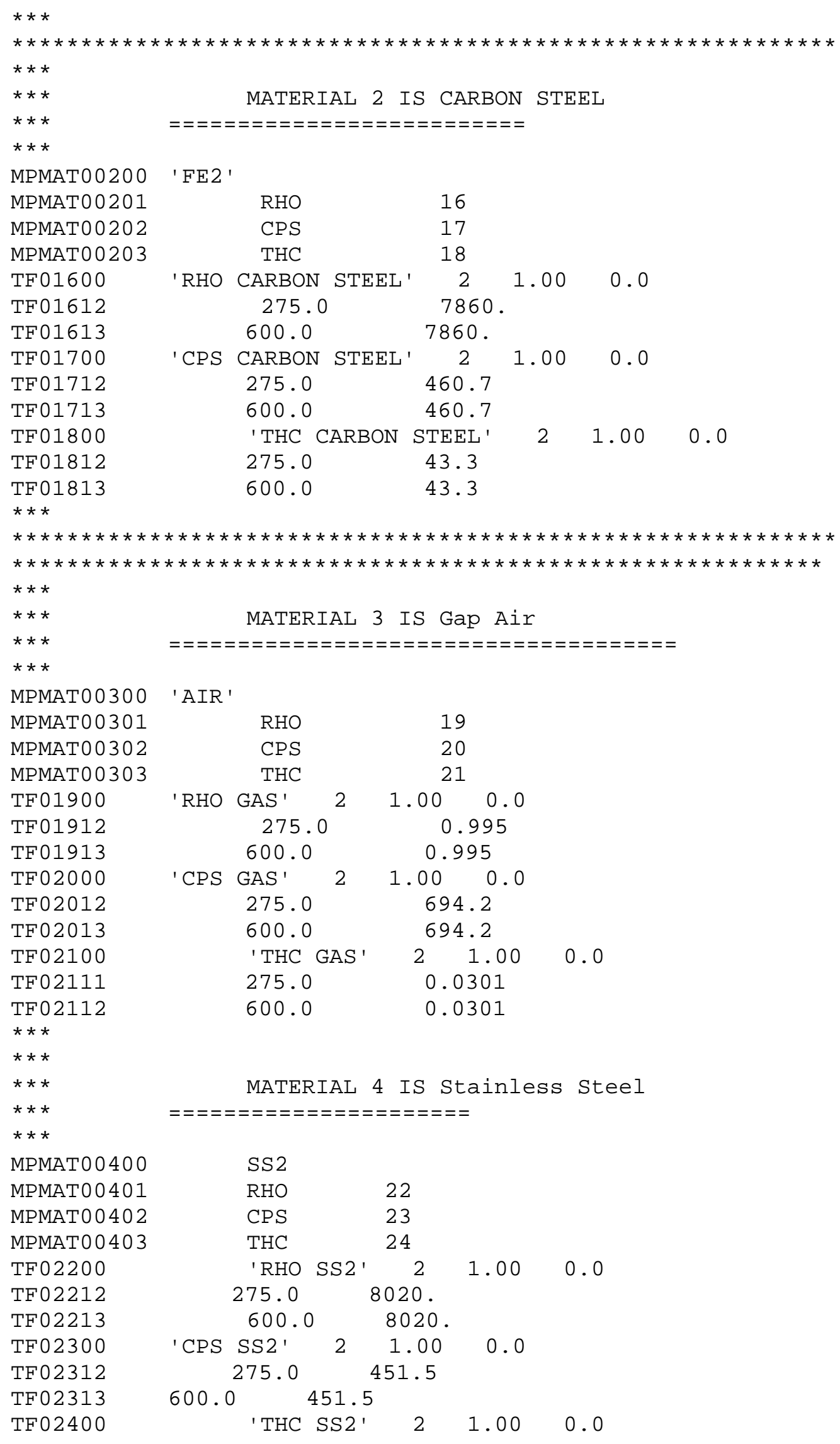




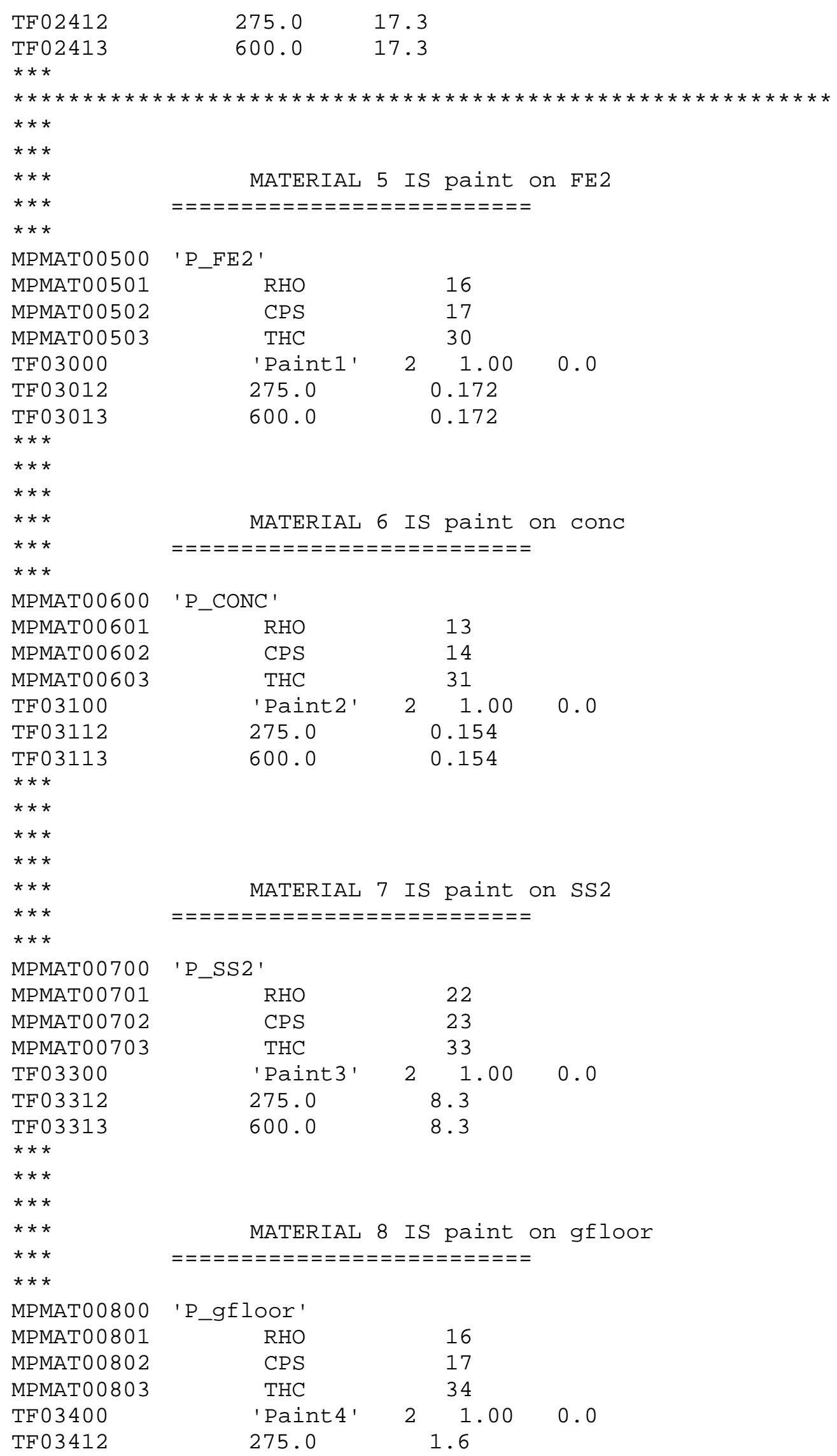




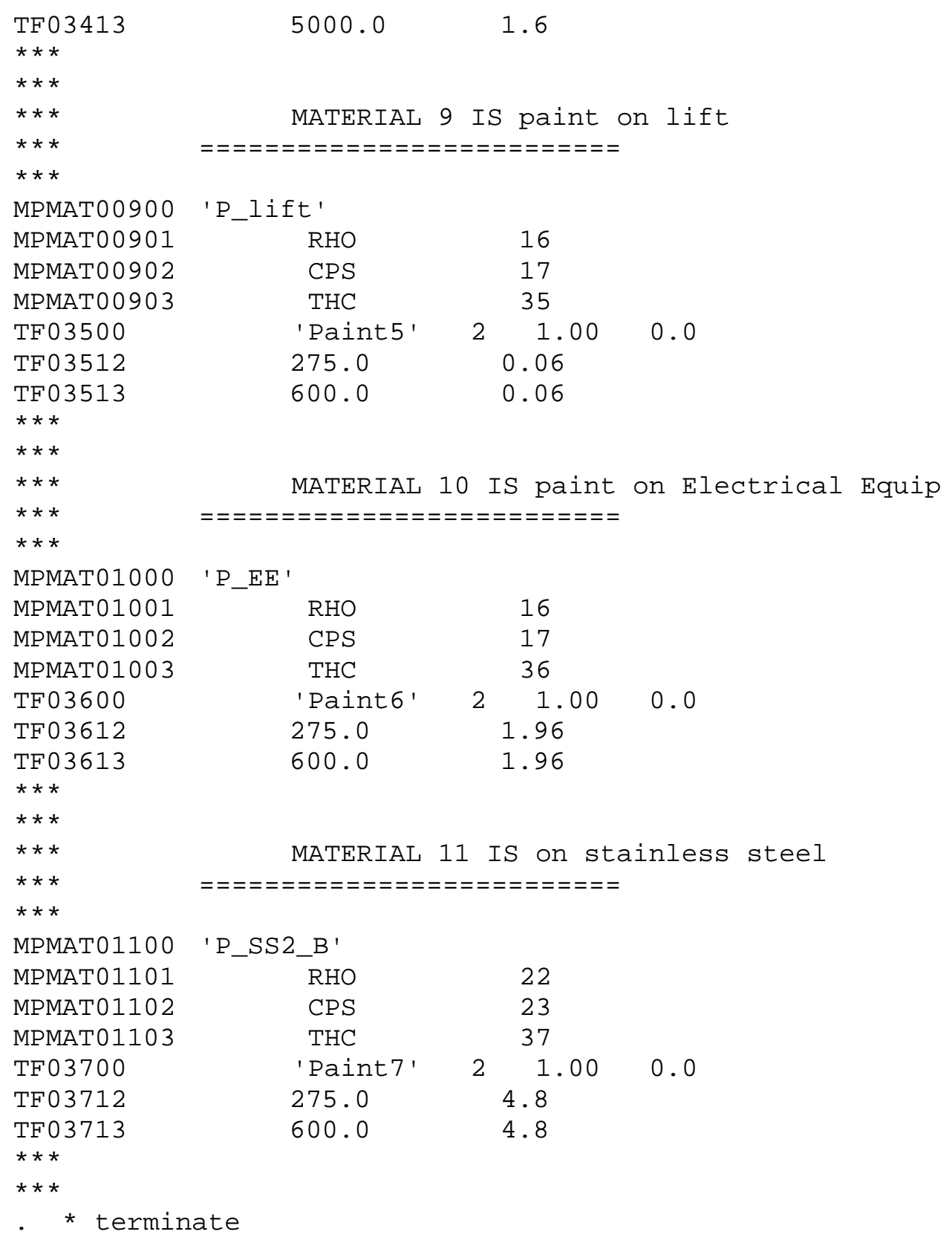




\section{Distribution:}

10 U.S. Nuclear Regulatory Commission Attn: Allen Notafrancesco 21 Church Street, Mail Stop C3A07M Washington, DC 20555-0001

$1 \quad$ Jennifer Uhle (electronic copy) U.S. Nuclear Regulatory Commission 21 Church Street, Mail Stop C3A07M Washington, DC 20555-0001

1 Hossein Esmaili (electronic copy) U.S. Nuclear Regulatory Commission 21 Church Street, Mail Stop C3A07M Washington, DC 20555-0001

1 Richard Lee (electronic copy) U.S. Nuclear Regulatory Commission 21 Church Street, Mail Stop C3A07M Washington, DC 20555-0001

1 Michael Salay (electronic copy) U.S. Nuclear Regulatory Commission 21 Church Street, Mail Stop C3A07M Washington, DC 20555-0001

1 Allen Notafrancesco (electronic copy) U.S. Nuclear Regulatory Commission 21 Church Street, Mail Stop C3A07M Washington, DC 20555-0001

$1 \quad$ Jack Tills \& Associates, Inc. (electronic copy) Sandia Park, New Mexico 87047-0549

1 MS 0736 D.A. Powers, 06770 (electronic copy)

1 MS 0736 M.C. Walck, 06760 (electronic copy)

1 MS $0748 \quad$ R.O. Gauntt, 06762 (electronic copy)

1 MS $0748 \quad$ L.H. Humphries, 06762 (electronic copy)

1 MS $0748 \quad$ D.A. Kalinich, 06762 (electronic copy)

1 MS $0748 \quad$ J.D. Brewer, 06762 (electronic copy)

1 MS 0899 Technical Library, 09536 (electronic copy) 


\section{(1) Sandia National Laboratories}

